\title{
Constructive Technology Assessment of Gene Expression Profiling for Breast Cancer
}

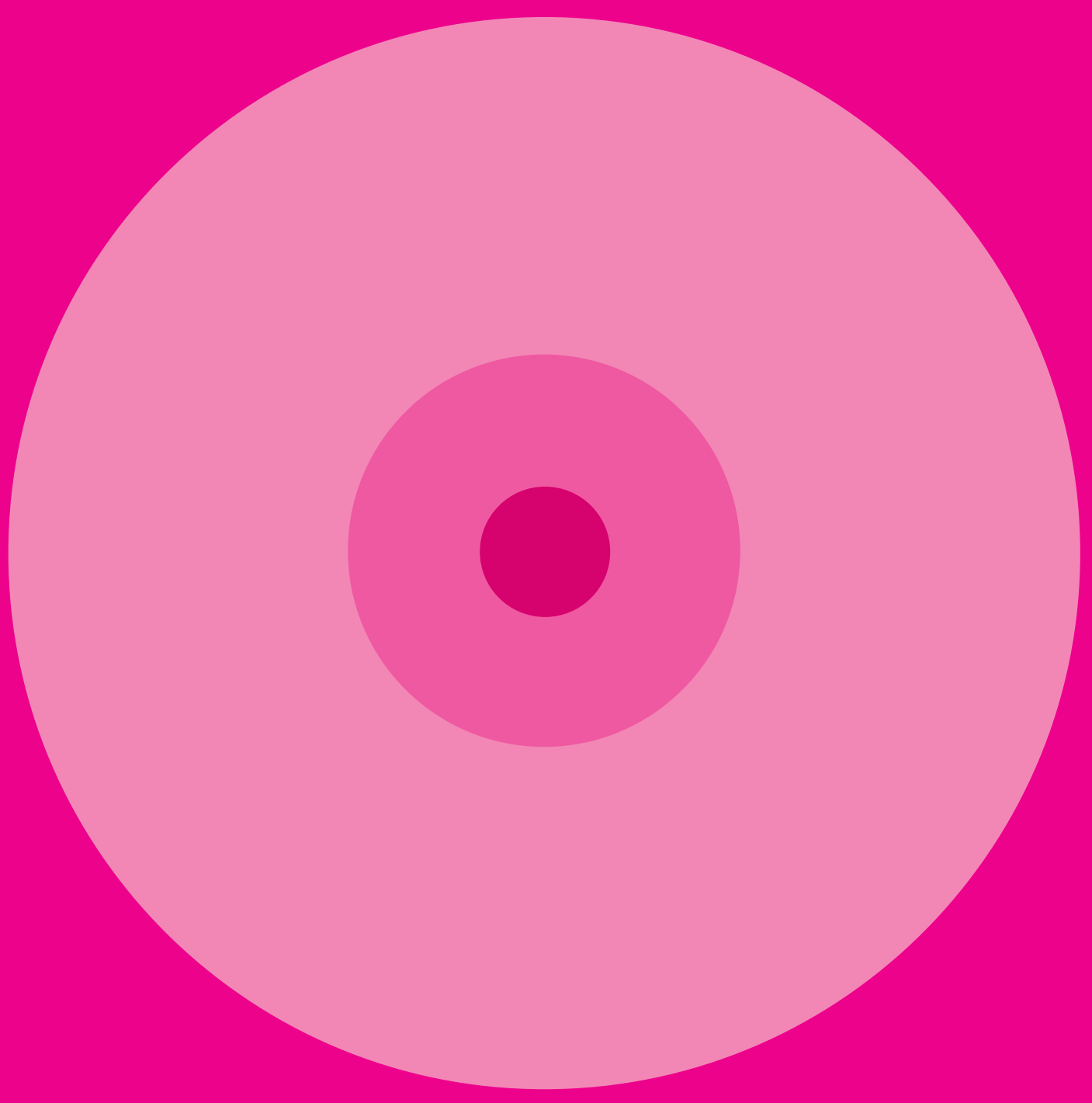

Valesca Retèl 


\title{
CONSTRUCTIVE TECHNOLOGY ASSESSMENT OF GENE EXPRESSION PROFILING FOR BREAST CANCER
}

\author{
Valesca Pavlawna Retèl
}


Address of correspondence:

Valesca Retèl

Route du Châtelard 22

$\mathrm{CH}-1018$ Lausanne

Switzerland

0031641327196

valescaretel@hotmail.com

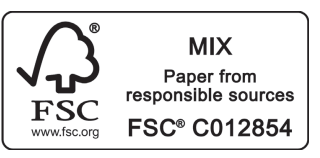

Cover design: Ine Reijnen - www.thtot.nl

Lay-out: $\quad$ Valesca Retèl \& Christian Louter

Printed by: Gildeprint Drukkerijen - www.gildeprint.nl

ISSN: $\quad 1878-4968$

HSS-10-004: Health Technology and Services Research, University of Twente

This study has been performed at the Netherlands Cancer Institute-Antoni van Leeuwenhoek Hospital, Amsterdam, The Netherlands

The studies in this thesis are supported by grants of the Dutch Health Care Insurance Board (College voor Zorgverzekeringen, CvZ).

Publication and distribution of this dissertation was financially supported by: University of Twente, Department of Health Technology and Services Research (HTSR), Netherlands Cancer Institute (NKI-AVL), Agendia B.V., Novartis B.V., Pfizer B.V. and Sanofi Aventis. 


\title{
CONSTRUCTIVE TECHNOLOGY ASSESSMENT OF GENE EXPRESSION PROFILING FOR BREAST CANCER
}

\author{
PROEFSCHRIFT \\ ter verkrijging van \\ de graad van doctor aan de Universiteit Twente, \\ op gezag van de rector magnificus, \\ prof. dr. H. Brinksma, \\ volgens besluit van het College van Promoties \\ in het openbaar te verdedigen \\ op vrijdag 7 oktober 2011 om 12.45 uur
}

door

Valesca Pavlawna Retèl

geboren op 23 mei 1980

te Alkmaar 
Dit proefschrift is goedgekeurd door:

Promotor: Prof. dr. W.H. van Harten (Universiteit Twente)

Assistent promotor: Dr. M.A. Joore (Universiteit Maastricht)

(C) Copyright 2011: Valesca P. Retèl, Amsterdam, the Netherlands

All rights reserved. No part of this thesis may be reproduced or transmitted in any form or by any means, electronic or mechanical, including photocopying, recording or any information storage or retrieval system, without permission in writing from the author, or, when appropriate, from the publishers of the publications.

ISBN: 978-90-365-3250-1

DOI nummer: 10.3990./1.9789036532501 


\section{Promotiecommissie}

Voorzitter/secretaris:

Prof. dr. R.A. Wessel

Universiteit Twente

Promotor:

Prof. dr. W.H. van Harten

Universiteit Twente

Assistent promotor:

Dr. M.A. Joore

Universiteit Maastricht

Overige leden:

Prof. dr. M.J. IJzerman

Universiteit Twente

Prof. dr. T.H. Ruers

Universiteit Twente

Prof. dr. J.L. Severens

Erasmus Universiteit Rotterdam

Dr. S.C. Linn

Nederlands Kanker Instituut -

Antoni van Leeuwenhoek ziekenhuis

Paranimfen:

Christian Louter

Cindy van den Hengel 

Voor mijn ouders

\& Christian 

Table of contents

Part I Introduction

Chapter 1 General introduction and outline of the dissertation

\section{Part II CTA methodology}

Chapter 2 Constructive Technology Assessment (CTA) as a tool in 70 -gene prognosis signature for breast cancer diagnostics Int J Technol Assess Health Care 2009; 25:73-83.

Chapter 3 Review of early Technology Assessments in Nanotechnologies

Molecular Oncology 2009; 3(5-6):394-401.

\section{Part III Application of CTA to the 70-gene signature}

Chapter 4 Tumour tissue: who is in control?

Chapter 5 Genomic testing: What is the impact on patients?

Chapter 6 Cost-effectiveness of the 70-gene signature versus Sankt

Gallen guidelines and Adjuvant Online for early breast cancer

European Journal of Oncology 2010; 46(8):1382-1391.

Chapter 7 Head-to-head comparison of the 70-gene signature versus the 21-gene assay: Cost-effectiveness and the effect of compliance

Breast Cancer Res Treat accepted for publication

Chapter 8 Value of Research versus Value of Development in early stages of development of new medical technologies In revision

Chapter 9 How to anticipate future developments in Comparative Effectiveness Research

Submitted 
Part IV Retrospect \& Prospect

$\begin{array}{lll}\text { Chapter } 10 \text { General discussion } & 201\end{array}$

$\begin{array}{lll}\text { Chapter } 11 \text { Summary/Samenvatting } & 221\end{array}$

Chapter 12 Dankwoord 237

Curriculum Vitae $\quad 243$

List of publications 246 

Abbreviations
$95 \% \mathrm{Cl}$
95\% Confidence Intervals
AC
Doxorubicine, Cyclofosfamide
ANOVA
Analysis of Variance
AO
Adjuvant Online
BCSS
Breast Cancer Specific Survival
CBO
Centraal BegeleidingsOrgaan
CEA
Cost-Effectiveness Analysis
CEAC
Cost-Effectiveness Acceptability Curve
CED
Coverage with Evidence Development
CE plane
Cost-Effectiveness plane
CER
Comparative Effectiveness Research
$\mathrm{Cl}$
Confidence Interval
CTA
Constructive Technology Assessment
CUA
Cost-Utility Analysis
CVZ
College voor Zorgverzekeringen
DFS
Disease Free Survival
DHCIB
Dutch Health Care Insurance Board
DM
Distant Metastasis
EBM
Evidence Based Medicine
ENBD
Expected Net Benefit of Development
ENBS
Expected Net Benefit of Sampling
EORTC
European Organisation for Research and Treatment of Cancer
$E Q-5 D$
EuroQol-5 dimension
ER
Estrogen Receptor
EVPI
Expected Value of Perfect Information
EVPPI
Expected Value of Perfect Partial Information
EVSI
Expected Value of Sampling Information
FACT-B
Functional Assessment of Cancer Therapy for Breast cancer
FDA
Food and Drug Administration
FEC
5-Fluorouracil, Epirubicine, Cyclofosfamide 
FFT

G-CSF

HER2

HTA

HRQoL

ICER

LY

MINDACT

MP

MTA

NICE

NMB

PAC

PAR

PR

QALY

QoL

RASTER

RNA

RT_PCR

SD

SE

TAC

TAILOR-X

VAT
Fresh Frozen Tissue

Granulocyte colony stimulating factor

Human Epidermal growth factor Receptor 2

Health Technology Assessment

Health related Quality of life

Incremental Cost-Effectiveness Ratio

Life Years

Microarray In Node-negative and 1 to 3 positive lymph node

Disease may Avoid ChemoTherapy; EORTC 10041/BIG 3-04

MammaPrint ${ }^{\mathrm{TM}}$

Medical Technology Assessment

National Institute for Health and Clinical Excellence

Net Monetary Benefit

Paclitaxel, Doxorubicine, Cyclofosfamide

Paraffin

Progesterone Receptor

Quality Adjusted Life Years

Quality of Life

microarRAy prognoSTics in breast cancER

Ribonucleic acid

Reverse transcription polymerase chain reaction

Standard Deviation

Standard Error

Docetaxel, Doxorubicine, Cyclofosfamide

Trial Assigning IndividuaLized Options for Treatment (Rx)

Value Added Tax 




\section{Part I}

Introduction

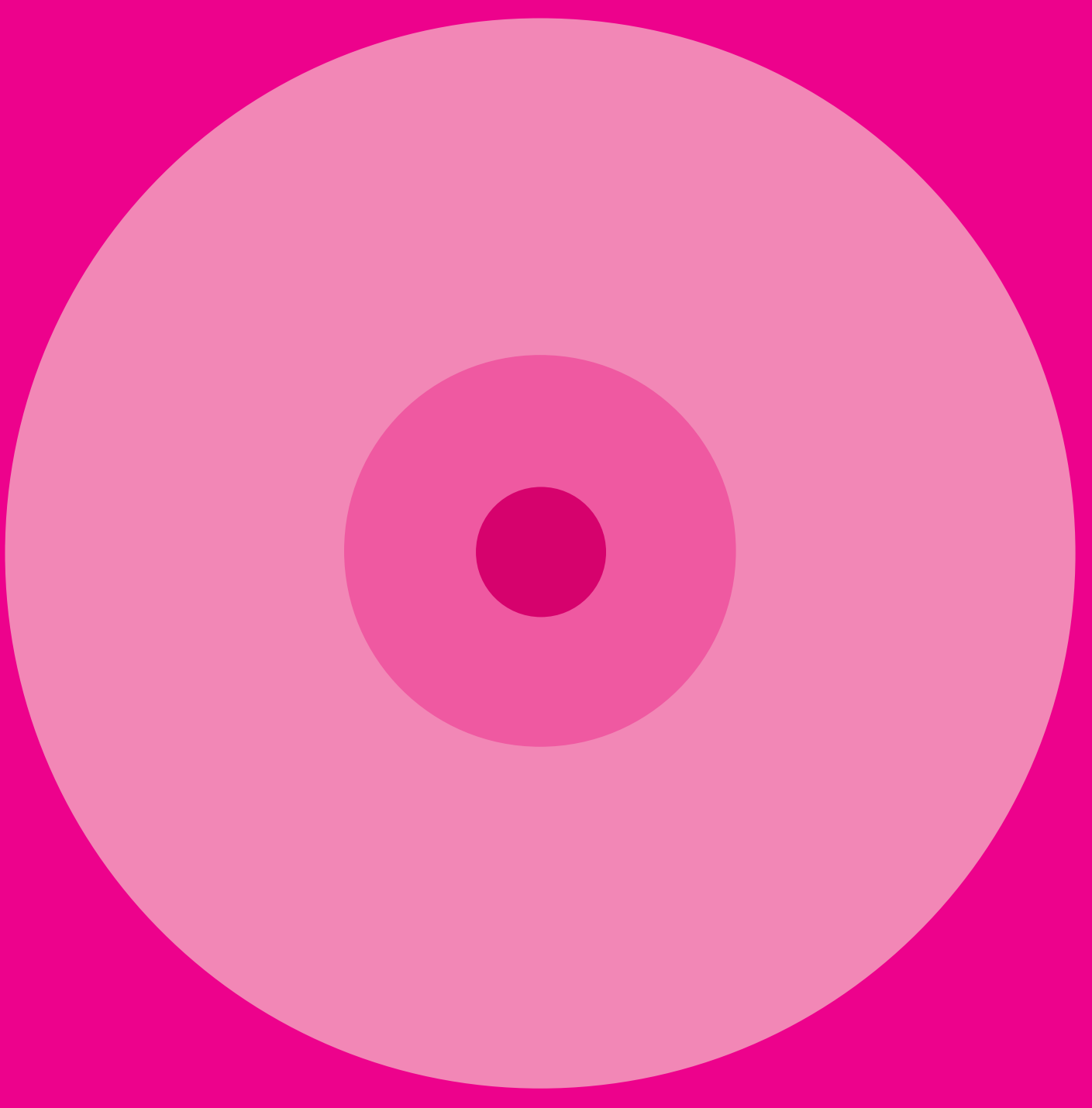




\section{Part I}

Introduction

\section{Chapter 1}

General introduction

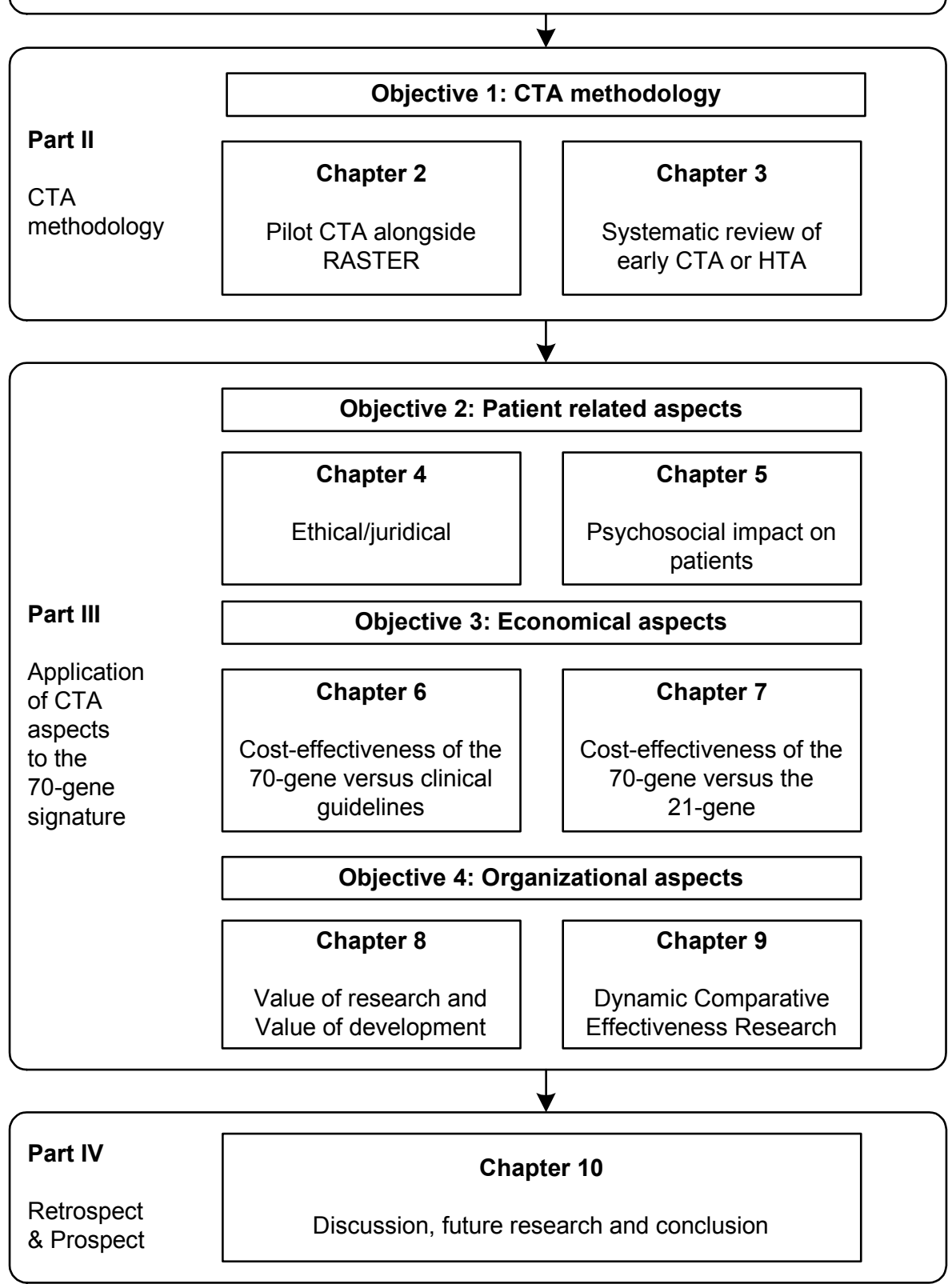




\section{Chapter 1}

General introduction and outline of the dissertation 
Chapter 1 


\section{Introduction}

The aim of this dissertation was to contribute to the knowledge on early stage Health Technology Assessment by performing a Constructive Technology Assessment for the introduction and diffusion of gene expression profiling for breast cancer patients. As a clinical case, the introduction and diffusion of the 70-gene prognosis signature (MammaPrint ${ }^{\mathrm{TM}}$ ) using microarray analysis was evaluated.

In the current chapter, the origin of the commonly used method Health Technology Assessment and the rationale behind the use of the method Constructive Technology Assessment is explained. Subsequently, the case of the 70-gene signature is sketched. Furthermore, the design of the study is described, the applied research methods, the general objectives are stated and finally the outline of the dissertation is provided.

\section{Health Technology Assessment}

Health Technology Assessment (HTA) is a field of research, which has become the mainstream in evaluation research in health care over the last decennia. HTA is part of the much broader field of Evidence Based Medicine (EBM). ${ }^{1}$ The escalating costs associated with health care was one of the most prominent and crucial consequences to arise from the technological revolution many years ago. To solve the problem of the escalating costs, solutions were sought in the economic sector. The investigation led to the development and application of cost-effectiveness analysis. It became apparent that besides the cost-effectiveness analysis much more information was needed, hence the concept of Medical Technology Assessment (MTA), which later became known as HTA, was established. ${ }^{1}$

The definition of HTA is "a multi-disciplinary field of policy analysis that examines the medical, economic, social and ethical implications of the incremental value, diffusion and use of a medical technology in health care." In Habbema et al., this concept is illustrated as an HTA-flower, in which the flower petals represent the separate disciplines (Figure 1). ${ }^{3}$ The term HTA is increasingly used instead of MTA to emphasize that Technology Assessment is not confined to new drugs, diagnostic or screening activities in health care, but also includes evaluation of the organization of care and its infrastructure. ${ }^{4}$ HTA can be seen as a bridge between the scientific evidence and policy decision-making. ${ }^{5}$ The results of HTA could be used by various groups of (health care) professionals from different levels of decision making. Nowadays, HTA is frequently used to enable decisions both on coverage and reimbursement of new technologies. ${ }^{6}$ 


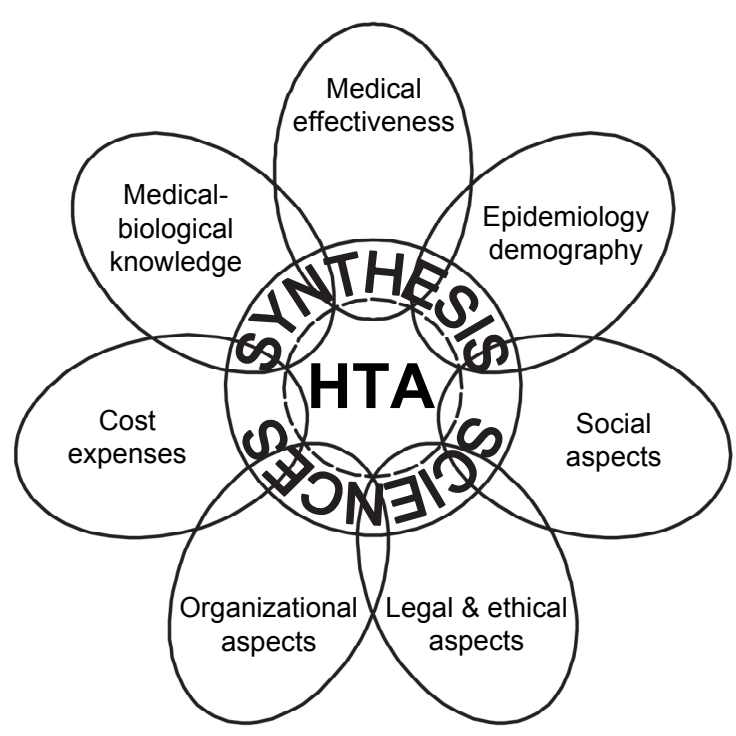

Figure 1. The HTA flower (adapted from Habbema et al.)

The main focus of HTA is mostly on performing an economic evaluation. Economic evaluation is the "comparative analysis of alternative courses of action in terms of both their costs and consequences". The basic goals of an economic evaluation are to identify, measure, value and compare the costs and consequences of the alternatives that are being considered. A cost-effectiveness analysis (CEA) is one of the four types of economic evaluation. ${ }^{7}$ In a CEA the incremental effectiveness of an intervention is quantified and compared with its incremental costs (Figure 2).
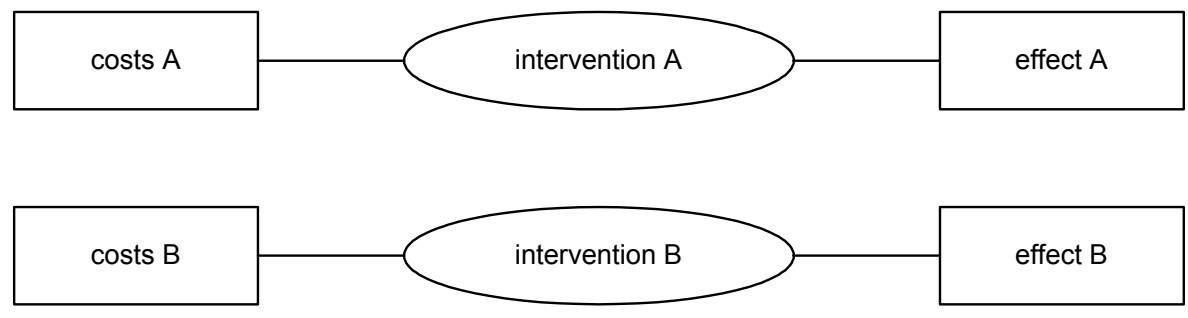

difference in costs?

relationship? Cost-effectiveness

difference in effects?

Figure 2. Economic evaluation 
Effectiveness is mostly measured using the outcomes life years (LY) or quality adjusted life years (QALY). ${ }^{7}$ The results of the simulation of a hypothetical cohort of 1000 patients can be illustrated in a Cost-Effectiveness (CE) plane; each quadrant indicates whether a strategy is more or less expensive and more or less effective (Figure 3). ${ }^{8}$ A new medical technology is said to "dominate" the currently used technology, being less costly and more effective if it is located in the South East (SE) quadrant and vice versa, the current technology dominates the new if it is located in the North West (NW) quadrant. In these two circumstances it is clearly appropriate to implement the least costly and most effective technology. However, far more often is the situation when the new technology is more effective, but also more costly (North East (NE) quadrant). In such circumstances, a decision must be made as to whether the additional health benefits are worth the additional costs. Incremental cost-effectiveness ratios (ICERS) are calculated by dividing the incremental costs $(\Delta C)$ by incremental effects $(\Delta E)$.

$$
I C E R=\frac{\Delta \mathrm{C}}{\Delta \mathrm{E}}
$$

If the ICER of the new technology is less than the acceptable maximum ICER (threshold ratio) of the decision maker, then the new technology should be adopted. ${ }^{7}$

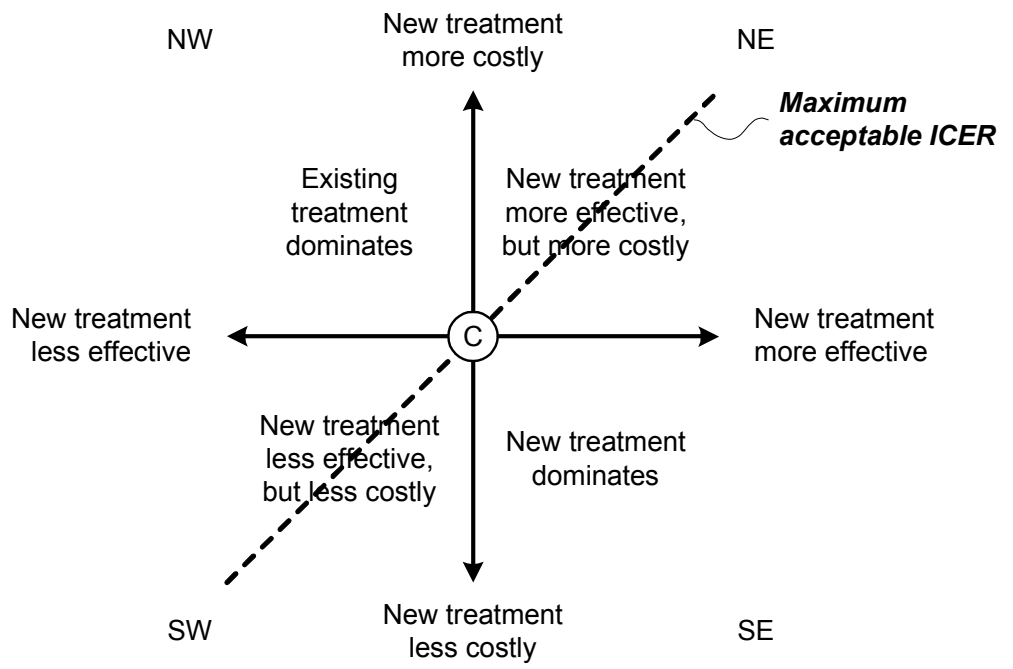

Figure 3. Cost-effectiveness plane 
Another, recently used term in the field of HTA is Comparative Effectiveness Research (CER), which attention was raised as part of restructuring the US health care system in $2009 .^{9}$ The discipline uses a wide range of methods including synthesis of existing evidence, analysis of routinely collected data, and the generation of new evidence through prospective registries and clinical trials. ${ }^{10}$ Comparing risks and benefits of different treatment strategies has been a longstanding goal of clinical research and HTA, and it is an essential part of research in CER. ${ }^{10}$ The ultimate result should be clinically relevant, timely information to inform clinical and policy decisions. Furthermore, it may be useful for rapidly evolving interventions, especially when outcomes occur soon enough to permit adaptation of the trial design or technology. ${ }^{9}$

\section{Health Technology Assessment in early stages}

Technologies in an early stage of development and/or diffusion present numerous challenges to a range of decision makers in healthcare including policy makers, payers and providers of healthcare services, health professionals, and the users of the technology. While the traditional challenges often include lack of resources (e.g. financial, human and knowledge) and lack of strong scientific evidence for introduction of the technology in the health system, there are other challenges such as motivation for implementation, sustainability of the technology or (improper) change management in the system where the new technology will be implemented. When in case of a promising new technique certain stakeholders find reason to speed up implementation in clinical practice, the effectiveness, safety, and costs are preferred to be evaluated and supported by an HTA in an early stage.

However, an HTA generally starts after the technology is stabilized and proven to be valid in clinical trials, to be able to choose between comparable technologies or alternatives for the existing situation. ${ }^{11-13}$ While the usual path of adoption in clinical practice would take at least 8-10 years, including a prospective randomized trial, during this time many changes in available treatments can occur, which results in HTA subsequently answering -at least partly- outdated questions. It commonly presumes a "ceteris paribus" (static) situation, whereas it has become evident that environment and technology are often dynamic and mutually influencing each other. ${ }^{14}$ Clinical implementation and performing an HTA for policy decisions may be premature in the absence of prospective data of the actual benefits. However, if we wait to perform an HTA, it might very well be that worthwhile technology is withheld from the public. ${ }^{15}$ This paradox has become known as Buxton's law; "It is always too early, until suddenly, it is too late...." ${ }^{16}$ 
In recent years, the need to fill this gap in the approach of HTA became apparent. ${ }^{14}$ The focus of HTA studies needs to shift from studying the quality of a new technology to optimizing the technology's quality and effectiveness under dynamic circumstances. In 2005, the Centers for Medicare and Medicaid Services decided to provide the option for "Coverage with Evidence Development" (CED) as a way out to make promising innovations accessible in an early stage. ${ }^{17}$ Instead of having to wait for the extensive, time-consuming process of generating evidence, early introduction is combined with obligatory participation in registration and research. These developments ask for appropriate methods of technology assessment. ${ }^{14}$

\section{Constructive Technology Assessment}

Constructive Technology Assessment (CTA) can be used as a complementary approach to HTA, especially for the early and dynamic introduction of new technologies in a controlled way. ${ }^{14}$ CTA was first used in the 1980 s outside the health care arena. CTA is based on the idea that during the course of technology development, choices are constantly being made about the form, the function, and the use of that technology. ${ }^{18}$ Instead of influencing policy making in health care, CTA attempts to influence the development and diffusion of a new technology. ${ }^{19}$

This influence is based on technical, medical, social and economical information provided by the diverse actors that shape development and diffusion. ${ }^{19}$ To actually effectuate changes in development and diffusion, the practices of CTA would benefit from some adjustments. In general, the methods of CTA, including technology-forcing programs, platforms, consensus development conferences, social experiments, and dialogue workshops, have been applied at a national macro level, distant from technology development. Therefore, there has been limited feedback to the technological developers and the outcomes have had little impetus. ${ }^{18}$ It has been suggested that a method of CTA applied close to the technological development activities can overcome these problems. ${ }^{20}$ By acknowledging the sociodynamic processes and in that way influence the technology's development and implementation in a desired direction, more attention should be given to aspects of technology dynamics. ${ }^{14}$

Only a limited number of publications are available describing the application of CTA in health care. ${ }^{14}$ An example is the introduction of quality management as a management technology. ${ }^{21,22}$ Another example is the use of systematic decision support as a tool to guide decisions that shape technology development and application. ${ }^{23}$ 
In this dissertation the mixed method approach of CTA covers besides aspects of quality of care following the Institute of Medicine $(I O M)^{24}$ and Poulsen ${ }^{25}$, also diffusion scenarios to monitor the dynamics (Table 1). Based on Poulsen and the IOM, HTA should at least include an integral assessment of clinical, economic, patient-related, ethical/juridical, and organizational domains. Diffusion scenarios, which are commonly applied in industry to anticipate on their strategies concerning future development, have been adapted to monitor the dynamics in this study. At different phases of CTA, the focus will shift to the aspects most likely to change during the introduction of these new technologies.

Table 1. Aspects studied in CTA (Douma et al. $)^{14}$

\begin{tabular}{ll}
\hline Parameters & Aspects \\
\hline Clinical & Efficacy, safety, effectiveness, outcomes, and the effect on the population \\
Patient-related & $\begin{array}{l}\text { Social and environmental impact, ethics, acceptability, psychological } \\
\text { reactions, patient centeredness, and other patient-related aspects }\end{array}$ \\
Economic & Cost-effectiveness \\
Organizational & $\begin{array}{l}\text { Diffusion, dissemination, organizational implementation, accessibility/equity, } \\
\text { skills/routines, education/training, and other organizational aspects }\end{array}$ \\
\hline
\end{tabular}

\section{Clinical case: breast cancer}

Breast cancer is the leading cause of cancer death in women in Europe and the second in the United States. ${ }^{26}$ In the Netherlands the incidence of breast cancer is approximately $12,500 .^{27}$ Adjuvant systemic therapy for early breast cancer improves disease-free and overall survival. ${ }^{28}$ The majority of early breast cancer patients, particular with lymph node-negative disease (60-70\%), has a fairly good 10 -year overall survival with local-regional treatment alone, with $30-40 \%$ developing distant metastasis (Figure 4). ${ }^{28}$ Nevertheless, according to current guidelines, most lymph node-negative patients are offered chemotherapy, likely causing an important proportion of over-treatment. ${ }^{29}$ Since this treatment has severe side effects, and is very costly, a careful selection of patients is important. A new diagnostic tool for breast cancer patients, 70-gene signature, is a promising technology. ${ }^{30}$ It outperforms currently used clinical factors in predicting disease outcome and thereby predicting which women do need chemotherapy and which will be spared chemotherapy. To not withhold this new technology from the public and to overcome the disadvantages of performing a static and -relatively lateHTA, it was chosen to perform a CTA, which takes technology dynamics into account. 


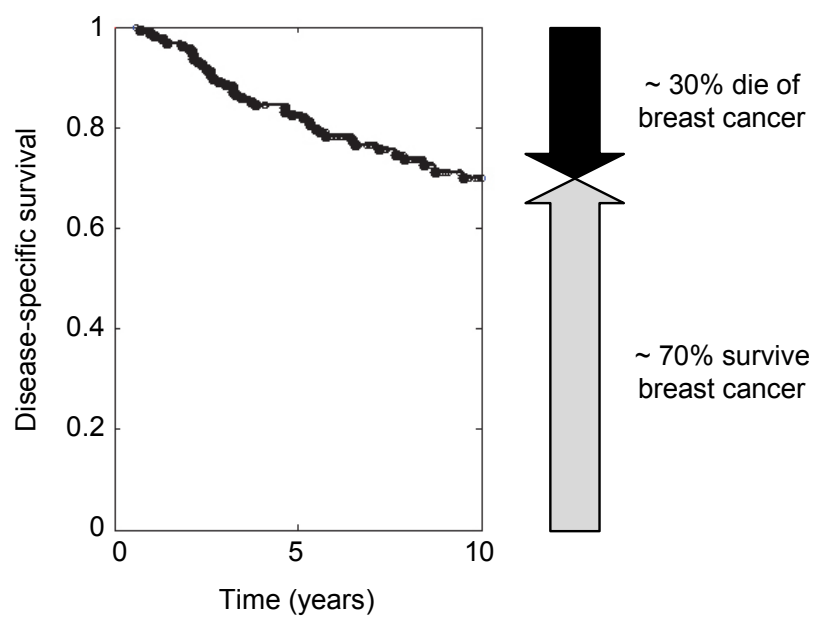

Figure 4. Survival of early stage breast cancer patients after loco-regional treatment

\section{The 70-gene signature for breast cancer}

The 70-gene prognosis signature (MammaPrint ${ }^{\mathrm{TM}}$ ) was identified in 2002 using microarray analysis for lymph node-negative breast cancer patients. ${ }^{30}$ This prognosis signature has since been validated in several retrospective patient series. ${ }^{31-33}$ These validation studies confirmed that the 70 -gene signature accurately discriminates between patients with a high and low risk of developing distant metastasis. Patients with a "good" signature were deemed to have a good prognosis and, therefore, could be spared adjuvant systemic treatment, whereas patients with a "poor" signature were judged to have a poor prognosis or a high risk of development metastasis and should be considered for adjuvant systemic treatment. 
In 2004, the multicenter microarRAy prognoSTics in breast cancER (acronym RASTER)-study was started. The main aims were to assess prospectively the feasibility of implementation of the 70-gene signature in community-based setting and to analyze the differences between adjuvant systemic treatment advice for breast cancer based on clinical guidelines and the 70-gene signature, taking into account patients' preferences. ${ }^{34}$ The feasibility study was designed to investigate the technical implementation of the 70-gene signature in daily practice in order to collect good-quality breast tumor Ribonucleic acid (RNA) in fresh frozen tissue (FFT), which is necessary for obtaining the signature. Between January 2004 and December 2006, 812 women aged under 61 years with primary breast carcinoma (clinical T1-4NOM0) were enrolled. However, a need for a higher level of evidence of the performance of the 70-gene signature remained. Therefore, the currently ongoing randomized phase III clinical trial, the MINDACT (Microarray In Nodenegative and 1 to 3 positive lymph node Disease may Avoid ChemoTherapy; EORTC 10041/BIG 3-04) trial, was designed. ${ }^{35,36}$ The MINDACT trial investigates whether the 70-gene signature selects the right patients for adjuvant chemotherapy (CT) as compared to standard clinicopathological criteria. Genomic $(G)$ and clinical (C) high risk patients are proposed adjuvant CT and G-low and C-low risk patients do not receive CT. Discordant patients (G-low/C-high or G-high/C-low) are randomized between decision of adjuvant $\mathrm{CT}$ based on the genomic or clinical assessment. All estrogen receptor (ER) positive patients are offered endocrine therapy. The trial plans to prospectively accrue 6000 patients, it started in 2007 and is expected to finish in 2012.

\section{CTA of 70 -gene signature}

The main focus of CTA in this setting is the controlled introduction of the 70-gene signature. The effects of the introduction of the microarray technology on cancer diagnostics and prognostics and decisions about adjuvant treatment will be analyzed. What are the effects on safety, effectiveness, patient centeredness, timeliness and equity within the different hospitals? Based on the theory of sociodynamics, it becomes clear that these aspects, in combination with the characteristics of the microarray analysis and the diagnostic process, can play a role in slowing down or accelerate the implementation process. ${ }^{14}$ Analyzes will be performed to identify which points of improvement are present for the microarray technology. In this way safety, effectiveness, patient-centeredness, timeliness and equity can be optimized. Accordingly, predictions can be made to optimize the cancer prognostics process and decision making about adjuvant treatment. In the following paragraphs the aspects are explained in more detail. 


\section{Patient related aspects}

Part of implementing the 70-gene signature is creating confidence among patients. Patient involvement and experiences are relevant in studying patient centeredness in using genomic tests. Patient centeredness is an approach to improve health care quality: providing care that is respectful of and responsive to individual patient preferences, needs and values and ensuring that patient values guide all clinical decisions. $^{24}$

\section{Economical aspects}

A cost-effectiveness analysis (CEA) provides a systematic comparative analysis of the available prognostic tests for node-negative breast cancer patients, preferably not only based on test performance and long-term survival, but also on quality of life and costs. The information resulting from this analysis is important for the decision to implement the 70 -gene signature and enable decisions on coverage. ${ }^{6}$

\section{Organizational aspects}

The organizational domain focuses on the delivery models of the technology, analyzing processes, resources, management and cultural issues within a variety of stakeholders, in the intra- and inter-organizational and health care system level. Understanding organizational aspects may reveal essential challenges and barriers in implementing health technologies. In an organizational analysis both qualitative and quantitative research data are often required. ${ }^{37}$

The diffusion of a new technology resembles a normal curve. Rogers' technology adoption process distinguishes several phases or 'prototypes' which represent the speed and willingness to adopt an innovation (Figure 5). ${ }^{38}$ In the innovation phase, the new technique is developed and the first organisations (innovators) adopt the technology in their daily practice. The early adoption phase describes the implementation in more hospitals: the logistics are being established and physicians increasingly base their decisions on the new technology. The early majority phase describes the implementation in a gradually increasingly number of hospitals (e.g. participating in a randomized clinical trial). The late majority is conservative and waits until the logistics are established and there is no debate on the effectiveness. The laggards are (very) hard to convince. ${ }^{38}$ 


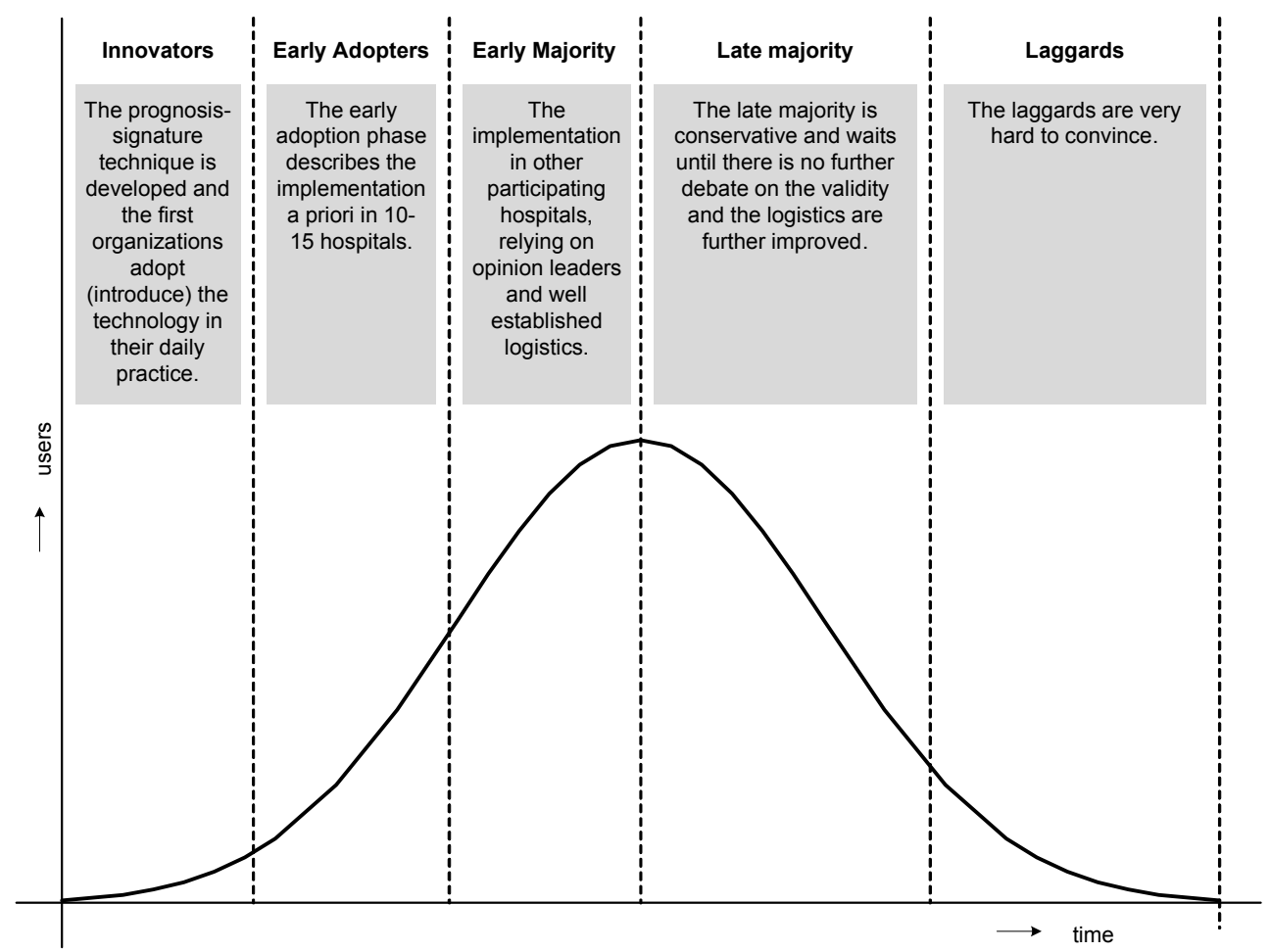

Figure 5. Rogers' adoption curve ${ }^{38}$

\section{Aim and general objectives of this dissertation}

The overall aim of this dissertation was twofold: first, to evaluate the CTA method in early stages of technology development and second, to apply the CTA method in clinical practice to the case of the 70-gene signature for breast cancer, in order to support and anticipate the introduction of this new diagnostic test, taking different CTA aspects into account (Figure 6).

Within the overall aim, four general objectives are stated as described below:

1 To evaluate the CTA method; Chapter 2 \& 3

2 To evaluate patient related aspects, more specifically ethical and juridical issues and the impact of genomic profiling on patients; Chapter 4 \& 5

3 To evaluate economical aspects by performing cost-effectiveness analyses comparing the 70-gene signature to relevant alternatives; Chapter 6 \& 7

4 To evaluate organizational aspects regarding further improvement and to address the dynamic nature of technology development by means of scenario construction; Chapter 8 \& 9 


\section{Research aspects and design}

\section{CTA method (Objective 1)}

In Chapter 2, the CTA methodology is described and was pilot tested alongside the RASTER-study by conducting pre- and post introduction interviews and questionnaires. These interviews and questionnaires contained logistic issues, patient related aspects and scenario drafting, carried out in 16 hospitals with all relevant involved professionals.

In Chapter 3, available evidence regarding various aspects of the HTA/CTA methodology is explored in the literature in the field of nanotechnologies in oncology, of which microarray technology can be seen as an early example.

\section{Patient related aspects (Objective 2)}

In the case of the 70-gene signature, patient related aspects are studied in two ways. First, Chapter $\mathbf{4}$ focuses on the ethical and juridical aspects that were raised when it became apparent that there is no strict guideline for patient rights on tissue use and storage. Together with lawyers, ethicists, researchers, clinicians and patient representatives, the problem was explored and formulated into a concept guideline.

Second, in Chapter 5, the impact of genomic testing is described. Patients' experiences and emotions such as worries and distress during the period of decision making for (possible) adjuvant treatment, as well as understandability, knowledge, risk perception and satisfaction were measured through interviews and questionnaires. Standardized question items were used, such as the Lerman scale for the cancer worry scale ${ }^{39}$, Lynch scale for distress ${ }^{40}$, and the FACT-B for Health related Quality of Life $(\mathrm{HRQOL})^{41}$. Unstandardized items were created for the additional factors.

\section{Economical aspects (Objective 3)}

Cost-effectiveness analyses (CEAs) were performed, which provide a systematic comparative analysis of the available prognostic tests for node-negative breast cancer patients. These analyses are not only based on test performance and longterm survival, but also on quality of life and costs. In Chapter 6, the costeffectiveness of the 70-gene signature is compared to the commonly used guidelines in Europe; the St. Gallen guidelines ${ }^{42}$ and Adjuvant Online software. ${ }^{43}$ 
In Chapter 7, a concurrent test is added to this comparison; the 21-gene assay (Oncotype DX) ${ }^{44}$ developed in the US, because it is preferable to compare all relevant alternatives in one analysis. In addition, information on compliance of physicians regarding the use of the genomic profiles was incorporated.

\section{Organizational aspects (Objective 4)}

Organizational aspects pilot tested during the RASTER-study are already described in Chapter 2, in Chapter 8 and 9 these aspects are explored in more detail. Chapter 8 focuses on organizational aspects concerning the possible development of an improved version of the 70-gene signature; more user-friendly and less sensitive for failures, resulting from interviews with experts. In an already known analytical framework, used to inform two separate but related decisions: whether a technology is cost-effective and thus should be adopted (I), and whether existing uncertainty warrants more research to support this decision (II) ${ }^{45}$, an additional question was stated: is there value in investing in further development of the new technology (III)? Especially in early stages of a new health care technology several options concerning the further development still exist and uncertainty levels are likely to be high. Therefore, a framework was proposed that simultaneously informs these three separate but related decisions, and applied it to the case of the 70-gene signature.

In Chapter 9, several scenarios are drafted. Scenario construction was based on the Shell method (Royal Dutch Shell Company), and using timelines described by the diffusion curve of Rogers. ${ }^{38}$ In the view of the Shell method, background research is performed, different scenarios and "what if.." options or future choices are described, structured feedback by experts is obtained, and accordingly revision of these drafts is performed. ${ }^{46}$ The most likely scenarios resulting from a scenario workshop were incorporated in a baseline cost-effectiveness model to provide information regarding the dynamics of the introduction of the 70-gene signature.

Some of the papers in this dissertation are presented as published. Some details were improved; this latter is indicated as "based on". 


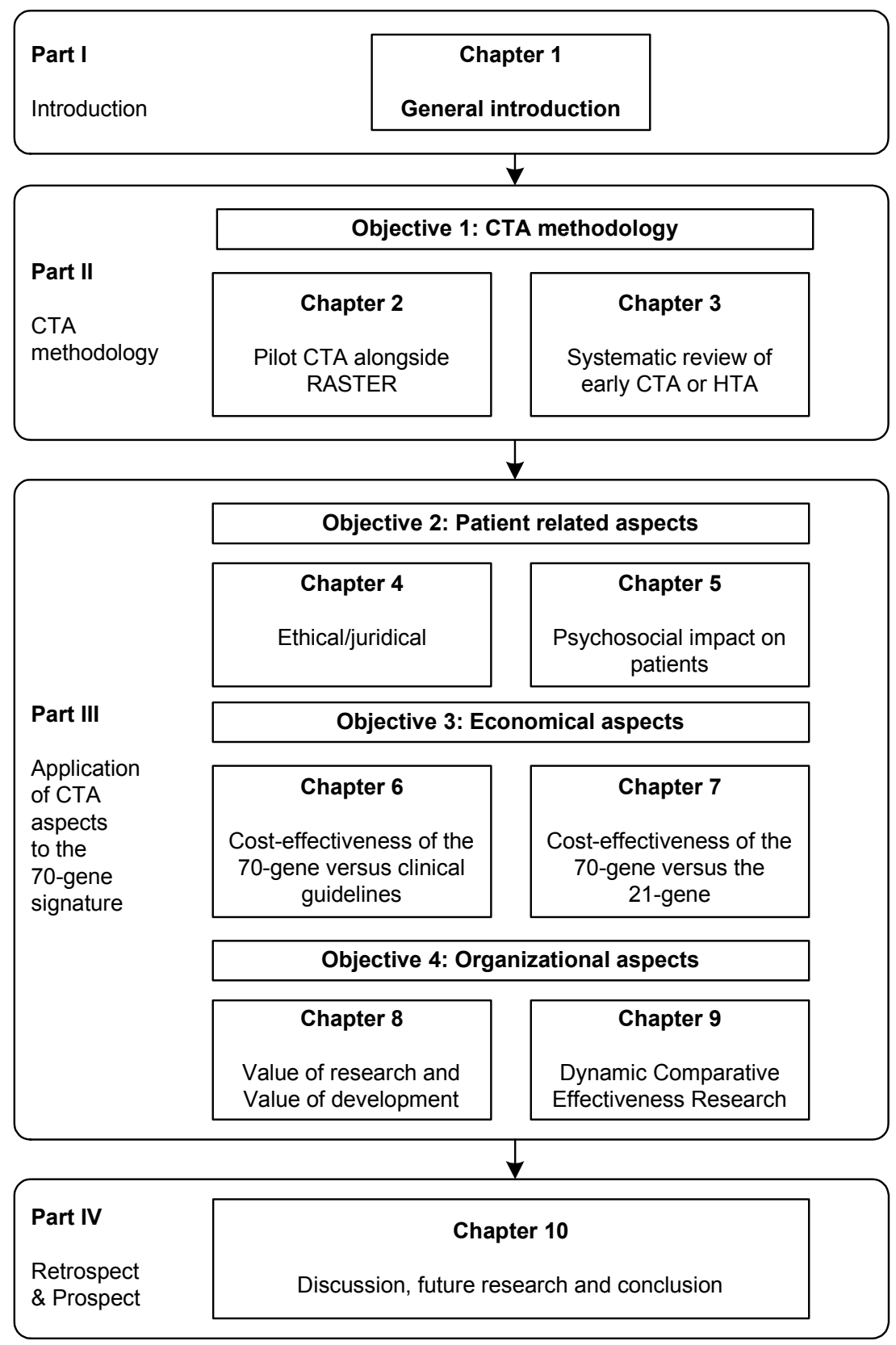

Figure 6. Outline of the dissertation 


\section{References}

1. Banta HD, Luce BR. Health care technology and its assessment, an international perspective. Oxford; Oxford University Press (1993)

2. International Network of Agencies for Health Technology Assessment. (May 15, 2009). "HTA resources.". INAHTA. http://inata.episerverhotell.net/HTA/

3. Habbema JDF, Casparie AF, Mulder JH, Rutten FFH. Medical Technology Assessment and health care policy (in Dutch). Stafleu Samson 1989.

4. Platform HTA. Promotion of HTA in the Netherlands (in Dutch). 2001. The Hague: Raad voor Gezondheidsonderzoek.

5. Battista RN and Hodge MJ: The evolving paradigm of health technology assessment: reflections for the millennium. Canadian medical Association Journal. 1999; 160(10):1464-7.

6. Hutton J, Trueman P, Henshall C: Coverage with evidence development: an examination of conceptual and policy issues. Int J Technol Assess Health Care. 2007; 23:425-432.

7. Drummond MF, Sculpher MJ, Torrance GW et al. Methods for the economic evaluation of health care programmes. Oxford: Oxford University Press; 2005.

8. Fenwick E, Claxton K, Sculpher M. Representing uncertainty: the role of costeffectiveness acceptability curves. Health Econ 2001; 10:779-787.

9. American College of Physicians. Information on Cost-Effectiveness: An Essential Product of a National Comparative Effectiveness Research Program. Ann Intern Med 2008; 148:957-961.

10. Tunis SR, Pearson SD. US moves to improve health decisions. BMJ 2010; 341:c3615.

11. Berg M, van der Grinten T, Klazinga N. Technology assessment, priority setting, and appropriate care in Dutch health care. Int J Technol Assess Health Care 2004;20:3543.

12. Draborg, E, Gyrd-Hansen, D, Poulsen, PB, Horder, M. International comparison of the definition and the practical application of health technology assessment. Int J Technol Assess Health Care 2005;21:89-95.

13. Leys $M$. Health technology assessment: The contribution of qualitative research. Int $J$ Technol Assess Health Care 2003;19:317-329.

14. Douma KF, Karsenberg K, Hummel MJ et al: Methodology of constructive technology assessment in health care. Int J Technol Assess Health Care 2007; 23:162-168.

15. Ioannidis JP: Is molecular profiling ready for use in clinical decision making? Oncologist. 2007; 12:301-311.

16. Buxton MJ. Problems in the economic appraisal of new health technology: The evaluation of heart transplants in the UK. In: Drummond MF ed. Economic appraisal of health technology in the European Community. Oxford: Oxford Medical Publications; 1987:103-118.

17. Tunis SR, Pearson SD. Coverage options for promising technologies: Medicare's coverage with evidence development. Health Affairs.2006; 5:1218-1230.

18. Schot JW: Constructive Technology assessment and Technology Dynamics: The Case of Clean Technologies. Science, Technology \& Human Values. 1992; 17:36-56.

19. Schot J, Rip A: The Past and Future of Constructive Technology Assessment. Technological Forecasting and Social Change. 1996; 54:251-268.

20. Van Eijndhoven JCM. Technology Assessment: product or process. Technological Forecasting and Social Change 1997;54:269-286. 
21. Van Harten $\mathrm{WH}$. The design and construction of a quality management system in rehabilitation. In Dutch. PhD dissertation. University of Twente, Enschede, 1997.

22. Van Harten WH, Casparie AF, Fisscher OA. Methodological considerations on the assessment of quality management systems. Health Policy 2000;54:187-200.

23. Hummel JM. Supporting medical technology development with the analytic hierarchy process. PhD dissertation. University of Groningen, 2001.

24. Institute of Medicine (IOM): Crossing the quality chasm: A new health system for the 21st century. National Academy Press. 2001.

25. Poulsen PB. Health Technology Assessment and Diffusion of health technology. Denmark: Odense University Press; 1999.

26. Parkin DM, Bray F, Ferlay J, Pisani P. Global cancer statistics, 2002. CA Cancer J Clin 2005; 55:74-108.

27. Dutch Comprehensive Centres, available at www.IKCnet.nl http://www.ikcnet.nl/uploaded/docs/Landelijk/cijfers/incidentie\%202007/A01_NL.xls.

28. Early Breast Cancer Trialists' Collaborative Group (EBCTCG). Effects of chemotherapy and hormonal therapy for early breast cancer on recurrence and 15year survival: an overview of the randomised trials. Lancet 2005; 365:1687-1717.

29. Mook S, Van't Veer LJ, Rutgers EJ et al. Individualization of therapy using Mammaprint: from development to the MINDACT Trial. Cancer Genomics Proteomics 2007; 4:147-155.

30. van 't Veer LJ, Dai $\mathrm{H}$, van de Vijver MJ et al. Gene expression profiling predicts clinical outcome of breast cancer. Nature 2002; 415:530-536.

31. van de Vijver MJ, He YD, van 't Veer LJ et al. A Gene-Expression Signature as a Predictor of Survival in Breast Cancer. N Engl J Med 2002; 347:1999-2009.

32. Buyse $M$, Loi $S$, van't Veer $L$ et al. Validation and Clinical Utility of a 70-Gene Prognostic Signature for Women With Node-Negative Breast Cancer. J Natl Cancer Inst 2006; 98:1183-1192.

33. Bueno-de-Mesquita JM, Linn SC, Keijzer R et al. Validation of 70-gene prognosis signature in node-negative breast cancer. Breast Cancer Res Treat 2009;117(3):483495.

34. Bueno-de-Mesquita JM, van Harten W, Retèl VP et al. Use of 70-gene signature to predict prognosis of patients with node-negative breast cancer: a prospective community-based feasibility study (RASTER). The Lancet Oncology 2007;8:10791087.

35. Bogaerts J, Cardoso F, Buyse M et al. Gene signature evaluation as a prognostic tool: challenges in the design of the MINDACT trial. Nat Clin Pract Oncol 2006; 3:540-551.

36. Cardoso F, Van't Veer L, Rutgers $E$ et al. Clinical application of the 70-gene profile: the MINDACT trial. J Clin Oncol 2008; 26:729-735.

37. Fronsdal KB, Facey K, Klemp M et al. Health Technology Assessment in health technology utilization: Using implementation initiatives and monitoring processes. Int $\mathrm{J}$ Technol Assess Health Care 2010; 36(3):309-316.

38. Rogers EM: Diffusion of Innovations. 5th edition. New York: Free Press, 2003

39. Lerman C, Daly M, Masny A et al. Attitudes about genetic testing for breast-ovarian cancer susceptibility. J Clin Oncol 1994; 12:843-850.

40. Lynch HT, Lemon SJ, Durham C et al. A descriptive study of BRCA1 testing and reactions to disclosure of test results. Cancer 1997; 79:2219-2228.

41. Brady MJ, Cella DF, Mo F et al. Reliability and validity of the Functional Assessment of Cancer Therapy-Breast quality-of-life instrument. J Clin Oncol 1997; 15:974-986.

42. Goldhirsch A, Glick JH, Gelber RD et al: Meeting highlights: International Consensus Panel on the Treatment of Primary Breast Cancer. Seventh International Conference on Adjuvant Therapy of Primary Breast Cancer. J Clin Oncol 2001; 19:3817-3827. 
43. Ravdin PM, Siminoff LA, Davis GJ et al. Computer program to assist in making decisions about adjuvant therapy for women with early breast cancer. J Clin Oncol 2001; 19:980-991.

44. Paik S, Shak S, Tang $\mathrm{G}$ et al. A multigene assay to predict recurrence of tamoxifentreated, node-negative breast cancer. N Engl J Med 2004; 351:2817-2826.

45. Claxton K, Sculpher M, Drummond M. A rational framework for decision making by the National Institute For Clinical Excellence (NICE). Lancet 2002; 360:711-715.

46. Royal Dutch Shell Company. www.shell.com, Available at http://wwwstatic.shell.com/static/public/downloads/brochures/corporate_pkg/scenarios/explorers _guide.pdf 



\section{Part II}

CTA methodology

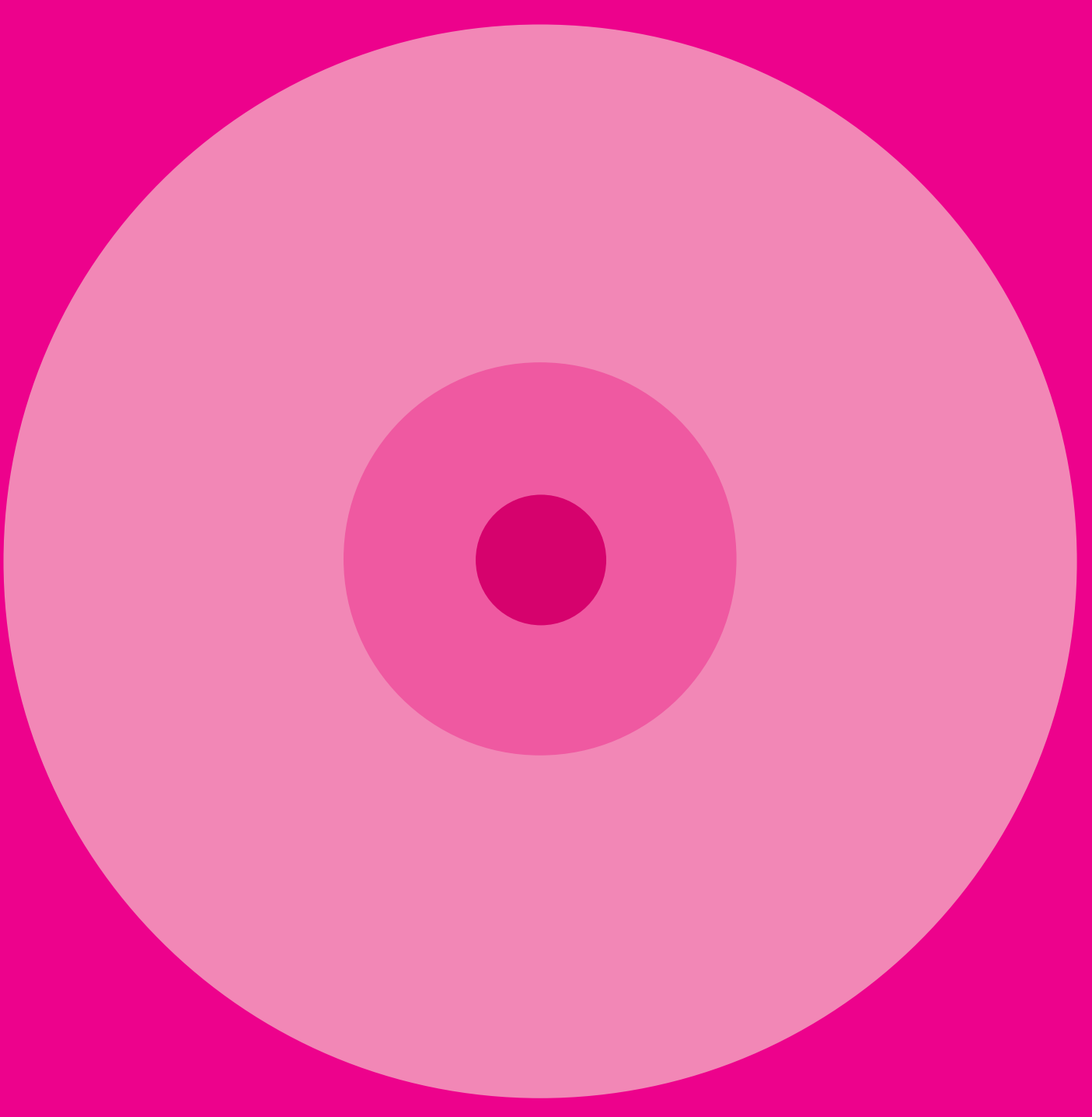




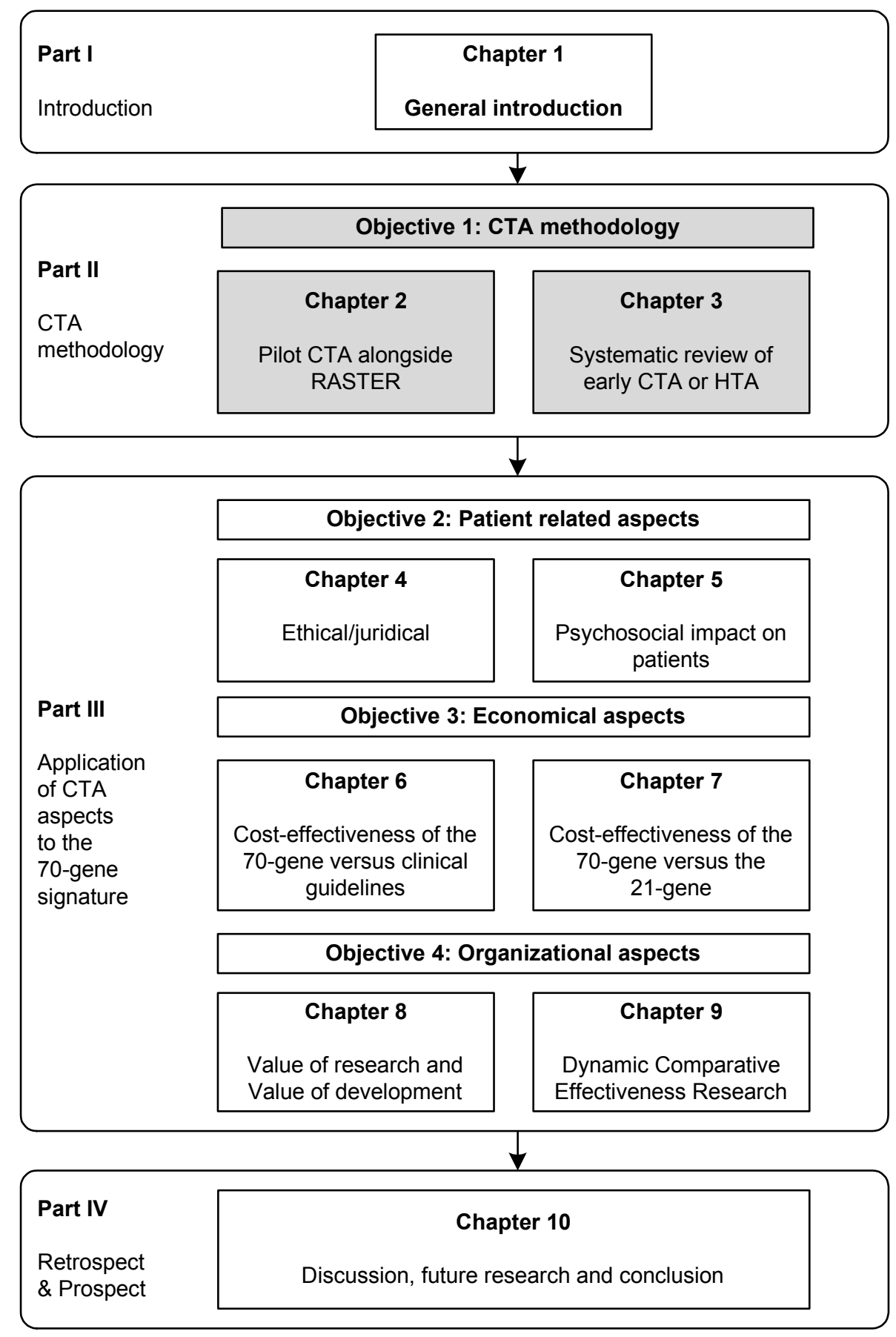




\title{
Chapter 2
}

Constructive Technology Assessment (CTA) as a tool in Coverage with Evidence Development: the case of the 70-gene prognosis signature for breast cancer diagnostics

\author{
Valesca P. Retèl \\ Jolien M. Bueno-de-Mesquita \\ Marjan J.M. Hummel \\ Marc J. van de Vijver \\ Kirsten F.L. Douma \\ Kim Karsenberg \\ Frits S.A.M. van Dam \\ Cees van Krimpen \\ Frank E. Bellot \\ Rudi M.H. Roumen \\ Sabine C. Linn \\ Wim H. van Harten
}




\section{Abstract \\ Objectives}

Constructive Technology Assessment (CTA) is a means to guide early implementation of new developments in society, and can be used as an evaluation tool for Coverage with Evidence Development (CED). We used CTA for the introduction of a new diagnostic test in the Netherlands, the 70-gene prognosis signature (MammaPrint ${ }^{\top \mathrm{M}}$ ) for node-negative breast cancer patients.

\section{Methods}

Studied aspects were (organizational) efficiency, patient-centeredness and diffusion scenarios. Pre-post structured surveys were conducted in 15 community hospitals concerning changes in logistics and teamwork as a consequence of the introduction of the 70-gene signature. Patient-centeredness was measured by questionnaires and interviews regarding knowledge and psychological impact of the test. Diffusion scenarios, which are commonly applied in industry to anticipate on future development and diffusion of their products, have been applied in this study.

\section{Results}

Median implementation-time of the 70-gene signature was 1.2 months. Most changes were seen in pathology processes and adjuvant treatment decisions. Physicians valued the addition of the 70-gene signature information as beneficial for patient management. Patient-centeredness ( $N=77$, response $78 \%$ ): patients receiving a concordant high-risk and discordant clinical low/high risk-signature showed significantly more negative emotions with respect to receiving both testresults compared to concordant low-risk and discordant clinical high/low risksignature patients. The first scenario was written in 2004 before the introduction of the 70-gene signature and identified hypothetical developments that could influence diffusion; especially the "What if-deviation" describing a discussion on validity among physicians proved to be realistic.

\section{Conclusions}

Differences in speed of implementation and influenced treatment decisions were seen. Impact on patients seems especially related to discordance and its successive communication. In the future, scenario drafting will lead to input for model-based cost-effectiveness analysis. Finally, CTA can be useful as a tool to guide CED by adding monitoring and anticipation on possible developments during early implementation, to the assessment of promising new technologies. 


\section{Introduction}

Many new genomic- and genetic related findings have lately been published. Health policy challenges arise when the promising new technology is in its early development phase and certain stakeholders find reason to speed up implementation in clinical practice. Nowadays, Technology Assessment (TA) is a frequently used evaluation approach to enable decisions on coverage and reimbursement of new technologies. ${ }^{1}$ However, the point at which a new technology should be assessed remains a contentious issue. ${ }^{2}$ Broad clinical implementation and performing a TA for policy decisions may be premature in the absence of prospective data of the actual benefits. However, if we wait to perform a TA, it might very well be that worthwhile technology is withheld from the public. ${ }^{3}$ Coverage decisions usually have to be made at a time when the data on all the relevant variables and adequate comparisons are not available from high-quality studies. "Coverage with Evidence Development" (CED) is one of several policy options that have been posited to overcome the problems associated with making coverage decisions under uncertainty. ${ }^{1}$

In the Netherlands, the Dutch Health Care Insurance Board (DHClB) has experimented with a program of controlled introduction of promising innovations in an early stage of development from 2004 onwards. Our case, the use of the 70gene signature, was one of the three technologies to be studied. At present, the DHCIB and the ministry of Health Care are discussing the most appropriate way of stimulating innovations, for instance through a "Coverage with Evidence Development" program.

In 2002, researchers at the Netherlands Cancer Institute (NKI, Amsterdam, the Netherlands) identified a new genomic technology: the 70-gene prognosis signature (MammaPrint ${ }^{\mathrm{TM}}$ (70-gene prognosis signature, performed by Agendia, Amsterdam; MammaPrint ${ }^{\circledR}$ Agendia's 'Mammaprint diagnostic service' is cleared by the Food and Drug Administration as an IVDMIA medical device and is ISO-

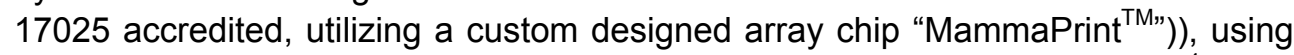
microarray analysis for lymph node-negative breast cancer patients. ${ }^{4}$ This signature was presumed to outperform currently used clinical factors in predicting disease outcome and overall survival. A patients' prognosis is usually based on clinical and pathological factors, such as age, nodal status, tumor diameter and histological grade. However, these factors do not accurately predict the exact clinical behavior of breast tumors, and therefore, patients can be under-treated or especially over-treated. It is generally agreed that patients with a poor prognosis or clinical high risk for metastasis will benefit from adjuvant systemic treatment. ${ }^{5}$ However, since these treatments can have severe side effects, a careful selection of those high-risk patients is very important. Using the 70-gene signature, the 
selection of patients that will benefit most from adjuvant systemic treatment could be more accurate. The signature has meanwhile been validated in three retrospective patient series. ${ }^{6-8}$ It would take at least 8-10 years to bring the signature into clinical practice, via the usual path of prospective trials. Therefore it was decided that a controlled introduction would be appropriate to evaluate this technology. The DHCIB sponsored this controlled introduction study, along with a technology assessment to ensure and improve the quality of implementation. ${ }^{9}$ The MicroarRAy PrognoSTics in Breast CancER (acronym RASTER)-study was a clinical, multicenter, prospective observational study. The main aim was to analyze the differences between adjuvant systemic treatment advice for breast cancer based on the Dutch $\mathrm{CBO}$ guidelines ${ }^{10}$ and the prognosis signature, taking into account patients' preferences. ${ }^{11}$ We chose to support the controlled introduction of the 70-gene signature with a comprehensive technology assessment, which takes technology dynamics into account, and decided to perform a Constructive Technology Assessment (CTA). CTA is based on the idea that during the course of technology development, choices are constantly being made about the form, the function, and the use of that technology. ${ }^{12}$ CTA has developed from assessing the impact of a new technology to a broader approach, including the analysis of design, development, and implementation of that new technology.$^{13}$ CTA is related to Health Technology Assessment (HTA), which predominantly implies a CostEffectiveness Analysis (CEA). HTA generally starts after the technology is stabilized and proved to be valid in clinical trials. It commonly presumes a "ceteris paribus" (static) situation, whereas it has become evident that environment and technology are often dynamic and mutually influencing each other. Besides 'studying' changes, 'influencing' changes is sometimes necessary to improve effectiveness. During this time many changes in available treatments can occur, which results in that HTA subsequently answers -at least partly- outdated questions. CTA can be used as a complementary approach to HTA, especially for the early and dynamic introduction of new technologies in a controlled way. ${ }^{9}$ Only a limited number of publications are available describing the application of CTA in health care. ${ }^{9,14}$ At different phases of CTA, the focus will shift to the aspects most likely to change during the introduction of these new technologies. In this study the mixed method approach of the CTA covers aspects of quality of care following the Institute of Medicine (IOM) $)^{15}$ and uses diffusion scenarios to monitor the dynamics. Diffusion scenarios, which are commonly applied in industry to anticipate on their strategies concerning future development, have been adapted in this study. 
Our aim was to perform a CTA on the controlled introduction of the 70-gene prognosis signature in the participating community hospitals, in order to anticipate in modern decision- and policy making.

The following sub studies were performed:

0) Clinical effectiveness: studied in the clinical feasibility study, the MicroarRAy PrognoSTics in Breast CancER (acronym RASTER)-study, and more detailed reported by Bueno-de-Mesquita et al., 2007 (4). The most important results of the clinical implementation study were: out of 812 accrued patients, 427 prognosis signatures were assessed, $51 \%$ of the patients (219/427) had a good and $49 \%$ (208/427) a poor prognosis signature. The prognosis signature was discordant with risk assessment based on the Dutch CBO-guidelines in 30\% of the cases, which resulted in change of treatment in $54 \%$ of the discordant patients (Figure 1a, 1b and 1c). Discordant cases are patients who are clinically low risk and according to the signature high risk or clinically high risk and according to the signature low risk.

In this paper we report on:

1) Organizational efficiency: What are the changes to the actual care provision processes, logistics and teamwork, and which organizational aspects influence the implementation?

2) Patient centeredness: Analyzing understanding, psychological impact of the test results, satisfaction and decision-making process.

3) Diffusion scenarios: Are diffusion scenarios, commonly used in industry, applicable for new technologies in health care? And how can we use these diffusion scenarios to guide the implementation process in this study? 


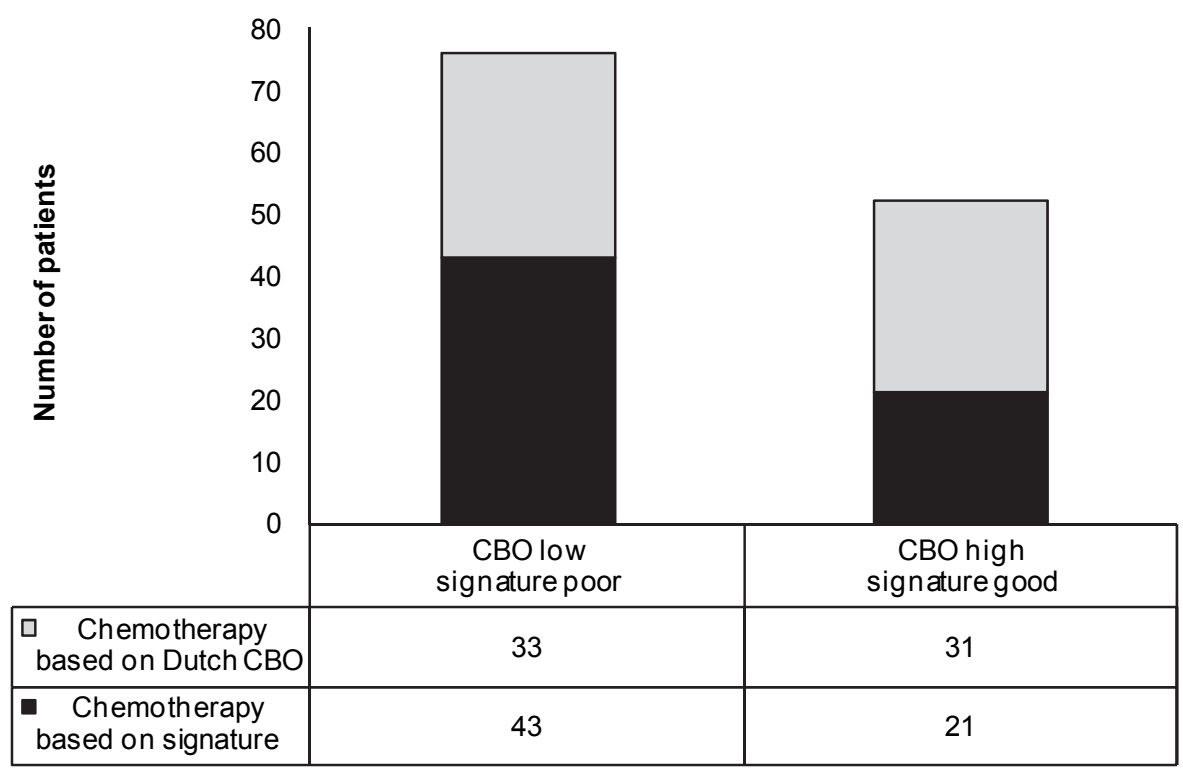

Figure 1a. Adjuvant chemotherapy in discordant patients based either on prognosis signature or clinical risk (based on Dutch CBO guidelines). RASTER numbers from Bueno-de-Mesquita et al. ${ }^{11}$

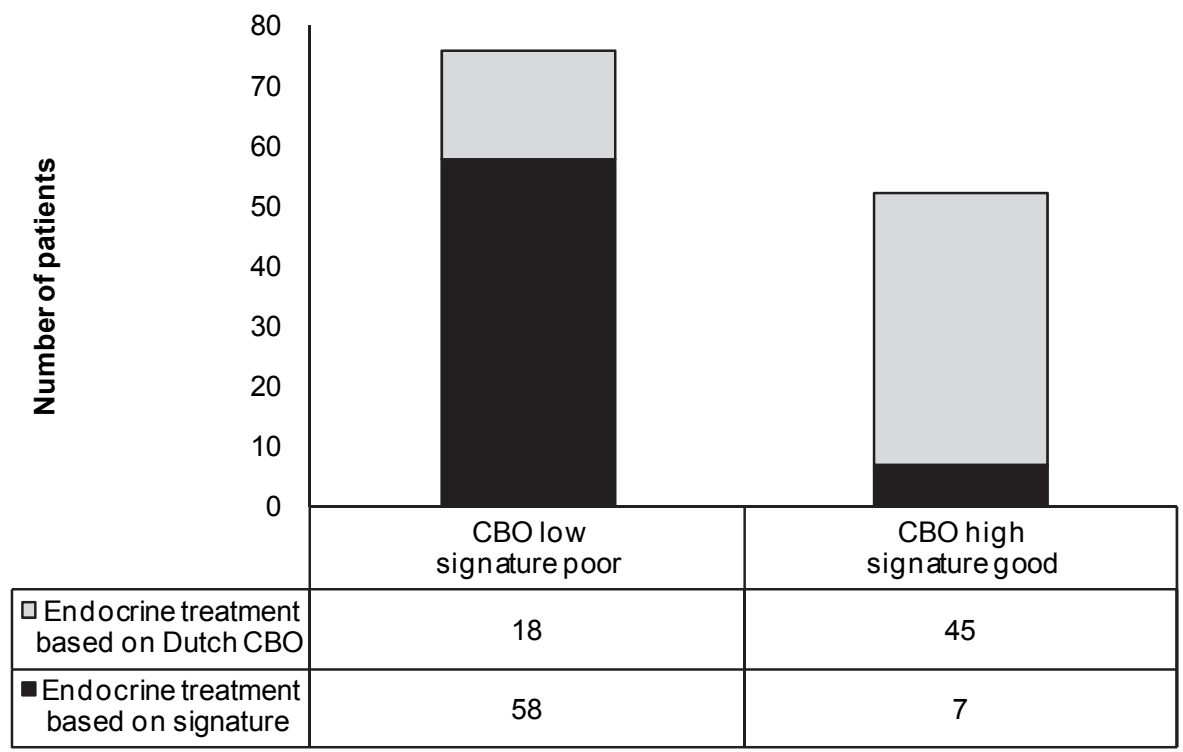

Figure 1b. Adjuvant endocrine treatment in discordant patients based either on prognosis signature or clinical risk (based on Dutch CBO guidelines). RASTER numbers from Bueno-de-Mesquita et al. ${ }^{11}$ 


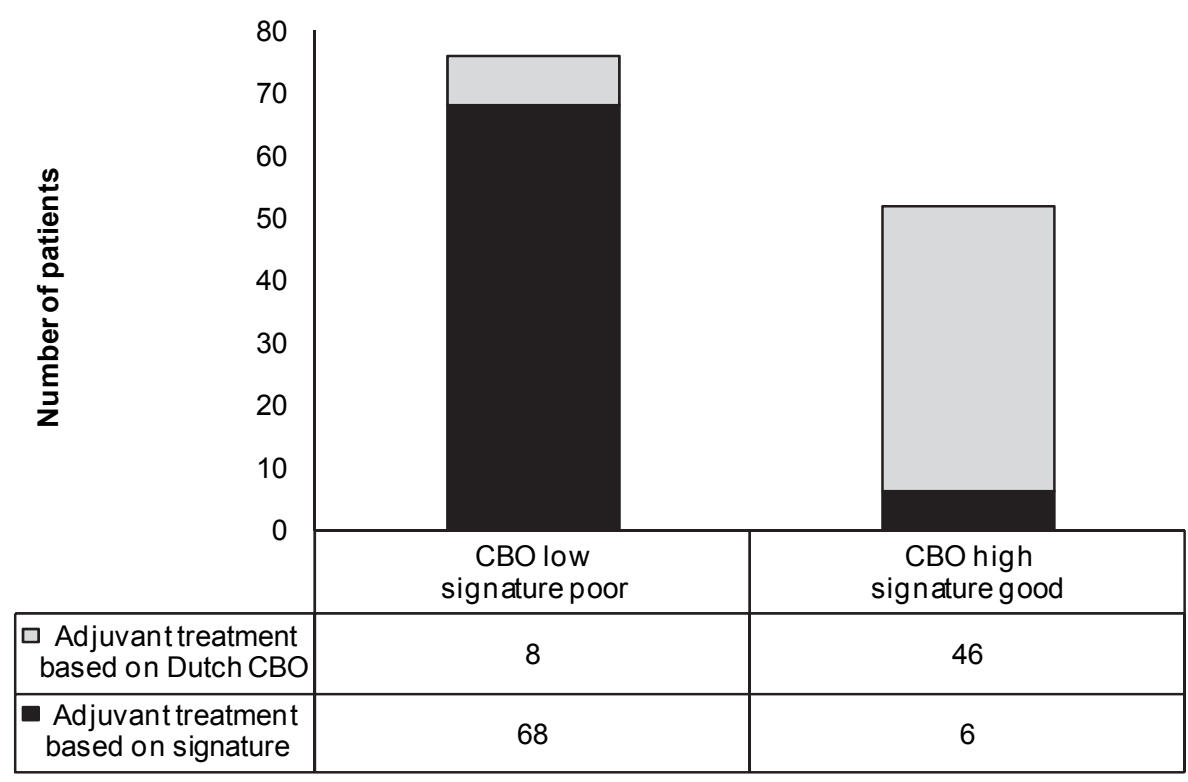

Figure 1c. Adjuvant systemic treatment (chemotherapy and/or endocrine therapy) in discordant patients based either on prognosis signature or clinical risk (based on Dutch CBO guidelines). RASTER numbers from Bueno-de-Mesquita et al. ${ }^{11}$

\section{Methods}

The CTA-study was part of the clinical RASTER-study, using the same procedures and thus the same hospital team-members and (part of the) patient population. ${ }^{11}$ The Institutional Review Board of the Netherlands Cancer Institute approved this side-study.

\section{Organizational efficiency: Logistics and Teamwork}

In the participating hospitals, semi-structured baseline and post-survey interviews were conducted, involving all relevant breast cancer care team members. The post-survey was conducted at a minimum of 6 months after the first included patient. Information was gathered regarding changes of the total clinical and pathological processes, and processes of multidisciplinary meetings and related patient contacts. Finally, the team members were questioned about their expectations regarding the role this signature would play in future clinical practice. 


\section{Patient centeredness}

Based on a pilot series of structured interviews, a questionnaire was constructed and was sent to patients from 3 of the 16 participating hospitals at 4 weeks after surgery. At that moment, patients had received the results of the pathological report, the prognosis signature outcome and the final adjuvant systemic treatment advice. The main topics were: was the information about the prognosis signature and its consequences clear to the women and what was the impact of the prognosis signature outcome on these women? This was measured according to the following parameters. 1) Knowledge questions to assess the insight of the patients in the consequences of the 70-gene signature 2) Perception of satisfaction regarding the whole trajectory, informational process of the prognosis signature, receiving the outcomes and the treatment decision; 3) Psychological impact, conducted by a questionnaire (developed by Lynch et al. ${ }^{16}$ and adapted for the Dutch population by Bleiker ${ }^{17}$ ), was used to assess the respondents' emotional reaction to the test results, also called 'negative affects', and the Cancer Worriesscale developed by Lerman et al. ${ }^{18}$ which assessed the amount of worries the women had after receiving the 70-gene signature. Calculations were done with SPSS (version 15.0), using univariate analysis, factor analysis and ANOVA.

\section{Diffusion scenarios}

Scenarios can be used to monitor the implementation process through the various diffusion phases and can support and identify the need for evaluation or even interfere through formal decision making. ${ }^{9}$ The method used to describe scenarios is based on the Royal Dutch Shell approach, using a most likely course of development with 'There Is No Alternative' (TINA) elements and alternative course projections represented by 'what if'-deviations. A baseline description was drafted, regarding the consensus of expert opinions. It was written before the prognosis signature was introduced in the Netherlands (mid-2004), using the timeline of diffusion phases as described by Rogers' diffusion theory, $2003 .{ }^{19}$ In the innovation phase, the prognosis signature technique is developed and the first organizations adopt (introduce) the technology in their daily practice, in this phase the presence of a champion (an opinion leader) is necessary. The early adoption phase describes the implementation a priori in 10-15 hospitals. The early majority phase describes the implementation in other participating hospitals that are relying on opinion leaders and well established logistics. The late majority is conservative and waits until there is no further debate on the validity and clinical value of the test and the logistics are further improved. A second scenario was drafted based on the first experiences (mid-2005). 


\section{Results}

\section{Organizational efficiency: Logistics and Teamwork}

Baseline and post-surveys were conducted in 15 of the 16 participating hospitals in the RASTER-study (Table 1). All hospitals succeeded in implementing the required tumor sampling logistics. The duration of the implementation, measured from consent to participate till first patient inclusion, varied from 0.2-9.4 months (median 1.2). ${ }^{11}$ The two outliers (4.3 and 9.4 months) especially had start-up problems in the pathology process. The change in routine work-up for tissue handling (fresh frozen tissue versus paraffin embedding) and the onsite availability of the pathologist were most difficult to achieve. However, if those logistics were in place, no other major problems appeared. The time between surgery and start of radiotherapy or adjuvant systemic treatment did not change as a result of the new technology in any of the hospitals. In the beginning, the explanation of both the nature of the prognosis signature and the study design to the patients was timeconsuming (reported in thirteen hospitals), but once accustomed to the procedure, consultation times returned to normal. As the results could be either concordant or discordant with existing clinical guidelines, oncologists had to be careful concerning the moment and manner of giving the results of both the tests to the patient. Because of the longer waiting time (about 10-14 days for execution of the signature and the nodal status), discordant patients were either discussed twice in the multidisciplinary team, or the medical-oncologist took a final decision as soon as both were available. The overall trend was to initially follow the pathology report and to communicate this with the patient, stating that the treatment advice could be changed based on the signature result. Six hospitals indicated to make the treatment-decision based only on the pathology report, because they questioned the value of the prognosis signature considering lack of validation studies available at that time. However, of the total number of discordant patients $(n=128$ in the RASTER-study), the decision to use adjuvant treatment compared to the CBO guidelines was changed in $54 \%$ of these patients. ${ }^{11}$ This resulted in an additional increase of $1 \%$ of patients who were advised chemotherapy, $9 \%$ of patients who were advised endocrine treatment and $2 \%$ of patients who were advised both. 11 Clinicians and patients seemed to base their decision on the more unfavorable predictor, regardless whether this was the genomic or clinical (Figures 1a, 1b and 1c). All interviewed physicians expected that the signature will eventually become part of future regular diagnostics. Some expected the signature to be performed in all patients; others considered it as complementary parameter especially in difficult cases. In general, the physicians rated the addition of the 70-gene signature as beneficial for patient management; however several medical-oncologists tended to look for more confirmative data concerning the validity of the signature. 
Table 1. Logistics and teamwork as an aspect of efficiency, per hospital $(\mathrm{N}=15)$.

\begin{tabular}{|c|c|c|c|c|c|c|c|}
\hline $\begin{array}{l}\frac{\infty}{N} \\
\frac{\pi}{0} \\
\frac{0}{0} \\
\frac{0}{x}\end{array}$ & 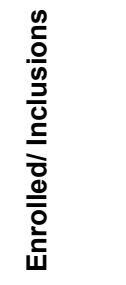 & 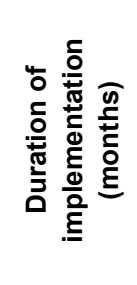 & 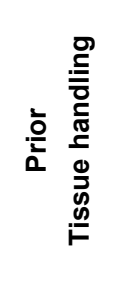 & $\begin{array}{l}\text { ত̀े } \\
\text { 응 } \\
\text { 휴 } \\
0\end{array}$ & 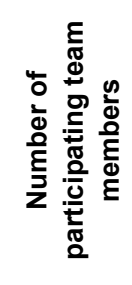 & 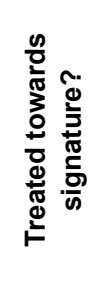 & $\begin{array}{l}5 \\
\frac{5}{\alpha} \\
\frac{0}{0} \\
\frac{0}{0} \\
\frac{0}{0}\end{array}$ \\
\hline 1 & $172 / 106$ & 1.2 & Dry & Inside & 5 & Yes & MDM \\
\hline 2 & $124 / 65$ & 1.7 & Dry & Inside & 5 & Yes & MDM \\
\hline 3 & $114 / 41$ & 0.4 & Formalin & Outside & 5 & Yes & MDM \\
\hline 4 & $103 / 52$ & 1.1 & Dry & Inside & 6 & Yes & Onc \\
\hline 5 & $66 / 40$ & 1.1 & Dry & Outside & 4 & Yes & Onc \\
\hline 6 & $59 / 31$ & 0.3 & Dry & Inside & 6 & Yes & MDM \\
\hline 7 & $40 / 19$ & 2.3 & Dry & Inside & 9 & Yes & MDM \\
\hline 8 & $31 / 28$ & 1.4 & Formalin & Inside & 10 & Yes & MDM \\
\hline 9 & $21 / 9$ & 9.4 & Dry & Inside & 6 & No & Onc \\
\hline 10 & $21 / 14$ & 1.5 & Dry & Inside & 5 & No & MDM \\
\hline 11 & $18 / 13$ & 0.9 & Formalin & Outside & 8 & No & Onc \\
\hline 12 & $13 / 4$ & 1.6 & Dry & Inside & 7 & Yes & Onc \\
\hline 13 & $6 / 3$ & 0.7 & Formalin & Outside & 4 & No & Onc \\
\hline 14 & $4 / 0$ & 0.2 & Formalin & Outside & 7 & No & Surg \\
\hline 15 & $4 / 3$ & 4.3 & Formalin & Inside & 7 & No & Onc \\
\hline Total & $812 / 427$ & Med 1.2 & $9 / 6$ & $11 / 5$ & Med 6 & $9 / 6$ & $7 / 7 / 1$ \\
\hline
\end{tabular}

Inclusions of patients/numbers of signatures performed; Duration of implementation in months: calculated from Review Board Approval until the first included patient; Prior tissue handling: tumor tissue storage before start of the RASTER-study, based on paraffin (formalin) or fresh frozen (dry); Pathology lab inside or outside the hospital; Number of participating team members in the RASTERstudy; The result of the gene signature part of the adjuvant treatment advice; Disciplinary eventually decided on adjuvant systemic (AST) treatment: MDM: multidisciplinary meetings, onc: medical oncologist, surg: surgeon. Med: median 


\section{Patient centeredness}

In total, 29 interviews and 48 questionnaires were analyzed, $N=77$ (response rate of the questionnaires was $78 \%$ ). The mean age of the responders was 48 years (range 27-59) (Supplementary Table 1), which did not differ from the total RASTER population, but the distribution of the risk groups were different (more concordant low-risk patients).

The results from the knowledge test are presented in Figure 2 and were not different in the three hospitals. Important issues were the predictive accuracy of the test ( $87 \%$ wrong answers) and the consequences of the test (66\% wrong answers).

Significant differences $(p=0.001)$ were found between the different risk groups for emotional reactions after receiving the 70-gene signature. Women with discordant clinical low/high risk-signature and clinical high risk/no signature (no signature due to failure in process) had the highest negative affect-scores $(N=77)$. Remarkably, women with a clinical high/good signature scored almost the same as women with clinical low/good signature (Figure 3 ). The scores of "thought about chances of getting cancer again influencing the mood" on the Cancer Worries-scale $(N=77)^{18}$ were significantly different $(p=0.01)$ per risk-group: $43 \%$ of patients with clinical low/poor signature and $29 \%$ clinical high/no signature often worried about getting a recurrence, compared with $0 \%$ of the patients with clinical high/good signature, $20 \%$ clinical low/no signature, $13 \%$ clinical high/poor signature and $3 \%$ clinical low/good signature. This was consistent with the Lynch-scale.

The satisfaction about receiving the 70 -gene signature per risk-group was $76 \%$. 6 out of 70 patients $(8.6 \%)$ were very dissatisfied, 4 of those patients had a discordant clinical low/high risk-signature, 2 (no discordant patients) were dissatisfied about the way the result of the 70-gene signature was communicated. 11 patients had a neutral opinion. The overall satisfaction regarding the total trajectory, from diagnosis to the time of interviewing, around 2 months after surgery, was $82 \%(N=77)$. For more results, see Supplementary Table 2. 


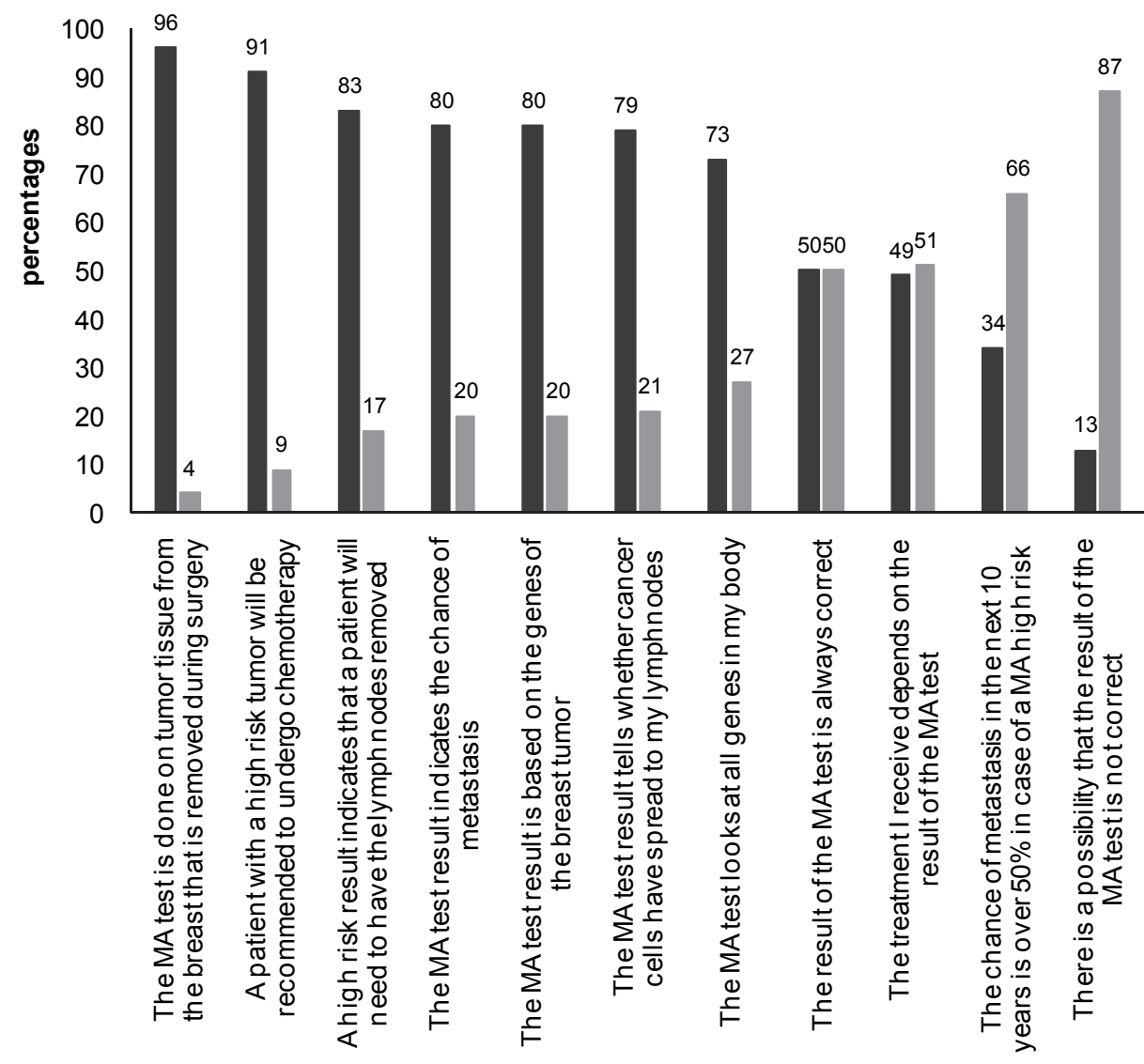

- \% Questions correctly an swered

\% Questions not correctly answered

Figure 2. Knowledge items

Results of the knowledge questions $(N=77)$. MA test: microarray test. Percentage $(\%)$ correctly answered questions by the patient and not correctly answered questions by the patient. 


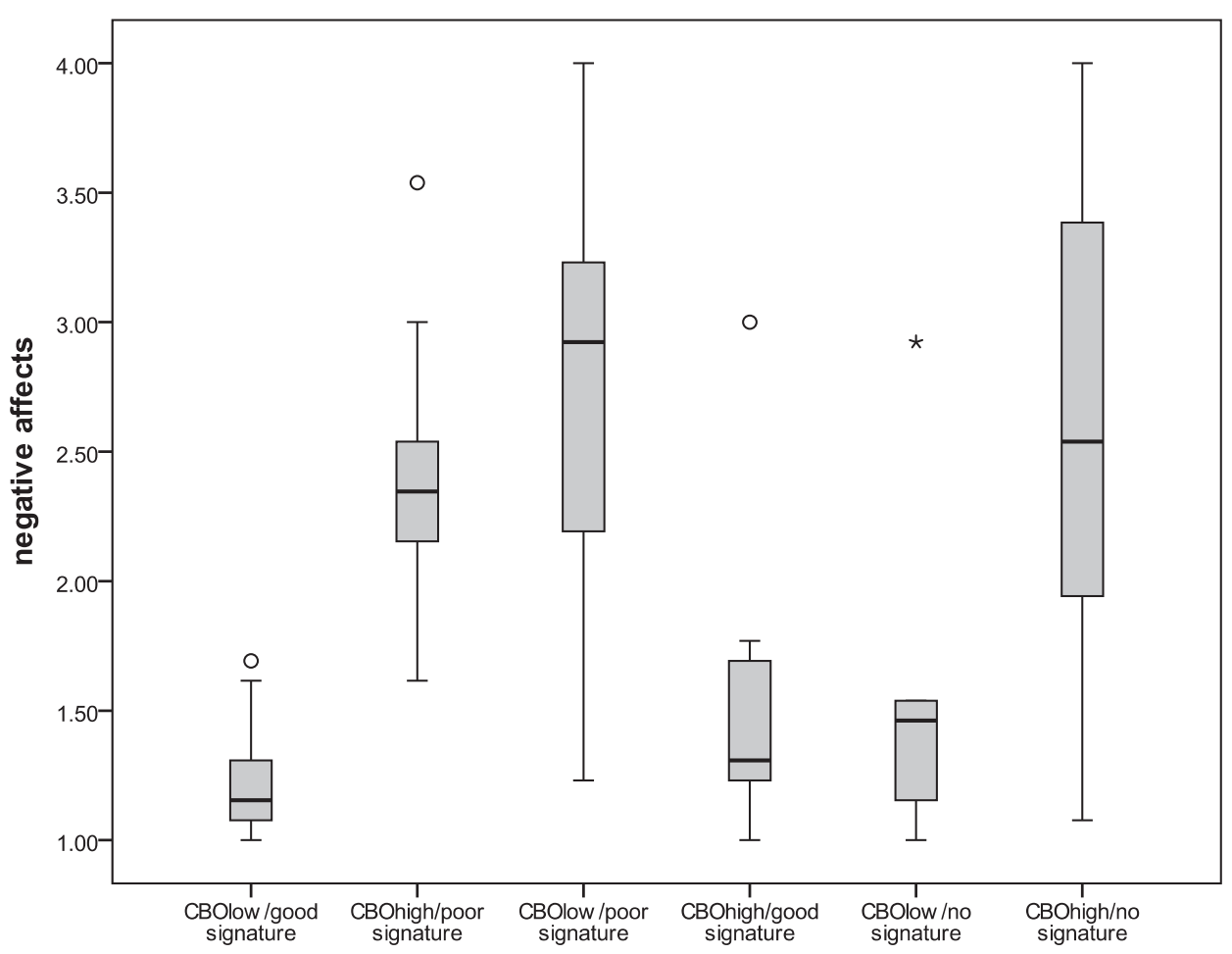

Figure 3. Negative affects

Respondents' psychological reaction to the 70-gene prognosis signature results, received after the pathological test results (CBO). Higher scores means more negative feelings experienced by the patients $(n=74)$. Scales 1-4: Mean scores of negative affects: 1 : not at all, 2: a little, 3: a lot, 4: very much. $p=0.001$ calculated for the mean scores of negative affect. 


\section{Diffusion scenarios}

Two rounds of scenarios were written, taking various socio-dynamic interactions into account. The original scenario was written in 2004 and revised mid-2005, using professional feedback. The initial expectation among the direct involved researchers and professionals was that less adjuvant chemotherapy would be needed compared to guideline based treatment and that the impressive potential of the test would lead to swift diffusion. ${ }^{20}$ The current Dutch СBO guidelines, however, proved to be more restrictive in the prescription of adjuvant systemic treatment, compared to the St. Gallen guidelines on which the first analysis was based. It became apparent that the signature in combination with the CBO guidelines (with the physicians tending to follow the highest risk) led to more chemotherapy prescription in the RASTER study, instead of less. Although an unexpected result, it might lead to improved selection of patients and ultimately, an improved survival outcome. ${ }^{11}$

A second important issue was the "what-if deviation" that suggested that the complex bio-informatics used to select the relevant genes, was incomprehensible for the average clinician. As a consequence, if a discussion would start concerning the validity an expectative attitude might be the result, leading to a prolonged early adoption phase. Although not considered very likely at the time of starting the study, this proved to be reality especially in Europe (Figure 4).

\section{Discussion}

This study evaluates the methodology of CTA as a means to guide the controlled early implementation of a promising technology and its possible use for coverage decisions: the 70-gene signature in the treatment of node-negative breast cancer patients. An important goal of CTA is to inform policy makers in an early stage about possible advantages or disadvantages of new developments and, ultimately, to aid a decision on usage and coverage.

The logistics necessary for profiling was complex but successfully implemented in all participating hospitals. Changes in the pathology process and multidisciplinary decision- making on treatment advice particularly influenced the duration of the implementation (median 1.2 months). However, physicians rated the addition of the 70-gene signature as beneficial for patient management. 


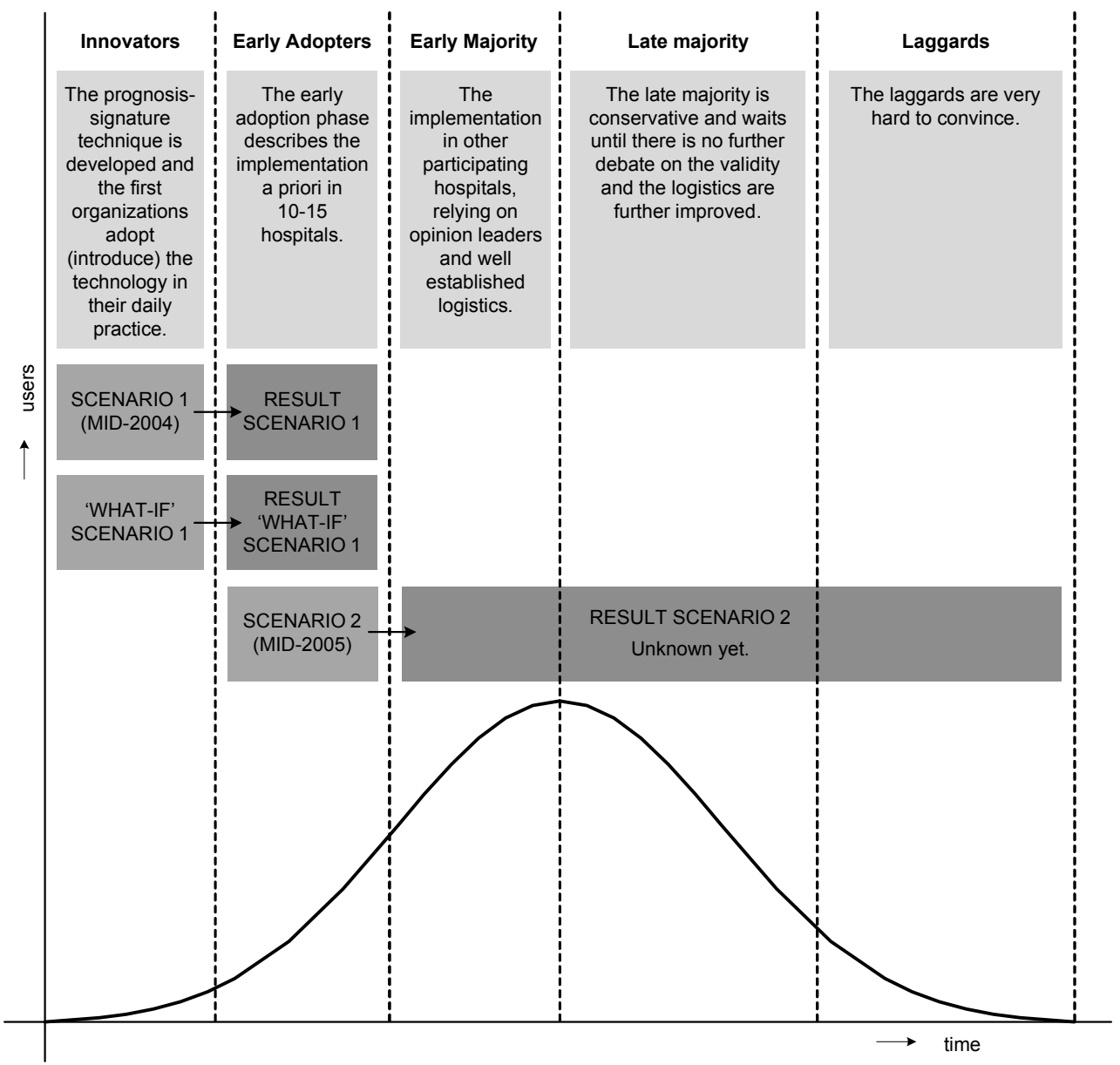

SCENARIO 1 (MID-2004): The initial expectation among the direct involved researchers and professionals was that less adjuvant chemotherapy would be needed compared to guideline based treatment and that the impressive potential of the test would lead to swift diffusion.

RESULT SCENARIO 1: It became appearant that the signature in combination with the restrictive Dutch CBO guidelines led to more prescription of adjuvant chemotherapy, because the tendency of physicians to treat to the highest risk.

'WHAT-IF' SCENARIO 1: The underlying bioinformatics and statistics are complex. In case of an opinion leaderdiscussion about the validity of the 70 -gene prognosis signature, the transition from the early adoption phase to the early minority phase could take much more time than initially foreseen.

RESULT 'WHAT-IF' SCENARIO 1: A professional discussion on validity and the emergence of alternative (microarray) tests, was elaborated. Although considered unlikely by professionals at that time, this proved surprisingly relevant for the Dutch situation.

SCENARIO 2 (MID-2005): The developments in the area of genomics are evolving quickly. It can be expected that a test of protein (proteomics) identification could compete with the prognosis signature, since it should be more (cost-) effective.

Figure 4. Technology Adoption Process (source Rogers ${ }^{19}$ ) 
The patient interviews and questionnaires $(N=77)$ showed that, regarding the level of knowledge about the (consequences of the) 70-gene signature, there is room for improvement for the patient information. The impact on patients seems to depend on the nature of the test results and the way these were communicated to the patient. Because the women received their results in succession (first the clinical risk assessment, followed by the signature), a 'framing effect' could have been realized. The 'framing theory' suggests that the way content is presented influences the opinion people develop. ${ }^{21}$ The 'frame', a low clinical risk result, followed by a poor signature result causes consequently more negative affects. To reduce a possible framing effect, we recommend that physicians communicate all diagnostic results in one appointment after surgery.

The scenarios, especially the "what if-deviations" proved relevant to picture the possible future developments; in a further round these are expected to be useful to specify parameters in planned cost-effectiveness modeling.

The selection of participating hospitals was not at random. In agreement with the $\mathrm{DHClB}$, regional/urban and size differences were taken into account when selecting hospitals interested in participating. As a consequence, all were probably early adaptors and willing to put effort in the implementation process, which could have been negatively influenced by random selection. Other diffusion groups might not have a comparable positive attitude towards spending money or efforts in implementing the test.

The amount of patient questionnaires was too small to conduct extensive statistical analysis, though it may be large enough to give an exploratory insight of the impact of the prognosis signature, and this will be elaborated in the continuation of the CTA. The distribution per risk-group in this part of the study was not equal to the total RASTER-population. Since more questionnaires were returned by concordant low risk patients, these might be more inclined towards responding or the present results might depict a too positive situation.

The DHCIB was of the opinion that a CEA was not yet relevant in the very early phase of the study, since the development and diffusion of the signature was not sufficiently advanced. However, the results of the CTA led to a positive decision on performing a CEA and a discussion on the possibility of provisional coverage.

There are several remaining issues for further research. First, patient-related aspects that appeared to be relevant or significant in this study, such as quality of life and knowledge of the 70-gene signature, have to be elaborated. Second, a third round of scenario drafting is planned for mid-2008, in a formal set-up with opinions to be obtained from international acknowledge experts. Third, ethical and juridical aspects will be studied, involving patients' rights concerning future 
diagnostic use of banked tissue. Finally, a model based CEA will be performed, using several scenario deviations as input to calculate expected costs and outcomes.

The introduction of the 70-gene signature had and will have several clinical implications. The prognosis signature resulted in $30 \%$ discordant cases compared to the Dutch CBO 2004 guidelines, whereas using the USA based Adjuvant! Online Software resulted in $38 \%$ discordance. ${ }^{22,23}$ Thus the use of this prognosis signature, for example in the US, could lead to greater reduction of adjuvant systemic treatment compared to the present Dutch situation, where the guidelines were more restrictive in prescription of adjuvant systemic treatment. However, in the concept CBO guidelines of $2008^{24}$ the criteria for adjuvant systemic treatment will be less restrictive, which can also result in greater reduction of chemotherapy in the Netherlands.

In the US, the 70-gene signature is meanwhile FDA approved, based on the available validation studies. Although officially accepted in the US, basing a possible catalogue decisions just on retrospective validation series caused serious debate in the Netherlands. Countries thus can have different implementation and diffusion patterns, possibly related to their attitude towards technology innovation. Consensus among opinion leaders on the value of this type of prognostics appears to be essential for further diffusion. The validity discussion in Europe initiated a prospective randomized phase III clinical trial, the MINDACT (Microarray In Nodenegative and 1 to 3 positive lymph node Disease may Avoid ChemoTherapy) trial. $^{25,26}$ The MINDACT trial has, however, a very complex design and organization, and feasibility and compliance might prove to be issues in its execution. The CTA will be continued alongside the MINDACT trial as this study produced a number of aspects which need further attention.

Clinicians have a tendency to prefer traditional 'ceteris paribus' HTA designs and to challenge the CTA with its broad approach and acknowledgement of dynamic aspects of technology diffusion. Intensive discussions with clinicians can therefore be anticipated. Furthermore, the complexity of a broad CTA using a mixed method design demands a lot of effort, organization, costs and knowledge on different areas such as psychology, economics and medical science. ${ }^{13}$ To achieve a manageable design, it is important to select the most relevant aspects to be researched, which again demands a thorough discussion. Furthermore, finding a balance between broadness and depth will inevitably play a role in publishing CTA results. 
It proved that the CTA method is suitable for evaluation of this type of technology and we suggest that it can be used as a tool for early stage coverage decisions. Especially in case of a CED-program, due to the comprehensive evaluation, with its mixed method approach, CTA can, in this qualitative manner, be more helpful in decision making, especially. ${ }^{27}$ We therefore assume that it is appropriate for evaluation of other complex technologies, especially during the early controlled introduction in a dynamic environment. It can be expected that a score of new (personalized) diagnostic tests based on genomics, proteomics and/or nanotechnology will be developed. The complex analytical methods, the design of the various elements of technologies and the possible costs make CTA a logical approach in early stages of development and diffusion of new promising techniques.

Supplementary Table 1. Patient characteristics

\begin{tabular}{|c|c|c|c|c|}
\hline \multirow[t]{2}{*}{ Patient characteristics } & \multicolumn{3}{|c|}{ 70-gene signature result } & \multirow[t]{2}{*}{ Total $(N=77)$} \\
\hline & $\begin{array}{l}\text { Low risk } \\
(n=43)\end{array}$ & $\begin{array}{l}\text { High risk } \\
(n=22)\end{array}$ & $\begin{array}{c}\text { No result } \\
(n=12)\end{array}$ & \\
\hline Age & & & & $\mathrm{n}=77$ \\
\hline Mean-yr (range) & $48(27-58)$ & $47(33-59)$ & $49(53-54)$ & $48(27-59)$ \\
\hline$<50 \mathrm{yr}$ & $25(32)$ & $13(17)$ & $9(12)$ & $47(61)$ \\
\hline$>50 \mathrm{yr}$ & $18(23)$ & $9(12)$ & $3(4)$ & $30(39)$ \\
\hline Born in the Netherlands? & & & & $n=76$ \\
\hline Yes & $39(51)$ & $20(26)$ & $9(12)$ & $68(89)$ \\
\hline No & $4(5)$ & $2(3)$ & $2(3)$ & $8(11)$ \\
\hline Education & & & & $\mathrm{n}=77$ \\
\hline Undergraduate & $23(30)$ & $9(12)$ & $11(14)$ & $43(56)$ \\
\hline College or post graduate & $20(26)$ & $13(17)$ & $1(1)$ & $34(44)$ \\
\hline Marital status & & & & $\mathrm{n}=77$ \\
\hline Neither married nor with partner & $11(14)$ & $5(7)$ & $1(1)$ & $17(22)$ \\
\hline Married or with partner & $32(42)$ & $17(22)$ & $11(14)$ & $60(78)$ \\
\hline
\end{tabular}


Supplementary Table 2. Variables questionnaire

\begin{tabular}{|c|c|c|c|c|}
\hline \multirow[t]{2}{*}{ Variables questionnaire } & \multicolumn{3}{|c|}{ 70-gene signature result } & \multirow{2}{*}{$\begin{array}{l}\text { Total } \\
(N=77)\end{array}$} \\
\hline & $\begin{array}{l}\text { Low risk } \\
(n=43)\end{array}$ & $\begin{array}{c}\text { High risk } \\
(n=22)\end{array}$ & $\begin{array}{l}\text { No result } \\
(n=12)\end{array}$ & \\
\hline \multicolumn{4}{|l|}{ I needed some time to understand written info } & $\mathrm{n}=74$ \\
\hline True & $26(35)$ & $17(23)$ & $7(10)$ & $50(68)$ \\
\hline Not true & $15(20)$ & $5(7)$ & $4(5)$ & $24(32)$ \\
\hline \multicolumn{4}{|l|}{ Verbal information of my physician was clear } & $n=77$ \\
\hline Yes & $41(55)$ & $18(24)$ & $10(13)$ & $69(92)$ \\
\hline No & $1(1)$ & $3(4)$ & $2(3)$ & $6(8)$ \\
\hline \multicolumn{4}{|c|}{ I would recommend other women in my situation to have the test } & $\mathrm{n}=76$ \\
\hline Yes & $36(49)$ & $16(21)$ & $10(13)$ & $62(83)$ \\
\hline No & $3(4)$ & $2(2)$ & $2(2)$ & $7(8)$ \\
\hline I don't know & $4(5)$ & $3(4)$ & 0 & $7(9)$ \\
\hline \multicolumn{4}{|c|}{ How many weeks did you have to wait for the test result? } & $\mathrm{n}=74$ \\
\hline$<2$ weeks & $14(19)$ & $5(7)$ & $9(12)$ & $28(38)$ \\
\hline 2-3 weeks & $16(22)$ & $8(11)$ & $1(1)$ & $25(34)$ \\
\hline$>3$ weeks & $11(15)$ & $9(12)$ & $1(1)$ & $21(28)$ \\
\hline \multicolumn{4}{|l|}{ How did you find your way to the hospital? } & $n=76$ \\
\hline I discovered it myself & $18(23)$ & $9(12)$ & $6(8)$ & $33(43)$ \\
\hline discovered by mammogram-screening & $12(15)$ & $2(3)$ & $2(3)$ & $16(21)$ \\
\hline I got a second opinion & $12(16)$ & $7(9)$ & $3(4)$ & $22(29)$ \\
\hline I was already under control & $0(0)$ & $4(6)$ & $1(1)$ & $5(7)$ \\
\hline \multicolumn{4}{|l|}{ CBO 2004 risk } & $\mathrm{n}=77$ \\
\hline Low risk & $34(44)$ & $8(10)$ & $5(7)$ & $47(61)$ \\
\hline High risk & $9(12)$ & $14(18)$ & $7(9)$ & $30(39)$ \\
\hline
\end{tabular}

\section{Acknowledgements}

The present CTA study and the RASTER study were financed by the Dutch Health Care Insurance Board. We are indebted to the women who participated in this study and to all co-workers in the 16 hospitals. Special acknowledgements to Laura van 't Veer, Chad Gundy, Guus Hart and Fiona Stewart for their input. 


\section{References}

1. Hutton J, Trueman P, Henshall C: Coverage with evidence development: an examination of conceptual and policy issues. Int $\mathrm{J}$ Technol Assess Health Care 2007;23:425-432.

2. Mowatt G, Bower DJ, Brebner JA et al: When and how to assess fast-changing technologies: a comparative study of medical applications of four generic technologies. Health Technol Assess 1997;1:i-149.

3. Ioannidis JP: Is molecular profiling ready for use in clinical decision making? Oncologist 2007;12:301-311.

4. Van 't Veer LJ, Dai H, van de Vijver MJ et al: Gene expression profiling predicts clinical outcome of breast cancer. Nature 2002;415:530-536.

5. Early Breast Cancer Trialists' Collaborative Group (EBCTCG): Effects of chemotherapy and hormonal therapy for early breast cancer on recurrence and 15year survival: an overview of the randomised trials. Lancet 2005;365:1687-1717.

6. van de Vijver MJ, He YD, van 't Veer LJ et al: A Gene-Expression Signature as a Predictor of Survival in Breast Cancer. N Engl J Med 2002;347:1999-2009.

7. Buyse M, Loi S, van't Veer $L$ et al: Validation and Clinical Utility of a 70-Gene Prognostic Signature for Women With Node-Negative Breast Cancer. J Natl Cancer Inst 2006;98:1183-1192.

8. Bueno-de-Mesquita JM, Linn SC, Keijzer R et al. Validation of 70-gene prognosis signature in node-negative breast cancer. Breast Cancer Res Treat 2009; 117(3):483495.

9. Douma KF, Karsenberg K, Hummel MJ et al: Methodology of constructive technology assessment in health care. Int J Technol Assess Health Care 2007;23:162-168.

10. Kwaliteitsinstituut voor de Gezondheidszorg CBO, Vereniging voor Integrale Kankercentra: Adjuvante Systemische Therapie voor het Operabel Mammacarcinoom. Richtlijn Behandeling van het Mammacarcinoom 2005. 2005:4670.

11. Bueno-de-Mesquita JM, van Harten W, Retèl VP et al: Use of 70-gene signature to predict prognosis of patients with node-negative breast cancer: a prospective community-based feasibility study (RASTER). The Lancet Oncology 2007;8:10791087.

12. Schot JW: Constructive Technology assessment and Technology Dynamics: The Case of Clean Technologies. Science, Technology \& Human Values 1992;17:36-56.

13. Schot J, Rip A: The Past and Future of Constructive Technology Assessment. Technological Forecasting and Social Change 1996;54:251-268.

14. Retèl VP, Hummel MJ, van Harten WH: Early phase Technology Assessment of nanotechnology in oncology. Tumori 2008; 94:284-290.

15. Institute of Medicine (IOM): Crossing the quality chasm: A new health system for the 21st century. National Academy Press 2001.

16. Lynch HT, Lemon SJ, Durham $C$ et al: A descriptive study of BRCA1 testing and reactions to disclosure of test results. Cancer 1997; 79:2219-2228.

17. Bleiker EM, Hendriks JH, Otten JD et al: Personality factors and breast cancer risk: a 13-year follow-up. J Natl Cancer Inst 2008; 100:213-218.

18. Lerman C, Seay J, Balshem A et al: Interest in genetic testing among first-degree relatives of breast cancer patients. Am J Med Genet 1995; 57:385-392.

19. Rogers EM: Diffusion of Innovations. 5th edition. New York: Free Press 2003. 
20. Goldhirsch A, Glick JH, Gelber RD et al: Meeting highlights: International Consensus Panel on the Treatment of Primary Breast Cancer. Seventh International Conference on Adjuvant Therapy of Primary Breast Cancer. J Clin Oncol 2001; 19:3817-3827.

21. Tversky A, Kahneman D: The framing of decisions and the psychology of choice. Science $1981 ; 211: 453-458$.

22. Ravdin PM, Siminoff LA, Davis GJ et al: Computer program to assist in making decisions about adjuvant therapy for women with early breast cancer. J Clin Oncol 2001; 19:980-991.

23. Olivotto IA, Bajdik CD, Ravdin PM et al: Population-based validation of the prognostic model ADJUVANT! for early breast cancer. J Clin Oncol 2005; 23:2716-2725.

24. Kwaliteit Instituut voor de Gezondheidszorg CBO VvIK: Conceptrichtlijn Mammacarcinoom 2008. 2008:123-145.

25. Bogaerts J, Cardoso F, Buyse $\mathrm{M}$ et al: Gene signature evaluation as a prognostic tool: challenges in the design of the MINDACT trial. Nat Clin Pract Oncol 2006;3:540-551.

26. Mook S, Van't Veer LJ, Rutgers EJ et al: Individualization of therapy using Mammaprint: from development to the MINDACT Trial. Cancer Genomics Proteomics 2007;4:147-155.

27. Tunis SR, Chalkidou K: Coverage with evidence development: a very good beginning, but much to be done. Commentary to Hutton et al. Int J Technol Assess Health Care 2007; 23:432-435. 



\section{Chapter 3}

\section{Review of early Technology Assessments of Nanotechnologies in Oncology}

Valesca P. Retèl Marjan J.M. Hummel

Wim $\mathrm{H}$. van Harten 


\begin{abstract}
Nanotechnology is expected to play an increasingly important role in the diagnostics, prognostics, and management of targeted cancer treatments. While papers have described promising results for nanotechnology in experimental settings, the translation of fundamental research into clinical applications has yet to be widely adopted. In future, policy makers will need to anticipate new developments for clinical implementation and introduce technology assessments. Here we present an overview of the literature on the technology assessments that have already been undertaken on early stage nanotechnology in cancer care, with particular emphasis placed on clinical efficacy, efficiency, logistics, patient-related features and technology dynamics.

Owing to the current stage of development of most nanotechnologies, we found only a limited number of publications describing the application of either Health Technology Assessment (HTA) or Constructive Technology Assessment (CTA). In spite of the promising conclusions of most papers concerning the benefits of clinical implementation, actual clinically relevant applications were rarely encountered, and so far only a few publications report application of systematic forms of technology assessment. Most articles consider aspects of environmental safety, regulation and ethics, often mentioning the need to investigate such issues more thoroughly. Evaluation of financial and organizational aspects is often missing. In order to obtain a realistic perspective on the translation and implementation process there is a need for a broad and systematic evaluation of nanotechnologies at early stages of development. Assessment methods taking technology dynamics into account, such as Constructive Technology Assessment (CTA) should be considered for evaluation purposes.
\end{abstract}




\section{Introduction}

Nanotechnology is a promising technology that is playing an increasingly important role in the diagnostics, prognostics, prediction and management of targeted cancer treatment. While most research in this field is still in its infancy, there is widespread agreement that the findings may have an enormous impact on society, with the potential to improve the quality of human life. A widely used definition for nanotechnology is: "The creation and utilization of materials, devices, and systems through the control of matter on the nanometer scale (1-100 nm), i.e., at the level of atoms, molecules, and supramolecular structures". ${ }^{1}$ Resulting from this size range, nanotechnology is suitable for manipulation at the molecular level, with potential applications in drug delivery, imaging, early detection of cancer and cancer research. ${ }^{2-4}$ However, the translation process from a fundamental research tool into clinical practice will need to overcome many hurdles. To guarantee sustainable development, there is an urgent need to understand the impact that novel nanomaterials could have on human health, and to develop reliable methods for risk assessments. ${ }^{5,6}$ The US Food and Drug Administration (FDA) has indicated that it views regulation of the nano-industry as a challenge, from the aspect of safety and effectiveness. ${ }^{7}$ In the early stage of development, technology dynamics plays an important role since both the technology and the environment influence each other in an interactive way. Methods for evaluating nanotechnologies need to take technology dynamics, related to the development stage, into account. Health Technology Assessment (HTA) is a frequently used evaluation approach, used primarily to enable decisions on coverage and reimbursement of new technologies. ${ }^{8}$ However, the point at which a new technology should be assessed remains contentious. ${ }^{9}$ An HTA generally starts after the technology has been stabilized and proved to be valid in clinical trials. The period between drafting the research design and presentation of the results can take from 6-15 years. During this time many changes in existing treatments can occur, with the result that HTA can be answering outdated questions (Figure 1). ${ }^{10}$ This is a particularly important issue in the field of nanotechnology, where the pace and scope of developments has the potential to exert a far-reaching impact on health care.

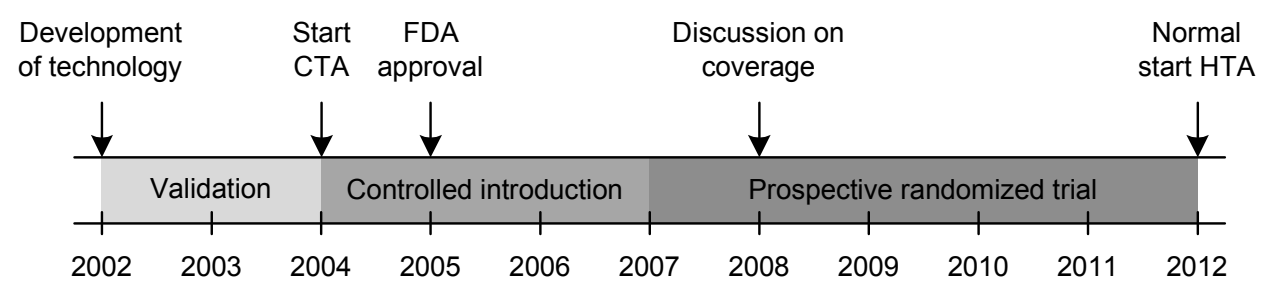

Figure 1. Timelines CTA and HTA, for the case of the 70-gene signature 
The theory of Constructive Technology Assessment (CTA) contends that TA can be used to guide technology development in the most beneficial way. In the absence of prospective data defining benefits, clinical implementation of TA for policy decisions may be premature. If, however, we wait to perform a TA, it might very well be that valuable technology is withheld from the public. ${ }^{11}$ Genomic knowledge is leading to the introduction of new and increasingly personalized diagnostics and treatments, which in turn are leading to even more complex and expensive evaluation designs. Technology dynamics teaches us that, during the course of technology development, choices are constantly being made about the form, function, and use of particular technologies. ${ }^{12}$ CTA has progressed from strictly assessing the impact of a new technology to a broader approach, including the analysis of design, development, and implementation of the new technology. ${ }^{13}$ At different phases of CTA, the focus will shift to the aspects most likely to change during the introduction of these new technologies. CTA covers a broad range of aspects of quality of care following the Institute of Medicine (IOM) (Institute of Medicine (IOM), 2001) $)^{14}$ recommendations as well as the criteria defined by Poulsen ${ }^{15}$ (Table 1). Furthermore, CTA uses diffusion scenarios to monitor the dynamics and spread (diffusion) of technology implementation. Diffusion scenarios, which are commonly applied in industry to guide strategies concerning future developments, have been adapted for use in health care technology assessments. $^{16}$

The aim of this review is to present current literature on methods and results concerning the evaluation of nanotechnologies in cancer care at an early stage and at various stages of diffusion. Related to the early stage of development, we developed a scoring system based on the CTA aspects and criteria. Previously, we used these aspects to perform assessments of early implementation of new (nano) technologies in cancer care. ${ }^{10,17}$

Table 1. Search terms for CTA

\begin{tabular}{ll}
\hline Parameters & Aspects \\
\hline Clinical & Safety, efficacy, effectiveness \\
Economic & Cost-effectiveness \\
Patient-related & Ethical/juridical, acceptability, psychosocial reactions, patient centeredness \\
Organizational & Diffusion, adoption, implementation, timeliness, equity, \\
& skills/routines/logistics, education/training \\
\hline Scenarios/ roadmap & Diffusion scenario (using Rogers phases) \\
\hline
\end{tabular}

CTA covers aspects of quality of care following the Institute of Medicine (IOM) $)^{14}$ and criteria defined by Poulsen ${ }^{15}$ and uses diffusion scenarios to monitor the dynamics. 


\section{Methods}

Nanotechnology in oncology encompasses many applications, making it difficult to cover all these uses in one review. We formulated a scoring-system (based on criteria defined by Poulsen ${ }^{15}$ and quality aspects of the Institute of Medicine $(\mathrm{IOM})^{14}$ ) that included factors on clinical and economic information as well as patient-related organizational aspects and scenarios (Table 1). ${ }^{10}$ These aspects were first used in two studies that performed an early technology assessment (Constructive Technology Assessment, CTA) on microarray technology for breast cancer patients. In addition, the mixed method approach of the CTA adapted diffusion scenarios, of the type commonly used in industry to guide future development, was used to monitor the dynamics. ${ }^{16,17}$ Since new technologies are often dynamic, especially at an early stage of development, the focus of evaluation assessments shifted to the aspects most likely to change during the introduction of new technologies.

In this review, we focused on the terms "nanotechnology" and "oncology" combined with the several CTA aspects. References were obtained by PubMed searches using combinations of MeSH search terms, such as : "nanotechnology"/ "nanobiotechnology"/ "nano-arrays"/ "micro-arrays"/ "biomarkers"/ "nanoparticles", AND "Oncology"/"Cancer" AND "Evaluation"/ "Assessment"/ "Diffusion"/ "Research"/ "Effectiveness"/ "Efficiency"| "Efficacy"/ "Safety"/ "Ethics"/ "Juridical"/ "Organizational"/ "Cost-effectiveness"|"Quality of life" and "Dynamics". During the search it became apparent that several applications of nanotechnologies are also described by terms such as "nano particles" and "nanooncology". We therefore decided to extend our search with these additional terms, combined with the two CTA-aspects "safety" and "cost-effectiveness", which appeared to be the most relevant aspects evaluated in the field of nanotechnology. No limits were applied to the year of publication, language, or study design. In addition to formal publications and databases, (non)governmental websites, reports, and white papers on nanotechnology and technology assessments were included in the search. 


\section{Results}

The first search using the terms "nanotechnology" AND "oncology" led to a total of 91 results, made up of 46 fundamental articles, 24 reviews, 20 other specified reports and 1 technology assessment (TA) as shown in Table 2 and Figure 2. All articles resulting from the extended search using specific aspects were duplicates of the original search for "nanotechnology" AND "oncology". The paper explicitly directed at TA gives two examples of technology assessments on nanotechnologies which were evaluated at an early stage of development by monitoring patient related aspects, efficiency, and scenario drafting. ${ }^{17}$

Most reviews debate the assessment of safety risks on theoretical grounds, with no actual safety analyses or systematic risk assessments undertaken. Most reviews summarize results of studies reporting the potential for clinical implementation, while the possible implications are often described in the discussion, specifying the need for a form of technology assessment. The major areas where nano medicine is currently being developed in cancer are early detection and diagnostics and drug delivery devices. The results of the search have been structured according to Jain's classification in the Handbook of Nanomedicine ${ }^{1}$ and include a short description of the technology involved. 


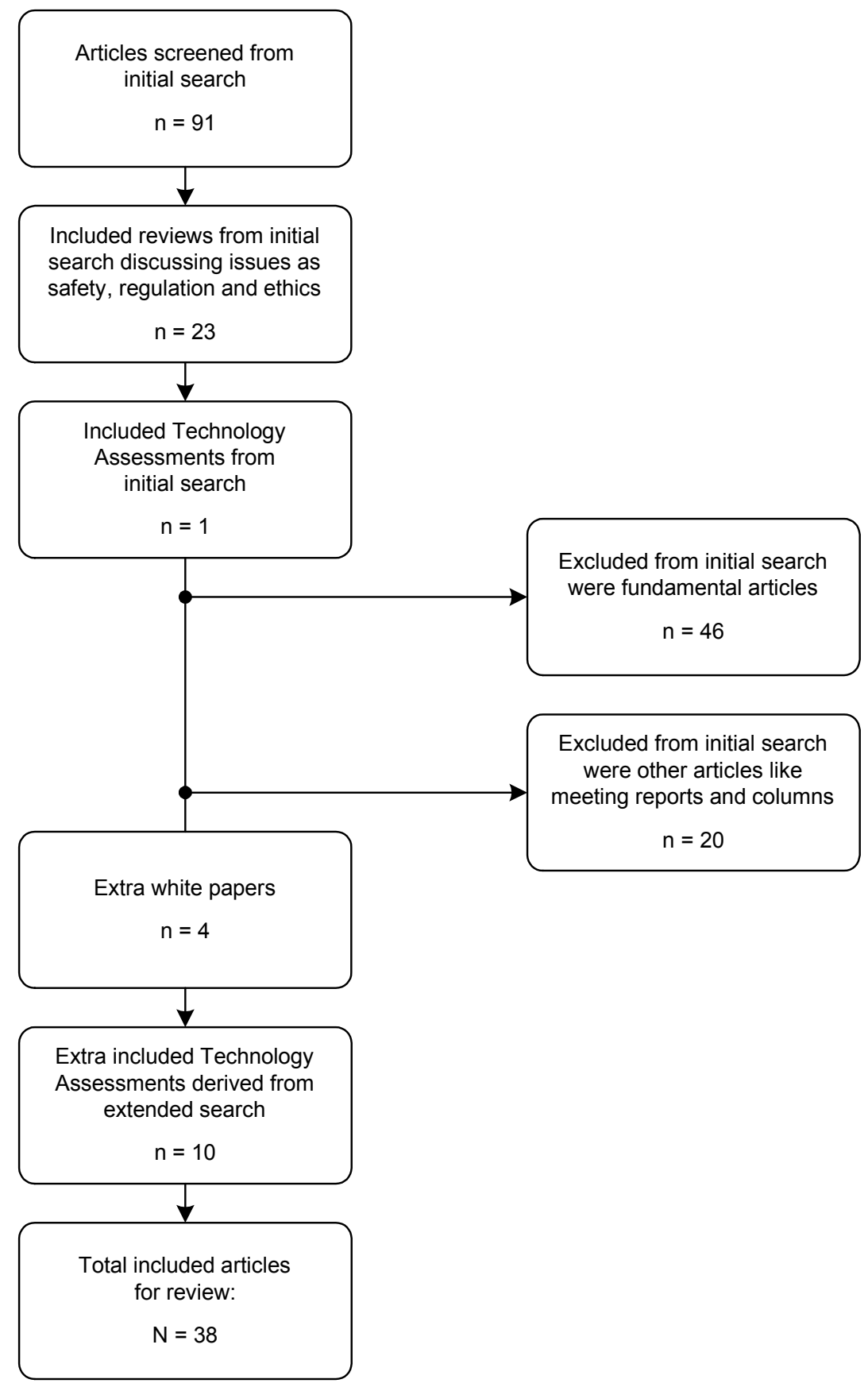

Figure 2. Inclusion scheme: Included and excluded papers from initial and extended search. 
Table 2. Search results

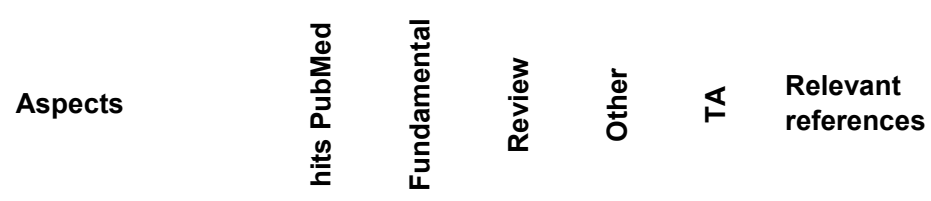

\begin{tabular}{|c|c|c|c|c|c|c|c|c|}
\hline NT & Onc & & 90 & 46 & 24 & 19 & $1^{*}$ & $17,48^{*}$ \\
\hline NBT & Onc & & 3 & - & 2 & - & * & 17 \\
\hline NT & Onc & Evaluation & 11 & 9 & - & 2 & - & \\
\hline NT & Onc & Assessment & 4 & 1 & - & 2 & * & 17 \\
\hline NT & Onc & Diffusion & 3 & 2 & - & - & * & 17 \\
\hline NT & Onc & Research & 64 & 36 & 17 & 9 & * & $17,42,49$ \\
\hline NT & Onc & Effectiveness & 7 & 4 & 3 & - & * & 17 \\
\hline NT & Onc & Efficiency & 4 & 4 & - & - & - & \\
\hline NT & Onc & Efficacy & 12 & 6 & 5 & - & * & 17 \\
\hline NT & Onc & Safety & 5 & 3 & 1 & - & * & 17 \\
\hline NT & Onc & Ethics & 3 & - & 1 & 1 & * & 17 \\
\hline NT & Onc & law and legal & 1 & - & - & - & * & 17 \\
\hline NT & Onc & Organization & 27 & 6 & 13 & 7 & * & 17,48 \\
\hline NT & Onc & Cost-effectiveness & 1 & - & - & - & * & 17 \\
\hline NT & & Cost-effectiveness & 16 & 11 & 4 & - & * & 40,50 \\
\hline NT & & QoL & 2 & 1 & - & - & * & 17 \\
\hline NT & Onc & Scenarios & 1 & - & - & - & * & 17 \\
\hline NT & Onc & Dynamics & 0 & - & - & - & - & \\
\hline NO & & & $2^{* *}$ & - & 2 & - & - & 47,48 \\
\hline NA & cancer & & $4^{* *}$ & 2 & 2 & - & - & \\
\hline MA & cancer & Cost-effectiveness & $8^{* *}$ & 3 & 3 & - & $2^{*}$ & 16,17 \\
\hline \multirow[t]{2}{*}{ NP } & Onc & Cost-effectiveness & $9^{* *}$ & & & & 9 & $4,7,30,32,33,36$ \\
\hline & & & & - & - & - & & $38,41,51$ \\
\hline
\end{tabular}

Other: Meeting reports, columns, TA: Technology Assessment, *Appeared from one article, ${ }^{* *}$ Appeared from extended search, NT: nanotechnology, NBT: nanobiotechnology, NO: nano-oncology, NA: Nanoarrays, MA: microarrays, NP: nanoparticles 


\section{Nanotechnology-based Detection}

Nanotechnology-based detection includes cancer detection, biomarkers, and diagnostics. Photodynamic therapy (PDT) provides one example of cancer detection, also offering the potential for treatment, and involving three key components, a photosensitizer, light and oxygen. 5-Aminolaevulinic acid (ALA) is an endogenous cellular component that is metabolized within the haem biosynthetic pathway to produce protoporphyrin IX (PpIX), a potent endogenous photosensitizer. Following exogenous administration of 5-ALA, PpIX is generated intra cellularly, and can then activated by visible light for PDT treatment. ${ }^{18} \mathrm{~A}$ costeffectiveness analysis of PDT as a treatment for advanced head and neck tumors was performed by Hopper et al. ${ }^{19}$ and a TA description of the implementation process was performed by Retèl et al. ${ }^{17}$

The second example of cancer detection is Rapid Detection of Single Nucleotide Polymorphism (SNP), an emerging technology in the field of biomarkers using a Nano Magnetic Device. Here DNA microarrays labeled with gold nanoparticles (Au$\mathrm{np}$ ) are used to make the detection of SNPs, known to be associated with hereditary conditions and cancers, more efficient and less time consuming. It is, however, not clear what costs will be involved and what the exact application of this field will be. ${ }^{20-22}$ While there are eight articles describing what the cost efficiency of SNP should be relative to other cancer detection methods, no solid costeffectiveness analyses have been undertaken on the subject.

For cancer diagnostics, Quantum Dots (QDs), coated with a polyacrylate cap and covalently linked to antibodies, have been used for immunofluorescence labeling of the breast cancer marker Her-2. ${ }^{23}$ An article by Hardman et al. was identified concerning QDs in general and the potential for toxicity for humans (see also below). ${ }^{24}$ Microarray analysis, used for gene expression profiling, offers another diagnostic and prognostic approach. An example is the 70-gene prognosis signature, identified at the Netherlands Cancer Institute (NKI-AVL) in Amsterdam, with a performed early cost-effectiveness analysis regarding the potential benefits and policy implications of gene expression profiling in clinical practice. ${ }^{25}$ Furthermore, a Constructive Technology Assessment (CTA) appeared to be a helpful approach to monitor, evaluate and anticipate the early introduction of this new technology in daily practice. Moreover, the CTA method was helpful in Coverage with Evidence Development (CED) procedure. ${ }^{16}$ 


\section{Nanotechnology-based Imaging}

Quantum Dots (QDs) Aided Lymph Node Mapping is an improved method for performing sentinel lymph node (SLN) biopsy, where the QDs emit NIR light that is used to identify lymph nodes during surgery. ${ }^{26}$ SLN mapping has already revolutionized cancer surgery and the introduction of NIR QDs offers the possibility to improve the technique further. However, since QDs are composed of heavy metals they pose potential risks to human health and the environment, and therefore have yet to be approved for human applications. ${ }^{24}$

\section{Nanotechnology-based Drug delivery}

Nanoscale devices can serve as targeted drug-delivery vehicles carrying chemotherapeutic agents or therapeutic genes directly into malignant cells. Examples of such drug delivery devices for breast or non-small-cell lung cancer include albumin-bound $130 \mathrm{~nm}$ particle formulation of paclitaxel for injectable suspension ('Abraxane ${ }^{\circledR}$ ', Abraxis BioScience, Inc.), approved by the FDA for metastatic breast cancer, and doxorubicin-loaded, long-circulating, polyethylene glycol-coated liposomes ('Doxil[', ALZA Corp.). A phase III trial evaluating use of Abraxane $\AA$ as a vehicle showed it eliminated solvent-related toxicities and overcame the need for steroid and antihistamine premedication. ${ }^{27}$ An economic evaluation of albumin-bound paclitaxel versus Docetaxel has been performed, with a favorable result for albumin-bound paclitaxel. ${ }^{28}$ The second FDA approved nanoparticle formulation for drug delivery is the folate-linked liposomal doxorubicin (Doxil), a reformulated version of Doxorubicin. Doxil has been validated in a phase III trial for multiple myeloma patients and is also indicated for metastatic ovarian cancer and AIDS-related Kaposi's sarcoma. ${ }^{29}$ Nine cost-effectiveness analyses were performed regarding pegylated liposomal doxorubicin, and two costminimization analyses. ${ }^{30,31}$ CEA's concerning ovarian cancer ${ }^{32-34}$, multiple myeloma ${ }^{35}$, AIDS-related Kaposi's sarcoma ${ }^{36,37}$, and head and neck cancer ${ }^{38}$ all found in favor of the new technology. It should, however, be noted that most of the economic evaluations dealt with only with one good quality randomized controlled trial (RCT), and as a result most evaluations concluded that more evidence was needed to provide a clearer picture of clinical effectiveness.

\section{Nanoparticles}

Nanoparticles have been used in several applications such as imaging, targeting tumors, drug delivery and in combination with other physical agents for tumor ablation, such as brachytherapy. ${ }^{1}$ BrachySil $^{\mathrm{TM}}$ a nanoengineered Silicon for Brachytherapy, was shown to be safe and effective in a phase lla trial for primary liver cancer. ${ }^{39}$ Faunce, however, has raised major concerns regarding highly 
reactive and mobile engineered nanoparticles (ENPs), suggesting that they may present health risks when used in medical applications. Disturbingly, there appears to be no effective methods for monitoring ENP exposure in patients or health care workers. ${ }^{40}$ Wang et. al. raised critical questions, such as whether there might be changes in the safety profile of nanoparticles after conjugation, that they say need to be addressed before further clinical development. ${ }^{41}$ Hede \& Huilgol have reported on various applications of nanotechnology in oncology, particularly on those that are already in clinical trial and those which are in the pipeline for commercialization, like radioactive nanoparticles (ongoing phase II, 2006) and nanoparticles of Paclitaxel (ongoing phase I, 2006). They state that these nanoparticle ionizing radiation and chemotherapeutic agents are the only nanotechnology innovations that at present seem to be feasible for implementation in clinical practice in terms of "improvised" treatment and cost-effectiveness. They conclude that extensive studies on environmental safety aspects should be conducted and predictive models must be developed to forecast long-term toxicities. ${ }^{42}$ Jain has reported on several applications of nanooncology ${ }^{43-48}$, pointing out that there are still many unanswered questions concerning the introduction of nanoparticles into the living body. Empirical evidence for the basis of those concerns, however, is not provided. One recent development, the use of nanoparticles in oncoproteomics, although promising, has yet to be translated from bench to bedside. ${ }^{46}$ Jain described safety concerns relating to the potential toxic effects of in vivo nanoparticles, raising questions about the environmental effects of releasing nanoparticles during the manufacturing process. ${ }^{45}$

\section{Regulation of nanotechnologies in general}

In the Journal of Law, Medicine and Ethics, Wilson states that it is unclear whether and to what degree nanotechnology is safe, suggesting that the response should be to the real rather than the perceived or theoretical risks. ${ }^{49}$ In another article in the same journal, Faunce and Shats argue that a broader approach to the regulation of nanotherapeutics needs to be taken, and that issues such as workplace safety and environmental impact should not be ignored. Many individuals, they add, are concerned that "nanoparticles could become the asbestos of the $21^{\text {st }}$ century" ${ }^{50}$

\section{Ethics}

Ethical issues most often appear in "general health" articles about nanotechnologies, for example those concerning food manipulation, and are not specific for the oncology field.

Quality of life issues are not yet reported, but have on occasion been mentioned briefly in reviews. 


\section{Additional Reports}

Besides the PubMed search, relevant white papers were found such as Ontario, a Horizon Scanning Appraisal ${ }^{51}$, a Technology Assessment on nanotechnologies from TA-Swiss ${ }^{52}$, a RAND report ${ }^{53}$, and a FDA report, $2007^{54}$. The papers, which descriptively review the recent literature, identified promising technologies and conclude that clinical implementation and research is still rare, and that no systematic TA had been performed.

\section{Discussion}

The aim of this review was to present an abridged interpretation of the current literature on methods and results of studies evaluating nanotechnologies in cancer care. While the literature regarding fundamental research on nanotechnologies can appear overwhelming, reports on technology assessments of actual clinical applications and implementation processes are scarce. We found that while most articles focus on the theoretical aspects of regulation and (environmental) safety, they lack empirical data, and provided no structured evaluation of dynamics, health economics or organizational aspects. Abraxane and Doxil are two nanotechnology based products that have received FDA approval for treating cancer. CEAS concerning these products have concluded that the technologies are less costly than current approaches, but require further high-quality randomized controlled trials to provide a clearer picture of clinical effectiveness. Discussions on theoretical safety issues seem to dominate the debate on clinical translation and implementation, with few papers concerning clinical effectiveness and cost. The paucity of research addressing these issues appears to have halted progress on broader evaluation. At the level of the technology, aspects of technical feasibility, clinical utility, and potential areas of application are being studied, all of which may steer further technological development. Evidently, knowledge about biological interaction and function is needed to understand the underlying mechanisms. At a societal level, studies focus on ethical considerations and the environmental impact of nanotechnology to public health, with such research supporting policy making with respect to law and regulation. Even though the first treatments based on nanotechnology have received FDA approval there has been little sign of any moves to introduce legal regulation, despite growing concerns that "nanoparticles could become the asbestos of the $21^{\text {st }}$ century". A more comprehensive type of technology assessment, as conducted by a Constructive Technology Assessment, can improve the pro-active fine tuning of the decision-making processes of both governmental policy makers and technological developers. Regulation can then take the traditional safety issues into account, in addition to issues such as workplace safety and environmental impacts as suggested by Faunce \& Shats. ${ }^{50}$ What has been lacking in the current research is an analysis of the effects of 
nanotechnology at the level of health care organization. For instance, if new devices or selective/targeted therapies are to be introduced, health care processes are likely to undergo radical changes, affecting patients as well as health care professionals. Nanotechnology is likely to impact the organization of care, and in its turn, the organizational context will influence how nanotechnology can be applied to the new processes of care. Hospital-based technology assessment will be required, evaluating the consequences of using specific technologies in organizational settings, which should consider aspects such as the diffusion rate of the technology, implementation, and logistics. In hospital based technology assessments perhaps the first place to start would be an evaluation of devices such as lab-on-a-chip or single nucleotide polymorphisms. Ultimately in the hospital setting, nanotechnology is likely to have an impact on patient communication, guidelines, safety protocols and investments in staffs and other resources. For a start to be made on the assessment process it is important to leave theoretical considerations to one side and focus attention first on actual early stage technology. In addition to consideration of effectiveness and safety, it will be necessary to monitor and evaluate organizational aspects of nanotechnology including adoption, routines and logistics, and to observe the environment in which the technology is being utilized. Initially in the early phases of introduction it is likely that just a few experts will adopt the technology, but it is important to consider potential implications of wider use, such as whether the technology is difficult to understand or to implement in daily routines and whether it might prove controversial. As the technology adopted by more user sites it will be important to canvass patient opinion and to consider the financial implications. In addition it may be valuable to consider future scenarios that may be helpful in detecting potential areas for concern.

To conclude, in this paper we have established that a chasm exists between the potential for clinical use of nanotechnology and the actual evidence base derived from technology assessments. Performing HTA or CTA at an early stage as possible should help decide on the priorities to be set both the development of nanotechnology and also in defining our subsequent approach to assessments.

\section{Acknowledgements}

Special acknowledgements to Jacques Neefjes, Theo Ruers and Fiona Stewart for their input. 


\section{References}

1. Jain KK. The Handbook of Nanomedicine: Totowa, USA, Springer/ Humana Press.2008

2. National Cancer Institute. A Snapshot of Nanotechnology. available at http://planning.cancer.gov/disease/Nanotechnology-Snapshot.pdf .2008

3. National Cancer Institute. Nanotechnology in cancer: Tools to relieve human suffering available at http://nano.cancer.gov/resource center/tech backgrounder.asp . 2008

4. Portney NG and Ozkan M. Nano-oncology: drug delivery, imaging, and sensing. Anal Bioanal Chem 2006; 384(3):620-630.

5. Maynard AD et al. Safe handling of nanotechnology. Nature 2006; 444(7117):267269.

6. Singh $S$ and Nalwa HS. Nanotechnology and health safety--toxicity and risk assessments of nanostructured materials on human health. J Nanosci.Nanotechnol 2007; 7(9):3048-3070.

7. Pietzsch JB and Pate-Cornell ME. Early technology assessment of new medical devices. Int J Technol Assess Health Care 2008; 24(1):36-44.

8. Hutton J, Trueman P, Henshall C. Coverage with evidence development: an examination of conceptual and policy issues. Int J Technol Assess Health Care 2007; 23(4):425-432.

9. Mowatt G, Bowe DJ, Brebner JA, et al. When and how to assess fast-changing technologies: a comparative study of medical applications of four generic technologies. Health Technol Assess 1997; 1(14):i-149.

10. Douma KF, Karsenberg K, Hummel MJ et al. Methodology of constructive technology assessment in health care. Int.J Technol.Assess. Health Care 2007; 23(2):162-168.

11. loannidis JP. Is molecular profiling ready for use in clinical decision making? Oncologist 2007; 12(3):301-311.

12. Schot JW. Constructive Technology assessment and Technology Dynamics: The Case of Clean Technologies. Science, Technology \& Human Values 1992;1:136-56.

13. Schot J and Rip A. The Past and Future of Constructive Technology Assessment. Technological Forecasting and Social Change 1996; 54:251-268.

14. Institute of Medicine (IOM), 2001, Crossing the quality chasm: A new health system for the 21st century. National Academy Press.

15. Poulsen PB. Health Technology Assessment and diffusion of health technology: Odense University Press, Denmark. 2000.

16. Retèl VP, Bueno de Mesquita JM, Hummel MJ et al. Constructive Technology Assessment (CTA) as a tool in Coverage with Evidence Development: The case of the 70-gene prognosis signature for breast cancer diagnostics. Int $\mathrm{J}$ Technol Assess Health Care 2009; 25(1):73-83.

17. Retèl VP, Hummel MJ, van Harten WH. Early phase Technology Assessment of nanotechnology in oncology. Tumori 2008; 94:284-290.

18. Yang TH, Chen CT, Wang CP, Lou PJ. Photodynamic therapy suppresses the migration and invasion of head and neck cancer cells in vitro. Oral Oncology 2007;43:358-365.

19. Hopper C, Niziol C, Sidhu M. The cost-effectiveness of Foscan mediated photodynamic therapy (Foscan-PDT) compared with extensive palliative surgery and palliative chemotherapy for patients with advanced head and neck cancer in the UK. Oral Oncol 2004; 40(4):372-382.

20. Cox, A et al. A common coding variant in CASP8 is associated with breast cancer risk. Nat Genet 2007; 39(3):352-358. 
21. Easton DF et al. Genome-wide association study identifies novel breast cancer susceptibility loci. Nature 2007; 447(7148):1087-1093.

22. Miller MR, Dunham JP, Amores A et al. Rapid and cost-effective polymorphism identification and genotyping using restriction site associated DNA (RAD) markers. Genomic Research 2008;17:240-248.

23. Wu X., Liu H, Liu J, et al. Immunofluorescent labeling of cancer marker Her2 and other cellular targets with semiconductor quantum dots. Nat.Biotechnol 2003; 21(1):41-46.

24. Hardman R. A toxicologic review of quantum dots: toxicity depends on physicochemical and environmental factors. Environ Health Perspect 2006; 114(2):165-172.

25. Oestreicher N, Ramsey SD, Linden HM, et al. Gene expression profiling and breast cancer care: what are the potential benefits and policy implications? Genet Med. 2005; 7(6):380-389.

26. Kim $S$ et al. Near-infrared fluorescent type II quantum dots for sentinel lymph node mapping. Nat.Biotechnol 2004; 22(1):93-97.

27. Green MR, Manikhas GM, Orlov S et al. Abraxane, a novel Cremophor-free, albuminbound particle form of paclitaxel for the treatment of advanced non-small-cell lung cancer. Ann Oncol 2006; 17(8):1263-1268.

28. Dranitsaris G, Cottrell W, Spirovski B, and Hopkins S. Economic analysis of albuminbound paclitaxel for the treatment of metastatic breast cancer. J Oncol Pharm Pract. 2009 Jun;15(2):67-78.

29. Hussein MA, Wood L, His E et al. A Phase II trial of pegylated liposomal doxorubicin, vincristine, and reduced-dose dexamethasone combination therapy in newly diagnosed multiple myeloma patients. Cancer 2002; 95(10):2160-2168.

30. Capri S and Cattaneo G. Cost-minimization analysis of pegylated liposomal doxorubicin versus topotecan for the treatment of ovarian cancer in Italy. Clin.Ther 2003; 25(6):1826-1845.

31. Ojeda B, de Sande LM, Casado A et al. Cost-minimisation analysis of pegylated liposomal doxorubicin hydrochloride versus topotecan in the treatment of patients with recurrent epithelial ovarian cancer in Spain. Br.J.Cancer 2003; 89(6):1002-1007.

32. Forbes C, Wilby J, Richardson G, A systematic review and economic evaluation of pegylated liposomal doxorubicin hydrochloride for ovarian cancer. Health Technol.Assess 2002; 6(23):1-119.

33. Main C, Bojke L, Griffin $S$ et al. Topotecan, pegylated liposomal doxorubicin hydrochloride and paclitaxel for second-line or subsequent treatment of advanced ovarian cancer: a systematic review and economic evaluation. Health Technol.Assess 2006; 10(9):1-132.

34. Smith $\mathrm{DH}$, Adams JR, Johnston SR, et al. A comparative economic analysis of pegylated liposomal doxorubicin versus topotecan in ovarian cancer in the USA and the UK. Ann Oncol 2002; 13(10):1590-1597.

35. Porter CA and Rifkin RM. Clinical benefits and economic analysis of pegylated liposomal doxorubicin/ vincristine/ dexamethasone versus doxorubicin/ vincristine/ dexamethasone in patients with newly diagnosed multiple myeloma. Clin.Lymphoma Myeloma 2007;7 Suppl 4:S150-S155.

36. Hjortsberg C, Persson U, Lidbrink E and Bennett C. Cost-effectiveness analysis of pegylated-liposomal doxorubicin and liposomal daunorubicin treatments in patients with Kaposi's sarcoma. Acta Oncol 1999; 38(8):1063-1067.

37. Vanni T, Fonseca BA and Polanczyk CA. Cost-effectiveness analysis comparing chemotherapy regimens in the treatment of AIDS-related Kaposi's sarcoma in Brazil. HIV Clin.Trials 2006; 7(4):194-202. 
38. Fountzilas $\mathrm{G}$ et al. Paclitaxel and gemcitabine vs. paclitaxel and pegylated liposomal doxorubicin in advanced non-nasopharyngeal head and neck cancer. An efficacy and cost analysis randomized study conducted by the Hellenic Cooperative Oncology Group. Ann Oncol 2006; 17(10):1560-1567.

39. Goh AS et al. A novel approach to brachytherapy in hepatocellular carcinoma using a phosphorous32 (32P) brachytherapy delivery device--a first-in-man study. Int J.Radiat.Oncol.Biol.Phys 2007; 67(3):786-792.

40. Faunce TA. Nanotherapeutics: new challenges for safety and cost-effectiveness regulation in Australia. Med J Aust 2007; 186(4):189-191.

41. Wang $X$, Yang $L$, Chen ZG and Shin DM. Application of nanotechnology in cancer therapy and imaging. CA Cancer J Clin 2008; 58(2):97-110.

42. Hede $S$ and Huilgol N. "Nano": the new nemesis of cancer. J Cancer Res Ther 2006;2(4):186-195.

43. Jain KK. Nanodiagnostics: application of nanotechnology in molecular diagnostics. Expert Rev Mol Diagn 2003; 3(2):153-161.

44. Jain KK. Role of nanobiotechnology in developing personalized medicine for cancer. Technol Cancer Res Treat 2005; 4(6):645-650.

45. Jain KK. Applications of nanobiotechnology in clinical diagnostics. Clin Chem 2007; 53(11):2002-2009.

46. Jain KK. Innovations, challenges and future prospects of oncoproteomics. Mol Onc 2008;2:153-160.

47. Jain KK. Nanomedicine: application of nanobiotechnology in medical practice. Med Princ Pract 2008; 17(2):89-101.

48. Jain KK. Recent advances in nanooncology. Technol Cancer Res Treat 2008; 7(1):113.

49. Wilson RF. Nanotechnology: the challenge of regulating known unknowns. J Law Med Ethics 2006; 34(4):704-713.

50. Faunce $T$ and Shats K. Researching safety and cost-effectiveness in the life cycle of nanomedicine. J Law Med 2007; 15(1):128-135.

51. The Medical Advisory Secretariat, OMoHaL-TC. Nanotechnology, Horizon Scanning Appraisal. 1-40. 2006.

52. Baumgartner W, Jackli B, Schmithusen B et al. Nanotechnology in medicine. TASWISS, Centre for Technology Assessment 2003:25-35. Bern.

53. Silberglitt $R$, Anton $P$, Howell $D$ and Wong A. The Global Technology Revolution 2020. Pittsburgh, RAND Corporation 2006:1-28.

54. US Food and Drug Administration Nanotechnology Taskforce. Nanotechnology, A Report of the U.S. Food and Drug Administration nanotechnology Task Force. Public Health Service 2007. 



\section{Part III}

Application of the CTA aspects to the 70-gene signature

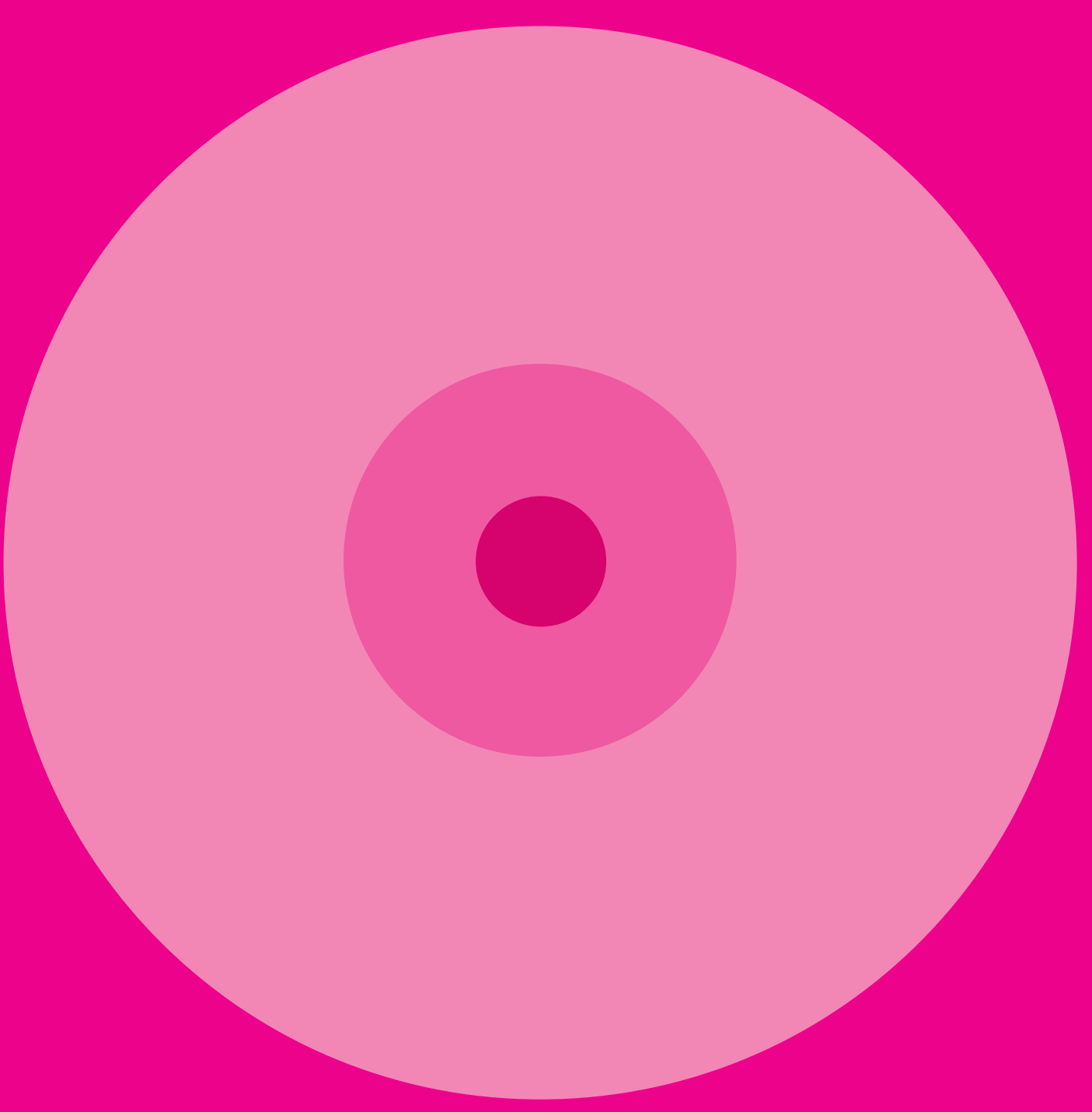




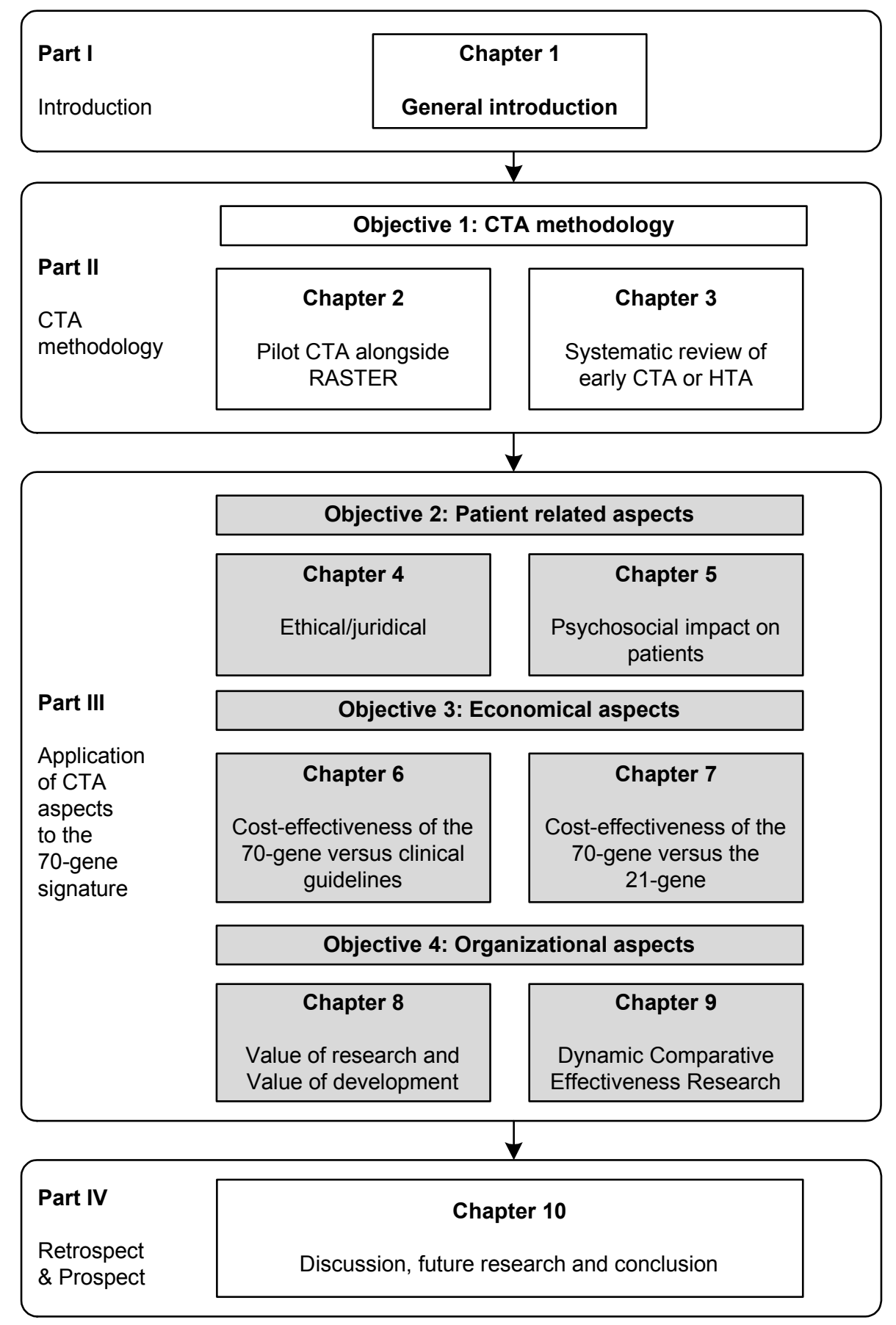




\section{Chapter 4}

\section{Tumor tissue: Who is in control?}

Corrette M.C. Ploem

Valesca P. Retèl

Sabine C. Linn

Hester H. van Boven

Marjanka K. Schmidt

Jean-Philippe de Jong Johannes K.M. Gevers

Wim H. van Harten 


\section{Introduction}

Recent developments in genomics have resulted in the increased availability of gene profiles for (early) diagnostics and prognostics in breast cancer. We expect that genetic analysis of a patient's (tumor) tissue will, in time, become a standard part of cancer treatment. A request from a Dutch woman to have her tumor tissue tested years after treatment confronted the Netherlands Cancer Institute (NKI) and its staff with legal, ethical, and practical questions regarding patients' rights in relation to residual tissue storage and its use for clinical purposes. Was the tissue required to perform the test still available? If so, could the woman (and her relatives) demand that the test be carried out? Or, could she demand that the tissue be transferred to another hospital? As it became apparent that appropriate guidance was lacking in this area, the NKI arranged for a group of professionals with legal and ethical expertise to develop a guideline. Subsequently, the relevant stakeholders, including oncologists, pathologists, medical researchers and patients' representatives, were invited to become involved. Consensus was reached on the guideline, including its main practical implications and the (p)reservation of a sufficient amount of a patient's residual tissue exclusively for future use in diagnostics and prognostics. Finally, the staff of the pathology department was asked to report on the practicality of the guideline given its current tissue banking procedures.

\section{Methods}

In the course of the feasibility and technology assessment study of the 70-gene signature (RASTER) in the Netherlands, it became clear that implementation of these new diagnostic and prognostic technologies generates new legal and ethical questions concerning the storage and use of a patient's tissue for clinical purposes. We refer here to the questions addressed in the introduction above. Further encouraged by an actual request from a Dutch woman, previously treated for breast cancer, to have the 70-gene signature performed on her tumor tissue, the hospital installed a group of lawyers and ethicists in order to study the new questions together with the professionals concerned, i.e. physicians of the departments of oncology and pathology and researchers in the field of genomic profiling. Following the exploratory phase, a draft guideline was written and discussed with professionals and patient representatives during two subsequent meetings. Finally, the hospital's department of pathology was requested to explore the feasibility of applying the guideline in daily clinical practice (Figure 1). 
Request Patient:

"Is it possible to perform the 70-gene signature on my breast tumor, after my surgery 4 years ago?"

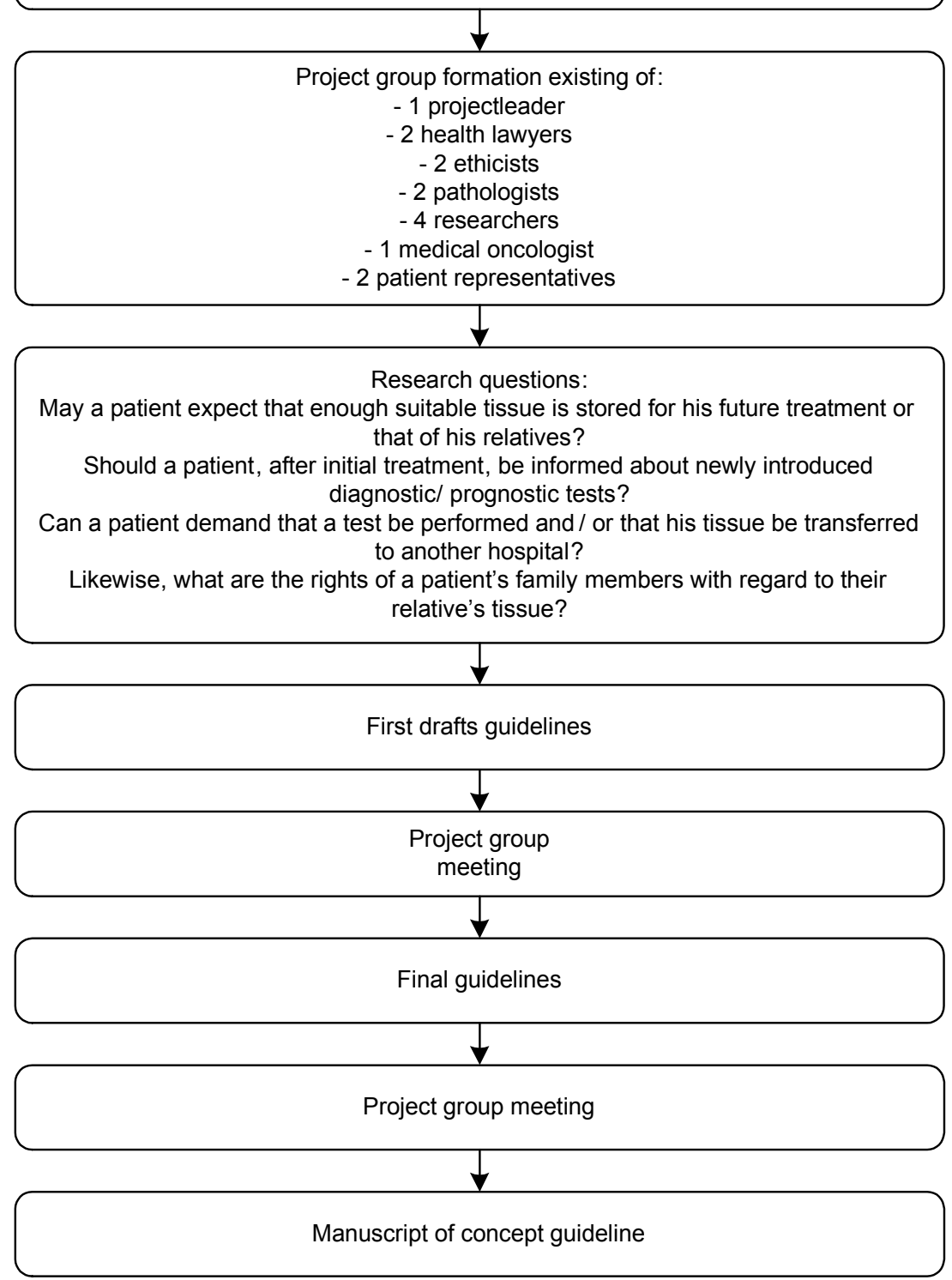

Figure 1. Process of developing concept guideline 


\section{Comment "Tumor tissue: Who is in control?" in Lancet Oncology, 2010}

Recent developments in genomics have resulted in the increased availability of gene profiles for (early) diagnosis and prognosis in breast cancer. A request from a Dutch woman to have her tumor tissue tested years after treatment confronted the Netherlands Cancer Institute (NKI) and its staff with legal, ethical, and practical questions regarding patients' rights in relation to residual tissue storage and its use for clinical purposes. Was her tissue still available? If so, could she demand that the test be carried out or her tissue be transferred to another hospital? As it became apparent that appropriate guidance was lacking in this area, we developed guidelines on the issue, with the involvement of relevant professionals and patient representatives within the framework of a Technology Assessment project. ${ }^{1}$

Gene expression profiling is an important development, which is likely to predict more accurately the diagnosis and prognosis of malignant diseases. ${ }^{2}$ Although it is not yet routine, several tests are already applied in clinical practice. Additionally, the 70-gene prognosis signature (MammaPrint ${ }^{\mathrm{TM}}$ ), using microarrays on fresh frozen tumor tissue, is being tested in a multicenter randomized trial (MINDACT). ${ }^{3}$ Although genomic profiling will transform cancer treatment into more effective medicine in the first place, it can be foreseen that it will be used in many other diseases and for other goals than prognostics. For a successful performance of such tests, availability of proper and sufficient (tumor) tissue is essential.

\section{Four general principles}

As to the guideline's underlying principles, tissue banking for clinical purposes has been much less addressed in the literature than tissue banking for research purposes. ${ }^{4}$ Since this counts also for (inter)national legislation and guidelines, we need to look at related legal and ethical documents. From these documents, ${ }^{5}$ we distinguish four general principles.

First, care providers have the moral and legal obligation to protect the clinical interests of their patients. ${ }^{6}$ In light of the emerging technologies, in our opinion good clinical care includes, apart from the more traditional elements, securing the availability of sufficient tissue for (future) clinical care, and access for patients to generally accepted diagnostic or prognostic tests on that tissue.

Second, irrespective of whether they can be considered "owners" of their removed tissue in their own jurisdiction ${ }^{7}$, patients have personal rights regarding their removed bodily material. We aim primarily at the right to consent or object to its storage and use for other purposes, such as research, than that for which it was removed. ${ }^{8}$ As care providers are likely to differ in their testing policies, patients 
should also be entitled to request tissue transfer in order to have their tissue tested elsewhere.

A third principle concerns the position of the patient's relatives. Here, the underlying question is whether a physician's duty to provide good clinical care involves the protection of the relatives' medical interests too. Looking at international standards the answer is affirmative, ${ }^{9,10}$ although it is generally acknowledged that physicians have less extensive obligations towards the patients' relatives than towards patients themselves as they are primarily responsible for the care of the persons who are seeking their assistance. The latter implies in our opinion that, as long as patients are capable of giving authorization, they should decide about whether their tissue shall be tested or transferred in the interest of family members.

A final principle that can be derived from international documents concerns the situation in which a patient's interests conflict with the general interests of medical science. We refer to UNESCO's Declaration on the Human Genome: "No research or research application concerning the human genome (...) should prevail over respect for the human rights, fundamental freedoms and human dignity of individuals or, where applicable, of groups of people". Therefore, in situations in which tissue has been stored for the purpose of medical care as well as scientific research and is insufficient to serve both purposes, the medical interest of the patient overrides the general interest of performing scientific research.

\section{Elements in guideline}

Taken these principles into account, a number of main elements are described in the guideline.

The hospital's primary responsibility is to see to it that, as far as is reasonably possible, enough of a patients' tissue is available for present or future clinical use. The practitioners responsible (i.e. surgeons and pathologists) should therefore ensure that sufficient tissue is stored and preserved in such a way - fresh- frozen or otherwise- that it is suitable for testing, even many years after initial diagnosis or treatment.

Second, after expiration of the storage period (this depends on national jurisdictions and medical practice guidelines), a hospital may destroy the remaining tissue, but only if the medical interests of patients or their relatives, or the general interest of medical science no longer require its retention.

Where the legal relationship between patient and hospital has come to an end and a patient or the relatives request so for a diagnostic purpose, the hospital should 
cooperate with transfer of the tissue to another hospital. The right to have one's tissue transferred to another hospital should also apply when the attending practitioner refuses to perform the requested test.

Furthermore, the hospital should elaborate local guidelines that cover all the relevant administrative aspects concerning tissue banking for clinical purposes, not least to be able to provide clear information to patients about their rights. As to the actual application of local guidelines, it could be helpful to appoint a "tissue bank manager", responsible for matters such as the further automatization of the record keeping of specimens and the assessment and handling of tissue.

Physicians should consider it their duty to keep the patient up-to-date about new tests that can be performed on stored tissue as soon as these tests can be considered an element of evidence based, good clinical care. It is a task of professional organizations together with patient representatives to develop more detailed standards on what the responsibilities of physicians should entail in this respect.

If a patient consents to it, relatives should be able to request tissue transfer and/or testing related to their legitimate personal health interests. When a patient has died or is incapable of giving consent, but the tissue is still available, relatives have the right to request continuation of storage, transfer and/or testing of the tissue.

Finally, to ensure that patients are aware that, for their benefit, tissue is being stored for a long time and that they have an important say about what happens to it, they should receive adequate information on the storage period and use of the tissue, their personal rights and those of the family members.

\section{Concluding remarks}

Although the guideline is primary developed for the storage policy on tumor tissue, we expect it can also be relevant for the storage of other types of tissue. We are aware that the presented elements require further reflection and debate. It is obvious that tissue storage for clinical purposes urgently needs further attention from a medical, ethical, legal and practical perspective. Hopefully, the guidance we propose will contribute to the discussion on this important issue.

\section{Acknowledgements}

We would like to thank all participants in the discussion meetings: F.E. van Leeuwen, E. Vermeulen, E. Vos, A. Vos, L.J. van 't Veer, S. Verhoef, M. Pernet, M.J. van de Vijver, D.L. Willems M. Witvliet, and A. Bless. 


\section{References}

1. Douma KF, Karsenberg K, Hummel MJ, Bueno-de-Mesquita JM, van Harten WH. Methodology of constructive technology assessment in health care. Int $\mathrm{J}$ Technol Assess Health Care. 2007;23:162-168.

2. Bertucci F, Houlgatte R, Nguyen $C$ et al. Gene expression profiling of cancer by use of DNA arrays: how far from the clinic? Lancet oncology $2001 ; 2: 674-682$.

3. Bueno-de-Mesquita JM, van Harten W, Retèl VP et al. Use of 70-gene signature to predict prognosis of patients with node-negative breast cancer: a prospective community-based feasibility study (RASTER). The Lancet Oncology 2007; 8:10791087.

4. Hansson MG, Dillner J, Bartram CR et al. Should donors be allowed to give broad consent to future biobank research? Lancet oncology 2006; 7:266-269.

5. Council of Europe, Convention on Human Rights and Biomedicine of 1997 with its additional protocols on Biomedical Research (2004) and Genetic Testing for Health Purposes (2008); UNESCO's International Declaration on Human Genetic Data (2003).

6. World Medical Association. Declaration of Geneva of 1948 (Physician's Oath). 1948.

7. Charo RA. Body of research--ownership and use of human tissue. $\mathrm{N}$ Engl J Med 2006; 355:1517-1519.

8. Council of Europe. Convention for the Protection of the Human Rights and Dignity of the Human Being with regard to the Application of Biology and Medicine, Article 22. 1997.

9. Council of Europe. Additional Protocol to the Biomedicine Convention concerning Genetic Testing, Articles 13-15.

10. Guðmundsdóttir v.lceland. Comparitive Law - genetic privacy - Icelandic Supreme Court holds that inclusion of an individual's genetic information in a national database infringes on the privacy interests of his child. Available at website: http://www.harvardlawreview.org/issues/118/Dec04/Recent\%20Cases/Guomundsdotti r_v_IcelandFTX.pdf . Harvard Law Review 2004; 118:810-817. 



\section{Chapter 5}

Genomic testing: What is the impact on patients?

Valesca P. Retèl

Catharina G.M. Groothuis-Oudshoorn

Neil K. Aaronson Noel T. Brewer

Emiel J.T. Rutgers

Wim H. van Harten 


\begin{abstract}
Background

Gene expression profiling is an example in the rapidly evolving field of personalized medicine. The primary aim of this study was to evaluate the impact of receiving a gene expression profile on breast cancer patients' well being.
\end{abstract}

\title{
Methods
}

Participants were Dutch women being treated for early stage breast cancer who were enrolled in a randomized clinical trial, 'Microarray In Node-negative and 1 to 3 positive lymph node Disease may Avoid ChemoTherapy; EORTC 10041/BIG 3-04" (MINDACT). As part of the trial, they received a recurrence risk estimate based on the 70-gene signature and standard clinical criteria as scores through Adjuvant Online. We mailed a questionnaire assessing understandability, risk perception, knowledge, satisfaction with provided information and process, and patients' well being using distress, cancer worries and Health Related Quality of life (HRQoL), 68 weeks after surgery and the decision regarding adjuvant chemotherapy treatment.

\section{Results}

Women $(N=347$, response rate $62 \%)$ reported high satisfaction and good understanding regarding the provided information. Low levels of distress were found in the groups scoring low risk for both tests, significantly higher distress levels were measured when patients received a high genomic risk, a "not available" profile or when there was discordance between the genomic profile and standard clinical criteria $(p<0.001)$. Cancer worries were highest for patients with high risk perception and low satisfaction $(p<0.001)$. Patients reported significantly lower $\mathrm{HRQ}$ L in case of concordant high risk profiles $(p=0.013)$ or a "not available" profile $(p<0.001)$.

\section{Conclusion}

Recommendations for clinical use of expression profiles are to increase physician awareness that genomic test results can affect patients well being, and when providing more specific support for patients with discordant and high-risk results, distress may be reduced. 


\section{Introduction}

Gene expression profiling, an example of personalized medicine, is evolving quickly. It is already incorporated in breast cancer treatment guidelines, including the National Comprehensive Cancer Network (NCCN), the American Society of Clinical Oncology (ASCO), the Dutch Clinical Guidelines (CBO) 2008 and St. Gallen. ${ }^{1}$ One of these is the 70 -gene prognosis signature (MammaPrint $\left.{ }^{\mathrm{TM}}\right)^{2,3}$, which can accurately distinguish breast tumors with a high metastatic capacity from tumors with a low risk of developing distant metastases, by measuring the expression level of 70 genes in tumor tissue. Several retrospective validation studies have confirmed its prognostic value. ${ }^{4-6}$

In 2007, the MINDACT (Microarray In Node-negative and 1 to 3 positive lymph node Disease may Avoid ChemoTherapy; EORTC 10041/BIG 3-04) trial started to prospectively evaluate whether the 70-gene signature selects the right patients for adjuvant chemotherapy as compared to standard clinicopathological criteria. ${ }^{7,8}$ This trial will enroll 6000 breast cancer patients throughout Europe, who will have their risk of disease recurrence assessed by both traditional clinicopathological criteria and the 70-gene signature. The 70-gene signature identifies low or high risk patients; Clinicopathological prognostic risk is being assessed through a modified version of Adjuvant Online. ${ }^{9}$ Low risk is defined as $>88 \%$ chance of 10 -years survival for estrogen receptor (ER)-positive breast cancer and $>92 \%$ for ERnegative breast cancer. Concordant genomic high (G-high) and clinicopathological high (C-high) risk patients are recommended to undergo adjuvant chemotherapy (CT) and concordant G-low and C-low risk patients are informed that CT is not recommended. Discordant patients ("G-low/C-high" or "G-high/C-low") are randomized to treatment-decision making based on the genomic risk assessment or treatment-decision making based on the clinical risk assessment. ${ }^{10}$

Since genomic testing is a recent development, relatively few studies have investigated psychosocial issues surrounding these tests. O'Neill et al., in a survey of 139 women who received breast cancer treatment before genomic profiling was available, found a strong interest in genomic testing. ${ }^{11}$ Richman et al., in a study of 78 breast cancer patients who had previously received gene expression profiling, reported that many women had an inadequate understanding of gene profiling. ${ }^{12}$ In an analysis of data from the same study, Tzeng et al. found that many breast cancer patients preferred a level of shared decision making that was different from what they experienced with their doctor. ${ }^{13}$ Lo et al. found that receiving gene expression profiling results lowered patients' $(N=89)$ anxiety. ${ }^{14}$ Both Tzeng et al. ${ }^{13}$ and Lo et al. ${ }^{14}$ found that patients' decisions were largely concordant with their gene expression profile results. These studies tended to have small samples, examined the effects of different risk results only minimally, and did not investigate 
the impact of the combination of gene profiling and clinical risk data in their analyses.

The primary aims of the current study were to evaluate the impact of receiving a gene expression profile on breast cancer patients' well being, and to compare the different risk groups, according to the genomic and clinical risk assessment. In addition, we focused on understandability of genomic test information received, risk perception, knowledge, satisfaction with provided information and process. We expected higher well being for the concordant C-low/G-low risk group, lower well being in patients who did not receive genomic result and lower well being for the discordant clinical-low and genomic-high patient risk groups, especially the group who did not receive chemotherapy (CT).

\section{Methods}

\section{Study sample}

Women taking part in the MINDACT trial from 10 hospitals in the Netherlands were approached to participate in the study. Eligible patients were those with early stage breast cancer (0-3 positive lymph nodes) who were able to read and write in Dutch or English. Besides the patients included in the MINDACT trial, we also included in our sample women who ultimately proved ineligible for the MINDACT trial due to "not available" genomic results. Clinical tests had two possible results (low or high recurrence risk) and genomic tests had three (low, high or a "not available" -narecurrence risk). In case of a "not available" profile, the 70-gene signature could not be processed due to for example $>3$ positive lymph nodes, insufficient RNA quality, or logistical problems. ${ }^{10}$ Crossing clinical and genomic results, and accounting for trial assignment of discordant test results, yielded 8 groups: 1) C-low/G-low, 2) Chigh/G-high, 3) C-low/G-high assigned to no CT, 4) C-low/G-high assigned to CT, 5) C-high/G-low assigned to CT, 6) C-high/G-low assigned to no CT, 7) C-low/Gna, 8) C-high/G-na (Figure 1).

\section{Procedures}

Patient recruitment began in September 2008 and continued until the end of August 2010. Eligible patients received an invitation letter signed by the treating physician, along with the general MINDACT trial information before surgery. Patients who enrolled in the MINDACT trial could choose whether to participate in the current study. Six to eight weeks after surgery, the questionnaire accompanied by an informed consent form was sent. By this time, patients had received the results of the clinical risk (C) and the genomic profile (G), had made a decision regarding adjuvant treatment, but had not yet started adjuvant treatment. Patients who did not respond to the initial invitation were sent a reminder two weeks later. 


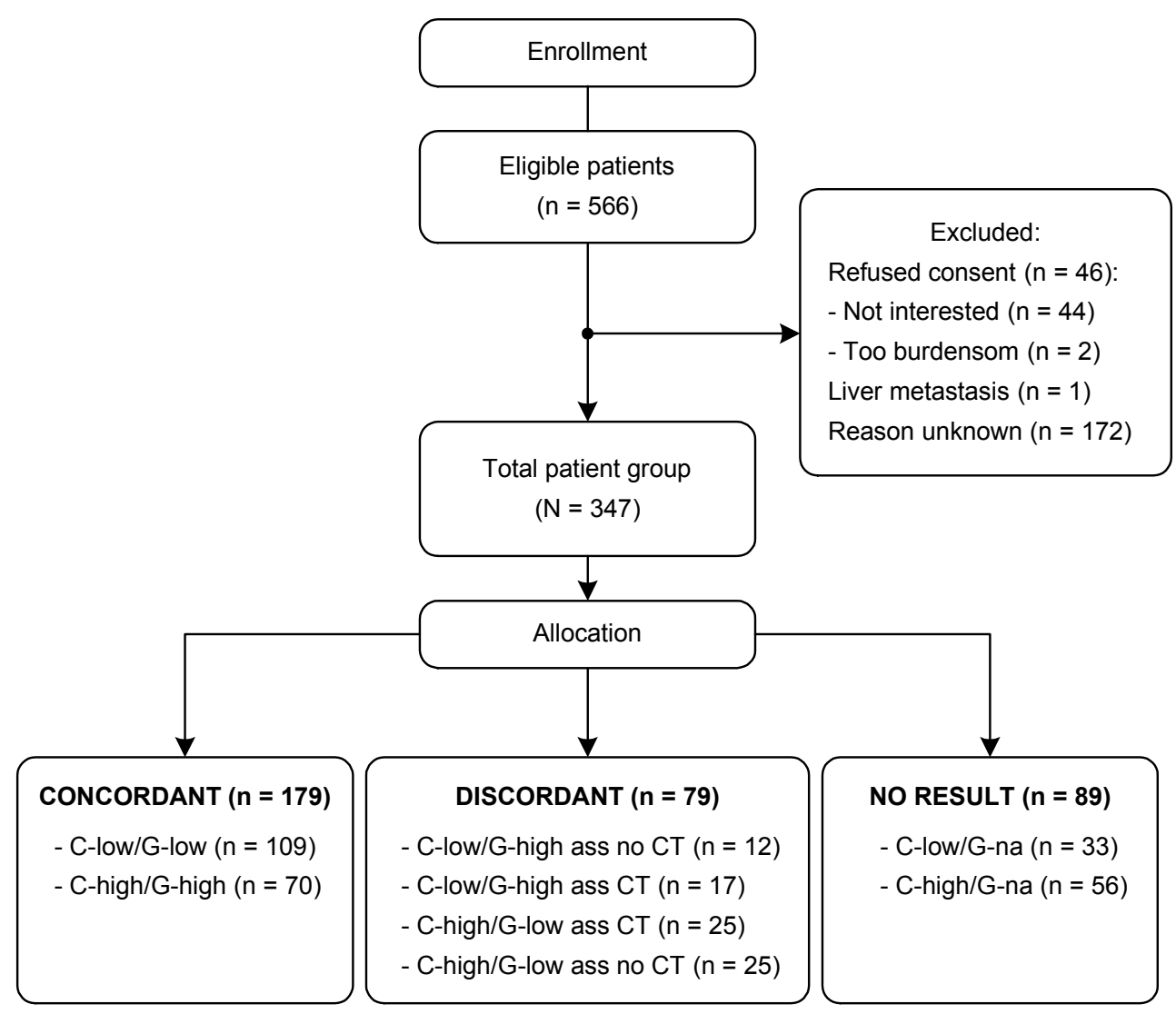

Figure 1. CONSORT diagram

C: clinical

G: genomic

ass: assigned to

CT: chemotherapy

na: not available (genomic profile) 


\section{Measures}

During a previous feasibility study, the MicroarRAy PrognoSTics in Breast CancER (RASTER) study $^{15}$, we interviewed 27 patients about their personal experiences dealing with the signature. Based on these interviews, we constructed a questionnaire and pilot tested it with 77 patients. ${ }^{16}$ The questionnaire was adjusted for the current study alongside the MINDACT trial.

The Dutch questionnaire assessed sociodemographic, clinical and psychosocial variables as shown in Table 1. The main study outcomes concerning patients' well being were genomic-specific distress (referred to subsequently as distress), cancer-specific worry, and health-related quality of life (HRQoL). The items for each scale were averaged to create 3 continuous composite variables. Distress was assessed with 10 items adapted from Lynch's distress scale ${ }^{17}(\alpha=0.91)$. An adapted 7-item version of Lerman's Cancer Worry Scale ${ }^{18}(\alpha=0.89)$, was used to measure cancer worries. The widely used Functional Assessment of Cancer Therapy-Breast questionnaire (FACT-B $)^{19}$ was used to assess HRQoL. Additionally, we measured additional factors which could also have influenced the way patients understood the results. We adapted 5 items from Degner et al., used for assessing decision making preference. ${ }^{20}$ This subscale distinguishes preference for an active role in decision making, a passive role or a shared role. We developed 5 items regarding understandability of the provided information $(\alpha=0.80), 21$ items assessing genomic test knowledge, forming a "knowledge" scale, 5 items regarding satisfaction with provided information and process, forming a "satisfaction" scale $(\alpha=0.78)$ and 1 item measuring the patients' risk perception. Finally, we measured whether women received both tests in one occasion or separately.

\section{Statistical analysis}

We assessed baseline differences between groups with Student's $t$, Mann Whitney- $U$, and chi-square tests. We used unadjusted univariate analysis of variance (ANOVA) to evaluate whether there were significant differences between risk groups in distress, worries and HRQoL. Multiple imputation was used in multiple regression analyses to infer data for missing responses $(n=61,17 \%)$ for all variables with one or more missing values, resulting in five complete datasets. Results of these datasets were pooled according to Rubin's rules. ${ }^{21}$ Block-wise multiple linear (adjusted) regression analysis was carried out to determine which variables were associated with distress, worry and HRQoL. The first block contained sociodemographic variables; the second contained relevant additional factors such as understandability, risk perception, satisfaction, knowledge and 
receiving both tests in one occasion; the third contained risk group variables (dummy coded with the "C-low/G-low" group as the reference).

Table 1. Survey measures

\begin{tabular}{|c|c|c|c|c|}
\hline & $\begin{array}{l}\text { No. of items } \\
\text { (response scale) }\end{array}$ & $\alpha$ & $\begin{array}{l}\text { Mean } \\
\text { (SD) }\end{array}$ & Description \\
\hline \multicolumn{5}{|c|}{ Predictor Variable } \\
\hline $\begin{array}{l}\text { Understanda- } \\
\text { bility }\end{array}$ & $\begin{array}{l}5 \text { items (4-point } \\
\text { scale) }\end{array}$ & 0.81 & $\begin{array}{l}2.89 \\
(0.42)\end{array}$ & $\begin{array}{l}\text { Did you find: 1) the verbal information } \\
\text { clear? 2) the written information } \\
\text { clear? 3) the information prior to the } \\
\text { test clear? 4) the information about } \\
\text { handling the results clear? 5) the total } \\
\text { information clear, for making a careful } \\
\text { decision? }\end{array}$ \\
\hline $\begin{array}{l}\text { Risk } \\
\text { perception }\end{array}$ & 1 item $(0-100 \%)$ & & & $\begin{array}{l}\text { What do you think is the chance your } \\
\text { cancer will come in the coming } 10 \\
\text { years? }\end{array}$ \\
\hline $\begin{array}{l}\text { Decision } \\
\text { making } \\
\text { preference }\end{array}$ & $\begin{array}{l}1 \text { item (5-point } \\
\text { scale) }\end{array}$ & 0.41 & $\begin{array}{l}2.55 \\
(1.00)\end{array}$ & $\begin{array}{l}\text { I prefer to make my decision } \\
\text { alone/shared/to leave it to my } \\
\text { physician }\end{array}$ \\
\hline $\begin{array}{l}\text { Results in } 1 \\
\text { occasion }\end{array}$ & 1 item (Yes/no) & & & $\begin{array}{l}\text { Did you receive the test results in one } \\
\text { occasion? }\end{array}$ \\
\hline Satisfaction & $\begin{array}{l}5 \text { items (5-point } \\
\text { scale) }\end{array}$ & 0.78 & $\begin{array}{l}2.06 \\
(0.65)\end{array}$ & $\begin{array}{l}\text { How satisfied were you with: } 1 \text { ) the } \\
\text { total medical care for breast cancer; } \\
\text { 2) the time you had to wait for the test } \\
\text { results; } 3 \text { ) the total information } \\
\text { provided; } 4 \text { ) the way the results were } \\
\text { conveyed; } 5 \text { ) the communication with } \\
\text { the medical and nursing staff? }\end{array}$ \\
\hline \multicolumn{5}{|l|}{ Outcomes } \\
\hline $\begin{array}{l}\text { Cancer } \\
\text { specific } \\
\text { cancer } \\
\text { worries }\end{array}$ & $\begin{array}{l}7 \text { items (4-point } \\
\text { scale) }\end{array}$ & 0.89 & $\begin{array}{l}1.79 \\
(0.58)\end{array}$ & $\begin{array}{l}\text { During the last } 4 \text { weeks: how often } \\
\text { have you thought about getting } \\
\text { cancer again; how often do you worry } \\
\text { about getting metastasis; or needing } \\
\text { chemotherapy again; did this affected } \\
\text { your mood or daily activities? }\end{array}$ \\
\hline $\begin{array}{l}\text { Genomic } \\
\text { specific } \\
\text { distress }\end{array}$ & $\begin{array}{l}10 \text { items (4-point } \\
\text { scale; a little, some, } \\
\text { very, a lot)) }\end{array}$ & 0.91 & $\begin{array}{l}1.99 \\
(0.79)\end{array}$ & $\begin{array}{l}\text { How did you feel when your doctor } \\
\text { told you the (genomic) test results? } \\
\text { Disappointed; sad; surprised; } \\
\text { confused; upset; insecure; angry; } \\
\text { helpless; anxious; somber. }\end{array}$ \\
\hline $\begin{array}{l}\text { Health-related } \\
\text { quality of life }\end{array}$ & $\begin{array}{l}9 \text { items (5 point } \\
\text { scale) }\end{array}$ & 0.63 & $\begin{array}{l}26.44 \\
(5.11)\end{array}$ & $\begin{array}{l}\text { Breast cancer subscale of the } \\
\text { FACT-B }\end{array}$ \\
\hline
\end{tabular}

$\alpha$ : Cronbach's alpha in the present study; FACT-B: Functional Assessment of Cancer Therapy - Breast; SD: Standard Deviation 
The R-squared explaining the variance was calculated according to the formula in Harel, $2009 .^{22}$ In order to maintain the family-wise Type 1 error at 0.05 over the multiple (correlated) tests, we set the critical alpha at a conservative 0.01. All analyses were carried out with SPSS version 17.0, except Rubin's rules, for which we used version 18.0.

\section{Results}

\section{Study sample}

In total, 347 of the 566 patients we invited to participate returned a completed questionnaire (62\% response rate) (Figure 1). The characteristics of the total group appear in Table 2. Concordant risk results were: "C-low/G-low" $(n=109)$ and "Chigh/G-high" ( $n=70)$. Discordant risk results were: "C-low/G-high assigned to no CT" ( $(n=12)$, "C-low/G-high assigned to CT" $(n=17)$, "C-high/G-low assigned to CT" $(n=25)$, and "C-high/G-low assigned to no CT" $(n=25)$. Genomic results deemed "not available" were: "C-low/G-na" ( $n=33)$ and "C-high/G-na" $(n=56)$.

\section{Understandability}

Few women $(n=21,6 \%)$ had heard of the 70 -gene signature before their diagnosis. Women recalled that they had received information about their risk of metastasis most often in words $(n=139,43 \%)$, less commonly in both words and numbers $(n=100,31 \%)$, and rarely in numbers only $(n=25,8 \%)$, the remaining patients did not respond to this question. In general, women found the information they received to be understandable: the written information was perceived as clear by $87 \%$ of the women, verbal information by $87 \%$, information prior to the test results by $85 \%$, information about adjuvant treatment by $82 \%$, and information necessary to make a careful decision by $83 \%$. Twenty-seven percent of the women received both test results in one occasion, $71 \%$ received them in two successive occasions, and for the remaining $2 \%$ this was unknown. 
Table 2. Characteristics of the respondents $(N=347)$

\begin{tabular}{lrcccc}
\hline & & N & $\%$ & Mean (range) & SD \\
\hline Age & & & & $55.3(26-71)^{\star}$ & 8.8 \\
& $\leq 35$ & 10 & 3 & & \\
$36-45$ & 37 & 11 & & \\
$46-55$ & 119 & 34 & & \\
$56-65$ & 139 & 40 & & \\
$\geq 66$ & 42 & 12 &
\end{tabular}

Marital status

$\begin{array}{rcc}\text { Living as married } & 274 & 79 \\ \text { Not living as married } & 73 & 21\end{array}$

Children

$\begin{array}{ccc}\text { Yes } & 274 & 79 \\ \text { No } & 73 & 21\end{array}$

Dutch citizen

$\begin{array}{ccc}\text { Yes } & 325 & 94 \\ \text { No } & 22 & 6\end{array}$

Level of education

$\begin{array}{rcc}\text { Primary school } & 46 & 13 \\ \text { High school } & 192 & 55 \\ \text { College or university } & 109 & 32\end{array}$

Family cancer history

$\begin{array}{lll}\text { Yes } & 152 & 44 \\ \text { No } & 189 & 55\end{array}$

Recurrence risk

$\begin{array}{rcc}\text { C-low/G-low } & 109 & 31 \\ \text { C-high/G-high } & 70 & 20 \\ \text { C-low/G-high assigned to no CT } & 12 & 4 \\ \text { C-low/G-high assigned to CT } & 17 & 5 \\ \text { C-high/G-low assigned to no CT } & 25 & 7 \\ \text { C-high/G-low assigned to CT } & 25 & 7 \\ \text { C-low/G-na } & 33 & 10 \\ \text { C-high/G-na } & 56 & 16\end{array}$

Note. C: clinical, G: genomic, CT: chemotherapy, SD: Standard Deviation, na: not available ${ }^{*}$ Age as continuous variable used in analyses 


\section{Knowledge}

Knowledge about genomic recurrence risk testing was relatively high (mean correct answers, across 21 items $=75 \%$ ). Three questions elicited substantially more "I don't know" responses (Table 3). These were: "The result of the genomic profile is always correct" (43\% don't know); "For a breast tumor with a high risk genomic profile, the chance of metastasis in the next 10 years is 50\%" (52\% don't know); and "Other medicines can change the effectiveness of chemotherapy" (49\% don't know). The three questions with the most incorrect answers were: "A high genomic profile indicates that a patient will need to have her lymph nodes removed" $(25 \%)$; "The genomic profile indicates the chance of metastasis" (23\%); and "For a breast tumor that the genomic profile indicates high risk, the chance of metastasis in the next 10 years is $50 \% "(21 \%)$.

\section{Decision making}

Fourty-eight percent of the women preferred to make a shared decision regarding their adjuvant treatment, $37 \%$ preferred to have an active role, and $15 \%$ preferred a passive role in their adjuvant treatment decision making. Ninety-five percent of the women indicated that they would be willing to participate in the MINDACT trial again. From the 4 randomized risk groups $(n=79), 52 \%(41 / 79)$ of the patients were concerned that their treatment advice was determined by chance. Most of these patients were from the "C-low/G-high group assigned to CT" $(10 / 17,59 \%)$ and "Chigh/G-low assigned to CT" $(15 / 25,60 \%)$. Seventy percent of the women would make the same decision regarding whether or not to undergo chemotherapy again ( $2 \%$ would not make the same decision, $28 \%$ did not answer this item). The majority $(89 \% ; 303 / 347)$ of the women would recommend other women in the same situation to have the 70-gene signature performed. Seven patients would not recommend the 70-gene signature (4 in the "C-low/G-low" risk group, 1 in "Chigh/G-low assigned to CT" and 2 in "C-low/G-na"). The remaining patients did not respond to this question. Fifteen patients (4\%) indicated that they had not followed their physicians' advice. Seven of these 15 patients had a discordant test result, 7 had a high risk result, and 1 patient had a low risk result.

\section{Satisfaction}

Almost all women $(97 \%)$ were satisfied with the entire diagnostic and treatment trajectory, from diagnosis up to the time that the questionnaire was completed. Similarly, $94 \%$ expressed overall satisfaction with the information received. Twentyeight percent of the patients were unsatisfied with the waiting time for the results. Based on self-report data, $6 \%$ received results within 1 week of surgery, $23 \%$ within 2 weeks, $29 \%$ within 3 weeks, $23 \%$ within 4 weeks, and $18 \%$ after more than 
4 weeks. Nine percent of the patients expressed dissatisfaction with the way in which the results were conveyed.

Table 3. Knowledge $(N=347)$

\begin{tabular}{|c|c|c|c|c|}
\hline \multicolumn{2}{|c|}{ Items regarding genomic profile } & $\begin{array}{l}\text { Responded } \\
\text { correctly, \% }\end{array}$ & $\begin{array}{l}\text { Responded } \\
\text { incorrectly, \% }\end{array}$ & $\begin{array}{l}\text { I don't } \\
\text { know \% }\end{array}$ \\
\hline \multicolumn{5}{|c|}{ True statements } \\
\hline a) & $\begin{array}{l}\text { The GP is done on tumor tissue from the } \\
\text { breast removed by surgery }\end{array}$ & 97 & 1 & 2 \\
\hline b) & $\begin{array}{l}\text { The GP is based on the genes of the } \\
\text { breast tumor }\end{array}$ & 90 & 4 & 6 \\
\hline c) & $\begin{array}{l}\text { The GP help some women avoid having } \\
\text { unneeded chemotherapy }\end{array}$ & 90 & 4 & 6 \\
\hline d) & $\begin{array}{l}\text { A patient with a high risk tumor will be } \\
\text { recommended chemotherapy }\end{array}$ & 86 & 5 & 9 \\
\hline e) & The GP gives the chance of metastasis & 67 & 23 & 10 \\
\hline f) & $\begin{array}{l}\text { For a high risk tumor, the chance of } \\
\text { metastasis in the next } 10 \text { years is }>50 \%\end{array}$ & 27 & 21 & 52 \\
\hline \multicolumn{5}{|c|}{ False statements } \\
\hline g) & $\begin{array}{l}\text { The GP is done before surgery that } \\
\text { removes the breast tumor }\end{array}$ & 88 & 6 & 6 \\
\hline h) & $\begin{array}{l}\text { Only the GP is used by the doctor to } \\
\text { recommend chemotherapy }\end{array}$ & 88 & 6 & 6 \\
\hline i) & $\begin{array}{l}\text { A GP tells whether other women in the } \\
\text { family have higher risk of breast cancer }\end{array}$ & 78 & 11 & 11 \\
\hline j) & $\begin{array}{l}\text { The GP tells whether cancer cells have } \\
\text { spread to the lymph nodes }\end{array}$ & 74 & 18 & 8 \\
\hline k) & $\begin{array}{l}\text { The GP can help women to decide about } \\
\text { the sort of surgery to undergo }\end{array}$ & 70 & 17 & 13 \\
\hline ।) & $\begin{array}{l}\text { The GP looks at all genes in a patient's } \\
\text { body }\end{array}$ & 69 & 14 & 17 \\
\hline m) & $\begin{array}{l}\text { A high risk GP indicates that a patient } \\
\text { will need to have lymph nodes removed }\end{array}$ & 62 & 25 & 13 \\
\hline n) & The GP is always correct & 38 & 19 & 43 \\
\hline
\end{tabular}

GP: genomic profile 


\section{Distress}

In the unadjusted (univariate) analysis, distress was significantly different among the risk groups $F(39,291)=1.601, p=0.017$ ) (Figure 2a). In the adjusted (regression) analysis, risk status remained significantly associated with distress levels after controlling for sociodemographic, information/knowledge, and risk perception variables (Table 4). The group "C-low/G-low" (reference) obviously reported the lowest distress, not significantly different for the group "C-high/G-low assigned to CT" $(p=0.18)$. Associated with higher distress compared to the reference group were the groups: not available genomic profile $(p=0.002$ and $p<0.001)$, the "C-high/G-high" group $(p=0.01)$ and the discordant groups "C-low/Ghigh assigned to CT" $(p<0.001)$ and "C-high/G-low assigned to no CT" $(p<0.001)$. The R-squared explaining the variance resulting from the final block of the regression analysis for distress was $38.5 \%$.

\section{Cancer Worries}

In the unadjusted (univariate) analysis, the 8 risk groups had similar levels of worry $F(19,327)=1.226, p=0.234$ ) (Figure $2 b)$. In the adjusted (regression) analysis, corrected for demographic factors, higher levels of worry were observed among women who expressed lower satisfaction $(p<0.001)$, and by women with a higher risk perception $(p<0.001$ ) (Table 4$)$. The $R$-squared for cancer worries was $25.1 \%$.

\section{Health related quality of life}

In the unadjusted (univariate) analysis, HRQoL was significantly different among the risk groups $F(26,307)=1.668, p=0.024$ ) (Figure 2c). In the adjusted (regression) analysis, higher age was associated significantly with better HRQoL $(p<0.001)$, while high risk perception was associated significantly with lower HRQoL $(p<0.001)$. HRQoL remained significantly different between the risk groups $(p<0.001)$, after controlling for demographic and process factors. Compared to the published normative mean of $24.1 \quad(S D=6.5, \alpha=0.63)^{19}$ for the breast cancer subscale of the FACT-B, the total patient group reported a significant higher QoL $(p<0.001)$. Only the "C-high-G-na" risk group reported a lower mean HRQoL (mean 23.83). In the current study, the groups "C-high/G-high" ( $p=0.013)$ and "C-high/Gna" $(p<0.001)$ risk groups reported significantly lower HRQoL compared to the reference group "C-low/G-low" (Table 4). The R-squared for cancer worries was $21.9 \%$.

The Pearson correlation of worry and HRQoL was -0.415 , worry and distress 0.456 , and HRQoL and distress -0.385 . 

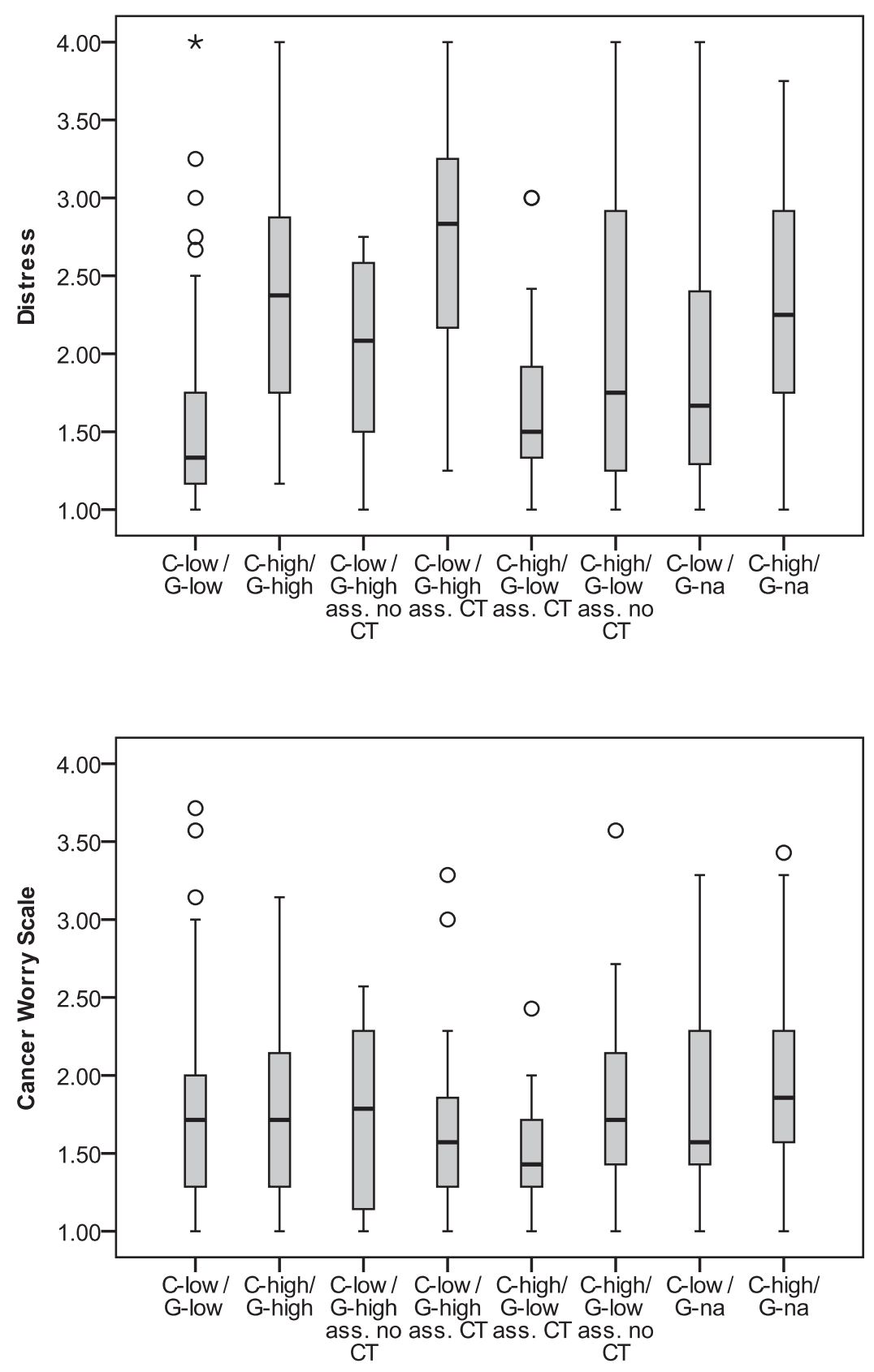

Figure 2a-b. Boxplots Distress and Cancer Worry Scale $(N=347)$ 


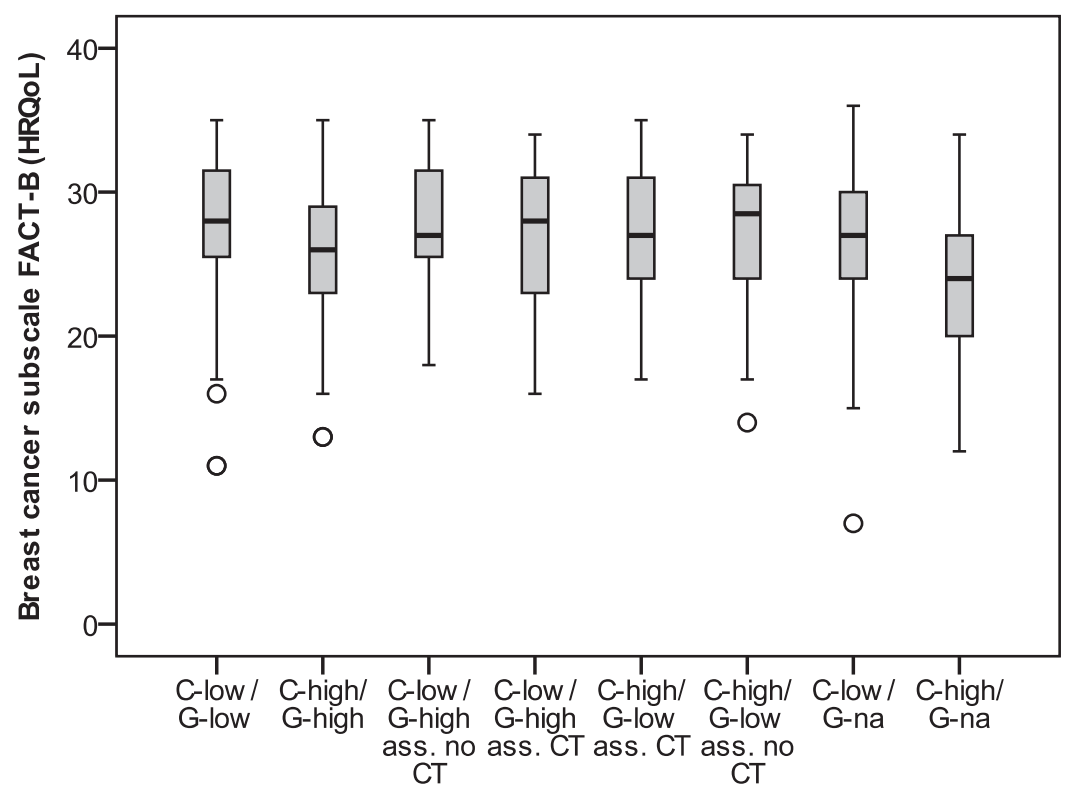

Figure 2c. Boxplot Breast cancer subscale FACT-B (HRQoL) ( $N=347)$

C: clinical, G: genomic, ass: assigned to, na: not available

\section{Discussion}

In general, women indicated that the information they had received regarding the test results was clear and satisfactory and resulted in a good understanding of the genomic profile and how to use their results. We found that patients with a "Clow/G-low" risk profile were the least distressed, followed by a "C-high/G-low assigned to CT". Patients were more distressed when they received a high risk profile, a discordant result, or a "not available" genomic profile.

We expected lower distress for the C-low/G-low group, which was confirmed. Our expectation that higher distress, more worries and lower HRQoL would be observed among the discordant "C-low/G-high" risk groups was not confirmed. Rather, higher distress levels compared to the reference group were observed for the "C-low/G-high assigned to CT" and "C-high/G-low not assigned to CT". 
Table 4. Correlates of distress, worry and quality of life

\begin{tabular}{|c|c|c|c|c|c|c|}
\hline & \multicolumn{2}{|c|}{ Distress } & \multicolumn{2}{|c|}{ Worry } & \multicolumn{2}{|c|}{ Quality of Life } \\
\hline & B & p & B & p & B & p \\
\hline \multirow{4}{*}{$\begin{array}{r}\text { Age } \\
\text { Married } \\
\text { Children }\end{array}$} & -0.001 & 0.821 & -0.042 & 0.049 & 0.122 & $0.000^{*}$ \\
\hline & -0.046 & 0.645 & 0.647 & 0.125 & 1.165 & 0.087 \\
\hline & 0.124 & 0.203 & -0.089 & 0.841 & -1.566 & 0.023 \\
\hline & -0.018 & 0.885 & -0.307 & 0.598 & -1.864 & 0.032 \\
\hline College (vs. High school) & -0.185 & 0.036 & -0.125 & 0.759 & 0.243 & 0.703 \\
\hline \multirow{5}{*}{$\begin{array}{r}\text { Knowledge } \\
\text { Information perception } \\
\text { Risk perception } \\
\text { Satisfaction } \\
\text { Test results in one occasion }\end{array}$} & -0.021 & 0.137 & -0.127 & 0.023 & 0.109 & 0.203 \\
\hline & -0.199 & 0.079 & -0.963 & 0.052 & -0.119 & 0.875 \\
\hline & 0.003 & 0.128 & 0.049 & $0.000^{*}$ & -0.043 & $0.000^{*}$ \\
\hline & 0.151 & 0.032 & 0.852 & $0.008^{*}$ & -0.517 & 0.282 \\
\hline & -0.016 & 0.849 & -0.224 & 0.554 & -0.187 & 0.753 \\
\hline C-high/G-high & 0.877 & $0.000^{*}$ & 0.107 & 0.827 & -1.908 & $0.013^{*}$ \\
\hline C-low/G-high assigned to no CT & 0.423 & 0.043 & -1.085 & 0.259 & 0.793 & 0.585 \\
\hline C-low/G-high assigned to CT & 1.115 & $0.000^{*}$ & -0.610 & 0.455 & -1.407 & 0.254 \\
\hline C-high/G-low assigned to CT & 0.211 & 0.175 & -1.230 & 0.081 & -1.131 & 0.296 \\
\hline C-high/G-low assigned to no CT & 0.611 & $0.000^{*}$ & 0.435 & 0.538 & -0.671 & 0.541 \\
\hline C-low/G-not available & 0.488 & $0.002^{*}$ & 0.427 & 0.512 & -1.752 & 0.075 \\
\hline C-high/G-not available & 0.710 & $0.000^{*}$ & 0.842 & 0.111 & -3.816 & $0.000^{*}$ \\
\hline
\end{tabular}

$B=$ standardized pooled coefficient, ${ }^{*} p<.01$, C: clinical, G: genomic, CT: chemotherapy. Note. Reference group for recurrence risk groups was C-low/G-low. Distress: Block $1 R^{2}=0.040$, Block $2 R^{2}=0.147$; Block 3: $R^{2}=0.385$. Cancer Worry Scale: Block $1 R^{2}=0.039$ Block $2 R^{2}=0.228$; Block $3: R^{2}=0.251$. Health related Quality of Life: Block $1 R^{2}=0.094$ Block $2 R^{2}=0.156$; Block $3 R^{2}=0.219$. The overall $R^{2}$ statistic indicates the percentage of variance explained by the variables in the model.

Because most of the women $(71 \%)$ received their results in succession (first the clinical risk assessment, followed by the signature), a 'reference point effect' could have been realized. Prospect theory suggests that the way content is presented influences the opinion people develop. ${ }^{23}$ In this case, the reference point was a low clinical risk result, followed by a high genomic result and followed by (unexpected) chemotherapy advice; this appears to have increased women's distress. To reduce a possible reference point effect, we recommend that physicians communicate all diagnostic results in one appointment after surgery. 
Although we expected high (inter)correlations between the three dependent variables, distress, worry and $\mathrm{HRQ}$ oL, they were only moderately correlated. Furthermore, we did find distinct correlates. Distress levels tended to vary primarily as a function of risk group, while worries were more likely to be associated with risk perception and satisfaction levels. Lower HRQoL was associated significantly with younger age, higher perceived risk, and risk group "C-high/G-high" and "C-high/Gna" result. These differences may be due to -partly- the varying focus of these three measures. The distress scale is concerned primarily with distress related to the genomic results, while the worry scale is concerned with breast cancer-related worries, while the HRQoL measure taps into both generic and breast cancerrelated issues.

Our results support earlier findings that satisfaction and knowledge can be important factors affecting levels of well being. Lo et al. ${ }^{14}$ observed negative impact on QoL among women who reported lower satisfaction with their adjuvant treatment decision. Richman et al. ${ }^{12}$ observed that higher knowledge was associated with having fewer concerns. Our results on the latter findings were statistically significant at $p<0.05$, but not at $p<0.01$.

Strengths of the study include its larger population compared to previous studies, its multicenter and prospective research design, and the use of standardized measures for assessing psychological outcomes. The distribution of patients across the subgroups and the general characteristics of the sample were comparable to those of the predefined pilot phase of the MINDACT trial. ${ }^{10}$ The study also had several limitations. First, while we were able to form 8 groups on the basis of clinical and genomic risk status and treatment decision, the groups with discordant risk estimates were relatively small, and thus may have limited the power of the study to detect group differences. This may explain, in part, why we did not confirm the hypothesis that the "C-low/G-high assigned to no CT" risk group would have increased distress levels. Second, the response rate in this study was moderate $(62 \%)$, although it should be noted that it is in line with that observed in other randomized EORTC trials. ${ }^{24,25}$ Third, in our study, clinical and genomic risk information was mostly communicated sequentially, which may be a consequence of the innovative character and may not be ideal in clinical practice. In the future, the genomic risk profile results may become incorporated into clinical guidelines, which results eventually in only one test outcome.

Our results suggest that patients indicated the provided information and understanding of the profile was sufficient. "C-low/G-low" risk patients have significantly lower distress compared to patients with a discordant risk, high risk and patients who did not receive a genomic test result. A lower HRQoL was also found for the latter two groups. Higher cancer worries were more related to lower 
satisfaction and higher risk perception. Clinicians should be aware that genomic test results may affect patients' well being. In anticipation of these effects, especially for patients with high and discordant test results, it may be useful to provide more and appropriate counseling, as counseling reduces distress from genomic (or at least genetic) testing. ${ }^{26}$

\section{Acknowledgements}

We first like to thank all patients who have participated in this study, and took the effort to fill in the questionnaire.

We would also like to thank Inge Eekhout, Jolanda Remmelzwaal, Stella Mook and Jolien Bueno de Mesquita for their input regarding the questionnaire.

In addition, the statistical support of Chad Gundy in the beginning of the study was greatly acknowledged. Furthermore, we thank Renate de Groot for support in the data processing.

This project was approved by the TRANSBIG and MINDACT Steering Committees. The MINDACT is supported by: grants from the European Commission Framework Programme VI, the Breast Cancer Research Foundation, Agendia B.V., Novartis, F. Hoffman La Roche, Sanofi-Aventis the National Cancer Institute $(\mathrm{NCl})$, the EBCC-Breast Cancer Working Group, the Jacqueline Seroussi Memorial Foundation, Prix Mois du Cancer du Sein, Susan G. Komen for the Cure, Fondation Belge Contre le Cancer, Dutch Cancer Society (KWF), Association Le cancer du sein, parlons-en! and Grant Simpson Trust and Cancer Research UK.

Finally, we would like to thank all the coordinators of the MINDACT study in the participating hospitals (included patients): A. Imholz, A. Hemels-van der Lans, E. ten Berge-Groen, Deventer Hospital, Deventer (32); E.J.T. Rutgers, L.J. van't Veer, I. Eekhout, J. Remmelzwaal, Netherlands Cancer Institute-Antoni van Leeuwenhoek Hospital, Amsterdam (101); D. de Vries, S. Hovenga, Nij Smellinghe Hospital; Drachten (10); O. Leeksma, B. de Valk, M. de Boer, Onze Lieve Vrouwen Gasthuis, Amsterdam (17); P. Neije, A. de Bes, Rijnland Hospital, Leiderdorp (46); J. Schrama, P. Hoekstra, Spaarne Hospital, Hoofddorp (28); H. de Graaf, R. la Roi, Medical Center Leeuwarden, Leeuwarden (13); J. van der Hoeven, M. Komen, Medical Center Alkmaar, Alkmaar (45); T. Smilde, A. Boonkamp, M. van Schijndel, Jeroen Bosch Hospital, Den Bosch (46); J. Brakenhoff, C. Boers, Waterland Hospital, Purmerend (9). 


\section{References}

1. Goldhirsch A, Ingle JN, Gelber RD et al. Threshold for therapies: highlights of the St. Gallen international expert consensus on the primary therapy of early breast cancer 2009. Ann Oncol 2009; 20:1319-1329.

2. Van 't Veer LJ, Dai H, van de Vijver MJ et al. Gene expression profiling predicts clinical outcome of breast cancer. Nature 2002;415:530-536.

3. Van de Vijver MJ, He YD, van 't Veer LJ et al. A Gene-Expression Signature as a Predictor of Survival in Breast Cancer. N Engl J Med 2002;347:1999-2009.

4. Buyse M, Loi S, van't Veer $L$ et al. Validation and Clinical Utility of a 70-Gene Prognostic Signature for Women With Node-Negative Breast Cancer. J Natl Cancer Inst 2006;98:1183-1192.

5. Bueno-de-Mesquita JM, Linn SC, Keijzer R et al. Validation of 70-gene prognosis signature in node-negative breast cancer. Breast Cancer Res Treat 2009;117:483495.

6. Paik S, Shak S, Tang $\mathrm{G}$ et al. A multigene assay to predict recurrence of tamoxifentreated, node-negative breast cancer. N Engl J Med 2004;351:2817-2826.

7. Cardoso F, Van't Veer L, Rutgers E et al. Clinical application of the 70-gene profile: the MINDACT trial. J Clin Oncol 2008;26:729-735.

8. Bogaerts J, Cardoso F, Buyse M, et al. Gene signature evaluation as a prognostic tool: challenges in the design of the MINDACT trial. Nat Clin Pract Oncol 2006;3:54051.

9. Ravdin PM, Siminoff LA, Davis GJ et al. Computer program to assist in making decisions about adjuvant therapy for women with early breast cancer. J Clin Oncol 2001;19:980-991.

10. Rutgers EJT, Piccart-Gebhart MJ, Delaloge S, van 't Veer LJ, Rubio I, Viale G, Bogaerts J. The EORTC 10041/BIG 03-04 MINDACT trial is feasible: first results of the pilot phase. Eur.J Cancer Suppl . 2010.

11. O'Neill SC, Brewer NT, Lillie SE et al. Women's interest in gene expression analysis for breast cancer recurrence risk. J Clin Oncol 2007;25:4628-4634.

12. Richman AR, Tzeng JP, Carey LA et al. Knowledge of genomic testing among earlystage breast cancer patients. Psycho-Oncology 2010.

13. Tzeng JP, Mayer D, Richman AR et al. Women's experiences with genomic testing for breast cancer recurrence risk. Cancer 2010;116:1992-2000.

14. Lo SS, Mumby PB, Norton J et al. Prospective multicenter study of the impact of the 21-gene recurrence score assay on medical oncologist and patient adjuvant breast cancer treatment selection. J Clin Oncol 2010;28:1671-1676.

15. Bueno-de-Mesquita JM, van Harten W, Retèl V et al. Use of 70-gene signature to predict prognosis of patients with node-negative breast cancer: a prospective community-based feasibility study (RASTER). The Lancet Oncology 2007; 8:10791087.

16. Retèl VP, Bueno-de-Mesquita JM, Hummel MJ et al. Constructive Technology Assessment (CTA) as a tool in coverage with evidence development: the case of the 70-gene prognosis signature for breast cancer diagnostics. Int $\mathrm{J}$ Technol Assess Health Care 2009;25:73-83.

17. Lynch HT, Lemon SJ, Durham $C$ et al. A descriptive study of BRCA1 testing and reactions to disclosure of test results. Cancer 1997;79:2219-2228.

18. Lerman C, Daly M, Masny A et al. Attitudes about genetic testing for breast-ovarian cancer susceptibility. J Clin Oncol 1994;12:843-850. 
19. Brady MJ, Cella DF, Mo F et al. Reliability and validity of the Functional Assessment of Cancer Therapy-Breast quality-of-life instrument. J Clin Oncol 1997; 15:974-986.

20. Degner LF, Sloan JA, Venkatesh P. The Control Preferences Scale. Canadian Journal of Nursing Research 1997; 29, 21-43.

21. Rubin DB, Schenker N. Multiple imputation in health-care databases: an overview and some applications. Stat Med 1991; 10:585-598.

22. Harel $\mathrm{O}$. The estimation of $\mathrm{R} 2$ and adjusted $\mathrm{R} 2$ in incomplete data sets using multiple imputation. Journal of Applied Statistics 2009; 36(10):1109-1118

23. Tversky A and Kahneman D. Advances in Prospect Theory: Cumulative Representation of Uncertainty. Journal of Risk and Uncertainty 1992;5(4):297-323.

24. Curran D, van Dongen JP, Aaronson NK et al. Quality of life of early-stage breast cancer patients treated with radical mastectomy or breast-conserving procedures: results of EORTC trial 10801. The European Organization for Research and Treatment of Cancer (EORTC), Breast Cancer Cooperative Group (BCCG). Eur J Cancer 1998;34(3):307-14.

25. De Haes JCJM, Curran D, Aaronson NK et al. Quality of life of breast cancer patients aged over 70 years, participating in the EORTC 10850 randomised clinical trial. Eur $\mathrm{J}$ Cancer 2003; 39(7):945-51.

26. Vadaparampil ST, Miree CA, Wilson C, Jacobsen PB. Psychosocial and behavioral impact of genetic counseling and testing. Breast Dis 2006; 27:97-108. 



\section{Chapter 6}

Cost-effectiveness of the 70-gene signature versus Sankt Gallen guidelines and Adjuvant Online for early breast cancer

Valesca P. Retèl Manuela A. Joore Michael Knauer Sabine C. Linn Michael Hauptmann Wim H. van Harten 


\begin{abstract}
Background

The 70-gene prognosis signature (MammaPrintTM) is a prognostic test used to guide adjuvant treatment decisions in patients with node-negative breast cancer. In order to decide upon its use, a systematic comparative analysis of the effects of the 70-gene signature, the Sankt Gallen guidelines and the Adjuvant Online Software for these patients on survival, quality of life and costs is warranted.
\end{abstract}

\title{
Methods
}

A Markov decision model was used to simulate the 20-year costs and outcomes (survival and quality-of-life adjusted survival (QALYs)) in a hypothetical cohort of node-negative, estrogen receptor positive breast cancer patients. Sensitivity and specificity of the three prognostic tools were based on 5 and 10 years breast cancer specific survival and distant metastasis as first event, derived from a pooled analysis consisting of 305 tumor samples from 3 previously reported validation studies concerning the 70 -gene signature.

\section{Results}

Small differences in survival, but substantial differences in quality-adjusted survival between the prognostic tools were observed. Quality-adjusted survival was highest when using the 70-gene signature. Based on costs per QALY, the 70-gene signature has the highest probability of being cost-effective for a willingness to pay for a QALY higher than $€ 4,600$. St. Gallen showed the highest survival rates compared to the 70-gene signature, but leads to a substantial larger amount of adjuvant chemotherapy and hence higher costs, thus demanding a willingness to pay of $€ 29,326$ to save a life year.

\section{Conclusions}

When deciding upon the cost-effectiveness of the prognostic tests, the 70-gene signature improves quality-adjusted survival and has the highest probability of being cost-effective. 


\section{Introduction}

Adjuvant systemic therapy for early breast cancer improves disease-free and overall survival. ${ }^{1}$ The majority of early breast cancer patients, particular with lymph node-negative disease $(60-70 \%)$, has a fairly good 10 -year overall survival with locoregional treatment alone, with 30-40\% developing distant metastasis. ${ }^{1}$ Nevertheless, according to current guidelines, most lymph node-negative patients are offered chemotherapy, likely causing an important proportion of overtreatment. ${ }^{2}$ Since this treatment has severe side effects, and is very costly, a careful selection of patients is important. In order to choose the optimal prognostic test, a tradeoff between survival, quality of life adjusted survival and costs is inevitable.

In 2002, the 70 -gene prognosis signature (MammaPrint ${ }^{\mathrm{TM}}$ ) was identified using microarray analysis for lymph node-negative breast cancer patients. ${ }^{3}$ This prognosis signature has been validated in several retrospective patient series. ${ }^{4-6}$ These studies confirmed that the 70-gene signature accurately discriminates between patients with a high and low risk of developing distant metastasis. The usual path of adoption in clinical practice would include a prospective randomized trial; however, this would take at least 8-10 years. Therefore, it was decided that it was appropriate to evaluate this technology in a non-randomized feasibility study. The Dutch Health Care Insurance Board sponsored this controlled introduction study, the multicenter microarRAy prognoSTics in breast cancER (acronym RASTER)-study. The main aim was to analyze the differences between adjuvant systemic treatment advice for breast cancer based on Dutch guidelines and the 70-gene signature, taking into account patients' preferences. ${ }^{7}$ However, a need for level I evidence of the performance of the 70-gene signature remained. Therefore, the currently ongoing randomized phase III clinical trial, the MINDACT (Microarray In Node-negative Disease may Avoid ChemoTherapy) trial, was designed., ${ }^{2,8}$ Alongside both studies a Constructive Technology Assessment is performed ${ }^{9}$, of which the cost-effectiveness analysis (CEA) underlying this paper takes part. The CEA provides a systematic comparative analysis of the available prognostic tests for node-negative breast cancer patients, which is not only based on test performance and long-term survival, but also on quality of life and costs. The results of this analysis are important to the decision to implement the 70-gene signature.

Earlier, in a cost-effectiveness analysis of the 70-gene signature performed by Oestreicher and colleagues, $2005^{10}$, the conclusion was that although gene expression profiling in breast cancer holds great promise, additional refinement and validation are needed before implementation in clinical practice. This analysis was performed on one retrospective validation series of Buyse and colleagues, $2006 .{ }^{5}$ 
Hornberger and colleagues, 2005 and Lyman and colleagues, 2007 performed a cost-effectiveness analysis concerning the 21-gene RT-PCR assay (Oncotype DX). ${ }^{11,12}$ They concluded that the gene expression profile predicted more accurately than current guidelines, and if applied appropriately, the assay was predicted to increase quality adjusted survival and save costs. The goal of our analysis was to show the expected cost-effectiveness of the use of the 70-gene signature compared to the currently used clinical guidelines Sankt Gallen and Adjuvant Online software, using a pooled database of three retrospective validation series. For this analysis, we developed a Markov model to compare long-term consequences of the use of three prognostic tools in patients with node-negative breast cancer: 1) the 70-gene signature (70-gene), 2) clinical pathological test result using the Sankt Gallen guidelines $(S G)^{13}, 3$ ) clinical pathological test result using the Adjuvant Online Software $(\mathrm{AO}){ }^{14}$ 


\section{Methods}

\section{Procedures}

This cost-effectiveness analysis was approved by the Institutional Review Board of the Netherlands Cancer Institute.

\section{Model description}

A Markov model was constructed with four mutually exclusive health states: disease free survival, relapse (including local and regional recurrences, secondary primary and contralateral breast cancer), distant metastasis, and death (Figure 1). The study adopts a health care perspective. The model simulated the course of events in a hypothetical cohort of 1000 patients aged 50 years with early, operable node-negative, estrogen receptor (ER)-positive breast cancer for three strategies: 70-gene signature, Sankt Gallen and Adjuvant Online. The specific selection of ER positive patients was made because the 70-gene signature is proven to have less additional clinical value for ER negative patients due to the high rates of high risk. ${ }^{15}$ In each strategy, based on the sensitivity and specificity of the prognostic test, patients were classified as having a true low, true high, false low, or false high risk of developing metastasis. It was assumed that both the prognostic test result and the treatment guidelines would be followed in all cases. We simulated in the model that all patients received endocrine treatment (ET); a second generation ET regimen: 2.5 years of Tamoxifen followed by 2,5 years of an Aromatase Inhibitor (mean of Anastrazol, Letrozol and Exemestane), and the $80 \%$ of high risk patients were assumed to receive six cycles of 5-Fluorouracil, Epirubicine, Cyclofosfamide (FEC 6*100), 10\% was assumed to receive six cycles of Docetaxel, Doxorubicine, Cyclofosfamide (TAC) and 10\% Doxorubicine, Cyclofosfamide (AC) and Paclitaxel $(4+12)$, in combination with Trastuzumab, according to the European guidelines. ${ }^{13,16}$ Trastuzumab (Herceptin) was given to $10 \%$ of the high risk patients, according to the proportion of HER2-neu positive patients in the node negative, ER positive group. ${ }^{17}$ Chronic congestive heart failure was modeled as an adverse event due to the administration of Trastuzumab in combination with anthracyclines and anthracyclines alone. Furthermore, consequences of congestive heart failure in terms of both costs and quality of life utility are incorporated, only modeled in relation to the adjuvant treatment. These model inputs are based on Keefe et al. (Table 2). ${ }^{18}$ The duration of the mean post-operative treatment (radiotherapy plus chemotherapy) was assumed to be finished within the first year. It was assumed that patients could only have one relapse, for which they received the best available treatment with the same costs, regardless which kind of adjuvant treatment the patient originally received for the primary tumor. However after experienced a relapse, the patient has a higher risk to develop distant metastasis. 
The calculations are performed per year, with a total simulated time horizon of 20 years.
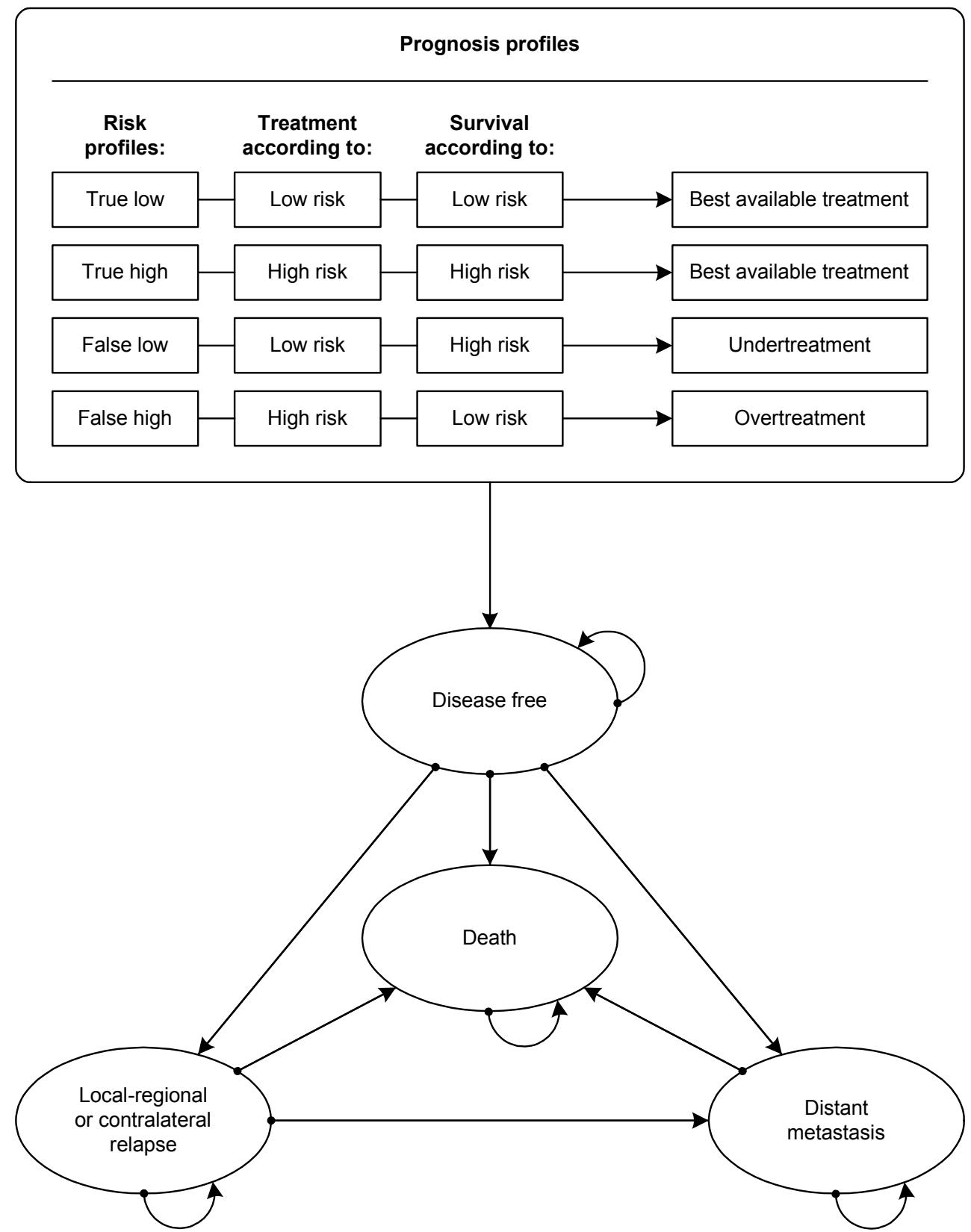

Figure 1. Model structure 


\section{Probabilities}

The sensitivity and specificity of each prognostic test were calculated from a pooled analysis consisting of 3 previously reported validation studies: van de Vijver and colleagues, 2002, Buyse and colleagues, 2006 and Bueno de Mesquita and colleagues, $2008 .^{4-6}$ From this database, a total of 305 untreated, node negative and ER-positive tumor samples were selected and classified by the 70-gene signature and the clinical pathological guidelines as low or high risk of developing distant metastasis. In the series of van de Vijver and colleagues, 2002, the 61 samples of the original development series were excluded. ${ }^{4,19}$ We calculated the sensitivity and specificity of the three strategies for breast cancer specific survival (BCSS) at 10 years (Table 1). Patients were evaluated as low clinical-pathological risk, if their 10-year disease specific survival (without chemotherapy or endocrine therapy) is estimated by "Adjuvant! Online" as greater than $88 \%$ for ER-positive patients. ${ }^{14}$ According to the Sankt Gallen guidelines, a low clinical risk was defined as estrogen and/or progesterone positive, and the following features: tumor size smaller or equal to $2 \mathrm{~cm}$, grade 1 (Elston \& Ellis), and equal or above 35 years. $^{20}$ All others were considered as high risk. It was simulated that patients classified as true low or false high risk had a zero probability to experience a relapse or distant metastasis (Table 2). For the true high patients, yearly transitions (constant in year 1-5, 5-10 and 10-20) from disease free survival to relapse and distant metastasis, and from relapse to distant metastasis, were based on a sample of 20624 Swedish breast cancer patients, derived from the study of Lidgren and colleagues, 2008. ${ }^{21}$ For the patients receiving Trastuzumab, a relative risk reduction with the hazard ratio of 0.64 (95\% confidence interval 0.54-0.76) was applied. ${ }^{21}$ Furthermore, the risk of distant recurrence for Her2neu-positive patients was assumed to be twice as high compared with Her2neu-negative patients. ${ }^{21,22}$ It was assumed that the false low patients had a $100 \%$ probability to experience a distant metastasis (corresponding with an annual probability of 0.499 ) and the risk of a relapse after the disease free state was modeled assumed to be twice as high compared with true high patients. Background mortality was based on age-specific death rates from the Central Bureau of Statistics of the Netherlands. ${ }^{23}$ All statistical analyses were performed with SPSS 17.0 for Windows (SPSS Inc, Chicago, IL).

\section{Health effects}

Quality of life was modeled by assigning utilities to the different health states. These utilities were based on Lidgren and colleagues, 2007 (Table 3). ${ }^{24}$ In Lidgren and colleagues, to calculate utility weights the EQ-5D norm values for the general population were used. For patients who received adjuvant treatment, the utilities were calculated as long as they received the treatment; in the first year for CT and over 5 years for ET. 


\section{Costs}

The costs of the health states DFS, relapse and distant metastasis (health states costs and one time costs of patients dying of breast cancer) were based on Lidgren and colleagues 2008, except the costs of chemotherapy and hormonal therapy (Table 3). ${ }^{21}$ The total Trastuzumab costs consist of the costs of Trastuzumab and administration costs $(€ 36,298) .{ }^{21}$ The costs of chemotherapy and hormonal therapy were not reported by Lidgren and collegues, and therefore based on Dutch sources. ${ }^{25,26}$ Chemotherapy costs consisted of drug costs, day care costs (including administration), laboratory and diagnostic imaging costs (including mammography, tumor markers) and prevention as the granulocyte colony stimulating factor (G-CSF, Neulasta) administration in combination of the taxanecontaining therapies. The costs of the 70 -gene signature were provided by Agendia B.V.; full costs including transport, additional specimen processing at the local hospital and Value Added Tax (VAT). Costs were expressed in 2005 Euros.

\section{Uncertainty Analysis}

We programmed the model in Microsoft Excel (Microsoft, Redmond, WA) and validated it using various sensitivity analyses. Future costs and effects were discounted to their present value by a rate of $4 \%$ and $1.5 \%$ per year respectively, according to Dutch guidelines. ${ }^{25}$ Incremental cost-effectiveness ratios (ICERS) were calculated by dividing the incremental costs by incremental life years (LYs) and by incremental quality adjusted life years (QALYs). Uncertainty in the input parameters was handled probabilistically, by assigning distributions to parameters (Table 2) ${ }^{27}$ Parameter values were drawn at random from the assigned distributions, using Monte Carlo simulation with 1000 iterations. The results of the simulation of the hypothetical cohort of 1000 patients are illustrated in a CostEffectiveness (CE) plane, each quadrant indicates whether a strategy is more or less expensive and more or less effective. ${ }^{28}$ To show decision uncertainty, costeffectiveness acceptability curves (CEACs) are presented. CEACs show the probability that a pathway has the highest net monetary benefit, and thus is deemed cost-effective, given different cost per QALY ratios. Whether a strategy is deemed efficient depends on how much society is willing to pay for a gain in effect, which is referred to as the ceiling ratio. ${ }^{28}$ In the Netherlands an informal ceiling ratio of $€ 80,000$ per QALY exists (Dutch Council for Public Health and Health Care 2006). This is a maximum ceiling ratio which applies when there is a high burden of disease. This is certainly the case for breast cancer. The National Institute for Health and Clinical Excellence in the United Kingdom uses a ceiling ratio between $£ 20,000-£ 30,000$ per QALY. 
Table 1. Sensitivity and Specificity of the diagnostics strategies

\begin{tabular}{|c|c|c|c|c|c|c|c|c|c|c|}
\hline \multirow[b]{2}{*}{ FU } & \multirow[b]{2}{*}{ Event } & \multicolumn{3}{|c|}{ 70-gene signature } & \multicolumn{3}{|c|}{ St. Gallen } & \multicolumn{3}{|c|}{ Adjuvant Online } \\
\hline & & Low & High & Total & Low & High & Total & Low & High & Total \\
\hline \multicolumn{11}{|c|}{ Outcome breast cancer specific survival (BCSS) } \\
\hline \multirow[t]{8}{*}{$10 y^{* *}$} & No & 153 & 110 & 263 & 29 & 234 & 263 & 141 & 122 & 263 \\
\hline & & $93 \%$ & $78 \%$ & $86 \%$ & $94 \%$ & $85 \%$ & $86 \%$ & $89 \%$ & $84 \%$ & $86 \%$ \\
\hline & Yes & 11 & 31 & 42 & 2 & 40 & 42 & 18 & 24 & 42 \\
\hline & & $7 \%$ & $22 \%$ & $14 \%$ & $6 \%$ & $15 \%$ & $14 \%$ & $11 \%$ & $16 \%$ & $14 \%$ \\
\hline & Total & 164 & 141 & 305 & 31 & 274 & 305 & 159 & 146 & 305 \\
\hline & & $100 \%$ & $100 \%$ & $100 \%$ & $100 \%$ & $100 \%$ & $100 \%$ & $100 \%$ & $100 \%$ & $100 \%$ \\
\hline & & \multicolumn{3}{|c|}{ Sensitivity: 0.74} & \multicolumn{3}{|c|}{ Sensitivity: 0.95} & \multicolumn{3}{|c|}{ Sensitivity: 0.57} \\
\hline & & \multicolumn{3}{|c|}{ Specificity: 0.58} & \multicolumn{3}{|c|}{ Specificity: 0.11} & \multicolumn{3}{|c|}{ Specificity: 0.54} \\
\hline \multirow[t]{8}{*}{$5 y$} & No & 161 & 126 & 287 & 30 & 257 & 287 & 153 & 134 & 287 \\
\hline & & $98 \%$ & $89 \%$ & $94 \%$ & $97 \%$ & $94 \%$ & $94 \%$ & $96 \%$ & $92 \%$ & $94 \%$ \\
\hline & Yes & 3 & 15 & 18 & 1 & 17 & 18 & 6 & 12 & 18 \\
\hline & & $2 \%$ & $11 \%$ & $6 \%$ & $3 \%$ & $6 \%$ & $6 \%$ & $4 \%$ & $8 \%$ & $6 \%$ \\
\hline & Total & 164 & 141 & 305 & 31 & 274 & 305 & 159 & 146 & 305 \\
\hline & & $100 \%$ & $100 \%$ & $100 \%$ & $100 \%$ & $100 \%$ & $100 \%$ & $100 \%$ & $100 \%$ & $100 \%$ \\
\hline & & \multicolumn{3}{|c|}{ Sensitivity: 0.83} & \multicolumn{3}{|c|}{ Sensitivity: 0.94} & \multicolumn{3}{|c|}{ Sensitivity: 0.67} \\
\hline & & \multicolumn{3}{|c|}{ Specificity: 0.56} & \multicolumn{3}{|c|}{ Specificity: 0.10} & \multicolumn{3}{|c|}{ Specificity: 0.53} \\
\hline \multicolumn{11}{|c|}{ Outcome distant metastasis (DM) as $1^{\text {st }}$ event } \\
\hline \multirow[t]{8}{*}{$10 y$} & No & 148 & 104 & 252 & 27 & 225 & 252 & 135 & 117 & 252 \\
\hline & & $90 \%$ & $74 \%$ & $83 \%$ & $87 \%$ & $82 \%$ & $83 \%$ & $85 \%$ & $80 \%$ & $83 \%$ \\
\hline & Yes & 16 & 37 & 53 & 4 & 49 & 53 & 24 & 29 & 53 \\
\hline & & $10 \%$ & $26 \%$ & $17 \%$ & $13 \%$ & $18 \%$ & $17 \%$ & $15 \%$ & $20 \%$ & $17 \%$ \\
\hline & Total & 164 & 141 & 305 & 31 & 274 & 305 & 159 & 146 & 305 \\
\hline & & $100 \%$ & $100 \%$ & $100 \%$ & $100 \%$ & $100 \%$ & $100 \%$ & $100 \%$ & $100 \%$ & $100 \%$ \\
\hline & & \multicolumn{3}{|c|}{ Sensitivity: 0.70} & \multicolumn{3}{|c|}{ Sensitivity: 0.92} & \multicolumn{3}{|c|}{ Sensitivity: 0.55} \\
\hline & & \multicolumn{3}{|c|}{ Specificity: 0.59} & & cificity: & & & cificity: & \\
\hline $5 y$ & No & 158 & 116 & 274 & 30 & 244 & 274 & 150 & 124 & 274 \\
\hline & & $96 \%$ & $82 \%$ & $90 \%$ & $97 \%$ & $89 \%$ & $90 \%$ & $94 \%$ & $85 \%$ & $90 \%$ \\
\hline & Yes & 6 & 25 & 31 & 1 & 30 & 31 & 9 & 22 & 31 \\
\hline & & $4 \%$ & $18 \%$ & $10 \%$ & $3 \%$ & $11 \%$ & $10 \%$ & $6 \%$ & $15 \%$ & $10 \%$ \\
\hline & Total & 164 & 141 & 305 & 31 & 274 & 305 & 159 & 146 & 305 \\
\hline & & $100 \%$ & $100 \%$ & $100 \%$ & $100 \%$ & $100 \%$ & $100 \%$ & $100 \%$ & $100 \%$ & $100 \%$ \\
\hline & & & sitivity: & & & sitivity: & & & sitivity: & \\
\hline & & & cificity: & & & cificity: & & & cificity: & \\
\hline
\end{tabular}

Based on three validation series ${ }^{4-6}{ }^{*}$ In this population $62 \%$ was T1, 38\% T2/3, $19 \%$ Grade $1,54 \%$ Grade 2, 26\% Grade 3, ${ }^{* *}$ Base case analysis, FU: follow-up 
Table 2. Base case parameters

\begin{tabular}{|c|c|c|c|c|c|c|c|}
\hline \multicolumn{4}{|l|}{ Parameter } & Mean & SE & Distribution & Ref \\
\hline \multicolumn{8}{|c|}{ Test performance } \\
\hline \multirow[t]{4}{*}{ 70-gene } & Low risk & \multicolumn{2}{|l|}{ True } & 0.502 & $+/-0.03$ & Dirichlet & $4-6$ \\
\hline & & \multicolumn{2}{|l|}{ False } & 0.036 & $+/-0.03$ & Dirichlet & \\
\hline & High risk & \multicolumn{2}{|l|}{ True } & 0.102 & $+/-0.07$ & Dirichlet & \\
\hline & & \multicolumn{2}{|l|}{ False } & 0.361 & $+/-0.03$ & Dirichlet & \\
\hline \multirow[t]{4}{*}{ St. Gallen } & Low risk & \multicolumn{2}{|l|}{ True } & 0.095 & $+/-0.06$ & Dirichlet & \\
\hline & & \multicolumn{2}{|l|}{ False } & 0.007 & $+/-0.01$ & Dirichlet & \\
\hline & High risk & \multicolumn{2}{|l|}{ True } & 0.131 & $+/-0.03$ & Dirichlet & \\
\hline & & \multicolumn{2}{|l|}{ False } & 0.767 & $+/-0.02$ & Dirichlet & \\
\hline Adjuvant & Low risk & \multicolumn{2}{|l|}{ True } & 0.462 & $+/-0.03$ & Dirichlet & \\
\hline \multirow[t]{3}{*}{ Online } & & \multicolumn{2}{|l|}{ False } & 0.059 & $+/-0.03$ & Dirichlet & \\
\hline & High risk & \multicolumn{2}{|l|}{ True } & 0.079 & $+/-0.08$ & Dirichlet & \\
\hline & & \multicolumn{2}{|l|}{ False } & 0.400 & $+/-0.03$ & Dirichlet & \\
\hline \multicolumn{8}{|c|}{ Transition probabilities per cycle (year) } \\
\hline \multicolumn{8}{|c|}{ Chronic Congestive Heart Failure due to: } \\
\hline & Trastuzumab & \multicolumn{2}{|c|}{ Year 1} & 0.160 & $+/-0.03$ & Beta & \\
\hline & & \multicolumn{2}{|c|}{ Year 2-20 } & 0.060 & $+/-0.02$ & Beta & \\
\hline & Anthracyclines & \multicolumn{2}{|c|}{ Year 1} & 0.030 & $+/-0.01$ & Beta & \\
\hline & & \multicolumn{2}{|c|}{ Year 2-20 } & 0.007 & $+/-0.01$ & Beta & \\
\hline \multicolumn{8}{|c|}{ DFS to Relapse } \\
\hline & Low risk & \multicolumn{2}{|l|}{ True } & 0.000 & fixed & & Ass \\
\hline & & \multicolumn{2}{|l|}{ False } & 0.000 & fixed & & Ass \\
\hline & High risk & True & $5 y$ & ${ }^{1} 0.016$ & $+/-0.00088$ & Beta & 21 \\
\hline & & & $10 y$ & 0.014 & $+/-0.00082$ & Beta & \\
\hline & & & $20 y$ & 0.013 & $+/-0.00080$ & Beta & \\
\hline & & False & & 0.000 & fixed & & Ass \\
\hline \multicolumn{8}{|c|}{ DFS to Distant Metastasis } \\
\hline & Low risk & \multicolumn{2}{|l|}{ True } & 0.000 & fixed & & Ass \\
\hline & & False & & 0.499 & $+/-0.03$ & Beta & Ass \\
\hline & High risk & True & $5 y$ & ${ }^{2} 0.020$ & $+/-0.00096$ & Beta & 21 \\
\hline & & & $10 y$ & 0.013 & $+/-0.00077$ & Beta & \\
\hline & & & $20 y$ & 0.010 & $+/-0.00069$ & Beta & \\
\hline & & False & & 0.000 & fixed & & Ass \\
\hline
\end{tabular}


Table 2. Continued

\begin{tabular}{|c|c|c|c|c|c|c|}
\hline \multicolumn{3}{|l|}{ Parameter } & Mean & SE & Distribution & Ref \\
\hline \multicolumn{7}{|c|}{ Transition probabilities per cycle (year) } \\
\hline \multicolumn{7}{|c|}{ Relapse to Distant Metastasis } \\
\hline \multirow[t]{2}{*}{ Low risk } & True & & 0.000 & fixed & & Ass \\
\hline & False & & 0.499 & $+/-0.03$ & Beta & Ass \\
\hline \multirow[t]{4}{*}{ High risk } & True & $5 y$ & ${ }^{2} 0.103$ & $+/-0.00096$ & Beta & 21 \\
\hline & & $10 y$ & 0.054 & $+/-0.00077$ & Beta & \\
\hline & & $20 y$ & 0.039 & $+/-0.00069$ & Beta & \\
\hline & False & & 0.000 & fixed & & Ass \\
\hline \multicolumn{3}{|c|}{ Hazard ratio Trastuzumab } & 0.640 & $+/-0.0988$ & Beta & 21 \\
\hline \multicolumn{3}{|c|}{ Distant metastasis to Death $1-5 y$} & 0.310 & $+/-0.0032$ & Beta & 21 \\
\hline \multicolumn{3}{|c|}{ Distant metastasis to Death $5-10 y$} & 0.025 & $+/-0.0011$ & Beta & \\
\hline \multicolumn{3}{|c|}{ Distant metastasis to Death $10-20 y$} & 0.004 & $+/-0.0004$ & Beta & \\
\hline \multicolumn{3}{|l|}{ Background mortality } & \multicolumn{3}{|c|}{ Age specific mortality figures } & 23 \\
\hline \multicolumn{7}{|c|}{ Adjuvant treatment high risk patients } \\
\hline \multicolumn{3}{|c|}{ Chemotherapy \& endocrine therapy } & 0.90 & \multicolumn{2}{|c|}{ (ER+, Her2- patients) } & \\
\hline \multicolumn{3}{|c|}{$\begin{array}{l}\text { Chemotherapy \& endocrine therapy \& } \\
\text { Trastuzumab }\end{array}$} & 0.10 & \multicolumn{2}{|c|}{ (ER+, Her2+ patients) } & \\
\hline \multicolumn{7}{|c|}{ Adjuvant treatment low risk patients } \\
\hline \multicolumn{3}{|l|}{ Endocrine Therapy } & 1.00 & & & Ass \\
\hline
\end{tabular}

Table 3. Base Case Utilities for health states

\begin{tabular}{|c|c|c|c|c|c|}
\hline \multicolumn{2}{|c|}{ Utilities per patient (20years) } & \multirow{2}{*}{\begin{tabular}{|l|} 
Mean \\
0.935
\end{tabular}} & \multirow{2}{*}{$\begin{array}{l}95 \% \mathrm{Cl} \\
+/-0.02\end{array}$} & \multirow{2}{*}{$\begin{array}{c}\text { Distribution } \\
\text { beta }\end{array}$} & \multirow{2}{*}{$\begin{array}{l}\text { Ref } \\
21,24\end{array}$} \\
\hline DFS & No adjuvant treatment year 1 & & & & \\
\hline & Disease free survival year 2 to 20 & 0.935 & $+/-0.02$ & beta & \\
\hline & Chemotherapy year 1 & 0.620 & $+/-0.04$ & beta & \\
\hline & Endocrine Therapy year 1 to 5 & 0.744 & $+/-0.05$ & beta & \\
\hline & Trastuzumab year 1 & 0.620 & $+/-0.04$ & beta & \\
\hline & Chronic Congestive Heart Failure & 0.700 & $+/-0.05$ & beta & ass \\
\hline \multicolumn{2}{|c|}{ Relapse } & 0.779 & $+/-0.04$ & beta & \\
\hline \multicolumn{2}{|c|}{ Distant Metastasis } & 0.685 & $+/-0.03$ & beta & \\
\hline
\end{tabular}

Cl: Confidence Interval; ass: assumption; Ref: reference; DFS: Disease Free Survival 
Table 4. Base Case Costs per year per patient per cycle (over 20 years)

\begin{tabular}{|c|c|c|c|c|c|c|}
\hline In Euros $€$ & Unit cost & Units & Base Case & $\%$ & $(95 \% \mathrm{Cl})$ & Ref \\
\hline \multicolumn{7}{|l|}{ Chemotherapy costs } \\
\hline FEC-regime & & & & $80 \%$ & & 25,26 \\
\hline FEC $100^{*}$ & 261 & 6 & 1,569 & & & \\
\hline Day care costs & 236 & 6 & 1,414 & & & \\
\hline Laboratory/imaging & 1200 & 1 & 1,438 & & & \\
\hline Subtotal per patient & & & 4,421 & 3,537 & Fixed & \\
\hline TAC-regime & & & & $10 \%$ & & 25,26 \\
\hline $\mathrm{TAC}^{\star *}$ & 1428 & 6 & 8,571 & & & \\
\hline G-CSF & 1319 & 6 & 7,917 & & & \\
\hline Day care costs & 236 & 6 & 1,414 & & & \\
\hline Laboratory/imaging & 1200 & 1 & 1,438 & & & \\
\hline Subtotal per patient & & & 19,340 & 1,934 & Fixed & \\
\hline PAC-regime & & & & $10 \%$ & & 25,26 \\
\hline Paclitaxel $^{\star \star *}$ & 626 & 12 & 7,513 & & & \\
\hline G-CSF & 1319 & 12 & 15,828 & & & \\
\hline Day care costs & 236 & 12 & 1,414 & & & \\
\hline Laboratory/imaging & 1200 & 1 & 1,438 & & & \\
\hline$A C^{* * *}$ & 315 & 4 & 1,260 & & & \\
\hline Day care costs & 236 & 4 & 1,414 & & & \\
\hline Laboratory/imaging & 1200 & 4 & 1,438 & & & \\
\hline Subtotal per patient & & & 31,257 & 3,126 & Fixed & \\
\hline Total per patient & & & & 8,596 & Fixed & \\
\hline \multicolumn{7}{|l|}{ Endocrine therapy costs } \\
\hline Tamoxifen & & & & $50 \%$ & & 25,26 \\
\hline 20 mg Tamoxifen & 0.17 & 365 & 62 & & & \\
\hline Additional costs ${ }^{\star * \star *}$ & & & 153 & & & \\
\hline Subtotal per patient & & & 216 & 108 & Fixed & \\
\hline Anastrozol & & & & $17 \%$ & & 25,26 \\
\hline $1 \mathrm{mg}$ Anastrozol & 3.38 & 365 & 1,235 & & & \\
\hline Additional costs & & & 153 & & & \\
\hline Subtotal per patient & & & 1,388 & 231 & Fixed & \\
\hline Letrozol & & & & $17 \%$ & & 25,26 \\
\hline $2.5 \mathrm{mg}$ Letrozol & 3.39 & 365 & 1,239 & & & \\
\hline Additional costs & & & 153 & & & \\
\hline Subtotal per patient & & & 1,392 & 232 & Fixed & \\
\hline
\end{tabular}


Table 4. Continued

\begin{tabular}{|c|c|c|c|c|c|c|}
\hline In Euros $€$ & Unit cost & Units & Base Case & $\%$ & $(95 \% \mathrm{Cl})$ & $\mathbf{R}$ \\
\hline Exemestane & & & & $17 \%$ & & 25, \\
\hline $2.5 \mathrm{mg}$ Exemestane & 3.71 & 365 & 1,353 & & & \\
\hline Additional costs & & & 153 & & & \\
\hline Subtotal per patient & & & 1,506 & 251 & Fixed & \\
\hline Total per patient (Switch 2.5 y Ta & $\mathrm{m} / 2.5$ y A.I) & & & 822 & Fixed & \\
\hline \multicolumn{7}{|l|}{ Other costs } \\
\hline Trastuzumab & & & 36,298 & & Fixed & 21 \\
\hline Chronic congestive heart failure & & & 3,453 & & Fixed & 21 \\
\hline Follow-up costs low risk & & & 1,179 & & Fixed & a \\
\hline Follow-up costs high risk & & & 2,359 & & & 21 \\
\hline In- and outpatient costs & & & 2,294 & & $1,751-3,200$ & \\
\hline Drug costs & & & 65 & & Fixed & \\
\hline Relapse first year & & & 12,181 & & & 21 \\
\hline In- and outpatient costs & & & 10,263 & & $8,307-12,986$ & \\
\hline Drug costs & & & 1,918 & & Fixed & \\
\hline Relapse after first year & & & 2,359 & & & 21 \\
\hline In- and outpatient costs & & & 2,294 & & $1,751-3,200$ & \\
\hline Drug costs & & & 65 & & Fixed & \\
\hline Distant metastasis state & & & 14,303 & & & 21 \\
\hline In- and outpatient costs & & & 9,563 & & $8,060-11,730$ & \\
\hline Drug costs & & & 4,740 & & Fixed & \\
\hline Distant metastasis last y of life & & & 6,813 & & Fixed & 21 \\
\hline 70-gene signature & & & 2,675 & & Fixed & $\mathrm{b}$ \\
\hline
\end{tabular}

* Fluorouracil $\left(500 \mathrm{mg} / \mathrm{m}^{2}\right)$, Epirubicin $\left(100 \mathrm{mg} / \mathrm{m}^{2}\right)$, Cyclofosfamide $\left(500 \mathrm{mg} / \mathrm{m}^{2}\right)$

** Docetaxel $\left(75 \mathrm{mg} / \mathrm{m}^{2}\right)$, Doxorubicin $\left(60 \mathrm{mg} / \mathrm{m}^{2}\right)$, Cyclofosfamide $\left(600 \mathrm{mg} / \mathrm{m}^{2}\right)$

*** Paclitaxel $(80 \mathrm{mg} / \mathrm{m} 2)$, Doxorubicin $(60 \mathrm{mg} / \mathrm{m} 2)$, Cyclofosfamide $(600 \mathrm{mg} / \mathrm{m} 2)$

${ }^{* * * *}$ Additional costs includes DEXA scan, consultation, laboratory, imaging

***** Assumed twice as low as follow-up costs high risk

Assumes a mean body surface area of $1.7 \mathrm{~m} 2$ and a weight of $70 \mathrm{~kg}$.

R: reference

$\mathrm{Cl}$ : Confidence Interval

a: assumption

b: Agendia B.V. 


\section{Sensitivity analyses using different scenarios}

In addition, we performed four one-way sensitivity analyses, using different scenarios. Firstly, we used DM as first event instead of BCSS as final outcome to determine the sensitivity and specificity of the diagnostics tests. In addition, we used 5 years of follow-up to final endpoint instead of 10 years for both outcomes. Secondly, we computed sensitivity and specificity separately for the three series (Table 6). Thirdly, because using QALY as an outcome in cost-effectiveness analyses in oncology is a debated issue, as this has proven to be difficult to estimate health state utilities among cancer patients. ${ }^{29}$, we used different QoLscores (utilities) for disease free survival with and without adjuvant systemic therapy. ${ }^{11,30}$ Fourthly, because the costs of chemotherapy are likely to become higher with the increase of novel regimens, the costs of chemotherapy were varied to $€ 20,000$ (Table 5). Cost-effectiveness acceptability Curves (CEACs) are used to show the impact of these changes in model input on the probability that the 70gene signature is cost-effective.

Table 5. Input parameters for sensitivity analyses

\begin{tabular}{|c|c|c|c|c|}
\hline Utilities & Mean & $95 \% \mathrm{Cl}$ & Distribution & Ref \\
\hline \multicolumn{5}{|l|}{ DFS } \\
\hline No adjuvant systemic treatment year 1 & 0.800 & $+/-0.04$ & beta & 11,29 \\
\hline Disease free survival year 2 to 20 & 0.890 & $+/-0.09$ & beta & 11,29 \\
\hline Chemotherapy year 1 & 0.500 & $+/-0.10$ & beta & 11,29 \\
\hline Endocrine Therapy year 1 to 5 & 0.750 & $+/-0.05$ & beta & 11,29 \\
\hline Trastuzumab year 1 & 0.500 & $+/-0.10$ & beta & 11,29 \\
\hline Chronic Congestive Heart Failure & 0.700 & $+/-0.05$ & beta & 11,29 \\
\hline Relapse & 0.700 & $+/-0.08$ & beta & 11,29 \\
\hline Distant Metastasis & 0.630 & $+/-0.05$ & beta & 11,29 \\
\hline Costs & Mean & & Distribution & Ref \\
\hline Chemotherapy & $€ 20,000$ & & Fixed & Ass \\
\hline
\end{tabular}

DFS: Disease Free Survival

Cl: Confidence Interval

Ref: reference

Ass: assumption 
Table 6. Input parameters for separate series (for BCSS 10years)

\begin{tabular}{|c|c|c|c|c|c|c|c|c|c|}
\hline \multirow[b]{2}{*}{ Event } & \multicolumn{3}{|c|}{ 70-gene signature } & \multicolumn{3}{|c|}{ St. Gallen } & \multicolumn{3}{|c|}{ Adjuvant Online } \\
\hline & Low & High & Total & Low & High & Total & Low & High & Total \\
\hline \multicolumn{10}{|c|}{ Pooled series $(N=305)$} \\
\hline \multirow[t]{2}{*}{0} & 153 & 110 & 263 & 29 & 234 & 263 & 141 & 122 & 263 \\
\hline & $93 \%$ & $78 \%$ & $86 \%$ & $94 \%$ & $85 \%$ & $86 \%$ & $89 \%$ & $84 \%$ & $86 \%$ \\
\hline \multirow[t]{2}{*}{1} & 11 & 31 & 42 & 2 & 40 & 42 & 18 & 24 & 42 \\
\hline & $7 \%$ & $22 \%$ & $14 \%$ & $6 \%$ & $15 \%$ & $14 \%$ & $11 \%$ & $16 \%$ & $14 \%$ \\
\hline \multirow[t]{4}{*}{ Total } & 164 & 141 & 305 & 31 & 274 & 305 & 159 & 146 & 305 \\
\hline & $100 \%$ & $100 \%$ & $100 \%$ & $100 \%$ & $100 \%$ & $100 \%$ & $100 \%$ & $100 \%$ & $100 \%$ \\
\hline & & Isitivity: & & & sitivity: & & & sitivity: $C$ & \\
\hline & & cificity: & & & cificity: & & & cificity: $\mathrm{C}$ & \\
\hline \multicolumn{10}{|c|}{ NEJM-series $(n=60)^{4}$} \\
\hline \multirow[t]{2}{*}{0} & 32 & 21 & 53 & 17 & 36 & 53 & 38 & 15 & 53 \\
\hline & $97 \%$ & $78 \%$ & $88 \%$ & $94 \%$ & $86 \%$ & $88 \%$ & $93 \%$ & $79 \%$ & $8 \%$ \\
\hline \multirow[t]{2}{*}{1} & 1 & 6 & 7 & 1 & 6 & 7 & 3 & 4 & 7 \\
\hline & $3 \%$ & $22 \%$ & $12 \%$ & $6 \%$ & $14 \%$ & $12 \%$ & $7 \%$ & $21 \%$ & $12 \%$ \\
\hline \multirow[t]{4}{*}{ Total } & 33 & 27 & 60 & 18 & 42 & 60 & 41 & 19 & 60 \\
\hline & $100 \%$ & $100 \%$ & $100 \%$ & $100 \%$ & $100 \%$ & $100 \%$ & $100 \%$ & $100 \%$ & $100 \%$ \\
\hline & & Isitivity: & & & sitivity: & & & sitivity: C & \\
\hline & & cificity: & & & cificity: & & & cificity: 0 & \\
\hline \multicolumn{10}{|c|}{ Buyse-series $(n=181)^{5}$} \\
\hline \multirow[t]{2}{*}{0} & 80 & 71 & 151 & 0 & 151 & 151 & 60 & 91 & 151 \\
\hline & $91 \%$ & $76 \%$ & $83 \%$ & $0 \%$ & $83 \%$ & $83 \%$ & $82 \%$ & $84 \%$ & $83 \%$ \\
\hline \multirow[t]{2}{*}{1} & 8 & 22 & 30 & 0 & 30 & 30 & 13 & 17 & 30 \\
\hline & $9 \%$ & $24 \%$ & $17 \%$ & $0 \%$ & $17 \%$ & $17 \%$ & $18 \%$ & $16 \%$ & $17 \%$ \\
\hline \multirow[t]{4}{*}{ Total } & 88 & 93 & 181 & 0 & 181 & 181 & 73 & 108 & 181 \\
\hline & $100 \%$ & $100 \%$ & $100 \%$ & $100 \%$ & $100 \%$ & $100 \%$ & $100 \%$ & $100 \%$ & $100 \%$ \\
\hline & & Isitivity: & & & sitivity: & & & sitivity: & \\
\hline & & cificity: & & & cificity: & & & cificity: & \\
\hline \multicolumn{10}{|c|}{ Bueno-series $(n=64)^{6}$} \\
\hline \multirow[t]{2}{*}{0} & 41 & 18 & 59 & 12 & 47 & 59 & 43 & 16 & 59 \\
\hline & $95 \%$ & $86 \%$ & $92 \%$ & $92 \%$ & $92 \%$ & $92 \%$ & $96 \%$ & $84 \%$ & $92 \%$ \\
\hline \multirow[t]{2}{*}{1} & 2 & 3 & 5 & 1 & 4 & 5 & 2 & 3 & 5 \\
\hline & $5 \%$ & $14 \%$ & $8 \%$ & $8 \%$ & $8 \%$ & $8 \%$ & $4 \%$ & $16 \%$ & $8 \%$ \\
\hline \multirow[t]{4}{*}{ Total } & 43 & 21 & 64 & 13 & 51 & 64 & 45 & 19 & 64 \\
\hline & $100 \%$ & $100 \%$ & $100 \%$ & $100 \%$ & $100 \%$ & $100 \%$ & $100 \%$ & $100 \%$ & $100 \%$ \\
\hline & \multicolumn{3}{|c|}{ Sensitivity: 0.60} & \multicolumn{3}{|c|}{ Sensitivity: 0.80} & \multicolumn{3}{|c|}{ Sensitivity: 0.60} \\
\hline & \multicolumn{3}{|c|}{ Specificity: 0.69} & \multicolumn{3}{|c|}{ Specificity: 0.20} & & cificity: 0 & \\
\hline
\end{tabular}




\section{Results}

\section{Mean results}

The strategies were found to be on average equally effective, but the St. Gallen strategy was more costly than the 70-gene and Adjuvant Online strategy. The total health care costs per patient were: $€ 28,045$ (70-gene), $€ 35,475$ (SG) and $€ 26,915$ (AO) (Table 5). The number of life years amounted to: 15.88 (70-gene), 16.14 (SG) and 15.68 (AO). The difference in costs per life year gained of the St. Gallen compared to the 70 -gene strategy resulted in $€ 29,326 / L Y$. Subsequently the 70-gene strategy was compared to the Adjuvant Online strategy, to assess the results in case the St. Gallen strategy would not be accepted, which resulted in $€ 5,736$ per life year gained. The 70 -gene strategy yielded more quality adjusted life years (12.44) than the AO strategy (12.20), and the SG strategy (11.24). Compared to the AO strategy the 70-gene strategy costs $€ 4,614$ per QALY gained. In comparison to the SG strategy, the 70-gene strategy yielded more QALYs and was less costly (Table 7).

\section{Uncertainty Analysis of mean results (probabilistic)}

The plots indicate that the strategies differ more in terms of quality adjusted survival than in terms of survival (Figure 2a-d). When focusing on survival, the St. Gallen strategy has the highest probability of being cost-effective if the maximum willingness to pay for one life year exceeds $€ 29,326 / \mathrm{LY}$. In case of costs and QALYs, the 70-gene signature has the highest probability of being cost-effective for ceiling ratios of $€ 4,614 / \mathrm{QALY}$ and higher.

\section{Different scenarios in sensitivity analyses}

For the first sensitivity analyses, the CEACs $1 \& 2$ showed that, when comparing costs and life years, the 70-gene signature has the highest probability of being cost-effective in case of BCSS and DM at 5 years; however the St. Gallen strategy appears to be more cost-effective in case of BCSS and DM at 10 years. When comparing costs and quality adjusted life years, the 70-gene signature remains the most cost-effective strategy. The sensitivity analyses for the Buyse-series separately showed no difference in results, however, the van de Vijver-series and the Bueno-de-Mesquita-series showed a slightly higher specificity of the Adjuvant Online compared to the 70-gene signature, which resulted in a more effective and less costly situation for the Adjuvant Online. Using other utility inputs did not change the results substantial, however using higher costs for chemotherapy resulted in more beneficial outcomes for the 70-gene signature, for both survival and quality adjusted survival (Figure 3a\&b). 
Table 7. Incremental cost-effectiveness results (mean (95\% confidence interval))

\begin{tabular}{|c|c|c|c|c|c|c|c|c|c|}
\hline \multirow[t]{2}{*}{$I$} & \multirow[t]{2}{*}{ LY } & \multirow[t]{2}{*}{ Costs } & \multirow[t]{2}{*}{ iLYs } & \multirow[t]{2}{*}{ iCosts } & \multirow[t]{2}{*}{ ICER } & \multicolumn{2}{|c|}{$\begin{array}{c}\% \text { More } \\
\text { effective }\end{array}$} & \multicolumn{2}{|c|}{$\begin{array}{c}\% \text { Less } \\
\text { effective }\end{array}$} \\
\hline & & & & & & $\begin{array}{l}\text { More } \\
\text { costs }\end{array}$ & $\begin{array}{l}\text { Less } \\
\text { costs }\end{array}$ & $\begin{array}{l}\text { More } \\
\text { costs }\end{array}$ & $\begin{array}{l}\text { Less } \\
\text { costs }\end{array}$ \\
\hline SG & 16.14 & $€ 35,475$ & & & & & & & \\
\hline \multirow[t]{2}{*}{$70 G$} & 15.88 & $€ 28,045$ & 0.25 & $€ 7,430$ & $€ 29,326$ & $78 \%^{a}$ & $0 \%^{\mathrm{a}}$ & $0 \%^{a}$ & $22 \%^{\mathrm{a}}$ \\
\hline & & & $\begin{array}{c}(-0.38 \text { to } \\
0.88)\end{array}$ & $\begin{array}{c}(3,880 \text { to } \\
11,757)\end{array}$ & $/ L Y^{a}$ & & & & \\
\hline \multirow[t]{2}{*}{$\mathrm{AO}$} & 15.68 & $€ 26,915$ & 0.20 & $€ 1,130$ & $€ 5,736$ & $65 \%{ }^{b}$ & $24 \%{ }^{b}$ & $1 \%^{b}$ & $10 \%^{b}$ \\
\hline & & & $\begin{array}{c}(-0.13 \text { to } \\
0.52)\end{array}$ & $\begin{array}{c}(-2,003 \\
\text { to } 4,037)\end{array}$ & $/ L Y^{b}$ & & & & \\
\hline \multirow[t]{2}{*}{ II } & QALY & Costs & iLYs & iCosts & ICER & \multicolumn{2}{|c|}{$\begin{array}{l}\% \text { More } \\
\text { effective }\end{array}$} & \multicolumn{2}{|c|}{$\begin{array}{l}\% \text { Less } \\
\text { effective }\end{array}$} \\
\hline & & & & & & $\begin{array}{l}\text { More } \\
\text { costs }\end{array}$ & $\begin{array}{l}\text { Less } \\
\text { costs }\end{array}$ & $\begin{array}{l}\text { More } \\
\text { costs }\end{array}$ & $\begin{array}{l}\text { Less } \\
\text { costs }\end{array}$ \\
\hline $70 G$ & 12.44 & $€ 28,045$ & & & & & & & \\
\hline \multirow[t]{2}{*}{$\mathrm{AO}$} & 12.20 & $€ 26,915$ & 0.24 & $€ 1,130$ & $€ 4,614$ & $68 \%^{\mathrm{b}}$ & $25 \%^{\mathrm{b}}$ & $0 \%{ }^{\mathrm{b}}$ & $7 \%^{\mathrm{b}}$ \\
\hline & & & $\begin{array}{l}(-0.09 \\
\text { to } 0.58)\end{array}$ & $\begin{array}{c}(-2,003 \\
\text { to } 4,037)\end{array}$ & $/ Q A L Y^{b}$ & & & & \\
\hline \multirow[t]{2}{*}{ SG } & 11.24 & $€ 35,475$ & 1.20 & $-€ 7,430$ & Dom. ${ }^{c}$ & $0 \%^{\mathrm{c}}$ & $0 \%^{\mathrm{c}}$ & $100 \%^{\mathrm{c}}$ & $0 \%^{\mathrm{c}}$ \\
\hline & & & $\begin{array}{c}(0.39 \\
\text { to } 1.54)\end{array}$ & $\begin{array}{l}(-11,757 \\
\text { to-3880) }\end{array}$ & & & & & \\
\hline
\end{tabular}

I) ICER: cost/LY (life years)

II) ICER: cost/QALY (quality adjusted life years)

20 -year costs and health outcomes per patient

${ }^{a}$ St. Gallen (SG) compared to 70-gene (70G)

${ }^{b} 70$-gene compared to Adjuvant Online (AO)

${ }^{\mathrm{c}}$ 70-gene compared to Sankt Gallen

Dom: dominant strategy

i: incremental (difference)

Note: Numbers in tables and texts may not add up to $100 \%$ or add up over $100 \%$ due to rounding off 


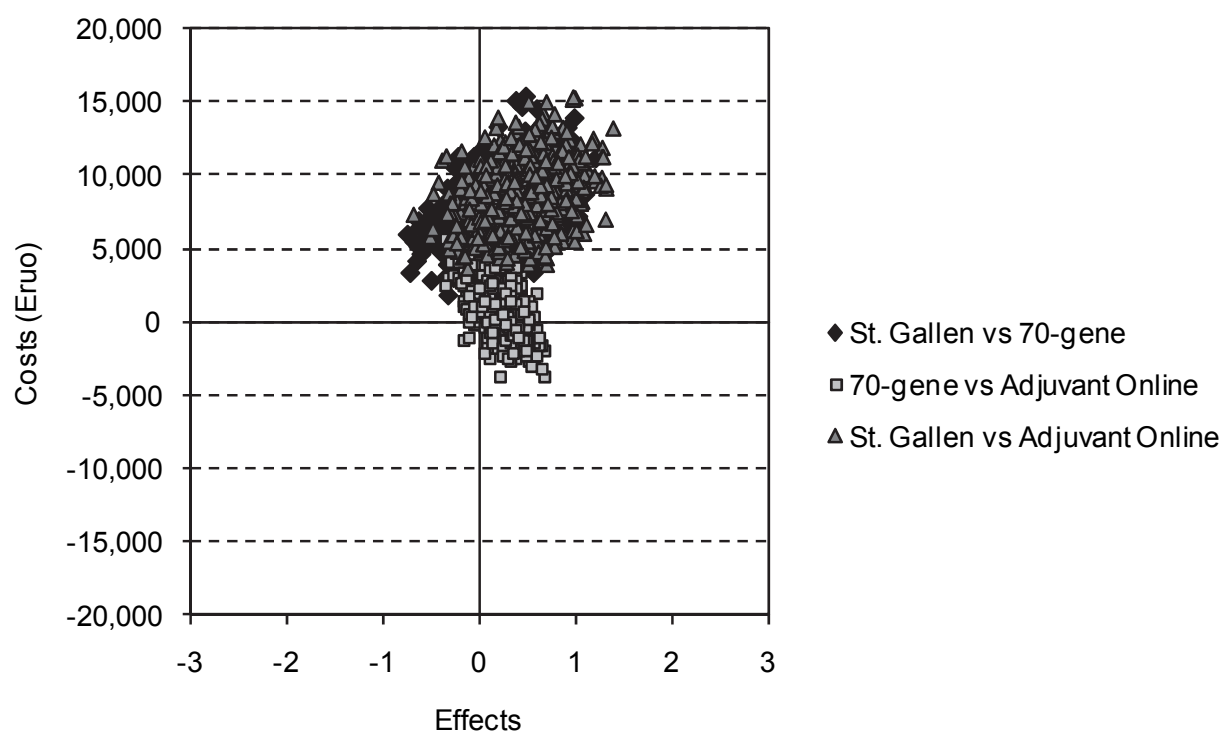

Figure 2a. Cost-Effectiveness plane Life Years

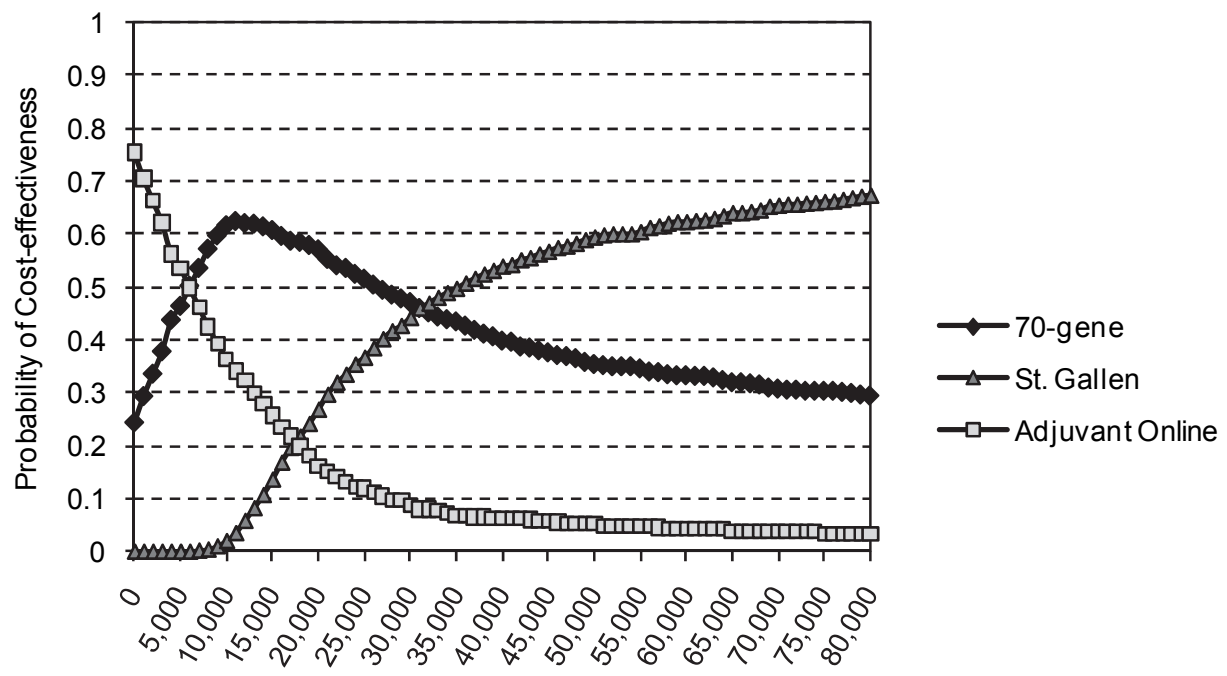

Willingness to pay fora Life Year (Euro)

Figure 2b. Cost-Effectiveness Acceptability Curve Life Years 


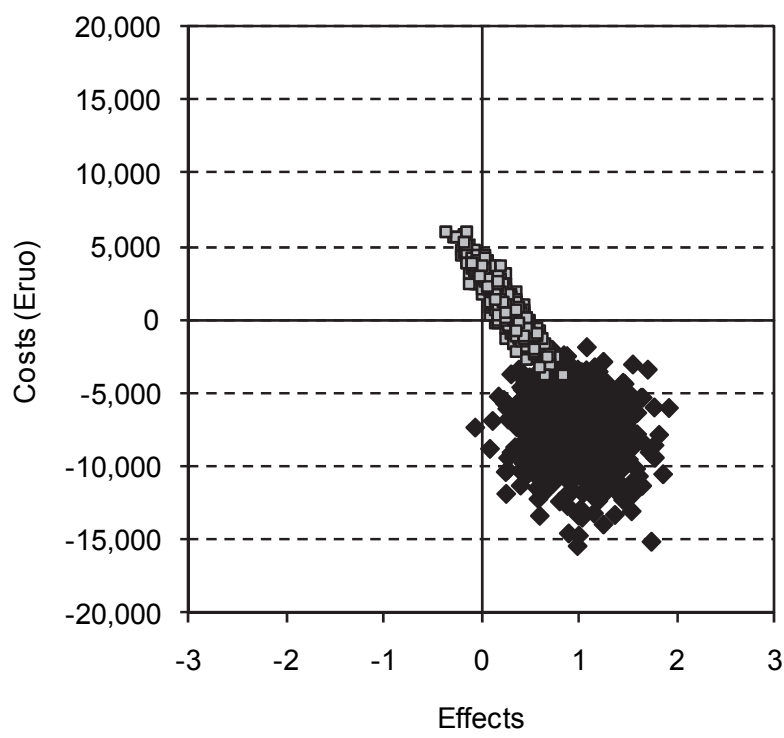

-70-gene vs St. Gallen

$\square 70-$ gene vs Adjuvant Online

Figure 2c. Cost-Effectiveness plane Quality Adjusted Life Years

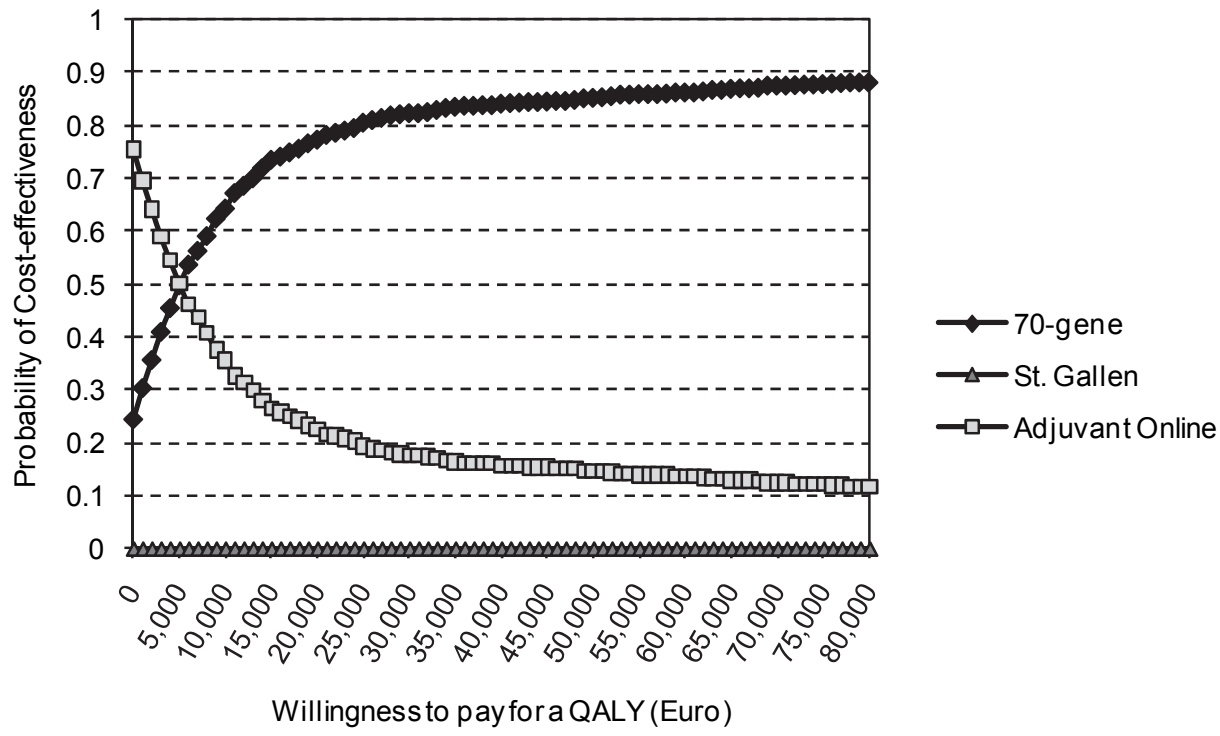

Figure 2d. Cost-Effectiveness Acceptability Curve Quality Adjusted Life Years 

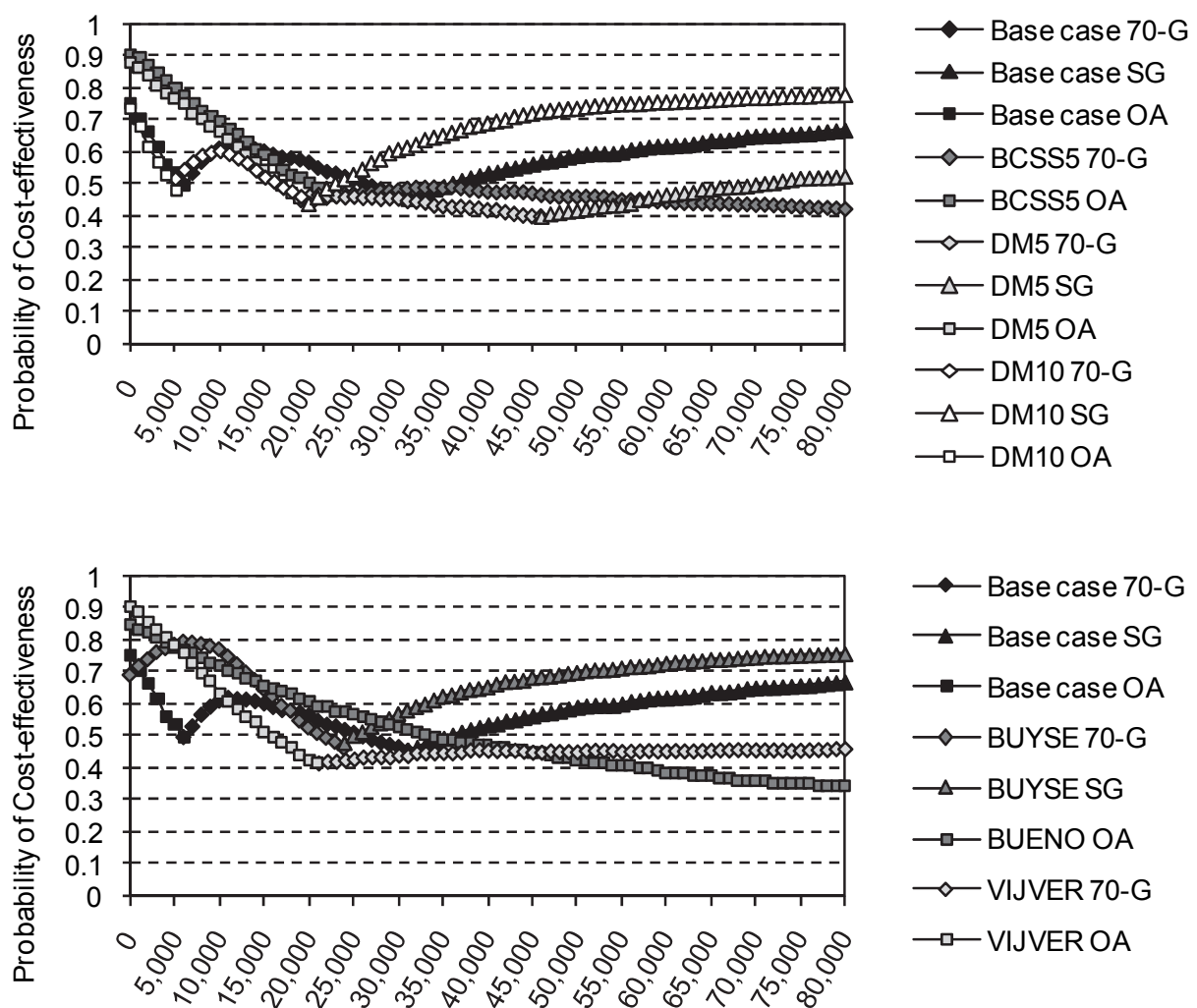

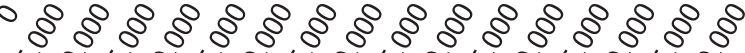

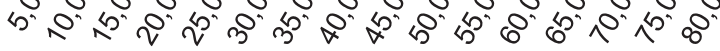
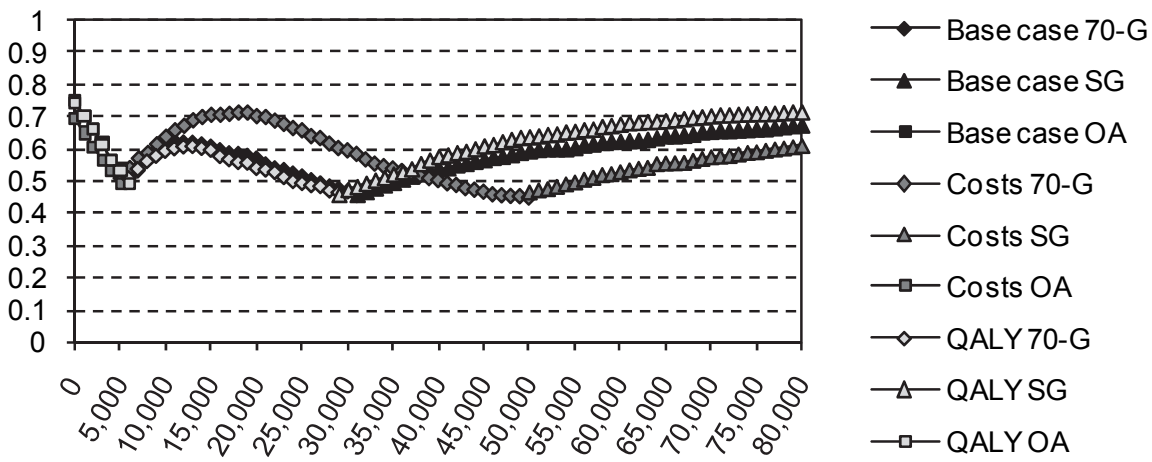

Willingness to pay fora LY (Euro)

Figure 3a. CEAC frontiers Sensitivity Analyses Life Years

BCSS: breast cancer specific survival, DM: distant metastasis 

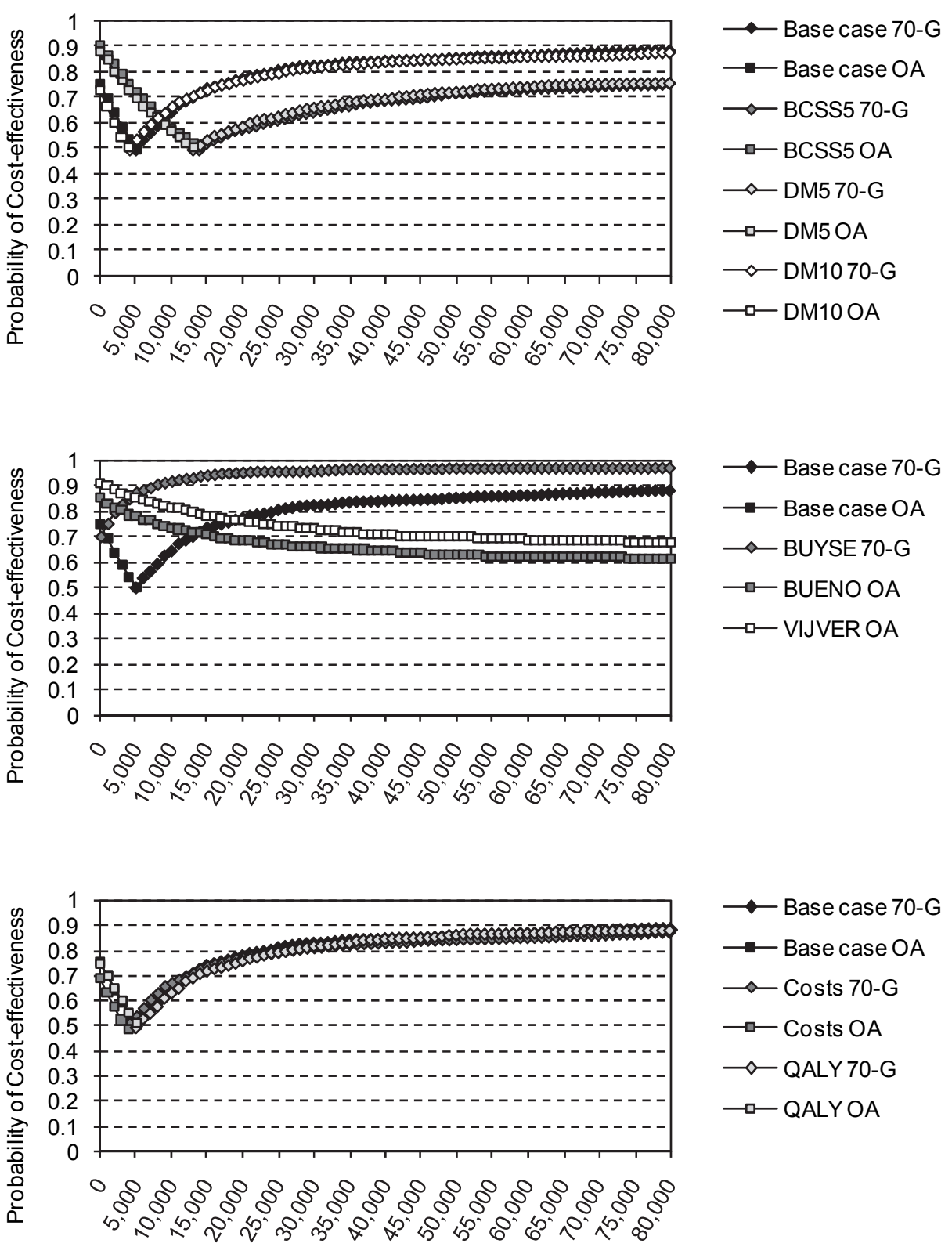

Willingness to pay for a QALY (Euro)

Figure 3b. CEAC frontiers Sensitivity Analyses Quality Adjusted Life Years BCSS: breast cancer specific survival, DM: distant metastasis 


\section{Discussion}

The model-based CEA showed that the three prognostic tests (70-gene, SG and $\mathrm{AO}$ ) in node-negative, estrogen receptor positive breast cancer patients are very comparable in terms of their long-term effect on survival, but they vary substantial in costs and quality adjusted life years. The 70-gene strategy is more costly than the AO strategy, but less costly than the SG strategy. Furthermore, the 70-gene strategy results in substantial more QALYs than both clinical prognostic tests. When comparing costs and quality adjusted life years, the 70-gene signature has the highest probability of being cost-effective.

When comparing costs and life years, modeled for a time horizon of 20 years, the 70 -gene signature has the highest probability of being cost-effective based on the pooled dataset using BCSS and DM at 5 years, however the St. Gallen strategy appears to be more cost-effective based on the pooled dataset using BCSS and $\mathrm{DM}$ at 10 years. This result is not surprising since the 70-gene signature was validated for BCSS and DM at 5 years.

It would be ideal to perform this analysis on a direct randomized comparison of the three prognostic tools. However the MINDACT trial is still ongoing, at the moment policy makers request information regarding the expected cost-effectiveness of the 70-gene signature. Therefore the Markov modeling technique has been used to integrate the currently available evidence.

Using QALY as an outcome in cost-effectiveness analyses in oncology is a debated issue, as it has proven to be difficult to estimate health state utilities among cancer patients. ${ }^{29}$ However, when applying a test aiming to focus and thus reduce chemotherapy over-treatment, as in this study, it seems inevitable to somehow quantify the effects of treatment on the quality of life of patients with cancer. This emphasizes the need for more data on the quality of life of cancer patients, and the importance of research directed at possible biases and innovative methodologies in measuring quality of life. The specific impact of the 70-gene signature and the consequences of this test on the quality of life of breast cancer patients are currently investigated in the MINDACT trial. However, these data are not yet available.

Besides for the utility input, the cost-effectiveness outcomes also are sensitive to changes in the cost inputs. It would be ideal to measure the costs and utilities alongside the multinational randomized controlled trial. We have chosen to model only one relapse per patient as this is a common assumption in breast cancer patients. ${ }^{31-33}$ Because we modeled only one relapse probability per patient, there could be an underestimation of the costs of a relapse (around $30 \%$ of the patients 
develop more than one relapse). As we only included health care costs, another underestimation of costs can be caused by not including productivity loss in case of chemotherapy. Possible carry-over effects for the specific treatments were not considered in the model, this can cause an underestimation of the effects. We included $10 \%$ administration of Docetaxel, however, this is regimen is currently being discussed for this -in principal- low risk group. ${ }^{16}$

As we compare our results to the three other CEAs with regard to the costeffectiveness of gene expression profiling in breast cancer $^{10-12}$, our conclusion agrees with the fact that the use of the 70-gene signature increases quality adjusted survival and is potentially cost saving.

In this study, it was assumed that both physicians and patients would be $100 \%$ compliant to the prognostic test result and the treatment guideline. Therefore, the results of this study indicate the cost effectiveness of the diagnostic tests assuming perfect implementation. This may not be feasible in real life. Currently, in a continuous CTA-study alongside the MINDACT trial, different (technical, societal and medical) scenarios are being constructed which show the possible implementation of the 70-gene signature in daily practice. These scenarios will be used as input for the Markov model underlying the current study and would result in more 'real world' cost-effectiveness estimates. ${ }^{34}$

Furthermore, there is discussion on what will be the best way to use the 70-gene signature, and in which different subgroups the 70-gene signature has an added value. According to new insights, Knauer and colleagues, 2008 distinguished more subgroups according to the HER2 status and ER status, which could influence the cost-effectiveness as well. ${ }^{35}$ Mook and colleagues, 2008 suggests to include also the 1-3 node positives besides the node negatives, which could cause a shift in the adjuvant treatment in the high risk groups ${ }^{36}$ Further research into the effectiveness and cost-effectiveness of the 70-gene signature in other populations or subtypes is certainly warranted. To conclude, according to our analyses using the 70-gene signature or clinical prognostic tests ( $\mathrm{SG}$ or $\mathrm{AO}$ ) in node-negative breast cancer patients results in comparable survival. In terms of quality adjusted survival, using the 70-gene signature is cost-effective compared to $A O$ and is more effective and less costly than SG. When deciding upon the cost-effectiveness of the prognostic tests, the 70-gene signature has the highest probability of being cost-effective.

\section{Acknowledgements}

We would like to thank the coordinators and the patients participating in the studies used for the input parameters in the analysis; Marc van de Vijver, Marc Buyse, Jolien Bueno de Mesquita and Laura van 't Veer. This study was funded by the Dutch Health Care Insurance Board (DHCIB, CVZ), the Netherlands. 


\section{References}

1. Early Breast Cancer Trialists' Collaborative Group (EBCTCG). Effects of chemotherapy and hormonal therapy for early breast cancer on recurrence and 15year survival: an overview of the randomised trials. Lancet 2005; 365:1687-1717.

2. Mook S, Van't Veer LJ, Rutgers EJ et al. Individualization of therapy using Mammaprint: from development to the MINDACT Trial. Cancer Genomics Proteomics 2007; 4:147-155.

3. van 't Veer LJ, Dai $H$, van de Vijver MJ et al. Gene expression profiling predicts clinical outcome of breast cancer. Nature 2002; 415:530-536.

4. van de Vijver MJ, He YD, van 't Veer LJ et al. A Gene-Expression Signature as a Predictor of Survival in Breast Cancer. N Engl J Med 2002; 347:1999-2009.

5. Buyse M, Loi S, van't Veer L et al. Validation and Clinical Utility of a 70-Gene Prognostic Signature for Women With Node-Negative Breast Cancer. J Natl Cancer Inst 2006; 98:1183-1192.

6. Bueno-de-Mesquita JM, Linn SC, Keijzer R et al. Validation of 70-gene prognosis signature in node-negative breast cancer. Breast Cancer Res Treat 2009;117(3):483495.

7. Bueno-de-Mesquita JM, van Harten W, Retèl VP et al. Use of 70-gene signature to predict prognosis of patients with node-negative breast cancer: a prospective community-based feasibility study (RASTER). The Lancet Oncology 2007;8:10791087.

8. Bogaerts J, Cardoso F, Buyse M et al. Gene signature evaluation as a prognostic tool: challenges in the design of the MINDACT trial. Nat Clin Pract Oncol 2006; 3:540-551.

9. Retèl VP, Bueno-de-Mesquita JM, Hummel MJ et al. Constructive Technology Assessment (CTA) as a tool in coverage with evidence development: the case of the 70-gene prognosis signature for breast cancer diagnostics. Int $\mathrm{J}$ Technol Assess Health Care 2009; 25:73-83.

10. Oestreicher N, Ramsey SD, Linden HM et al. Gene expression profiling and breast cancer care: what are the potential benefits and policy implications? Genet Med 2005; 7:380-389.

11. Hornberger J, Cosler LE, Lyman GH. Economic analysis of targeting chemotherapy using a 21-gene RT-PCR assay in lymph-node-negative, estrogen-receptor-positive, early-stage breast cancer. Am J Manag Care 2005; 11:313-324.

12. Lyman GH, Cosler LE, Kuderer NM et al. Impact of a 21-gene RT-PCR assay on treatment decisions in early-stage breast cancer: an economic analysis based on prognostic and predictive validation studies. Cancer 2007; 109:1011-1018.

13. Goldhirsch A, Wood WC, Gelber RD et al. Progress and promise: highlights of the international expert consensus on the primary therapy of early breast cancer 2007. Ann Oncol 2007; 18:1133-1144.

14. Ravdin PM, Siminoff LA, Davis GJ et al. Computer program to assist in making decisions about adjuvant therapy for women with early breast cancer. J Clin Oncol 2001; 19:980-991.

15. Bueno-de-Mesquita JM, Sonke GS, van de Vijver MJ, Linn SC. Additional value and potencial use of the 70-gene prognosis signatura in node-negative breast cancer in daily clinical practice. Ann Oncol 2009.

16. Goldhirsch A, Ingle JN, Gelber RD et al. Threshold for therapies: highlights of the St. Gallen international expert consensus on the primary therapy of early breast cancer 2009. Ann Oncol 2009; 20:1319-1329. 
17. Yamashita $H$, Nishio $M$, Toyama $T$ et al. Coexistence of HER2 over-expression and p53 protein accumulation is a strong prognostic molecular marker in breast cancer. Breast Cancer Res 2004; 6:R24-R30.

18. Keefe DL. Trastuzumab-associated cardiotoxicity. Cancer 2002; 95:1592-1600.

19. Dunkler D, Michiels S, Schemper M. Gene expression profiling: does it add predictive accuracy to clinical characteristics in cancer prognosis? EJCancer 2007;43:745-751.

20. Goldhirsch A, Glick JH, Gelber RD et al. Meeting highlights: International Consensus Panel on the Treatment of Primary Breast Cancer. Seventh International Conference on Adjuvant Therapy of Primary Breast Cancer. J Clin Oncol 2001; 19:3817-3827.

21. Lidgren $M$, Jonsson $B$, Rehnberg $C$ et al. Cost-effectiveness of HER2 testing and 1year adjuvant trastuzumab therapy for early breast cancer. Ann Onc 2008;19:487-95.

22. Joensuu $\mathrm{H}$, Kellokumpu-Lehtinen PL, Bono $\mathrm{P}$ et al. Adjuvant docetaxel or vinorelbine with or without trastuzumab for breast cancer. N Engl J Med 2006; 354:809-820.

23. Dutch National Center for Health Statistics, Centraal Bureau voor de Statistiek (in Dutch)availableat:http://statline.cbs.nl/StatWeb/publication/?VW=T\&DM=SLNL\&PA=7 052_95\&D1 $=0-1,7,30-31,34,38,42,49,56,62-63,66,69$ -

$71,75,79 \& D 2=0 \& D 3=0 \& D 4=a, ! 0-28 \& H D=080509-0829 \& H D R=G 2, G 1, G 3 \& S T B=T$

24. Lidgren $M$, Wilking $N$, Jonsson $B$ et al. Health related quality of life in different states of breast cancer. Qual Life Res 2007; 16:1073-1081.

25. Oostenbrink JB, Koopmanschap MA, Rutten FFH. Manual for cost analyses, methods and standard prices for economic evaluations in health care. Amstelveen (The Netherlands): Dutch Health Insurance Executive Board 2006 (in Dutch)

26. Health Care Insurance Board. Pharmacotherapeutic Compass (in Dutch), available at www.fk.cvz.nl . 2006. Amstelveen.

27. Weinstein MC. Recent developments in decision-analytic modeling for economic evaluation. Pharmacoeconomics 2006; 24:1043-1053.

28. Fenwick E, Claxton K, Sculpher M. Representing uncertainty: the role of costeffectiveness acceptability curves. Health Econ 2001; 10:779-787.

29. Earle CC, Coyle D, Evans WK. Cost-effectiveness analysis in oncology. Ann Oncol 1998; 9:475-482.

30. Tengs TO, Wallace A. One thousand health-related quality-of-life estimates. Med Care 2000; 38:583-637.

31. Kurian AW, Thompson RN, Gaw AF et al. A cost-effectiveness analysis of adjuvant trastuzumab regimens in early HER2/neu-positive breast cancer. J Clin Oncol 2007; 25:634-641.

32. Garrison LP, Jr., Lubeck D, Lalla D et al. Cost-effectiveness analysis of trastuzumab in the adjuvant setting for treatment of HER2-positive breast cancer. Cancer 2007; 110:489-498.

33. Liberato NL, Marchetti M, Barosi G et al. Cost effectiveness of adjuvant trastuzumab in human epidermal growth factor receptor 2-positive breast cancer. J Clin Oncol 2007; 25:625-633.

34. Retèl VP, Joore MA, and van harten WH. Scenario drafting as a tool to perform early cost-effectiveness analysis: the case of the 70-gene signature in breast cancer. International Health Economic Association, Beijing, China. 2009.

35. Knauer M, Cardoso F, Mook S et al. Identification of a low risk subgroup in HER2positive breast cancer by the 70-gene prognosis signature. San Antonio Breast Cancer Conferences. 2008.

36. Mook S, Schmidt MK, Viale G et al. The 70-gene prognosis-signature predicts disease outcome in breast cancer patients with 1-3 positive lymph nodes in an independent validation study. Breast Cancer Res Treat 2009; 116:295-302 



\section{Chapter 7}

Head-to-head comparison of the 70-gene signature versus the 21-gene assay: Cost-effectiveness and the effect of compliance

Valesca P. Retèl Manuela A. Joore Wim H. van Harten 


\begin{abstract}
Purpose

Both the 70-gene signature and the 21-gene assay are novel prognostic tests used to guide adjuvant chemotherapy decisions in patients with early breast cancer. Although the results of ongoing prospective trials will only become available in some years, the tests have already been included in clinical guidelines such as St. Gallen's. In literature, the cost-effectiveness of both tests as compared to conventional prognostic tests has been described. We report on a direct comparison of cost-effectiveness; as different compliance rates were reported, we also take these into account.
\end{abstract}

\title{
Patients and Methods
}

A Markov decision model with a time horizon of 20 years was developed to assess the effects, costs and cost-effectiveness of three alternatives; 21-gene assay, 70-gene signature, and St. Gallen (SG) or Adjuvant Online (AO), dependent on the dataset used in patients with early, node-negative breast cancer. Sensitivity and specificity were based on two datasets, incorporating compliances rates based on literature.

\section{Results}

For both datasets, whereas the 70-gene signature yielded more quality adjusted life years (QALYs) and was less costly; the 21-gene assay amounted more life years (LY) but was more costly. The decision uncertainty surrounding the probability of cost-effectiveness of the Thomassen-series amounted to $55 \%$ for both cost/LY and cost/QALY, for the Fan-series to $80 \%$ for $L Y$ and to $65 \%$ for QALYs. Taking reported compliance with discordant test results into account, in general, the effect of all strategies decreased, while the costs increased, without relatively influencing the CEA performance.

\section{Conclusions}

This comparison indicates that the performances of the 70-gene and the 21-gene based on reported studies are close. The 21-gene has the highest probability of being cost-effective when focusing on cost/LY, while focusing on cost/QALY, the 70-gene signature was most cost-effective. The level of compliance can have serious impact on the cost-effectiveness. With additional data, preferably from head-to-head outcome studies and especially on compliance concerning discordant test results, calculations can be made with higher degrees of certainty. 


\section{Introduction}

Both the 70-gene prognosis signature ${ }^{1}$ and the 21-gene Recurrence Score assay ${ }^{2}$ are relative new prognostic tests used to guide adjuvant treatment decisions in patients with early breast cancer. They outperform current guidelines, which offer most patients adjuvant chemotherapy, while $60-70 \%$ have a fairly good survival with loco-regional treatment alone. ${ }^{1,2}$ While there are many studies performed regarding both diagnostic tests separately, no head-to-head comparison has yet been made.

In the current running randomized clinical trials, the "Microarray In Node-negative Disease may Avoid ChemoTherapy" (MINDACT-trial) ${ }^{3}$ and "Trial Assigning IndividuaLized Options for Treatment (Rx)" (TAILOR-X trial) ${ }^{4}$, the additional clinical value of both diagnostic instruments is separately being tested. In the MINDACTtrial, patients with discordant test results (70-gene signature result versus the web tool Adjuvant! Online ${ }^{5}$ (AO); 70-gene low/AO high or 70-gene high/AO low) are randomized between decisions of adjuvant chemotherapy based on the 70-gene or AO risk assessment. In the TAILOR-X trial, patients with an intermediate 21-gene assay score are randomized to either adjuvant chemotherapy in combination with endocrine therapy or only endocrine therapy. Although the results of the prospective trials will only become available in some years, the tests have already been included in guidelines such as the National Comprehensive Cancer Network (NCCN), American Society of Clinical Oncology (ASCO), Dutch CBO 2008 and St. Gallen. However, the exact clinical use has to be established and the profiles have to be used selectively in cases where risk prediction is equivocal based on clinical variables. ${ }^{6}$ The 21 -gene assay may be more user friendly by using formalin-based tissue while the 70-gene signature needs fresh frozen tissue; the 70-gene however is more "decision friendly" using its dichotomous result "low" or "high" risk whereas the 21-gene assay provides an "intermediate" result, in part of the cases where the additional value of the decision using the prognostic test on whether or not to give adjuvant chemotherapy is unclear.

In the field of cost-effectiveness, six cost-effectiveness analyses (CEAs) have been performed regarding gene expression profiles in breast cancer; four regarding the $21-$ gene assay ${ }^{7-10}$ versus clinical guidelines such as NCCN, St. Gallen, and two CEAs are performed regarding the 70 -gene signature versus clinical guidelines such as St. Gallen, Adjuvant Online and the National Institute of Health guidelines $(\mathrm{NIH}){ }^{11,12}$ In the reported CEAs regarding the 21-gene assay, all patients with an intermediate or high risk were assumed to undergo hormonal therapy (if endocrine responsive) and chemotherapy. In one CEA of the 21-gene assay it was modeled in the sensitivity analysis that $50 \%$ of the patients with an intermediate risk test result would receive hormonal therapy and chemotherapy. ${ }^{9}$ Both CEAs of the 70 - 
gene signature assumed that patients with a high risk test result would undergo hormonal therapy (if endocrine responsive) and chemotherapy. In all CEAs the genomic profile in question was found to be cost-effective compared to the clinical guideline used.

A CEA shows the cost-effectiveness of a technology versus the next best alternative. A CEA should compare all relevant alternatives. ${ }^{13}$ Unfortunately, there is no CEA performed comparing both tests in one analysis, because a comparison of the "original" 70-gene signature and the "original" 21-gene assay in one independent dataset is not available. Answering the question which test performs best will require comparative effectiveness research. Government and industry seldom fund such studies because they may not offer as much additional therapeutic promise as new discoveries do, and because industry is not eager to fund direct comparisons with competitive products. ${ }^{14}$ The only articles in which both diagnostic tests are compared are Thomassen et al. ${ }^{15}$ and Fan et al. ${ }^{16}$, however, they do not use the "original" assays.

Why is it still important to perform a cost-effectiveness analysis directly comparing the tests in this case? Physicians have to choose between the two tests and the question which of the tests is most (cost-) effective, is relevant especially in view of the fact that the available data are not yet optimal. Data available should not guide the analysis; the decision problem should guide the analysis. ${ }^{17}$

Therefore, we performed a direct cost-effectiveness comparison using the sensitivity and specificity of the 70-gene signature, the 21-gene assay and the St. Gallen $2003^{18}$ based on the Thomassen-series ${ }^{15}$, or using the sensitivity and specificity of the 70-gene signature, the 21-gene assay and the Adjuvant Online based on the Fan-series. ${ }^{16}$ In addition, the impact of changes in compliance is calculated since it is known that there is seldom full compliance with guidelines and that for both prognostic tests compliance with the test result may be an issue, as shown in the pilot study of the MINDACT trial. ${ }^{19}$

\section{Methods}

\section{Sensitivity and specificity of the genomic tests}

The Thomassen-series $(\mathrm{N}=60)^{15}$ assessed both gene expression profiles and clinical characteristics using the same algorithms on one platform. In this study, the comparison of prediction of metastasis in a low-malignant breast cancer group is made. The study is designed with pairs of metastasizing and non-metastasizing tumors matched according to classic prognostic markers, developing classification algorithms reducing the effect of different platforms. ${ }^{15}$ All tumors in this database were included in the current study. In the model, each strategy was based on the 
sensitivity and specificity of the prognostic tests, which were derived from the figures $1 \mathrm{~B}$ and $1 \mathrm{H}$ from the Thomassen paper. ${ }^{15}$ Patients were classified as having a true low, true high, false low, or false high risk of developing metastasis. In the Thomassen-series, this classification was generated by a "probability of poor outcome" cut-off of 0.5 , applied to all classifications of the used diagnostic tests. ${ }^{15}$

In the Fan-series $(n=101)^{16}$, the gene-expression data set containing 295 tumors was derived by researchers from the Netherlands Cancer Institute and Rosetta Inpharmatics- Merck using oligonucleotide microarrays (Agilent). Tumors with Node negative and ER-positive characteristics were selected from this database. We calculated the sensitivity and specificity of the 70-gene, 21-gene and Adjuvant Online (Table 1). The intermediate risk patients of the 21-gene assay were grouped together with the high risk (as the former analysis also did), assuming that both intermediate and high risk patients received hormonal and chemotherapy.

\section{Compliance rates}

We used the compliance rates regarding discordant test results from the clinical trial data of the MINDACT pilot (first 800 patients). 19 The compliance rates were modeled for the discordant cases clinical low /genomic high risk (13\%) and clinical high/genomic low risk (4\%) for both strategies and both datasets. The compliance rates were incorporated in the sensitivity and specificity of the diagnostic tests (Table 2).

\section{Decision model}

Previously, a Markov decision model was developed to assess the effects (life years and quality adjusted life years), health care costs and cost-effectiveness of the 70-gene signature as compared to clinical guidelines (such as SG and AO) in patients with early, node-negative, estrogen receptor positive breast cancer patients. ${ }^{12}$ A quality adjusted life year (QALY) is defined as a life year multiplied by a quality of life weight between 0 and 1 , for instance two years with quality of life 0.8 amounts to 1.6 QALYs. The model was constructed with four mutually exclusive health states: disease free survival, relapse (including local and regional recurrences, secondary primary and contralateral breast cancer), distant metastasis, and death (Figure 1). The study adopted a health care perspective. For further model details, see Retèl et al. ${ }^{12}$ In the current analysis, the 21-gene assay was added as a comparator. The calculations are performed per year, with a total simulated time horizon of 20 years. Future costs and effects were discounted to their present value by a rate of $4 \%$ and $1.5 \%$ per year respectively, according to the Dutch guidelines. ${ }^{20}$ 


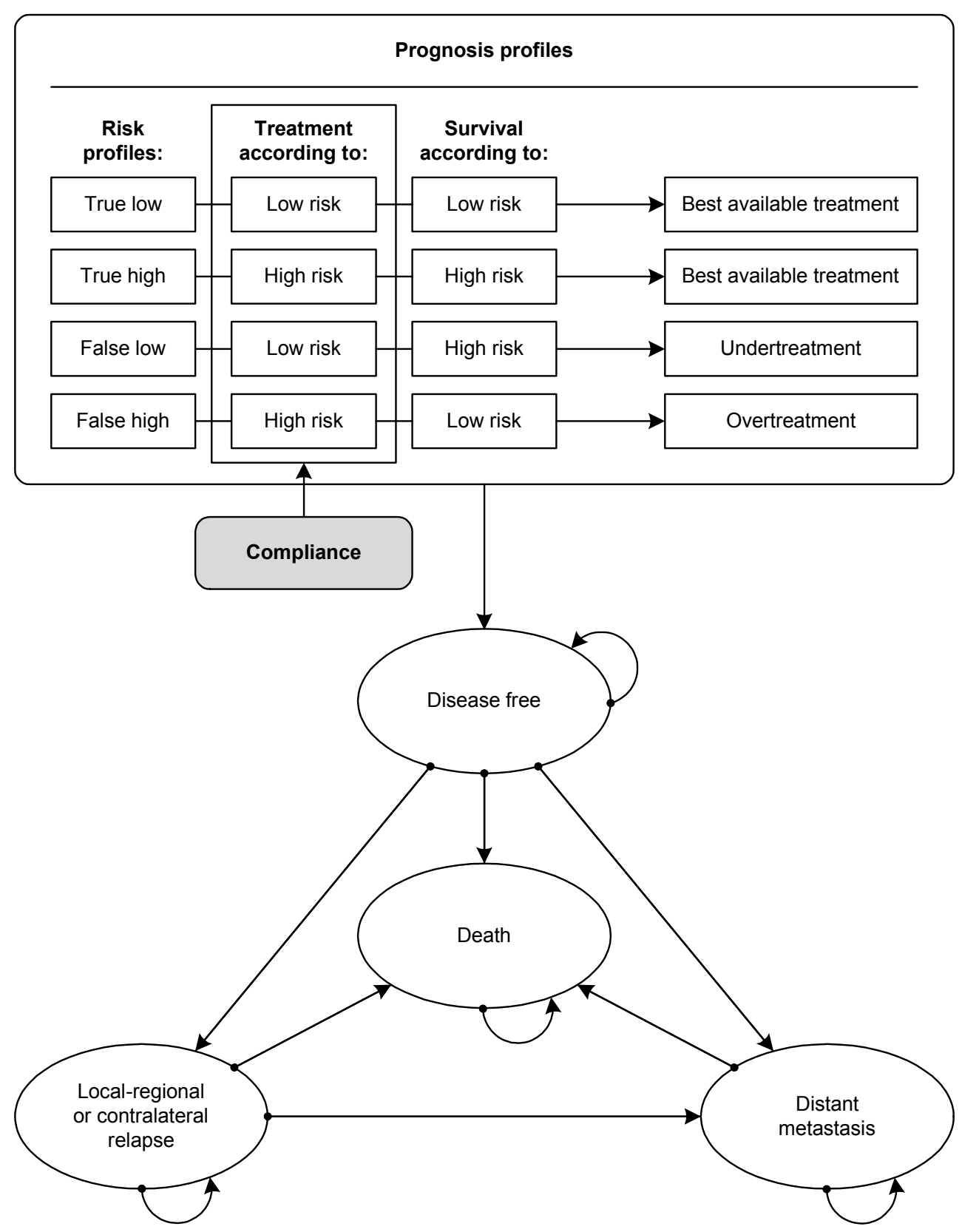

Figure 1. Model structure 


\section{Cost and utility input}

The costs of the 70 -gene signature were $€ 2,675$, provided by Agendia B.V.; full costs including transport, additional specimen processing at the local hospital and Value Added Tax (VAT). The costs of the 21-gene assay were $\$ 4,075(€ 3,179)$, derived from the website of Genomic Health Inc. Costs were expressed in 2005 Euros. For other cost and utility input, see Retèl et al. ${ }^{12}$

\section{Analysis}

Incremental cost-effectiveness ratios (ICERS) were calculated by dividing the incremental costs by incremental life years (iLYs) and by incremental quality adjusted life years (iQALYs). Uncertainty in the input parameters was handled probabilistically, by assigning distributions to parameters (Table 1). ${ }^{21}$ Subsequently, the results are simulated for 1000 patients representing the dataset. Whether a strategy is deemed efficient depends on how much society is willing to pay for a gain in effect, which is referred to as the ceiling ratio. ${ }^{22}$ In the Netherlands an informal ceiling ratio of $€ 80,000$ per QALY exists (Dutch Council for Public Health and Health Care 2006). ${ }^{23}$ This is a maximum ceiling ratio which applies when there is a high burden of disease. This is certainly the case for breast cancer. In the US this threshold is $\$ 50,000-100,000 / Q A L Y$. And in the UK, the National Institute for Health and Clinical Excellence (NICE) handles a threshold of $£ 20,000$ $30,000 /$ QALY. $^{24}$ In this study, we handled the Dutch ceiling ratio of $€ 80,000 / Q A L Y$. In theory, when the differences in costs divided by the differences in outcomes is above this ceiling ratio, the strategy is not considered cost-effective. To indicate this decision uncertainty, cost-effectiveness acceptability curves (CEACs) are presented. 
Table 1. Test performance base case for Thomassen ${ }^{15}$ and Fan ${ }^{16}$

\begin{tabular}{|c|c|c|c|c|c|c|c|c|c|}
\hline $\mathbf{P}$ & \multicolumn{2}{|c|}{ Risk group } & & $\mathrm{Se}$ & Sp & $\mathbf{P}$ & SE & Distr. & Ref \\
\hline \multicolumn{3}{|c|}{ Base case Thomassen } & $N$ & & & & & & \\
\hline \multirow[t]{4}{*}{$70-G$} & Low & True & 25 & 0.70 & 0.83 & 0.417 & 0.07 & Dirichlet & 15 \\
\hline & & False & 9 & & & 0.150 & 0.12 & Dirichlet & \\
\hline & High & True & 21 & & & 0.350 & 0.08 & Dirichlet & \\
\hline & & False & 5 & & & 0.083 & 0.07 & Dirichlet & \\
\hline \multirow[t]{4}{*}{$21-G$} & Low & True & 22 & 0.73 & 0.73 & 0.367 & 0.07 & Dirichlet & \\
\hline & & False & 8 & & & 0.133 & 0.12 & Dirichlet & \\
\hline & High & True & 22 & & & 0.367 & 0.08 & Dirichlet & \\
\hline & & False & 8 & & & 0.133 & 0.08 & Dirichlet & \\
\hline \multirow[t]{4}{*}{ SG } & Low & True & 13 & 0.57 & 0.43 & 0.217 & 0.09 & Dirichlet & \\
\hline & & False & 13 & & & 0.283 & 0.09 & Dirichlet & \\
\hline & High & True & 17 & & & 0.217 & 0.09 & Dirichlet & \\
\hline & & False & 17 & & & 0.283 & 0.09 & Dirichlet & \\
\hline \multicolumn{3}{|c|}{ Base case Fan } & $N$ & & & & & & \\
\hline \multirow[t]{4}{*}{$70-G$} & Low & True & 46 & 0.74 & 0.70 & 0.455 & 0.06 & Dirichlet & 16 \\
\hline & & False & 9 & & & 0.089 & 0.08 & Dirichlet & \\
\hline & High & True & 26 & & & 0.257 & 0.07 & Dirichlet & \\
\hline & & False & 20 & & & 0.198 & 0.06 & Dirichlet & \\
\hline \multirow[t]{4}{*}{$21-G$} & Low & True & 29 & 0.89 & 0.44 & 0.287 & 0.06 & Dirichlet & \\
\hline & & False & 4 & & & 0.040 & 0.05 & Dirichlet & \\
\hline & High & True & 31 & & & 0.307 & 0.05 & Dirichlet & \\
\hline & & False & 37 & & & 0.366 & 0.06 & Dirichlet & \\
\hline \multirow[t]{4}{*}{$\mathrm{AO}$} & Low & True & 41 & 0.66 & 0.62 & 0.406 & 0.06 & Dirichlet & \\
\hline & & False & 12 & & & 0.119 & 0.08 & Dirichlet & \\
\hline & High & True & 23 & & & 0.228 & 0.08 & Dirichlet & \\
\hline & & False & 25 & & & 0.248 & 0.06 & Dirichlet & \\
\hline
\end{tabular}

70-G: 70-gene signature

21-G: 21-gene Recurrence Score assay

SG: St. Gallen guidelines (2003)

AO: Adjuvant Online

Distr.: distribution

Sp: Specificity

Se: Sensitivity

P: probability

SE: standard error

Ref: reference 
Table 2. Test performance taking into account compliance

\begin{tabular}{|c|c|c|c|c|c|c|}
\hline Parameter & Risk group & & $\mathbf{P}$ & SE & Distr. & Ref \\
\hline \multicolumn{7}{|c|}{ Incorporated non-compliance rates in the Thomassen-series } \\
\hline \multirow[t]{2}{*}{ 70-G low } & SG high & Discordance & 0.640 & 0.09 & Beta & 15 \\
\hline & & Non-compliance & 0.040 & 0.02 & Beta & 19 \\
\hline \multirow[t]{2}{*}{ 70-G high } & SG low & Discordance & 0.360 & 0.09 & Beta & 15 \\
\hline & & Non-compliance & 0.130 & 0.05 & Beta & 19 \\
\hline \multirow[t]{2}{*}{ 21-G low } & SG high & Discordance & 0.560 & 0.10 & Beta & 15 \\
\hline & & Non-compliance & 0.040 & 0.02 & Beta & 19 \\
\hline \multirow[t]{2}{*}{ 21-G high } & SG low & Discordance & 0.440 & 0.10 & Beta & 15 \\
\hline & & Non-compliance & 0.130 & 0.05 & Beta & 19 \\
\hline \multicolumn{7}{|c|}{ Incorporated non-compliance rates in the Fan-series } \\
\hline \multirow[t]{2}{*}{ 70-G low } & AO high & Discordance & 0.530 & 0.08 & Beta & 16 \\
\hline & & Non-compliance & 0.040 & 0.02 & Beta & 19 \\
\hline \multirow[t]{2}{*}{ 70-G high } & AO low & Discordance & 0.470 & 0.08 & Beta & 16 \\
\hline & & Non-compliance & 0.130 & 0.05 & Beta & 19 \\
\hline \multirow[t]{2}{*}{ 21-G low } & AO high & Discordance & 0.430 & 0.08 & Beta & 16 \\
\hline & & Non-compliance & 0.040 & 0.02 & Beta & 19 \\
\hline \multirow[t]{2}{*}{ 21-G high } & AO low & Discordance & 0.570 & 0.08 & Beta & 16 \\
\hline & & Non-compliance & 0.130 & 0.05 & Beta & 19 \\
\hline
\end{tabular}

70-G: 70-gene signature

21-G: 21-gene Recurrence Score assay

P: probability

Distr.: distribution

SE: standard error

Ref: reference 


\section{Sensitivity Analyses}

We performed four sensitivity analysis (SA) concerning the used dataset, to show the robustness of the results. First, because we expect that the 21-gene assay could be in disadvantage ${ }^{25}$, we calculated a SA regarding higher sensitivity and specificity for the 21-gene assay. For each database, we improved the true low and true high group with one patient. Second, we used the compliance rates of the feasibility studies of Bueno de Mesquita et al. ${ }^{26}$ and Lo et al. ${ }^{27}$ as SA, to show the "worst case" scenario when including non-compliance. We incorporated noncompliance rates with the genomic test results based on two articles in which compliance was measured. The non-compliance rates were modeled for the discordant cases clinical low/genomic high risk and clinical high/genomic low risk. In Bueno-de-Mesquita et al. ${ }^{26}$, the non-compliance rate for the 70-gene signature in case of a clinical high and genomic low risk was $60 \%$, in case of clinical low and genomic high it was $43 \%$. In Lo et al. ${ }^{27}$, the non-compliance rate for the 21 -gene assay of respectively clinical high/genomic low and clinical low/genomic high was $25 \%$ and $88 \%$ (Table 2). In this calculation, we have taken together the intermediate and the high risk group who are assumed to receive chemotherapy. Third, because using QALY as an outcome in cost-effectiveness analyses in oncology is a debated issue, as this has proven to be difficult to estimate health state utilities among cancer patients ${ }^{28}$, we used different Quality of Life (QoL)scores (utilities) for disease free survival with and without adjuvant systemic therapy. ${ }^{29}$ Finally, because the costs of chemotherapy are likely to become higher in the future with the increase of novel regimens (e.g. Taxanes), the costs of chemotherapy were varied to $€ 20,000 .^{30}$ Cost-effectiveness acceptability Curves (CEACs) frontiers are used to show the impact of these changes in model input on the probability that the 70 -gene signature is cost-effective.

\section{Results}

\section{Mean results}

For both series, whereas the 70-gene signature yielded more QALYs and was less costly, the 21-gene assay amounted more life years but was more costly (Table 3).

For the Thomassen-series, the number of life years amounted to 14.76 for the 21gene, 14.61 for the 70 -gene, and 14.04 for the SG. The QALYs of the 70-gene yielded $11.41,11.33$ for the 21 -gene and 10.41 for the SG. The total health care costs per patient were $€ 40,393$ for the 70 -gene, $€ 41,868$ for the 21-gene and $€ 44,232$ for the SG. When focusing on survival, the 21-gene assay has the highest probability of being cost-effective, with a willingness to pay of $€ 1,475 / L Y$ and higher, taken into account a ceiling ratio of $€ 80,000 / Q A L Y$. In case of costs/QALY, 
the 70-gene signature has the highest probability of being cost-effective, with less costs and higher survival (Figure 2a\&b).

For the Fan-series, the number of life years amounted to: 15.26 (70-gene), 15.86 (21-gene) and 15.00 (AO). The QALYs amounted to: 11.92 (70-gene), 11.61 (21gene), and $11.61(\mathrm{AO})$. The total health care costs per patient were: $€ 38,779$ (21gene), $€ 34,858$ (70-gene) and $€ 34,115$ (AO). The difference in costs per life year gained of the 21-gene assay compared to the 70-gene signature resulted in equal life years but more costs for the 21-gene assay. While focusing on costs/QALY, the 70-gene signature yields more QALYs and less costs than the other strategies.

The uncertainty surrounded by the Thomassen-series amounted to $55 \%$ for the life years and $55 \%$ for the QALYs, for the Fan-series to $80 \%$ for the LY and $65 \%$ for the QALYs.

\section{Compliance}

Taking reported compliance with discordant test results into account resulted in general in a slightly decreased effect of all studies; the costs slightly increased and the decision uncertainty increased (Table 4, Figure 3a\&b).

\section{Sensitivity Analyses}

When improving the outcome for the 21-gene assay, the results of the costs/LY appeared stronger in both datasets, for the costs/QALY, the 70-gene signature remained most cost-effective in the Fan-series.

For the second sensitivity analyses regarding other compliance input, for the Thomassen-series, the 70-gene signature became the most cost-effective strategy when focusing on survival. When focusing on quality adjusted survival, the AO strategy became the most cost-effective strategy. For the Fan-series, the AO became most cost-effective for both LY and QALYs. For both analyses the probability of cost-effectiveness was around $50 \%$, which means that the decision of cost-effectiveness has substantial uncertainty in this case. Lower utilities and higher chemotherapy costs showed the same pattern as the base case, only slightly shifted (Appendix Figure 1a\&b). 
Table 3. Mean results base case for Thomassen and Fan

\begin{tabular}{|c|c|c|c|c|c|}
\hline Strategy & LYs & Costs & $\Delta \mathrm{LYs}(\mathrm{Cl})$ & $\Delta$ Costs (Cl) & ICER \\
\hline \multicolumn{6}{|l|}{ Thomassen } \\
\hline $21 G$ & 14.76 & $€ 41,868$ & NA & NA & NA \\
\hline $70 G$ & 14.61 & $€ 40,393$ & NA & NA & NA \\
\hline SG & 14.04 & $€ 44,232$ & NA & NA & NA \\
\hline $21 \mathrm{G}$ vs $70 \mathrm{G}$ & NA & NA & $0.14(-0.99$ to 1.27$)$ & $€ 1,475(-7,988$ to 10,920$)$ & $€ 1,475$ \\
\hline $21 G$ vs SG & NA & NA & $0.72(-0.51$ to 1.90$)$ & $-€ 2,364(-10,831$ to 6,519$)$ & DOM \\
\hline \multicolumn{6}{|l|}{ Fan } \\
\hline $21 G$ & 15.86 & $€ 38,799$ & NA & NA & NA \\
\hline $70 G$ & 15.26 & $€ 34,858$ & NA & NA & NA \\
\hline $\mathrm{AO}$ & 15.00 & $€ 34,115$ & NA & NA & NA \\
\hline $21 \mathrm{G}$ vs $70 \mathrm{G}$ & NA & NA & $0.40(-0.73$ to 0.77$)$ & $€ 3,941(-3,969$ to 8,945$)$ & $€ 9,272$ \\
\hline $70 G$ vs $A O$ & NA & NA & $0.26(-0.52$ to 1.05$)$ & $€ 743(-5,967$ to 6,727$)$ & $€ 2,913$ \\
\hline Strategy & QALYS & Costs & $\triangle Q A L Y s(C l)$ & $\Delta$ Costs (Cl) & ICER \\
\hline \multicolumn{6}{|l|}{ Thomassen } \\
\hline $70 G$ & 11.41 & $€ 40,393$ & NA & NA & NA \\
\hline $21 G$ & 11.33 & $€ 41,868$ & NA & NA & NA \\
\hline SG & 10.41 & $€ 44,232$ & NA & NA & NA \\
\hline $70 \mathrm{G}$ vs $21 \mathrm{G}$ & NA & NA & $0.08(-1.01$ to 1.11$)$ & $-€ 1,475(-10,920$ to 7988$)$ & DOM \\
\hline $70 G$ vs SG & NA & NA & $1.00(-0.06$ to 1.91$)$ & $€ 3,839(-13,307$ to 5,256$)$ & $€ 3,839$ \\
\hline \multicolumn{6}{|l|}{ Fan } \\
\hline $70 G$ & 11.92 & $€ 34,858$ & NA & NA & NA \\
\hline $21 G$ & 11.61 & $€ 38,799$ & NA & NA & NA \\
\hline $\mathrm{AO}$ & 11.61 & $€ 34,115$ & NA & NA & NA \\
\hline $70 G$ vs $21 G$ & NA & NA & $0.31(-0.49$ to 0.90$)$ & $-€ 3,941(-8,945$ to 3,969$)$ & DOM \\
\hline $21 \mathrm{G}$ vs $\mathrm{AO}$ & NA & NA & $0.00(-0.61$ to 0.86$)$ & $€ 4,684(-4,088$ to 9,457$)$ & $€ 1,6$ mill \\
\hline
\end{tabular}

Thomassen and Fan Incremental cost-effectiveness results (ICER)

$\mathrm{Cl}: 95 \%$ confidence interval

70-G: 70-gene signature

21-G: 21-gene assay

SG: St. Gallen guidelines (2003)

AO: Adjuvant Online

$\Delta$ : incremental

DOM: dominant

mill: million

vs: versus 
Table 4. Mean results base case taking into account compliance

\begin{tabular}{|c|c|c|c|c|c|}
\hline Strategy & LYs & Costs & $\Delta \mathrm{LYs}(\mathrm{Cl})$ & $\Delta$ Costs $(\mathrm{Cl})$ & ICER \\
\hline \multicolumn{6}{|l|}{ Thomassen } \\
\hline $21 G$ & 14.61 & $€ 42,227$ & NA & NA & NA \\
\hline $70 G$ & 14.51 & $€ 40,813$ & NA & NA & NA \\
\hline SG & 14.04 & $€ 44,232$ & NA & NA & NA \\
\hline $21 \mathrm{G}$ vs $70 \mathrm{G}$ & NA & NA & 0.10 (0.19 to 2.09$)$ & $€ 1,412(-10,211$ to 5,592$)$ & $€ 14,862$ \\
\hline $70 G$ vs SG & NA & NA & $0.47(-0.66$ to 1.77$)$ & $-€ 3,419(-10,862$ to 7,196$)$ & DOM \\
\hline \multicolumn{6}{|l|}{ Fan } \\
\hline $70 G$ & 15.14 & $€ 35,068$ & NA & NA & NA \\
\hline $21 G$ & 15.11 & $€ 37,135$ & NA & NA & NA \\
\hline $\mathrm{AO}$ & 15.00 & $€ 34,116$ & NA & NA & NA \\
\hline $70 G$ vs $21 G$ & NA & NA & $0.03(-0.26$ to 1.03$)$ & - $€ 2,067(-4,585$ to 7,558$)$ & DOM \\
\hline $21 \mathrm{G}$ vs $\mathrm{AO}$ & NA & NA & $0.11(-0.71$ to 0.89$)$ & $€ 3,019(-3,284$ to 9,646$)$ & $€ 28,123$ \\
\hline Strategy & QALY & Costs & $\triangle$ QALYs (CI) & $\Delta$ Costs $(\mathrm{Cl})$ & ICER \\
\hline \multicolumn{6}{|l|}{ Thomassen } \\
\hline $70 G$ & 11.32 & $€ 40,813$ & NA & NA & NA \\
\hline $21 G$ & 11.24 & $€ 42,227$ & NA & NA & NA \\
\hline SG & 10.41 & $€ 44,232$ & NA & NA & NA \\
\hline $70 G$ vs $21 G$ & NA & NA & $0.08(-0.31$ to 1.86$)$ & $-€ 1,412(-11,743$ to 6,069$)$ & DOM \\
\hline $21 G$ vs SG & NA & NA & 0.82 (0.39 to 1.97$)$ & $-€ 2,007(-12,437$ to 1,829$)$ & DOM \\
\hline \multicolumn{6}{|l|}{ Fan } \\
\hline $70 G$ & 11.86 & $€ 35,068$ & NA & NA & NA \\
\hline $21 G$ & 11.64 & $€ 37,135$ & NA & NA & NA \\
\hline $\mathrm{AO}$ & 11.61 & $€ 34,116$ & NA & NA & NA \\
\hline $70 G$ vs $21 G$ & NA & NA & $0.22(-0.46$ to 0.85$)$ & $-€ 2,067(-8,714$ to 4,435$)$ & DOM \\
\hline $21 \mathrm{G}$ vs $\mathrm{AO}$ & NA & NA & $0.03(-0.68$ to 0.75$)$ & $€ 3,019(-3,284$ to 9,646$)$ & $€ 79,470$ \\
\hline
\end{tabular}

Thomassen and Fan Incremental cost-effectiveness results (ICER) of sensitivity analyses Cl: $95 \%$ confidence interval

70-G: 70-gene signature

21-G: 21-gene assay

SG: St. Gallen guidelines (2003)

AO: Adjuvant Online

$\Delta$ : incremental

DOM: dominant

vs: versus 

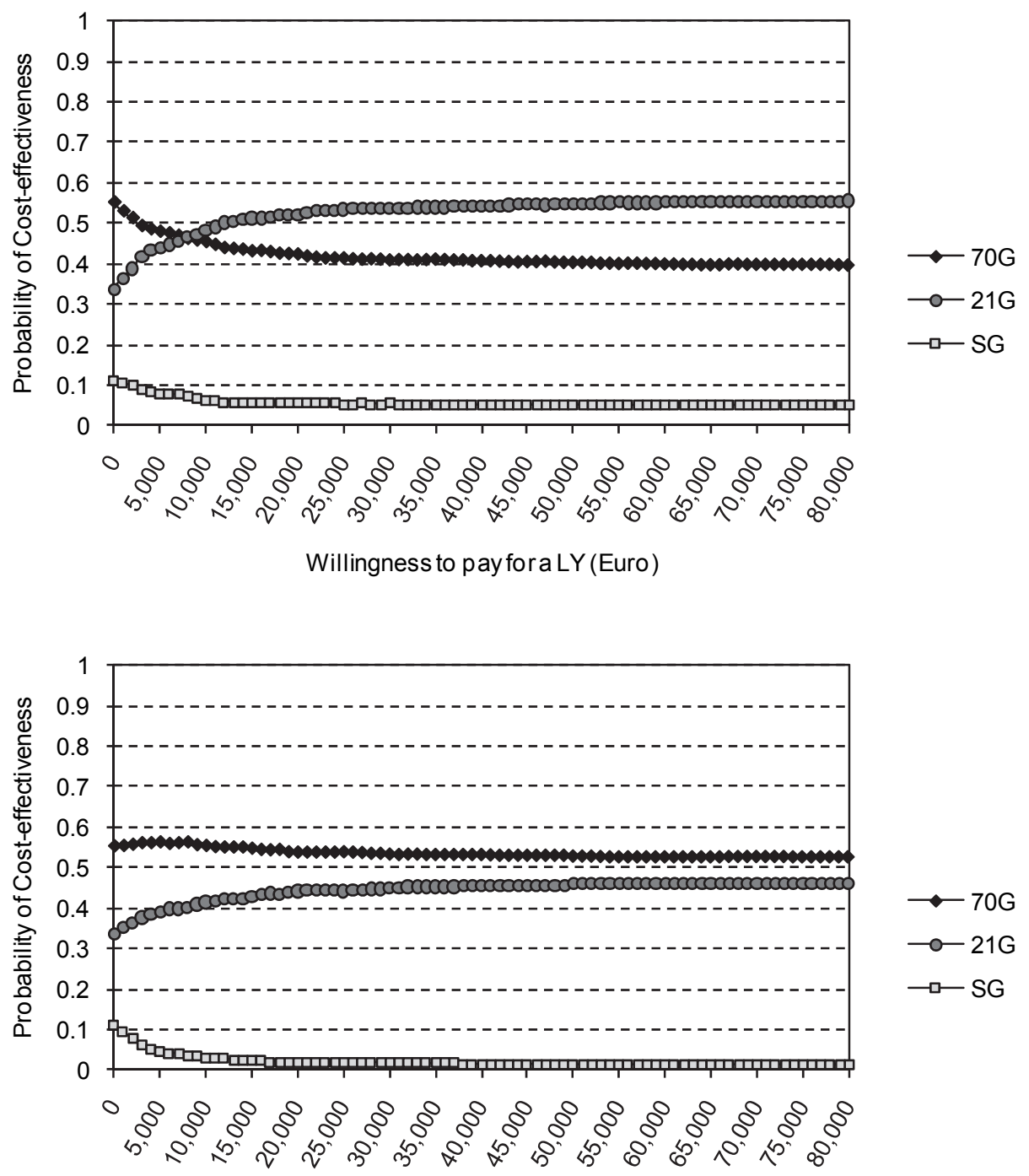

Willingness to pay for a QALY (Euro)

Figure 2a. Cost-Effectiveness Acceptability Curves (LY and QALY) based on the Thomassen-series, for the base case; presenting the probability of cost-effectiveness for a range of values of thresholds (ceiling ratios, willingness to pay for one QALY).

70-G: 70-gene signature

21-G: 21-gene assay

SG: St. Gallen guidelines (2003) 

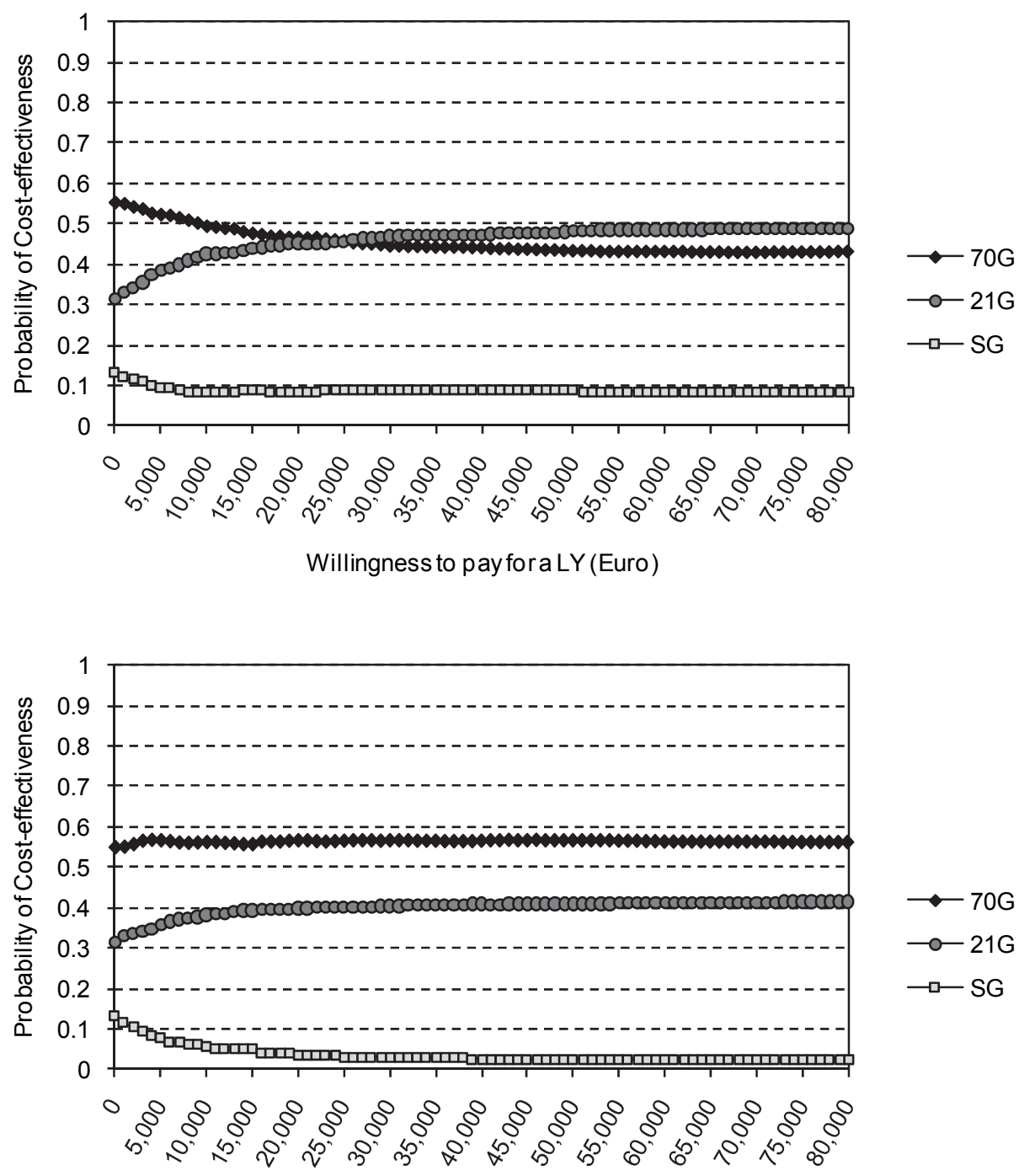

Willingness to pay fora QALY (Euro)

Figure 2b. Cost-Effectiveness Acceptability Curves (LY and QALY) based on the Thomassen-series, for including compliance; presenting the probability of cost-effectiveness for a range of values of thresholds (ceiling ratios, willingness to pay for one QALY).

70-G: 70-gene signature

21-G: 21-gene assay

SG: St. Gallen guidelines (2003) 

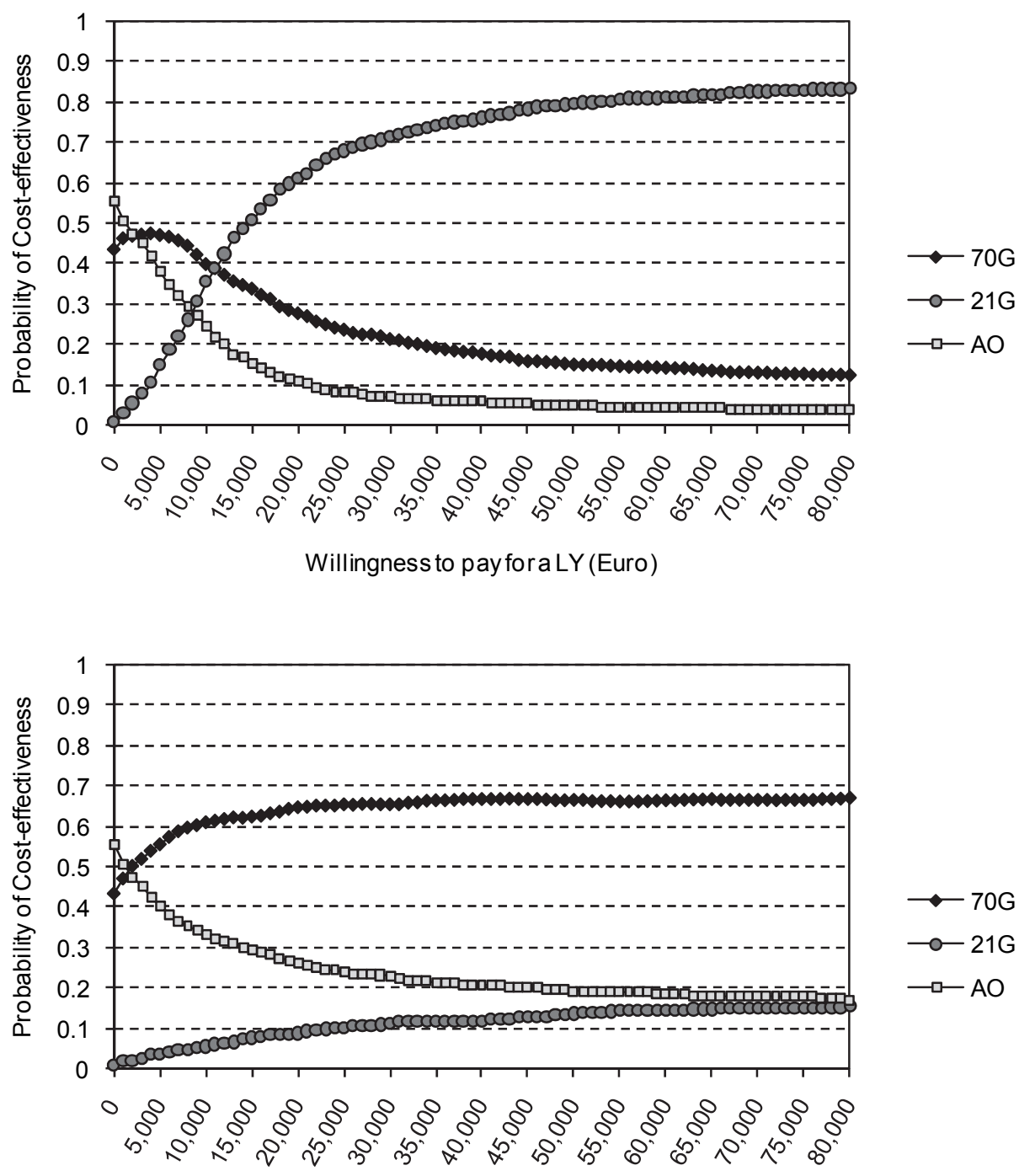

Willingness to pay fora QALY (Euro)

Figure 3a. Cost-Effectiveness Acceptability Curves (LY and QALY) based on the Fan-series, for the base case; presenting the probability of cost-effectiveness for a range of values of thresholds (ceiling ratios, willingness to pay for one QALY).

70-G: 70-gene signature

21-G: 21-gene assay

AO: Adjuvant Online 


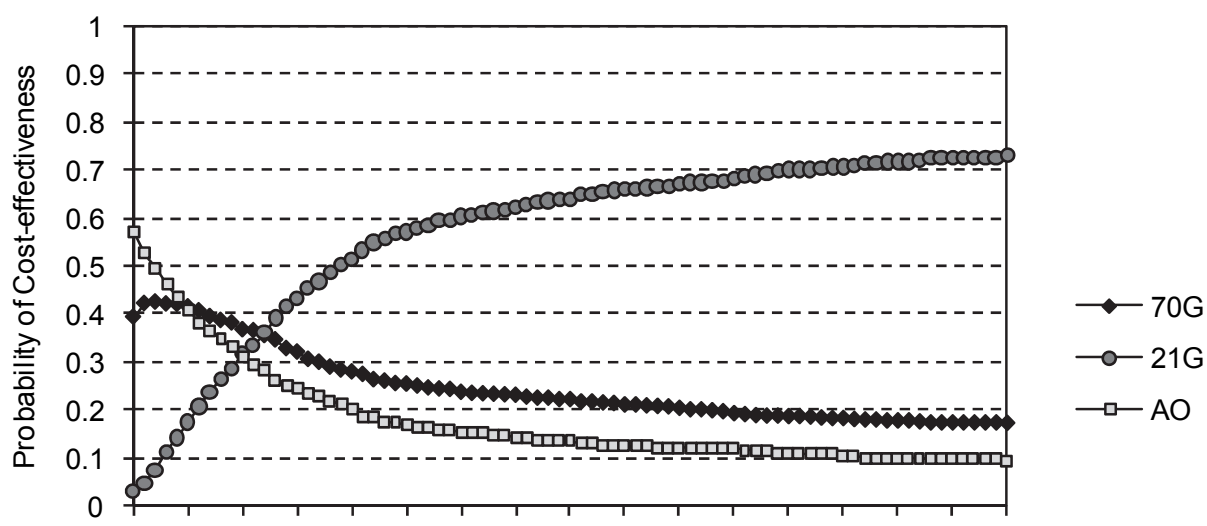

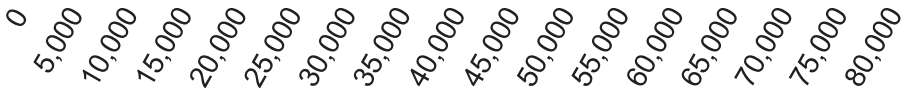

Willingness to pay fora LY (Euro)

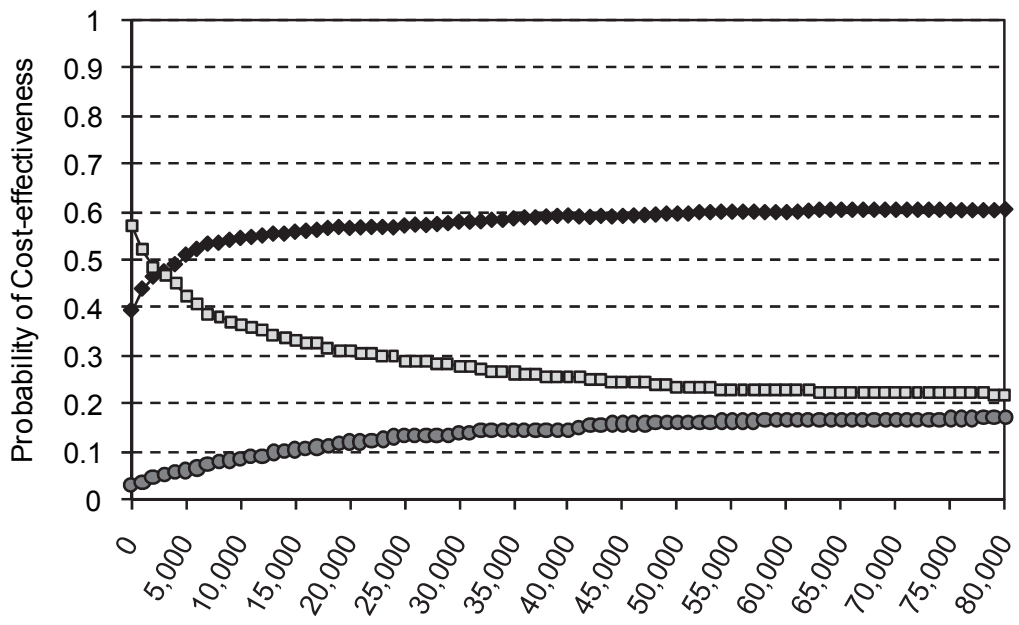

Willingness to pay fora QALY (Euro)

Figure 3b. Cost-Effectiveness Acceptability Curves (LY and QALY) based on the Fan-series, for including compliance; presenting the probability of cost-effectiveness for a range of values of thresholds (ceiling ratios, willingness to pay for one QALY).

70-G: 70-gene signature

21-G: 21-gene assay

AO: Adjuvant Online 


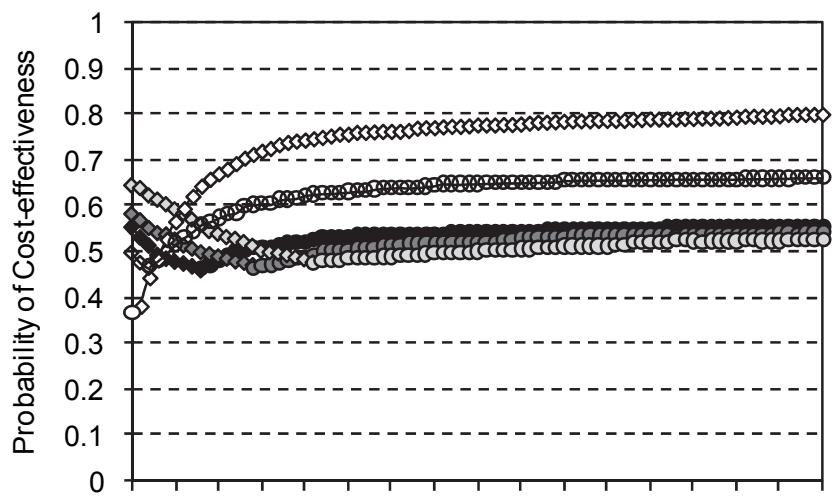

$\longrightarrow$ base case 70-G

$\longrightarrow$ base case 21-G

$\multimap$ QALY 70-G

- - QALY 21-G

$\multimap$ costs CT 70-G

$\multimap$ costs CT 21-G

$\multimap$ compliance lit $70-\mathrm{G}$

-O- compliance lit 21-G

$\multimap$ Bias 70-G

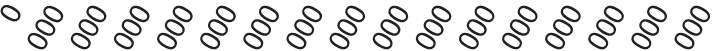

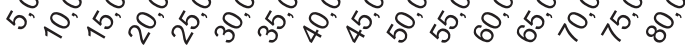

$\rightarrow$ Bias 21-G

Willingness to pay for a LY (Euro)

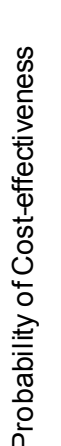

1
0.9
0.8
0.7
0.6
0.5
0.4
0.3
0.2
0.1
0

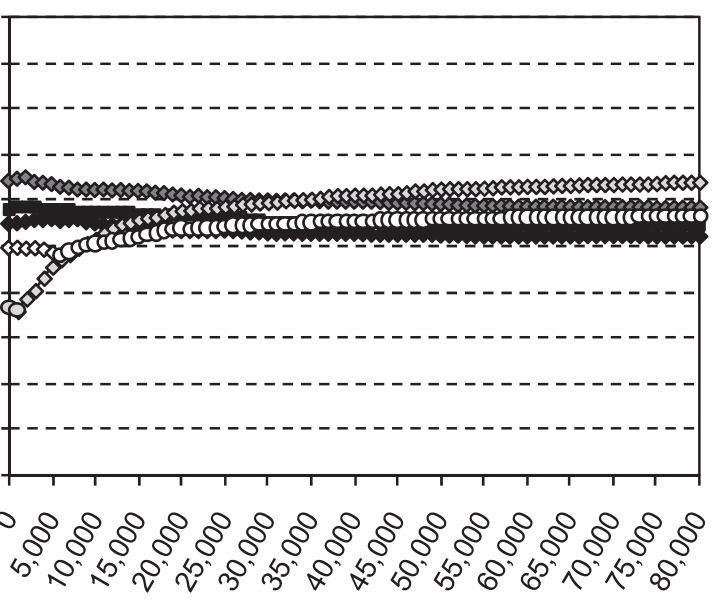

$\longrightarrow$ base case 70-G

$\longrightarrow$ QALY 70-G

$\multimap$ costs CT 70-G

$\multimap$ compliance lit 70-G

- - compliance lit 21-G

$\multimap$ Bias 70-G

$\multimap-$ Bias 21-G

Willingness to pay fora QALY (Euro)

Appendix Figure 1a. Cost-Effectiveness Acceptability Curve Frontier reflecting the base case versus the sensitivity analyses for Thomassen

Base case: base case analyses

QALY: sensitivity analysis changing for different utilities

Costs CT: sensitivity analysis changing for higher chemotherapy costs

Compliance lit: sensitivity analysis changing for compliance rates based on feasibility studies, reflecting the "worst case" scenario regarding non-compliance

Bias: sensitivity analysis changing for better outcomes for the 21-gene. 

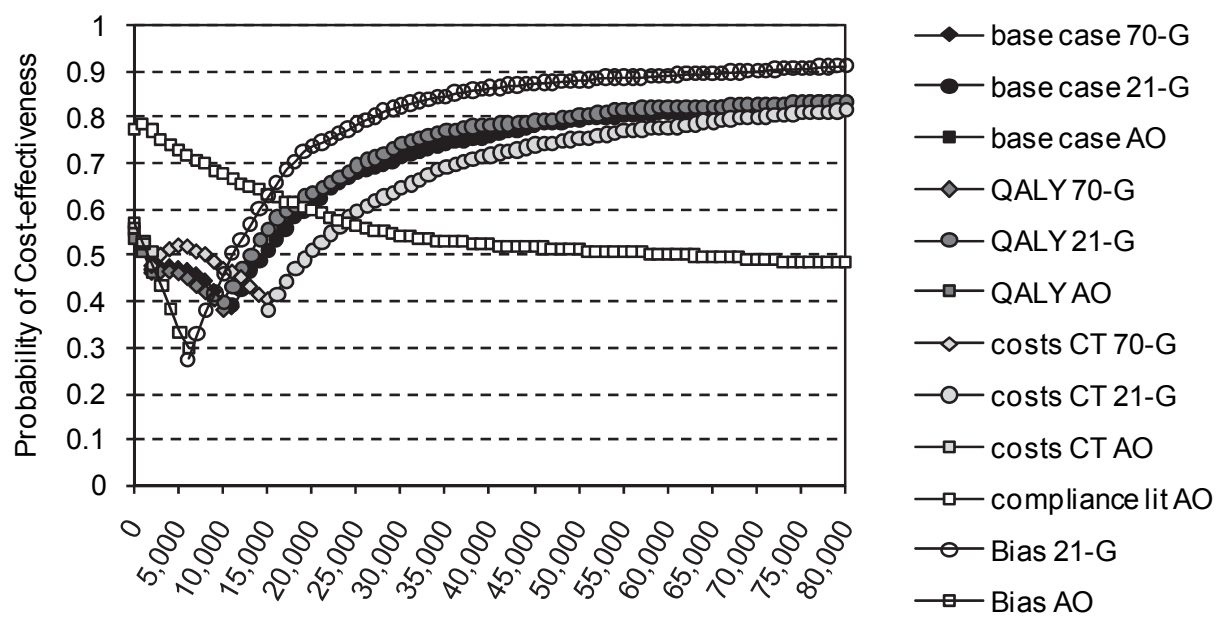

Willingness to pay fora LY (Euro)

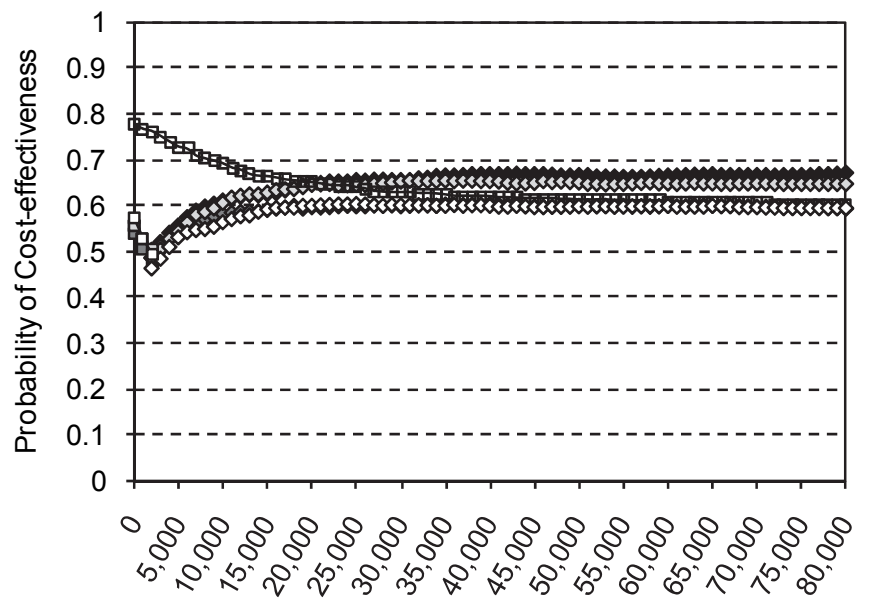

$$
\begin{aligned}
& \multimap \text { base case } 70-\mathrm{G} \\
& \longrightarrow \text { base case AO } \\
& \approx \text { QALY 70-G } \\
& \rightarrow-Q A L Y A O \\
& \multimap \text { costs CT 70-G } \\
& \longrightarrow \text { costs CT AO } \\
& \longrightarrow \text { compliance lit AO } \\
& \multimap \text { Bias 70-G } \\
& \longrightarrow \text {-Bias AO }
\end{aligned}
$$

Willingness to pay fora QALY (Euro)

Appendix Figure 1b. Cost-Effectiveness Acceptability Curve Frontier reflecting the base case versus the sensitivity analyses for Fan

Base case: base case analyses

QALY: sensitivity analysis changing for different utilities

Costs CT: sensitivity analysis changing for higher chemotherapy costs

Compliance lit: sensitivity analysis changing for compliance rates based on feasibility studies, reflecting the "worst case" scenario regarding non-compliance

Bias: sensitivity analysis changing for better outcomes for the 21 -gene. 


\section{Discussion}

Based on the currently available data, and assuming that there was $100 \%$ compliance in case of discordant test results, the 21-gene has the highest probability of being cost-effective when focusing on cost/LY, however, while when focusing on cost/QALY, the 70-gene signature has the highest probability of being cost-effective, taking into account a threshold of $€ 80,000 / Q A L Y$. The analyses yielded more uncertainty surrounding the Thomassen-series compared to the Fanseries, probably due to the small patient group. Using the reported non-compliance with discordant test results, the trend of the mean results remained, although a bit tempered and with higher uncertainty.

The data derived from both datasets have some remaining issues. ${ }^{25}$ For the Thomassen-series ${ }^{15}$, the profiles are performed on one algorithm, thus reducing on one hand the bias of different platforms, but producing on the other hand somewhat lower accuracy for both tests. In addition, hardly any patient has been treated with Tamoxifen, which is an eligibility criteria for the 21-gene assay. This could be in favor of the 70-gene signature. ${ }^{25}$ The data derived from the Fanseries $^{16}$ are based on the profiles which are partly performed on the original dataset of the development of the 70-gene signature, whereas the 21-gene assay is performed on fresh frozen tissue instead of paraffin, which could also suggest that the results were in favor of the 70 -gene signature. ${ }^{25}$ These possible biases were the reason we performed the sensitivity analyses with improved outcome for the 21-gene assay, which showed that when focusing on survival, the 21-gene assay remained cost-effective. However, when focusing on quality adjusted survival, the 70-gene signature remained most cost-effective. We can conclude that this is a main driver for outcomes and that the most ideal design should be a head-to-head prospective trial where both diagnostic tests are being compared in one population. A next step would be to synthesize all available evidence, by using Mixed Treatment Comparison (MTC). MTC allows for indirect comparisons and can therefore provide useful information for clinical and reimbursement decision-making in the absence of head-to-head data. ${ }^{31}$

We incorporated compliance rates from the MINDACT trial pilot. ${ }^{19}$ However, one could dispute whether these compliance rates are reflecting real world compliance as they are based on a randomized setting. Two other published articles, which were used in the sensitivity analysis, were available regarding compliance in a nonrandomized setting. The study of Bueno de Mesquita et al ${ }^{26}$ was the first who published compliance data and based on an early adoption phase trial, in which a suboptimal compliance can be expected upfront. The Lo-series have been commented regarding their way of presenting the compliance rates. ${ }^{32}$ However, both were feasibility studies (no randomization effect) and both were performed in 
the same time span; from 01/2004 till 12/2006 for the Bueno de Mesquita-series ${ }^{26}$ and from $12 / 2005$ till 08/2006 for the Lo-series ${ }^{27}$. The St. Gallen guidelines of 2003 were used in the Thomassen-series, ideally, we should use the more current guidelines of 2009. It would be interesting to take a closer look into the mechanisms behind non-compliance as they are of great influence on the cost effectiveness in daily practice; why do physicians decide whether or not to follow the guideline or the genomic test result? Apparently, it seems that the compliance increases over time as we can see in the MINDACT pilot phase, where the compliance to treatment according to the different categories is much higher $(95 \%) .{ }^{19}$ This issue also appeared to be a driver for outcomes; if a policy decision must be made based on the analyses incorporating compliance, the results using the compliance rates of the feasibility studies show that the results on costeffectiveness are different.

A last driver for policy decision making based on CEA outcomes is the question what is more important; costs per life year, or costs per quality adjusted life years? The measurements of utilities are debated, as it has proven to be difficult to estimate health state utilities, especially among cancer patients. ${ }^{28}$ However, the side effects of for example chemotherapy are impossible to ignore. As the decision on cost-effectiveness is different when only focusing on survival, or taking also the quality of those life years into account, this could cause more uncertainty in the cost/QALY calculations, which we covered with a sensitivity analysis.

In conclusion, the results of the previously performed CEAs all showed that both the 21-gene assay and the 70-gene signature are cost-saving and/or cost-effective strategies as compared to clinicopathological guidelines. However, one has to be careful in such a comparison because of the different settings in the reported trials. This study however, indicates that the CEA performances of the 70-gene signature and the 21-gene assay based on reported studies are close, and that the uncertainty is high. The 70-gene signature seems to have the highest probability to be cost-effective when focusing on cost/QALY, while the 21-gene assay seems to have the highest probability to be cost-effective when focusing on cost/LY. The level of compliance can have serious impact on the cost-effectiveness. With additional data, preferably from head-to-head outcome studies and especially on compliance concerning discordant test results, calculations can be made with higher degrees of certainty. Therefore, it is recommended to invest on knowledge transfer regarding the clinical value of the gene expression profiles.

\section{Acknowledgements}

We would like to thank Prof. dr. E.J.T. Rutgers and Dr. S.C. Linn for their input. 


\section{References}

1. Van 't Veer LJ, Dai H, van de Vijver MJ et al. Gene expression profiling predicts clinical outcome of breast cancer. Nature 2002; 415:530-536.

2. Paik S, Shak S, Tang $\mathrm{G}$ et al. A multigene assay to predict recurrence of tamoxifentreated, node-negative breast cancer. N Engl J Med 2004; 351:2817-2826.

3. Cardoso F, Van't Veer L, Rutgers E et al. Clinical application of the 70-gene profile: the MINDACT trial. J Clin Oncol 2008; 26:729-735.

4. Sparano JA, Paik S. Development of the 21-gene assay and its application in clinical practice and clinical trials. J Clin Oncol 2008; 26:721-728.

5. Ravdin PM, Siminoff LA, Davis GJ et al. Computer program to assist in making decisions about adjuvant therapy for women with early breast cancer. J Clin Oncol 2001; 19:980-991.

6. Goldhirsch A, Ingle JN, Gelber RD et al. Threshold for therapies: highlights of the St. Gallen international expert consensus on the primary therapy of early breast cancer 2009. Ann Oncol 2009; 20:1319-1329.

7. Hornberger J, Cosler LE, Lyman GH. Economic analysis of targeting chemotherapy using a 21-gene RT-PCR assay in lymph-node-negative, estrogen-receptor-positive, early-stage breast cancer. Am J Manag Care 2005; 11:313-324.

8. Lyman GH, Cosler LE, Kuderer NM et al. Impact of a 21-gene RT-PCR assay on treatment decisions in early-stage breast cancer: an economic analysis based on prognostic and predictive validation studies. Cancer 2007; 109:1011-1018.

9. Kondo $\mathrm{M}$, Hoshi SL, Ishiguro $\mathrm{H}$ et al. Economic evaluation of 21-gene reverse transcriptase-polymerase chain reaction assay in lymph-node-negative, estrogenreceptor-positive, early-stage breast cancer in Japan. Breast Cancer Res Treat 2008; 112:175-187.

10. Tsoi DT, Inoue M, Kelly CM et al. Cost-effectiveness analysis of recurrence scoreguided treatment using a 21-gene assay in early breast cancer. Oncologist 2010; 15:457-465.

11. Oestreicher N, Ramsey SD, Linden HM et al. Gene expression profiling and breast cancer care: what are the potential benefits and policy implications? Genet Med 2005; 7:380-389.

12. Retèl VP, Joore MA, Knauer $M$ et al. Cost-effectiveness of the 70-gene signature versus St. Gallen guidelines and Adjuvant Online for early breast cancer. Eur J Cancer 2010; 46:1382-1391.

13. Drummond MF, Sculpher MJ, Torrance GW et al. Methods for the economic evaluation of health care programmes. Oxford: Oxford University Press; 2005.

14. Marchionni L, Wilson RF, Wolff AC et al. Systematic Review: Gene Expression Profiling Assays in Early-Stage Breast Cancer. Ann of Int Med 2008;148:358-369.

15. Thomassen $M$, Tan $Q$, Eiriksdottir $F$ et al. Comparison of Gene Sets for Expression Profiling: Prediction of Metastasis from Low-Malignant Breast Cancer. Clin Cancer Res 2007;13(18):5355-5360.

16. Fan $\mathrm{C}$, Oh DS, Wessels $\mathrm{L}$ et al. Concordance among gene-expression-based predictors for breast cancer. N Engl J Med 2006; 355:560-569.

17. Grutters JPC, Seferina SC, Tjan-Heijnen VCG, et al. Bridging trial and decision: a checklist to frame health technology assessments for resource allocation decisions. Value Health. 2011 Jul-Aug;14(5):777-84.

18. Goldhirsch A, Wood WC, Gelber RD, et al. Meeting highlights: updated international expert consensus on the primary therapy of early breast cancer. J Clin Oncol 2003;21:3357-65. 
19. Rutgers EJT, Piccart-Gebhart MJ, Delaloge S, van 't Veer LJ, Rubio I, Viale G, Bogaerts J. The EORTC 10041/BIG 03-04 MINDACT trial is feasible: first results of the pilot phase. Eur.J Cancer Suppl . 2010.

20. Oostenbrink JB, Koopmanschap MA, Rutten FFH. Handleiding voor kostenonderzoek, methoden en richtlijnprijzen voor economische evaluaties in de gezondheidszorg. 2000. Amstelveen: College voor zorgverzekeringen.

21. Weinstein MC. Recent developments in decision-analytic modeling for economic evaluation. Pharmacoeconomics 2006; 24:1043-1053.

22. Fenwick E, Claxton K, Sculpher M. Representing uncertainty: the role of costeffectiveness acceptability curves. Health Econ 2001; 10:779-787.

23. Raad voor de Volksgezondheid en Zorg: Zinnige en duurzame zorg [Sensible and durable care]. Zoetermeer: Raad voor de Volksgezondheid en Zorg; 2006.(in Dutch)

24. Lothgren $M$, Zethraeus $N$. Definition, interpretation and calculation of costeffectiveness acceptability curves. Health Econ 2000; 9:623-630.

25. Haibe-Kains B, Desmedt C, Piette F et al. Comparison of prognostic gene expression signatures for breast cancer. BMC Genomics 2008; 9:394.

26. Bueno-de-Mesquita JM, van Harten W, Retèl V et al. Use of 70-gene signature to predict prognosis of patients with node-negative breast cancer: a prospective community-based feasibility study (RASTER). The Lancet Oncology 2007; 8:10791087.

27. Lo SS, Mumby PB, Norton J et al. Prospective multicenter study of the impact of the 21-gene recurrence score assay on medical oncologist and patient adjuvant breast cancer treatment selection. J Clin Oncol 2010; 28:1671-1676.

28. Earle CC, Coyle D, Evans WK. Cost-effectiveness analysis in oncology. Ann Oncol 1998; 9:475-482.

29. Tengs TO, Wallace A. One thousand health-related quality-of-life estimates. Med Care 2000; 38:583-637.

30. Goldhirsch A, Ingle JN, Gelber RD et al. Threshold for therapies: highlights of the St. Gallen international expert consensus on the primary therapy of early breast cancer 2009. Ann Oncol 2009; 20:1319-1329.

31. Jansen JP, Crawford B, Bergman G, Stam W. Bayesian Meta-Analysis of Multiple Treatment Comparisons: An Introduction to Mixed Treatment Comparisons. Value in Health 2008;11(5):956-964.

32. Brauchli $P$, Thürlimann $B$, Crowe $S N$, Hermann $R$. What is the Value of the 21-Gene Recurrence Score? J Clin Oncol 2010; 28(32):671-672. 



\section{Chapter 8}

\section{Value of research and value of development in early assessments of new medical technologies}

Valesca P. Retèl Janneke P.C. Grutters

Wim $\mathrm{H}$. van Harten Manuela A. Joore 


\section{Abstract \\ Objectives}

In the early stages of development of new medical technologies, there are conceptually separate but related societal decisions to be made with regard to the adoption, further development, and further research of the new technology. This paper presents a framework to simultaneously support these three decisions from a societal perspective. The framework is applied to the 70-gene signature (70G), a gene expression profile for breast cancer patients. This signature is performed on fresh frozen tissue (70G-FFT), but could be further developed to a paraffin-based signature (70G-PAR).

\section{Methods}

A Markov decision model comparing 70G-FFT, 70G-PAR and a clinical guideline Adjuvant Online was used to simulate 20-year costs and outcomes in a hypothetical cohort of early breast cancer patients. The 70G-PAR strategy was based on projected data from a comparable technology. First, incremental Net Monetary Benefits (NMBs) were calculated to support the adoption decision. Second, the expected net benefit of development (ENBD) and expected net benefit of sampling (ENBS) were calculated.

\section{Results}

The 70G-PAR had the highest NMB, followed by the 70G-FFT. The ENBD amounted to $€ 110$ million (assuming $€ 20$ million development costs). The ENBS amounted to $€ 21$ million for the optimal sample size of a $N=3,000$ trial.

\section{Conclusions}

We presented a feasible framework to simultaneously support adoption, development and research decisions in early stages of the development of medical technologies. In the case of the 70-gene signature, the results indicate that there is both value in the further development of the 70G-FFT into a paraffin based test and value in further research into this improved test. 


\section{Introduction}

In a budget-constrained health care system an analytical framework can be used to inform two separate but related decisions: whether a technology is cost-effective and thus should be adopted (I), and whether existing uncertainty warrants more research to support this decision (II). ${ }^{1}$ In early stages of the development of a new health care technology uncertainty levels are likely to be high. Moreover, often still several options concerning the further development of the technology exist. Therefore, an additional decision could be added: is there value in investing in the further development of the new technology (III)?

An example of an innovative technology in its early stages of development is the 70-gene prognosis signature (MammaPrint ${ }^{\mathrm{TM}}$ ), using micro-array analysis for breast cancer patients. ${ }^{2}$ Using the 70-gene signature, the selection of patients that will benefit most from chemotherapy could be more accurate, which reduces unnecessary treatment. The promising results of three retrospective validation studies $^{3-5}$ led to a prospective feasibility study (RASTER: MicroarRAy PrognoSTics in Breast CancER) from 2004 until $2006^{6}$, followed by a currently ongoing prospective, randomized clinical trial (MINDACT: Microarray In Node-negative and 1 to 3 positive lymph node Disease may Avoid ChemoTherapy) that started in $2007 .^{7}$ A recent cost-effectiveness analysis showed that the 70 -gene signature is cost-effective compared to clinical guidelines, based on the promising retrospective validation results. ${ }^{8}$ In this early stage, the technology is not yet stable and still many opportunities are available to improve the test. The feasibility study was designed to investigate the technical and organizational implementation of the 70gene signature in daily practice. It is for instance essential to collect good-quality breast tumor Ribonucleic acid (RNA) in fresh frozen tissue (FFT). However, in most hospitals as a routine, tumor samples are directly fixed in formalin and embedded in paraffin blocks. In a scenario study, the necessity to use FFT to obtain the 70gene signature was identified as a disadvantage. ${ }^{9}$ It was anticipated that the use of FFT would result in a higher percentage of failures. A solution to improve the test would be the further development of the 70-gene signature for use on paraffin blocks. However, at this point it is unclear whether it is valuable to invest in such a development.

Recently, three studies were published focusing on early-stage economic models for medical products while acknowledging the uncertainties concerning technology dynamics inherent in such a modeling enterprise. ${ }^{10-12}$ Girling et al. ${ }^{10}$ presented a method for valuing a new medical technology at the concept stage from the perspective of manufacturers, while Vallejo-Torres et al. ${ }^{11}$ and Garrison et al. ${ }^{12}$ used an iterative approach of decision analyses by integrating health economic modeling in the product development cycle. To our knowledge, the three integrated 
proposed decisions (adoption, further research and further development) have not yet been addressed simultaneously in one study.

Furthermore, the application of the societal perspective for both decisions has not yet been used. From a manufacturer's perspective an innovation should be profitable, while from a funder's perspective an innovation should lead to additional value in the form of net health benefits. In a health care market, patients (consumers) and doctors (their agents) are not very well placed to assess the value of a new technology, based on a synthesis of all available evidence. Therefore, in our opinion, a healthcare funder has the responsibility to assess and signal the value of health innovations on behalf of the population, especially as the manufacturer may decide to add the additional costs to the price. ${ }^{13}$ Under the principle of value based pricing, a societal perspective to assess the value of innovation is appropriate. It informs both the health care funder and the manufacturer on the value of innovation, and thus the maximum budget and price, given a certain threshold per QALY.

The present study adds to the existing knowledge by proposing a framework that simultaneously informs three separate but related decisions: (I) the adoption, (II) further development, and (III) further research. In this paper we applied the framework to address these three decisions for the 70-gene signature in early breast cancer.

\section{Methods}

\section{Analytical framework}

The analytical framework consists of three decisions (adoption, development, research) and is presented in Figure 1. The methodology for answering each of the questions is described below.

\section{Adoption decision}

The adoption decision depends on the expected Net Monetary Benefit (NMB). The expected NMB is calculated by multiplying the effect $(E)$ by the value of a single unit of effect $(\lambda)$ minus the costs $(C)$ :

$$
N M B=E * \lambda-C
$$

The technology with the highest expected NMB is cost-effective. ${ }^{14}$ Alternatively, a technology is cost-effective when it has a positive incremental NMB (iNMB) compared to the alternative technologies. 


\section{Development decision}

The development decision depends also on the expected NMB. To obtain the expected net benefit of development (ENBD), the iNMB of the improved version versus the next best alternative has to be decreased by the development costs. If the ENBD is positive, there is value in development.

$$
E N B D=(i N M B-D) * P
$$

The uncertainty surrounding the NMBs (and ENBD) was determined using the simulation results. Uncertainty in the input parameters was handled probabilistically, by assigning distributions to parameters. Subsequently, parameter values were drawn at random from the assigned distributions, using Monte Carlo simulation with 1000 iterations. In each of the iterations, the ENBD can be estimated. The probability of a positive ENBD is then equivalent to the proportion of the iterations for which the ENBD is positive. Also, confidence intervals can be calculated based on the simulation results.

\section{Research decision}

The decision regarding further research depends on the degree of decision uncertainty and the effective population. Generating more information through research is valuable when there is considerable uncertainty surrounding a decision and when that decision is likely to affect the health of a large number of people in a meaningful way. The value of generating more information is known as the expected value of perfect information (EVPI). ${ }^{15}$ The EVPI can be interpreted as the maximum amount society would be willing to spend to obtain perfect information. ${ }^{16}$ If there are $j$ alternative interventions, with unknown parameters $\theta$, the EVPI is the difference between the expected value of the decision made with perfect information about the uncertain parameters $\theta$, and the decision made on the basis of existing evidence. ${ }^{15}$ The EVPPI combines the importance of a parameter and its uncertainty.

$$
E V P I=\left(E_{\theta} \max _{j} N B(j, \theta)-\max _{j} E_{\theta} N B(j, \theta)\right) * P
$$

Furthermore, in order to identify the most valuable factor for further research, a parameter-specific or partial EVPI (EVPPI) can be calculated. The EVPPI combines the importance of a parameter and its uncertainty. First the simulation has to be calculated for the parameters $\Psi$ but with a particular value of $\varphi$ (an inner loop), then sample a new value of $\varphi$ (an outer loop) and rerun the simulation. This must be repeated until sufficient samples are taken from the distribution of $\varphi .^{15}$ 


$$
E V P P I_{\varphi}=\left(E_{\varphi} \max _{j} E_{\psi \mid \varphi} N B(j, \varphi, \psi)-\max _{j} E_{\theta} N B(j, \theta)\right) * P
$$

The EVPI analysis can be extended to establish the expected value of sample information (EVSI) for a sample of $n$ for particular research designs. Using EVSI analyses one can calculate the optimal sample size and/or design of a trial. The EVSI is the difference between the EVPI before the trial (bt) and after the trial (at). ${ }^{17}$

For each trial design, for example for trials with different sample sizes, the remaining costs of uncertainty are calculated. This requires an estimate of the outcome of the future trial. However, we do not know the actual results of a trial in advance. Therefore, EVSI is calculated for all possible outcomes of a trial design, and these are averaged to elicit an expected EVSI for this trial design. ${ }^{18}$

$$
E V S I=E V P I_{b t}-E V P I_{a t}
$$

Finally, the expected net benefit of sampling (ENBS) can be calculated by extracting the trial costs $(\mathrm{Cn})$ from the EVSI. ${ }^{19} \mathrm{Cn}$ is calculated by multiplying the trial costs per patient by the sample size (n). If the ENBS is positive, there is value in performing the research.

$$
E N B S=E V S I-C n
$$

A more detailed description of calculating the EVP(P)I, EVSI and ENBS can be found in Briggs et al. ${ }^{18}$

\section{Case Description}

Previously, a Markov decision model was developed to assess the effects (quality adjusted life years; QALYs), costs and cost-effectiveness of the 70-gene signature performed on fresh frozen tissue (70G-FFT) as compared to the clinical guideline Adjuvant! Online software ${ }^{20}(\mathrm{AO})$ in patients with early, node-negative, estrogen receptor positive breast cancer patients. In each strategy, based on the sensitivity and specificity of the prognostic test, patients were classified as having a true low, true high, false low, or false high risk of developing metastasis. The sensitivity and specificity of each prognostic test were calculated from a dataset consisting of 3 previously reported validation studies. ${ }^{3-5}$ From this database, a total of 305 untreated, node negative and ER-positive tumor samples were selected and classified by the 70-gene signature and the clinical pathological guidelines as low or high risk of developing distant metastasis. The high risk patients receive hormonal therapy and chemotherapy, low risk patients only hormonal therapy. The model simulated the course of events in a hypothetical cohort of 5000 patients 
aged 50 years. The calculations were performed per year, with a total simulated time horizon of 20 years. Uncertainty in the parameters was handled probabilistically, by assigning distributions. ${ }^{21}$ Parameter values were drawn at random from the assigned distributions; using Monte Carlo simulation with 5000 iterations. ${ }^{22}$ We programmed the model in Microsoft Excel (Microsoft, Redmond, WA). For details of the model see Retèl et al. ${ }^{8}$

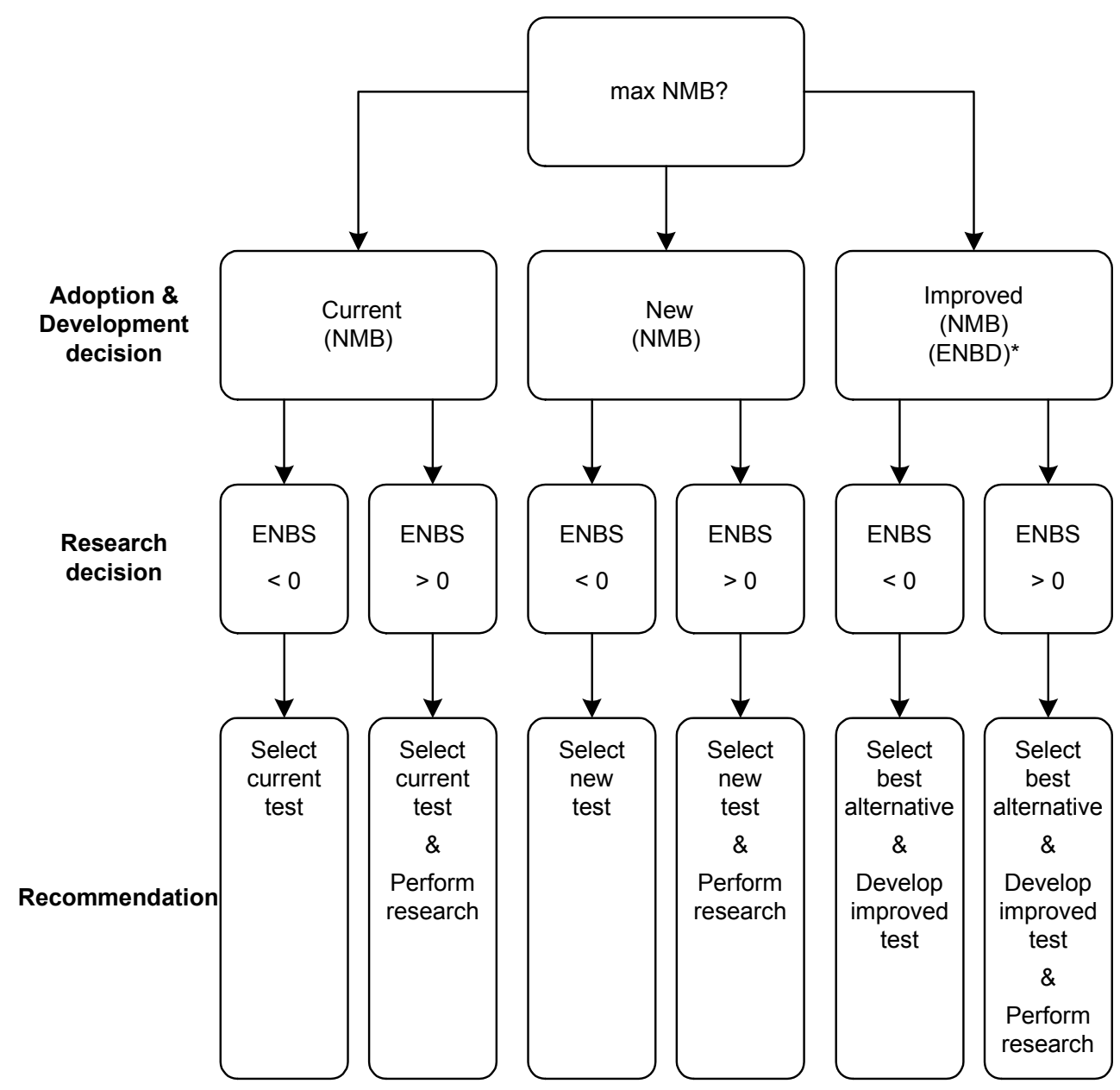

Figure 1. Analytical framework

NMB: Net Monetary Benefit, ENBD: expected net benefit of development, ENBS: expected net benefit of sampling 


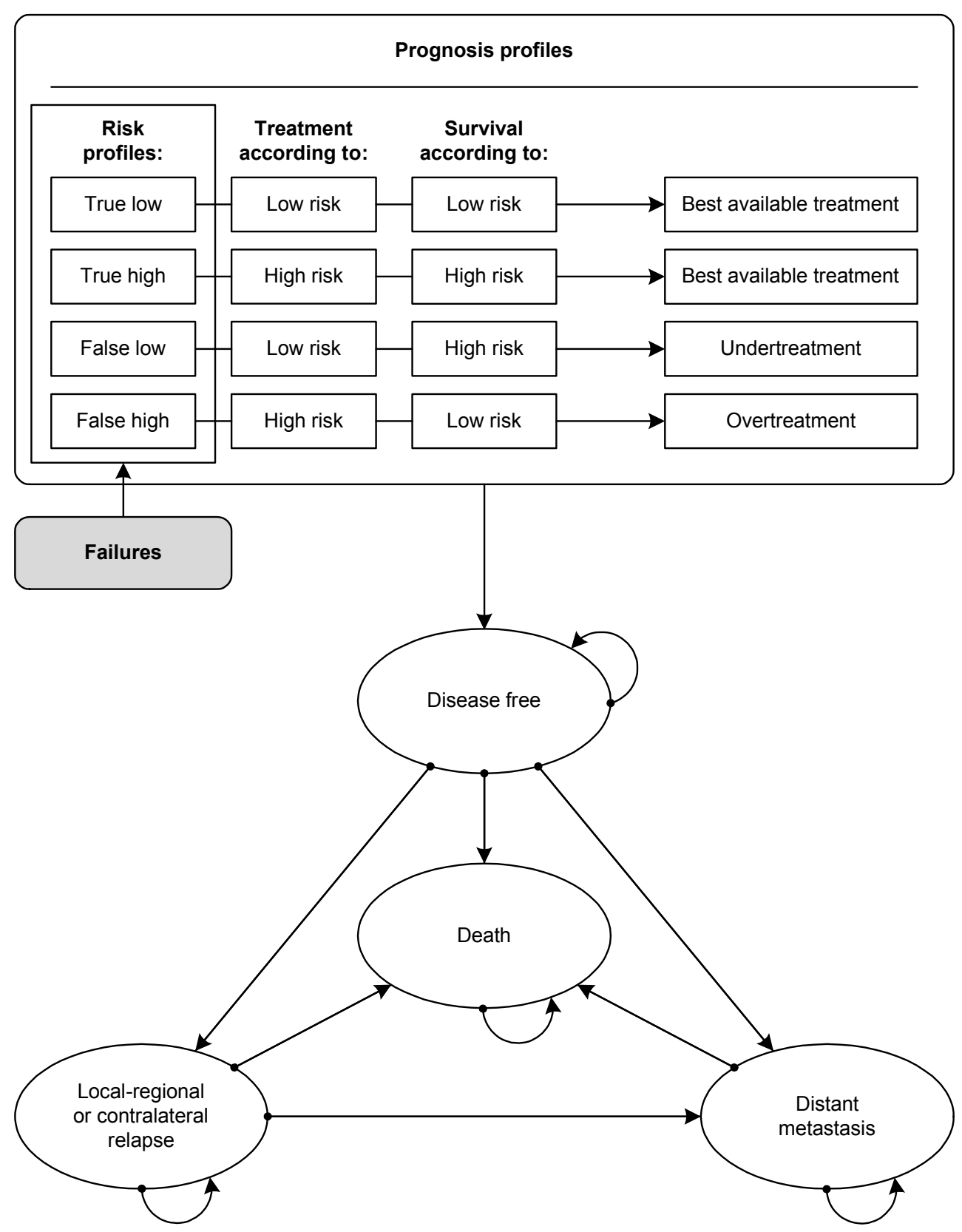

Figure 2. Model structure 
For the purpose of the current study, a strategy was added to the above described model: the improved 70-gene signature performed on paraffin blocks (70G-PAR). It was assumed that this, not yet available, strategy would resemble the 70G-FFT, except for the proportion of failures and its costs. Therefore, a "failure" parameter was added to the model. In case of a technical failure, it was assumed and modeled that the costs of the 70 -gene signature were made for $10 \%$ of the total costs and the final treatment advice was decided according to the clinical guideline (AO). The failure rate of the 70G-FFT was based on the RASTER-study. The mean failure rate was $27 \%$, calculated with a beta distribution using an alpha of 158 and beta of 427 , SE of $2 \%$. These failures include: insufficient RNA quality $(9 \%)$, less than $50 \%$ tumor cells in the sample $(47 \%)$, tumor too small for biopsy $(25 \%), 1$ sample lost in mail, 1 sample more than 5 days in the RNA-later (RNA preservation fluid; name has since changed to RNARetain; Asuragen, Austin, TX, USA) and 28 samples $(18 \%)$ were already prepared in formalin. ${ }^{6}$ The failure rate of the 70G-PAR was based on a published study performed on the 21-gene assay, which is a paraffin based gene expression profile for the same patient group. ${ }^{23}$ The mean failure rate of the 70G-PAR was $8 \%$, with a range from $0-27 \%$, using a beta pert distribution (the beta pert distribution emphasizes the "most likely" value over the minimum and maximum estimates, it allows the user to vary the degree of peakedness of the distribution within the constraints of the minimum, most likely and maximum values of the standard PERT distribution). Both failure rates of the 70-gene signature and the 21-gene assay were incorporated in the model as stochastic parameters. It was assumed that no failures occurred in the AO strategy. The mean costs per patient of the 70G-PAR were assumed to amount to the costs of the 70G-FFT test increased with the costs of the development of the 70G-PAR. The development costs of the 70G-PAR were based on expert opinion and assumed to be $€ 200$ per patient (range $€ 100-500$, uniform distribution). To inform the decisions, we integrally compared the iNMBs of the 70G-FFT, the 70G-PAR, and the AO. To calculate the (incremental) NMBs we used a threshold of $€ 30,000 / Q A L Y$ (which resembles the $£ 20,000-30,000 / Q A L Y$ threshold used by the National Institute for Health and Clinical Excellence (NICE) in the United Kingdom $^{24}$ ), for all calculations, if not stated otherwise. As a sensitivity analysis, the ENBD was calculated for a credibility interval of possible development costs for the 70G-PAR: from $€ 10$ to $€ 50$ million ( $€ 100-500$ per patient), with the base case of $€ 20$ million (€200 per patient). To calculate the value of research (III), we assumed the trial costs to be $€ 1000$ per patient (based on the MINDACT trial). ${ }^{7,25}$ Based on the annual incidence of 12,500 early breast cancer patients in the Netherlands ${ }^{26}$, the effective population $(P)$ was assumed to be 105,442 (discounted by $1.5 \%$ over 20 years). We choose the annual incidence of the Netherlands, because this can be seen as a representative group, as the validation series of the 70-gene signature were first performed on the Dutch population. Further validation series 
also included other EU countries, thus this population could be broader generalized.

\section{Sensitivity analyses}

In addition, we performed two one-way sensitivity analyses, using different scenarios. Firstly, we used the cost and utility discount rates (both 3,5\%) advised by the National Institute for Health and Clinical Excellence (NICE) 2008. ${ }^{27}$ Secondly, we incorporated an effective population of 2,4 million, based on the EU breast cancer incidence of 289,000 in $2008^{28}$, to show the generalizability to a larger population.

\section{Results}

\section{Adoption decision}

The total expected costs per patient over 20 years were $€ 27,956$ for the 70G-PAR, $€ 27,740$ for the 70G-FFT and $€ 26,915$ for the AO. The 70G-PAR yielded 12.42 QALYs, 70G-FFT 12.37 QALYs, and AO 12.20 QALYs. The NMB of 70G-PAR amounted to $€ 344,670$, for the $70 G-F F T$ to $€ 343,481$, and $€ 338,942$ for the $A O$ (Table 1). As it had the highest NMB, 70G-PAR was found to be cost-effective.

Table 1. Incremental cost-effectiveness results

\begin{tabular}{|c|c|c|c|c|c|c|c|c|}
\hline \multicolumn{2}{|c|}{ Strategy } & \multicolumn{2}{|c|}{ Results } & \multirow[b]{2}{*}{ Vs } & \multicolumn{4}{|c|}{ Incremental results } \\
\hline & $\begin{array}{l}\text { QALY } \\
\text { (Cl) }\end{array}$ & $\begin{array}{l}\text { Costs } \\
\text { (Cl) }\end{array}$ & $\mathrm{NMB}^{1}$ & & $\begin{array}{l}\text { QALY } \\
\text { (CI) }\end{array}$ & $\begin{array}{l}\text { Costs } \\
\text { (Cl) }\end{array}$ & CE-ratio & $\mathrm{NMB}^{1}$ \\
\hline $\begin{array}{c}70 G \\
- \\
\text { PAR }\end{array}$ & $\begin{array}{c}12.42 \\
(12.05 \text { to } \\
13.85)\end{array}$ & $\begin{array}{c}€ 27,976 \\
(23,544 \text { to } \\
33,758)\end{array}$ & $€ 344,650$ & & & & & \\
\hline $\begin{array}{c}70 G \\
- \\
\text { FFT }\end{array}$ & $\begin{array}{c}12.37 \\
(12.01 \text { to } \\
13.79)\end{array}$ & $\begin{array}{c}€ 27,810 \\
(23,495 \text { to } \\
33,440)\end{array}$ & $€ 343,412$ & $\begin{array}{l}\text { 70G- } \\
\text { PAR }\end{array}$ & $\begin{array}{c}0.05 \\
(-0.02 \\
\text { to } 0.11)\end{array}$ & $\begin{array}{c}€ 167 \\
(-425 \text { to } \\
780)\end{array}$ & $€ 3,564$ & $€ 1,237$ \\
\hline $\mathrm{AO}$ & $\begin{array}{c}12.20 \\
(11.80 \text { to } \\
13.64)\end{array}$ & $\begin{array}{c}€ 26,915 \\
(22,285 \text { to } \\
32,793)\end{array}$ & $€ 338,943$ & $\begin{array}{l}\text { 70G- } \\
\text { PAR }\end{array}$ & $\begin{array}{c}0.23 \\
(-0.09 \\
\text { to } 0.49)\end{array}$ & $\begin{array}{c}€ 1,061 \\
(-1,766 \\
\text { to } 3,901)\end{array}$ & $€ 4,704$ & $€ 5,707$ \\
\hline
\end{tabular}

${ }^{1}$ Based on a threshold of $€ 30,000$, original costs and QALYs before rounding (Cl: confidence interval, vs: versus), 70G-PAR: paraffine, 70G-FFT: fresh frozen tissue, NMB: net monetary benefit, Vs: versus, CE-ratio: cost-effectiveness ratio. 


\section{Development decision}

The iNMB of 70G-PAR versus 70G-FFT amounted to $€ 1,237$ (Table 1). The iNMB multiplied by the effective population $(P)$ gives us the maximal ENBD: $€ 130$ million (assuming development costs are zero). When further development of the 70-gene signature requires extra investment costs; the ENBD decreases (Figure 2). In our case the development costs were assumed to be $€ 20$ million, wherein the iNMB and ENBD amounted to $€ 1,037$ and to $€ 110$ million, respectively. If we assumed $€ 50$ million development costs, the iNMB was $€ 737$, and the ENBD $€ 80$ million. The probability that the ENBD was positive ranged from 0.89 ( $€ 10$ million development costs) to 0.88 ( $€ 20$ million development costs) and finally 0.81 ( $€ 50$ million development costs) (Figure 2).

\section{Research decision}

Taking into account a ceiling ratio of $€ 30,000 / Q A L Y$, the probability of 70G-PAR being cost-effective is $67 \%$. The population EVPI amounted to $€ 72$ million (based on 50,000 simulations). The EVPPI for test validity (including sensitivity and specificity) was $€ 65$ million, while for the other parameters the EVPPI was negligible (based on 2000 loops and 200 trials, taking around 1200 minutes on a Core i5 computer). Therefore, it was deemed valuable to perform a randomized clinical trial comparing the test validity of the 70-gene signature strategies versus the AO strategy. In this trial, it is assumed that discordant cases $(30 \%)$ are randomized to either the 70-gene signature or $\mathrm{AO}^{29}$ To calculate the EVSI the possible outcomes (sensitivity and specificity) of the future trial were drawn from a predictive distribution based on the data available before the trial. For each sample size, for 600 possible trial results the Monte Carlo simulation was run to calculate the corresponding EVSI. Subsequently, these $600 * 5000 \mathrm{EVSI}$ estimates were averaged to obtain an expected EVSI for that sample size. Figure 3 shows that the optimal sample size of this trial was around $\mathrm{N}=3,000$, with an EVSI of $€ 24$ million. The total trial costs are then 3 million, resulting in an ENBS of €21 million. A summary of the results is depicted in the rational framework in Figure 4.

\section{Sensitivity Analyses}

For the first sensitivity analysis regarding discount rates of $3.5 \%$, the iNMB amounted to $€ 949$. The second sensitivity analysis concerning an increased effective population had the largest impact on the EVPI which amounted up to $€ 1,7$ billion, a maximum ENBD of $€ 3$ billion, and an EVSI of $€ 642$ million. 


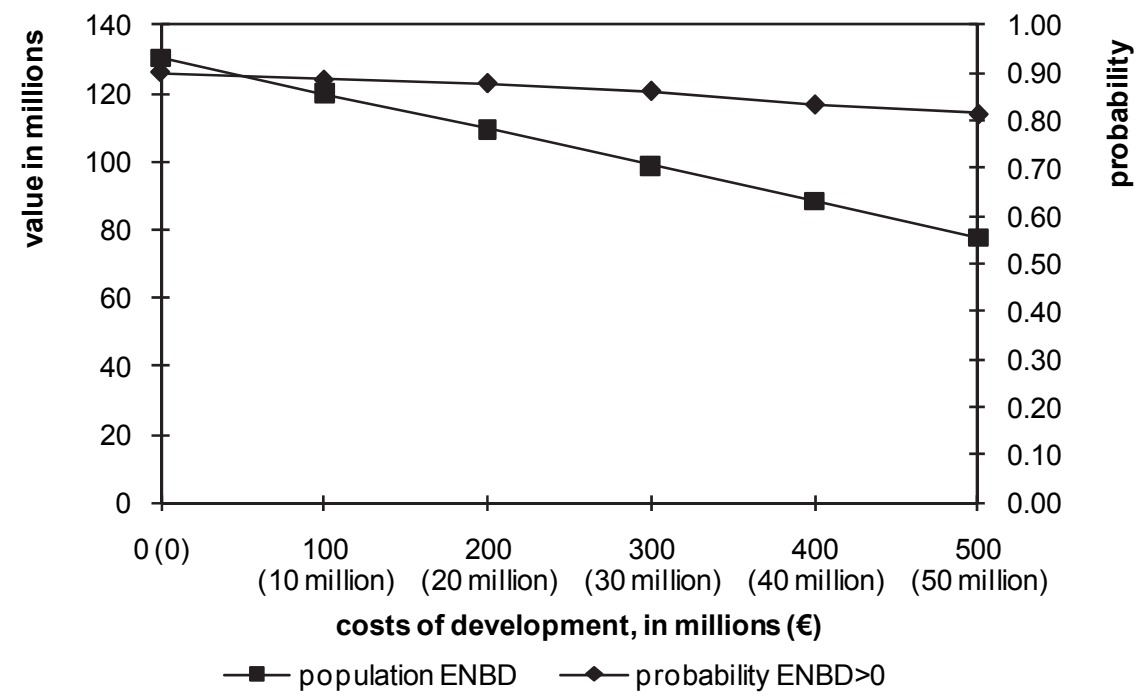

Figure 2. Expected Net Benefit of Development (ENBD) and associated uncertainty Uncertainty surrounding the expected net benefit of development (ENBD) on the z-axes, Value of development in million on the $y$-axes and costs of development per patient (population) on the $x$-axes for a threshold of $€ 30,000 / Q A L Y$.

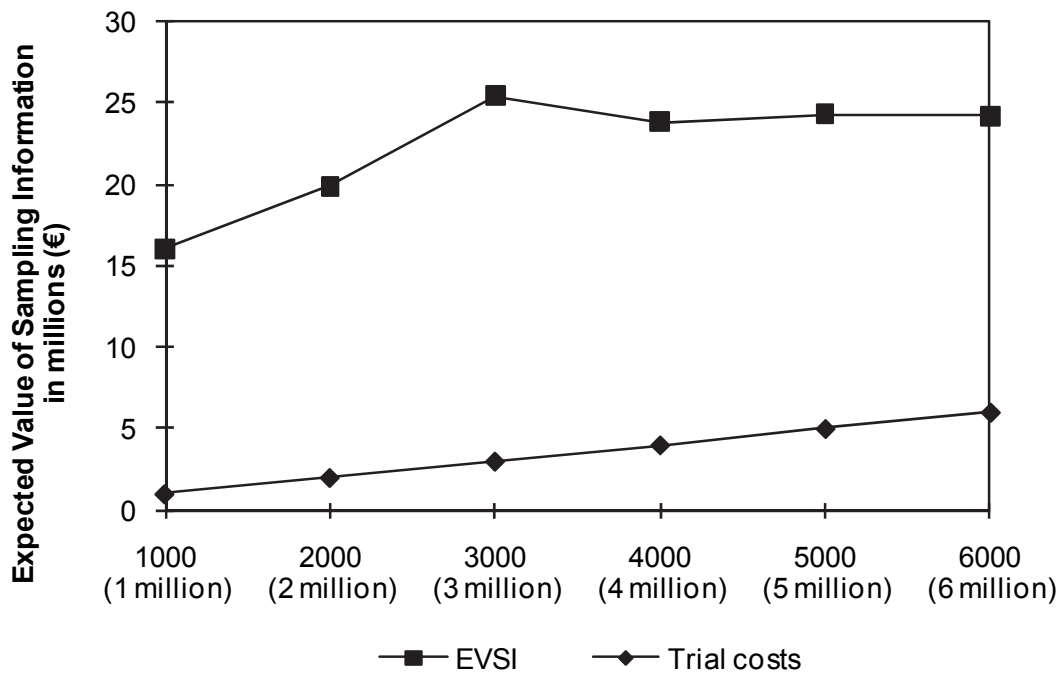

Figure 3: Expected Value of Sampling Information (EVSI) and trial costs for a range of sample sizes The EVSI in millions on the $y$-axes for the different sample sizes on the $x$-axes 


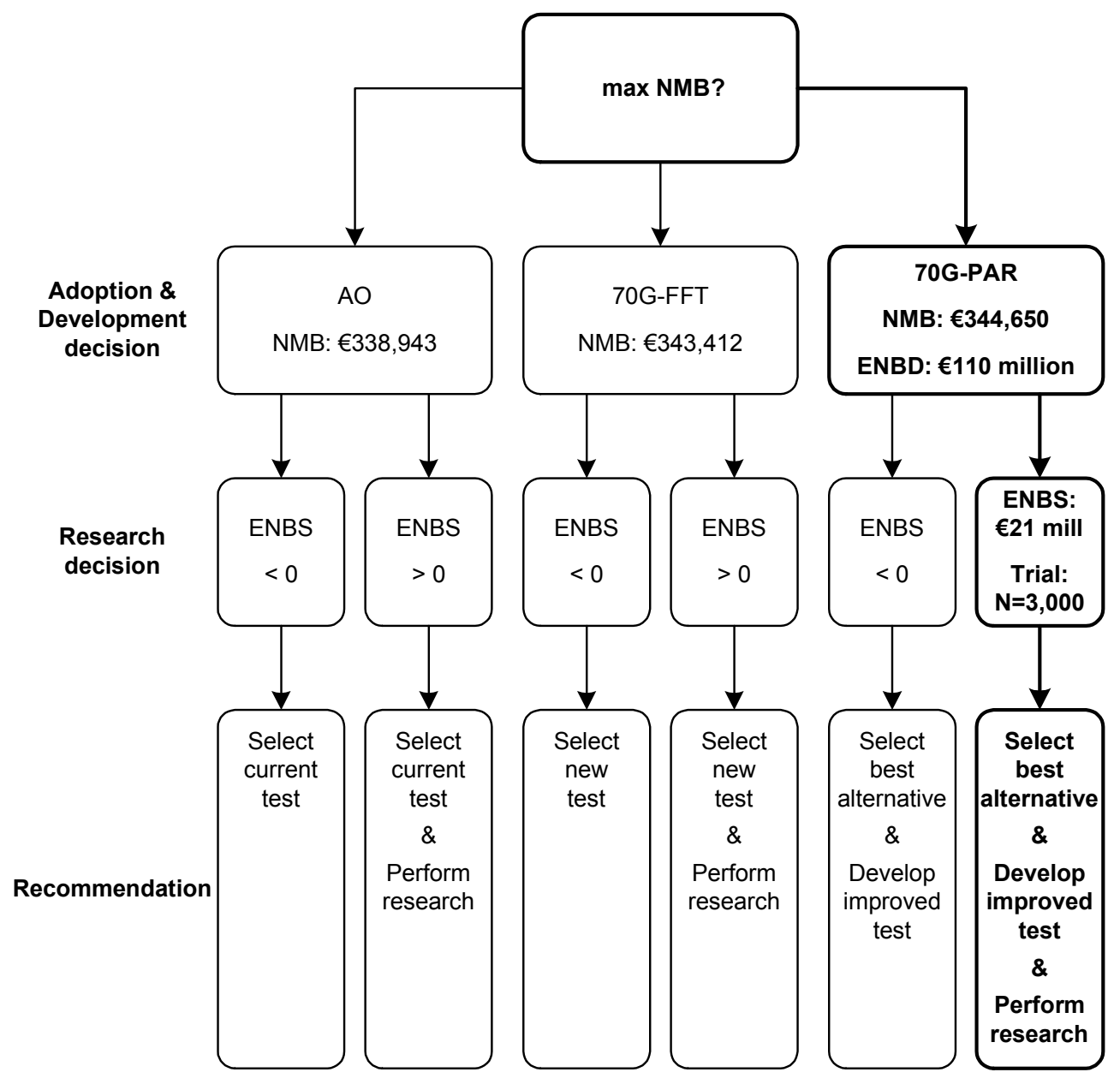

Figure 4. Applied framework

NMB: Net Monetary Benefit, ENBD: expected net benefit of development, ENBS: expected net benefit of sampling

\section{Discussion}

This paper presented a framework to simultaneously address decisions with regard to the adoption (I), further development (II), and further research (III) of a new, still dynamic, technology in an early stage of diffusion. The framework is applied to the 70-gene signature, a gene expression profile for breast cancer patients.

The results show that in this case the improved technology, 70G-PAR, is costeffective compared to the current technology, 70G-FFT, and standard care (AO). 
The ENBD (II) was positive and amounted to $€ 110$ million ( $€ 130$ million minus an investment of $€ 20$ million), and the ENBS (III) was also positive and amounted to $€ 21$ million ( $€ 24$ million minus an investment of $€ 3$ million). This indicates that there is both value in the further development of the 70G-FFT into a paraffin based test; the 70G-PAR, and value in further research into the test validity of this improved test. In this specific case, the uncertainty around the development costs did not have much impact on the EVPI results.

The value of development was obviously sensitive for changes in the development costs. Also, the results showed considerable uncertainty around the adoption decision. This resulted in high values of EVPI. A trial with 3,000 patients would yield the maximum ENBS of $€ 21$ million. Actually this further research currently takes place in the MINDACT trial $(N=6,000)$ where the discordant cases $(30 \%)$ are randomized to receiving chemotherapy or not. ${ }^{29}$ The suggested framework draws on a probabilistic decision analytical model, which can be considered standard practice to inform the adoption and research allocation decisions. In the 70G case a still to be developed paraffin based test, which was likely to yield an advantage in terms of the number of failures, was integrated in the analysis. The 'failure' parameter could be incorporated into the decision model relatively easy. In other cases, adapting the model structure may be more complicated. In our case, the improved outcome of the product had impact on the failure rate. However, any parameter could be altered or added to a decision model to reflect an improved version of the technology. For example, the improved product could have better efficacy, or fewer side effects. Also, we modeled only one direction of further development, because for this case this was the most realistic option. However, in reality, several directions for further development may be indicated instead of just one. The identification of directions of development may be based on quantifiable diffusion scenarios. ${ }^{9}$ In our case, evidence was available to obtain an estimate of the added parameter. However, for other cases it may be more complicated to anticipate on the possible advantages and disadvantages of a possible future development of the technology. Moreover, evidence to estimate parameters for the technology after further development may be lacking. This may force researchers to use expert opinion. Recently, Bojke et al. described a method to obtain expert elicitation and to use this by parameterizing the information, including the existing uncertainty, directly into the model. ${ }^{30}$ One could also first diminish the uncertainty around the added parameters. In our case, uncertainty was mainly associated with adoption of 70-FFT, the uncertainty of 70G-PAR versus 70G-FFT was nil. It could also be the case that the cost-effectiveness of the 70-FFT versus 70G-PAR is uncertain. In this case it is valuable to calculate the value of research for further development of the technology first, before considering investment in further development. A next question that could be answered is how a fixed budget for research and development should be allocated over different activities aimed at 
either further development or further research. To solve this issue, portfolio management, based on return on investment calculations, could be used. ${ }^{31}$ An additional question is whether we should wait for new evidence before further development. This question could be informed by a Real Options Analysis (ROA). ${ }^{32}$ ROA stems from financial literature, but was recently introduced as an addition to the value of information framework.$^{32}$ Its advantage is that it does not only consider whether the benefits of a technology outweigh its costs (as in costeffectiveness analyses), but that it also recognizes the option to postpone adoption or development of the technology. It can then assist the tradeoff between adopting a new technology and waiting for more evidence. Similarly, ROA could inform the tradeoff between developing a new technology and waiting for more evidence. Both portfolio management and ROA were beyond the scope of this paper but are an important area for further research. Both portfolio management and ROA were beyond the scope of this paper but are an important area for further research. Previously, publications focused on the evaluation of technologies early in the product life cycle. ${ }^{10-12}$ They focused on the dynamic nature of the technology under investigation, indicating the need for iterative assessments. Garrison et al. ${ }^{12}$ is highlighting the linkage between the concept of economic value in cancer care and the incentives for innovation. In this study, the key point is that value is also a dynamic and moving target, which is often not taken into account. Girling et al. ${ }^{10}$ developed a framework for valuing new medical devices at the concept stage that balances benefit to the health care provider against commercial costs. They conclude that quantifiable uncertainty that can be resolved before the device is brought into the market will generally enhance early-stage valuations of the device, and that this remains true even when some components of uncertainty cannot be fully described. Both papers adopt a perspective from the manufacturer and focus on technology development alone. None of these studies simultaneously address the value of research and the value of development from a societal perspective. In the societal perspective the effects and costs are considered regardless of who experiences the benefits or pays the costs. Our study was performed from a societal perspective. In our opinion, a health care funder has the responsibility to assess and signal the value of health innovations on behalf of the population. Under the principle of value based pricing, a societal perspective informs both the health care funder and the manufacturer on the value of innovation, and thus the maximum budget and price; given a certain threshold per QALY. ${ }^{13}$ Obviously it is the manufacturers decision whether or not to actually incorporate the additional costs in the products price.

The approach presented in this paper can be used to inform three conceptually separate but related questions: (I) what is the value of adoption? (II) what is the value of further development?, and (III) what is the value of research? This approach can support investment decisions in early stages of technology life cycle. 


\section{References}

1. Claxton K, Sculpher M, Drummond M. A rational framework for decision making by the National Institute For Clinical Excellence (NICE). Lancet 2002; 360:711-715.

2. van 't Veer LJ, Dai $H$, van de Vijver MJ et al. Gene expression profiling predicts clinical outcome of breast cancer. Nature 2002; 415:530-536.

3. van de Vijver MJ, He YD, van 't Veer LJ et al. A Gene-Expression Signature as a Predictor of Survival in Breast Cancer. N Engl J Med 2002; 347:1999-2009.

4. Buyse M, Loi S, van't Veer $L$ et al. Validation and Clinical Utility of a 70-Gene Prognostic Signature for Women With Node-Negative Breast Cancer. J Natl Cancer Inst 2006; 98:1183-92.

5. Bueno-de-Mesquita JM, Linn SC, Keijzer R et al. Validation of 70-gene prognosis signature in node-negative breast cancer. Breast Cancer Res Treat 2009; 117:483495.

6. Bueno-de-Mesquita JM, van Harten W, Retel V et al. Use of 70-gene signature to predict prognosis of patients with node-negative breast cancer: a prospective community-based feasibility study (RASTER). The Lancet Oncology 2007; 8:10791087.

7. Cardoso F, Van't Veer L, Rutgers $E$ et al. Clinical application of the 70-gene profile: the MINDACT trial. J Clin Oncol 2008; 26:729-735.

8. Retèl VP, Joore MA, Knauer M et al. Cost-effectiveness of the 70-gene signature versus St. Gallen guidelines and Adjuvant Online for early breast cancer. Eur J Cancer 2010; 46:1382-91.

9. Retèl VP, Joore MA, and van Harten WH. Scenario drafting as a tool to perform early cost-effectiveness analysis: the case of the 70-gene signature in breast cancer. International Health Economic Association, Beijing, China. 2009.

10. Girling A, Young T, Brown $C$ et al. Early-stage valuation of medical devices: the role of developmental uncertainty. Value Health 2010; 13:585-591.

11. Vallejo-Torres L, Steuten LM, Buxton MJ et al. Integrating health economics modeling in the product development cycle of medical devices: a Bayesian approach. Int $\mathrm{J}$ Technol Assess Health Care 2008; 24:459-464.

12. Garrison LP, Jr. Rewarding value creation to promote innovation in oncology: The importance of considering the global product life cycle. Oncologist 2010; 15 Suppl 1:49-57.

13. Claxton $\mathrm{K}$, Briggs $\mathrm{A}$, Buxton $\mathrm{MJ}$ et al. Value based pricing for NHS drugs: an opportunity not to be missed? BMJ 2008;336: 251-254.

14. Buxton, M. J. 2006. "Economic Evaluation and Decision Making in the UK." Pharmacoeconomics 24 (11): 1133-42.

15. Briggs A, Claxton K, Sculpher M. Decision Modelling for Health Economic Evaluation. Chapter 6; Decision-making, uncertainty and the value of information. Oxford University Press 2006, ISBN 0-19-852662-8.

16. Claxton K, Cohen JT, Neumann PJ. When is evidence sufficient? Health Aff (Millwood) 2005; 24:93-101.

17. Willan AR, Pinto EM. The value of information and optimal clinical trial design. Stat Med 2005; 24:1791-1806.

18. Briggs A, Claxton K, Sculpher M. Decision Modelling for Health Economic Evaluation. Chapter 7; Efficient research design. Oxford University Press 2006, ISBN 0-19852662-8.

19. Claxton $\mathrm{K}$ and Posnett $\mathrm{J}$. An economic approach to clinical trial design and research priority-setting. Health Economics 1996;(5): 513-524. 
20. Ravdin PM, Siminoff LA, Davis GJ et al. Computer program to assist in making decisions about adjuvant therapy for women with early breast cancer. J Clin Oncol 2001; 19:980-991.

21. Weinstein MC. Recent developments in decision-analytic modelling for economic evaluation. Pharmacoeconomics 2006; 24:1043-1053.

22. Fenwick E, Claxton K, Sculpher M. Representing uncertainty: the role of costeffectiveness acceptability curves. Health Econ 2001; 10:779-787.

23. Sparano JA, Paik S. Development of the 21-gene assay and its application in clinical practice and clinical trials. J Clin Oncol 2008; 26:721-728.

24. Lothgren $M$, Zethraeus $N$. Definition, interpretation and calculation of costeffectiveness acceptability curves. Health Econ 2000; 9:623-630.

25. Frantz S. New \& Analysis, Nature Reviews Drug discovery 2005; 4(5): 363.

26. Dutch Comprehensive Cancer Centres, 2007 www.IKCnet.nl, http://www.ikcnet.nl/uploaded/docs/Landelijk/cijfers/incidentie\%202007/AO1_NL.xls .

27. NICE 2008, Guide to the Methods of Technology Appraisal (June 2008), National Institute for Health and Clinical Excellence, London, UK. Available at www.nice.org.uk

28. Ferlay J, Shin HR, Bray F, et al. GLOBOCAN 2008 v1.2, Cancer Incidence and Mortality Worldwide: IARC CancerBase No. 10 [Internet] Lyon, France: International Agency for Research on Cancer; 2010. Available from: http://globocan.iarc.fr

29. Rutgers EJT, Piccart-Gebhart MJ, Delaloge S, van 't Veer LJ, Rubio I, Viale G, Bogaerts J. The EORTC 10041/BIG 03-04 MINDACT trial is feasible: first results of the pilot phase. Eur.J Cancer Suppl . 2010.

30. Bojke L, Claxton K, Bravo-Vergel $Y$ et al. Eliciting distributions to populate decision analytic models. Value Health 2010; 13:557-564.

31. O'Brien BJ, Sculpher MJ. Building uncertainty into cost-effectiveness rankings: portfolio risk-return tradeoffs and implications for decision rules. Med Care 2000;38(5):460-8.

32. Eckermann \& Willan. Expected Value of Information and Decision Making in HTA. Health Economics 2007;16:195-209. 



\section{Chapter 9}

\section{How to anticipate future developments in Comparative Effectiveness Research}

Valesca P. Retèl Manuela A. Joore

Sabine C. Linn Emiel J.T. Rutgers Wim $H$. van Harten 


\begin{abstract}
Purpose

Comparative Effectiveness Research (CER) information is needed to guide decisions, especially in early stages of technological development. However, there is uncertainty about the added value of CER, because in this early stage, evidence is limited and different development paths are still possible. When optimal diffusion of a technology is sought, incorporating process-uncertainty into CER may reveal unanticipated developments and can support implementation.
\end{abstract}

\title{
Methods
}

Ten possible scenarios regarding the introduction of the 70-gene signature for breast cancer (gene expression profile for selecting patients who will benefit most from chemotherapy) were drafted with European experts. The five most likely scenarios were quantitatively integrated in a decision-analytical model. For each scenario, the cost-effectiveness of the 70-gene signature expressed in Net Monetary Benefit (NMB) was compared to clinical guidelines, calculated from 20052020.

\section{Results}

Including all scenarios in 2005 , the NMB was negative $(-€ 1,859)$, meaning that the 70-gene signature was not yet cost-effective compared to the clinical guideline. The NMB for the 70-gene signature increased over time with a range of $-€ 2,061$ to $-€ 1,676$ in 2010 and $-€ 2,347$ to $€ 3,304$ in 2020 depending on the scenario used. The uptake-scenario had a strong influence on the cost-effectiveness, followed by the reduction of "technical failures" and reductions in "non-believers".

\section{Conclusions}

We showed that there is not just one outcome of cost-effectiveness. Scenarios incorporated into decision modeling can be useful as a tool in CER to reflect the dynamics in the development and gives the possibility to anticipate and act upon those developments. 


\section{Introduction}

Comparative Effectiveness Research (CER) is receiving increasing attention and the methodology is the subject of a number of governmental and scientific reports. ${ }^{1}$ The discipline uses a wide range of methods including synthesis of existing evidence, analysis of routinely collected data, and the generation of new evidence through prospective registries and clinical trials. ${ }^{2}$ Comparing risks and benefits of different treatment strategies has been a long-standing goal of clinical research and health technology assessment (HTA), and it is an essential part of research in $\mathrm{CER}^{2}{ }^{2}$ The purpose is to assist different stake-holders, such as consumers, clinicians, purchasers and policy makers, to make informed decisions that will improve health care at both the individual and population levels. ${ }^{3}$ The Institute of Medicine's (IOM) recommendations for a national system of CER, states that CER should recognize the dynamic state of disease, should develop robust information and should promote rapid adoption of CER findings. ${ }^{3}$ Especially in early stages of promising new technologies, CER information should be used to anticipate possible developments. The question is whether CER -in the broad sense of the term- can be conducted in advance of widespread adoption of a technology? This question has also been featured by a rich body of health technology assessment work published in the recent years ${ }^{4-7}$, however, none of these articles focused on qualitatively incorporation of scenarios from the perspective of various stakeholders into one cost-effectiveness model.

Performing an HTA requires sufficient patient numbers and, as a consequence, broad clinical implementation of new technologies may be premature in the absence of firm prospective data on the actual benefits. ${ }^{8}$ However, if we wait to perform an HTA, it might very well be that worthwhile technology is withheld from the public. ${ }^{9}$ This paradox has become known as Buxton's law: "It is always too early, until suddenly, it is too late..." . ${ }^{10}$ We feel that there is a need to integrate methods in CER for dealing with the various possible developments in early stages of technology development, both to support policy decision making and to anticipate developments encountered during the early introduction in clinical practice. Combining structured scenario drafting and decision modeling could be helpful to integrate these dynamics when calculating expected effects and costs.

An example of a promising technique in its early stages of development is the 70-gene prognosis signature (MammaPrint ${ }^{\mathrm{TM}}$ ) for breast cancer patients. ${ }^{11}$ Using the 70-gene signature, the selection of patients that will benefit most from chemotherapy could be more accurate, thereby reducing over-treatment. The promising results of three retrospective validation studies ${ }^{12-14}$ led to the performance of a prospective feasibility study (RASTER: MicroarRAy PrognoSTics in Breast CancER) from 2004 until $2006^{15}$, followed by a prospective, randomized 
clinical study (MINDACT: Microarray In Node-negative and 1 to 3 positive lymph node Disease may Avoid ChemoTherapy), which started in $2007 .{ }^{16}$ It would take at least 8-10 years to bring the signature into routine clinical practice via the usual path of prospective trials. It was therefore decided that the controlled introduction of this technology, which started in 2004, should be supported by an early and dynamic Constructive Technology Assessment (CTA). Combined with the clinical studies, it could be called "CER". The CTA-part focused on quality aspects that were most likely to change during the introduction of the 70-gene signature, such as: logistics, ethical/legal aspects, patient centeredness and cost-effectiveness. ${ }^{17-19}$ The main results of the cost-effectiveness findings were small differences in survival, but substantial differences in quality-adjusted survival between the three prognostic tools; the 70-gene signature, the St. Gallen guidelines ${ }^{20}$ and the Adjuvant Online. ${ }^{21}$ Quality-adjusted survival was highest when using the 70 -gene signature; St. Gallen showed the highest survival rates. Based on costs per QALY, the 70-gene signature had the highest probability of being cost-effective for a willingness to pay more than $€ 4,614 / \mathrm{QALY}{ }^{19}$

Simultaneous with the early introduction, scenarios were drafted to monitor and anticipate these changing aspects, in other words: the dynamics of the 70-gene signature diffusion. Two first scenarios were written in 2004 and revised mid-2005, with the initial expectation among the direct involved researchers and professionals that less adjuvant chemotherapy would be needed compared to guideline based treatment. However, it became apparent that the signature in combination with the national Dutch guidelines (with the physicians tending to follow the highest risk) led to more chemotherapy prescription in the RASTER study, instead of less. A second important issue was suggested that a discussion would start concerning the validity of the 70-gene signature, which could lead to a prolonged early adoption phase. Although not considered very likely at the time of starting the study, this proved to be reality especially in Europe. ${ }^{18}$

The technology-related developments and the diffusion pathway of the 70-gene signature are likely to have impact on the cost, effects and cost-effectiveness in the future. In cost-effectiveness analyses (CEAs), it is common to use different quantitative scenarios in sensitivity analyses to reflect the uncertainty of inputparameters. ${ }^{22}$ There are only a few examples in the literature where more comprehensive, qualitative scenarios were processed into a CEA. ${ }^{23,24}$

Our research objectives were first, to develop a multi-parameter method to assess dynamic CER-aspects to determine the effects, costs and cost-effectiveness of possible future diffusion patterns of technologies at an early stage of development. And second, to illustrate this method for the 70-gene signature versus the current Adjuvant Online (AO) treatment strategy for breast cancer patients. 


\section{Methods}

The following steps in dynamic CER can be distinguished: (I) Determination of the phases of diffusion; (II) Scenario construction; (III) Grouping of scenarios; (IV) Integration of the driving factors as parameters in the decision model; (V) Input parameters for the model; (VI) Model analysis.

\section{Determination of the phases of diffusion}

From the start of the 70-gene signature implementation, we used scenarios that were positioned in time using the Rogers adoption curve to monitor the diffusion. ${ }^{25}$ The scenarios were drafted reflecting the possible diffusion pathways of the technology related to the numbers of adopters (Figure 1). In the innovation phase (2003-2005), the prognosis signature technique was developed and the first organizations (innovators) adopted the technology in their daily practice. The early adoption phase (2005-2007) describes the implementation in 10-15 hospitals: the logistics were established and physicians increasingly based their adjuvant treatment decision on the signature result. The early majority phase (2007-2012 and beyond) describes the implementation in a gradually increasingly number of hospitals participating in the prospective randomized controlled MINDACT trial. ${ }^{18}$

\section{Scenario construction}

The Shell method was used for the scenario construction. ${ }^{26}$ This consists of background research, drafting one or two scenarios, structured feedback by experts and revision of these drafts. ${ }^{27,28}$ Subsequently, for the scenarios to be incorporated in the cost-effectiveness modeling we used a structured decision process. (Figure 2) Ten scenarios were initially introduced as "What if..." statements presented to genomic experts and breast cancer specialists by means of a semi-structured questionnaire in 2008. This was followed by a decision workshop, attended by 80 participants (surgeons, medical oncologists, molecular pathologists and radiotherapists). During the workshop, the experts were asked to vote on the "What if..." statements, whether each alternative was "likely" or "unlikely" to happen within 10 years. The scenarios are described in Table 1. 


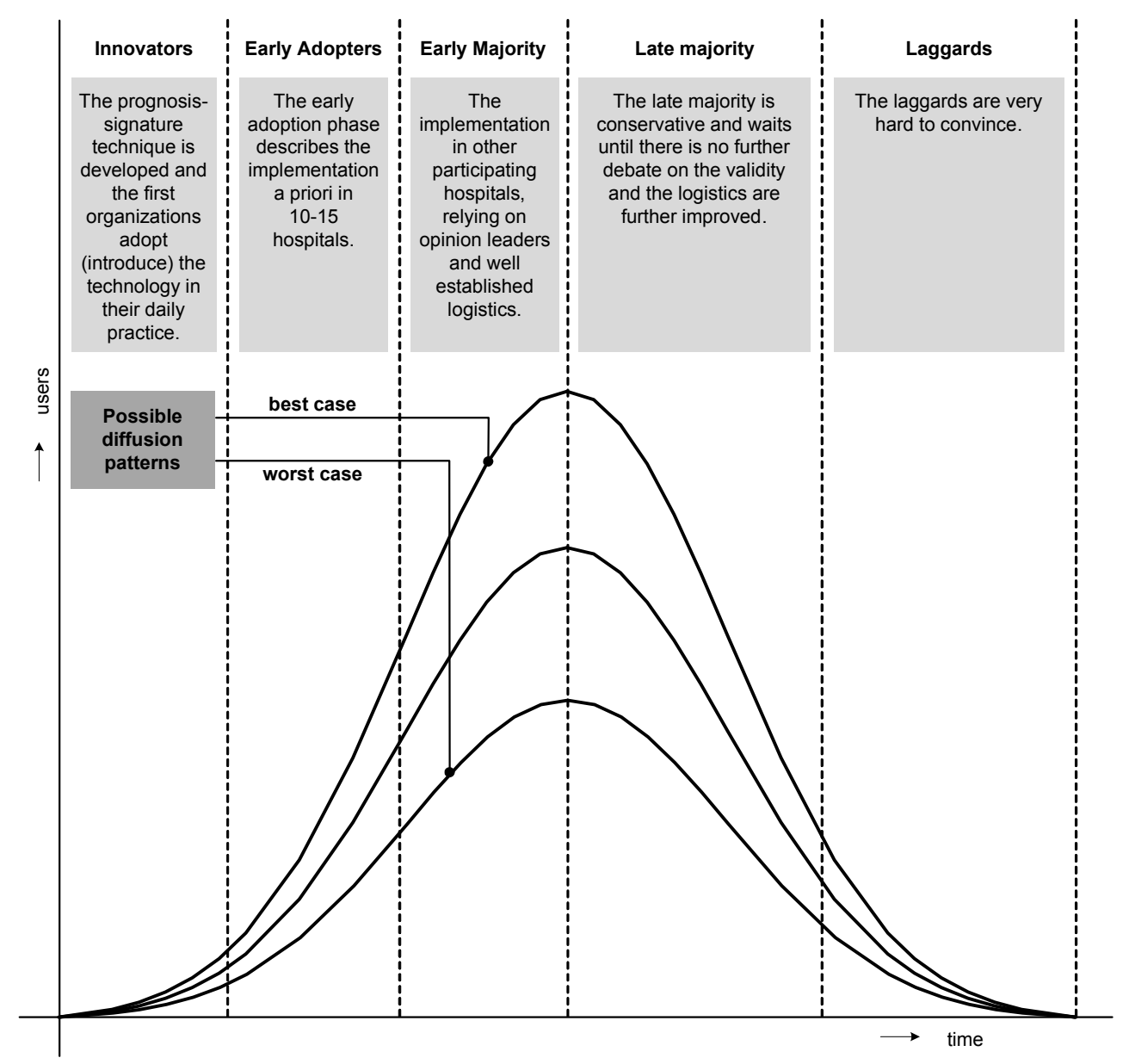

Figure 1. Rogers' adoption curve with possible diffusion patterns 
Scenario method

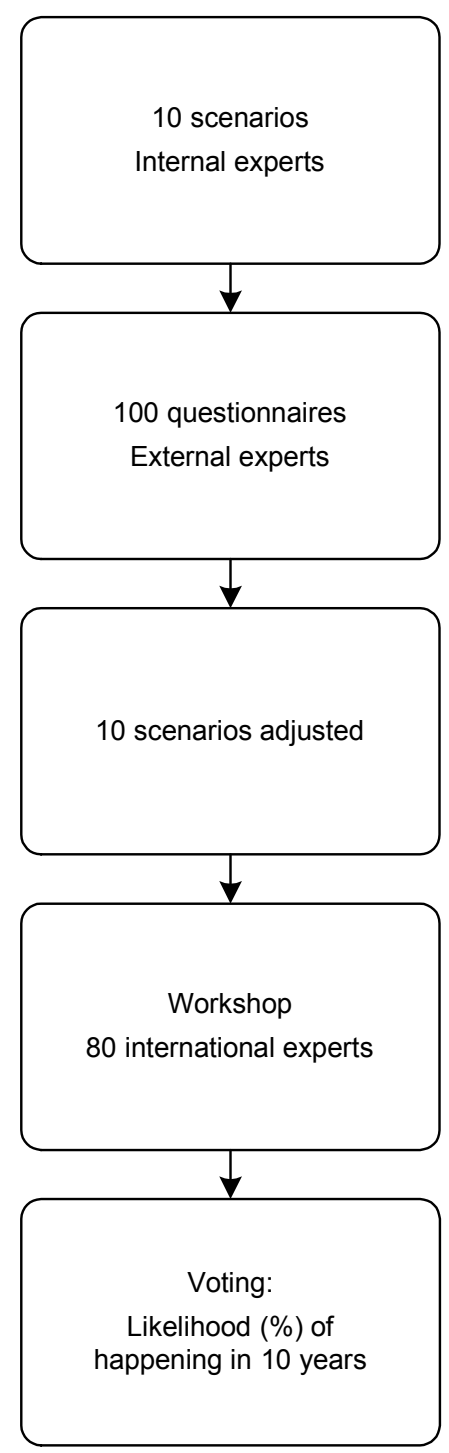

Structured decision

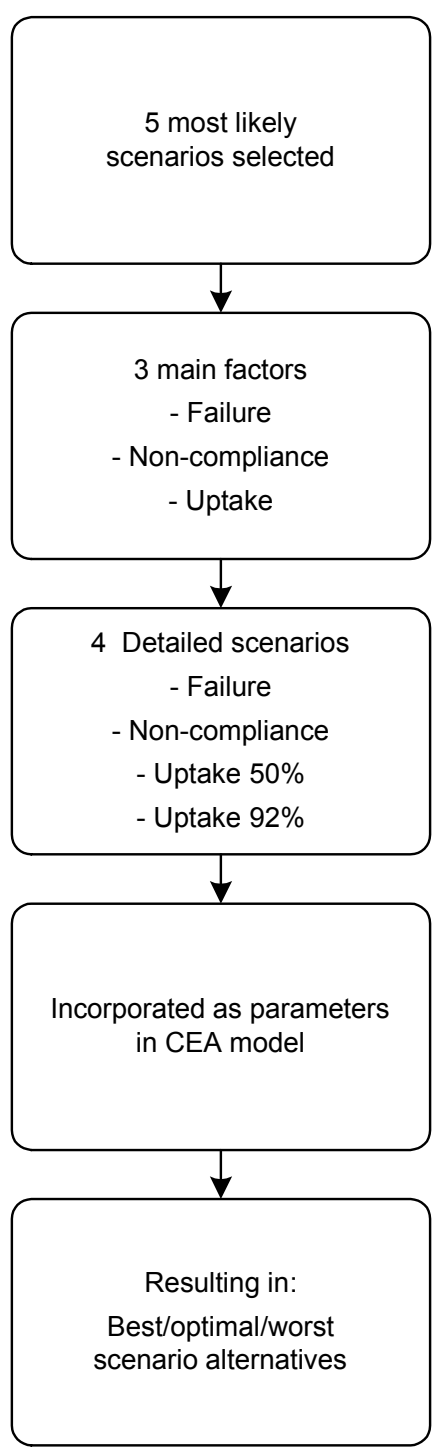

Figure 2. Scenario method and structured decision 
Table 1. Scenario results derived from the workshop

\begin{tabular}{|c|c|}
\hline Scenario & Description \\
\hline $\begin{array}{l}\text { Non-believers } \\
(100 \% \text { likely })\end{array}$ & $\begin{array}{l}\text { Professionals, who are not using the 70-gene signature until the results of the } \\
\text { MINDACT are released, will delay the diffusion (spreading of the signature) } \\
\text { process. This will be expressed in the proportion of non-compliance towards } \\
\text { the signature result. }\end{array}$ \\
\hline $\begin{array}{l}\text { User-friendliness } \\
\quad(90 \% \text { likely })\end{array}$ & $\begin{array}{c}\text { There is a mix of new functions possible on the (read-out) microarray; such as } \\
\text { ER/PgR/Her2 status, singles genes, with new possibilities for e.g. targeted } \\
\text { therapies. Furthermore, by using needle biopsies the application becomes } \\
\text { more user-friendly. This will be expressed in a decrease of failures of the } \\
\text { signature. }\end{array}$ \\
\hline $\begin{array}{l}\text { Progressive } \\
\text { techniques } \\
\text { (90\% likely) }\end{array}$ & $\begin{array}{c}\text { There is positive proof for the value of RNA-preservation instead of formalin- } \\
\text { based tissue for future research, which causes an increased use of the } 70 \text { - } \\
\text { gene signature. This will be expressed in a decrease of failures of the } \\
\text { signature. }\end{array}$ \\
\hline $\begin{array}{l}\text { Progressive } \\
\text { uptake } \\
\text { (90\% likely) }\end{array}$ & $\begin{array}{l}\text { The } 70 \text {-gene signature has developed further and can be used safely for all } \\
\text { node negative and } 1-3 \text { positive patients. The uptake is } 100 \% \text { in your county } \\
\text { and is embedded in the national guidelines. This will be expressed in an } \\
\text { increasing number of patients receiving signature. }\end{array}$ \\
\hline $\begin{array}{l}\text { Financial access } \\
\quad(75 \% \text { likely })\end{array}$ & $\begin{array}{l}\text { The insurance companies in the Netherlands don't reimburse the use of the } \\
\text { 70-gene signature yet (2008). If the insurers were to reimburse the } 70 \text {-gene } \\
\text { signature, the rate of reimbursement agreements would be rather more } \\
\text { progressive throughout Europe. This will be expressed in a -slightly slow- } \\
\text { increase of patients receiving the signature. }\end{array}$ \\
\hline $\begin{array}{l}\text { Other paraffin/ test } \\
\quad(60 \% \text { likely })\end{array}$ & $\begin{array}{l}\text { Another PRC-based, user-friendly test appears on the market, and the market } \\
\text { share of the } 70 \text {-gene signature decreases. }\end{array}$ \\
\hline $\begin{array}{l}\text { Competitive test } \\
(60 \% \text { likely })\end{array}$ & $\begin{array}{c}\text { The Oncotype DX 'wins' the competition; the market share of the 70-gene } \\
\text { signature decreases. }\end{array}$ \\
\hline $\begin{array}{l}\text { Era after: CTC? } \\
\quad(40 \% \text { likely })\end{array}$ & $\begin{array}{l}\text { A totally new (nano) technology has been developed (using fresh frozen tumor } \\
\text { samples) which has more value than the } 70 \text {-gene signature and - due to this } \\
\text { test - the market share of the } 70 \text {-gene signature decreases. }\end{array}$ \\
\hline $\begin{array}{l}\text { Provision on free } \\
\text { market } \\
(18 \% \text { likely })\end{array}$ & $\begin{array}{l}\text { Besides being used in the MINDACT trial, 70-gene signature is also available } \\
\text { on the free market, to prevent unethical situations due to patient selection. }\end{array}$ \\
\hline $\begin{array}{l}\text { Regulation/ } \\
\text { legislation barrier } \\
(5 \% \text { likely })\end{array}$ & $\begin{array}{c}\text { There is a probability of legal regulation by way of FDA clearance. Because the } \\
\text { 70-gene signature has FDA and IVDMIA (In Vitro Diagnostic Multivariate Index } \\
\text { Assay) approval, the market share of the Oncotype DX decreases. }\end{array}$ \\
\hline
\end{tabular}

CTC: circulating tumor cells 


\section{Grouping of scenarios}

From the ten discussed scenarios, the five most likely were selected and the most crucial accelerating or decelerating aspects were identified (drivers of the diffusion). This resulted in three main factors: technical failure, non-compliance with discordant test results, and uptake. Technical failure was based on the "userfriendliness" and "RNA preservation" scenario. Non-compliance was based on the "non-believers" scenario. Uptake was based on the "reimbursement" (moderate increase in uptake), and the "adoption" scenario (rapid increase in uptake). The three factors were incorporated as parameters in the decision model (Table 2).

Table 2. Input parameters

\begin{tabular}{|c|c|c|c|c|c|}
\hline Scenario & $\begin{array}{c}\text { Barrierl } \\
\text { facilitator }\end{array}$ & Likelihood & Factors & $\begin{array}{c}\text { Mean value } \\
\text { parameter }\end{array}$ & Source \\
\hline \multirow{4}{*}{$\begin{array}{c}\text { User- } \\
\text { friendliness } \\
+ \\
\text { Progressive } \\
\text { techniques }\end{array}$} & \multirow[t]{4}{*}{ barrier } & \multirow[t]{4}{*}{$90 \%$} & \multicolumn{3}{|l|}{ Failure } \\
\hline & & & 2005 & 0.27 & 10 \\
\hline & & & 2010 & 0.20 & Scenario ws \\
\hline & & & 2020 & 0.08 & Scenario ws \\
\hline \multirow{4}{*}{$\begin{array}{c}\text { Non- } \\
\text { believers }\end{array}$} & \multirow[t]{4}{*}{ barrier } & \multirow[t]{4}{*}{$100 \%$} & \multicolumn{3}{|c|}{ Non-compliance with discordant test result } \\
\hline & & & 2005 & 0.35 & 10 \\
\hline & & & 2010 & 0.26 & Scenario ws \\
\hline & & & 2020 & 0.08 & Scenario ws \\
\hline \multirow{2}{*}{$\begin{array}{c}\text { Financial } \\
\text { access }\end{array}$} & \multirow[t]{5}{*}{ facilitator } & & Uptake & & \\
\hline & & & 2005 & 0.03 & 10 \\
\hline \multirow{3}{*}{$\begin{array}{l}\text { Progressive } \\
\text { uptake }\end{array}$} & & & 2010 & 0.08 & 24 \\
\hline & & $75 \%$ & $\begin{array}{c}2020 \\
\text { "reimbursement } \\
\text { scenario" }\end{array}$ & 0.50 & Scenario ws \\
\hline & & $90 \%$ & $\begin{array}{l}2020 \text { "adoption } \\
\text { scenario" }\end{array}$ & 0.92 & Scenario ws \\
\hline
\end{tabular}

Scenario ws: scenario workshop 


\section{Integration of the driving factors as parameters in the decision model}

A Markov decision model was previously developed to assess the effects (qualityadjusted life years; QALYs), costs and cost-effectiveness of the 70-gene signature compared to clinical-pathological guidelines (such as Adjuvant! Online ${ }^{21}$ ) for patients with early, node-negative, estrogen receptor (ER) positive breast cancer. In each strategy, based on the sensitivity and specificity of the prognostic test calculated from a dataset consisting of 3 previously reported validation studies, patients were classified as having a true low, true high, false low, or false high risk of developing metastasis. It was assumed that both the prognostic test result and the treatment guidelines would be followed in all cases. We simulated in the model that all patients received endocrine treatment, and in case of a high risk, the patient received also chemotherapy. The model was constructed with four mutually exclusive health states: disease free survival, relapse (including local and regional recurrences, secondary primary and contralateral breast cancer), distant metastasis, and death (Figure 3). It was assumed that patients could only have one relapse, for which they received the best available treatment with the same costs, regardless which kind of adjuvant treatment the patient originally received for the primary tumor. The calculations are performed per year, with a total simulated time horizon of 20 years. We programmed the model in Microsoft Excel (Microsoft, Redmond, WA). ${ }^{19}$ In case of a technical failure, it was assumed and modeled that the costs of the 70 -gene signature were made for $10 \%$ of the total costs and the final treatment advice was decided according to the clinical guideline (AO). In case of non-compliance with a discordant test result (low risk signature and high risk $\mathrm{AO}$ or vice versa), it was assumed that patients would be treated according to the AO. The uptake parameter reflected the proportion of the target population (patients who actually did receive the 70-gene signature divided by all patients who are in principle eligible for the signature (target population)) (Figure 4). 


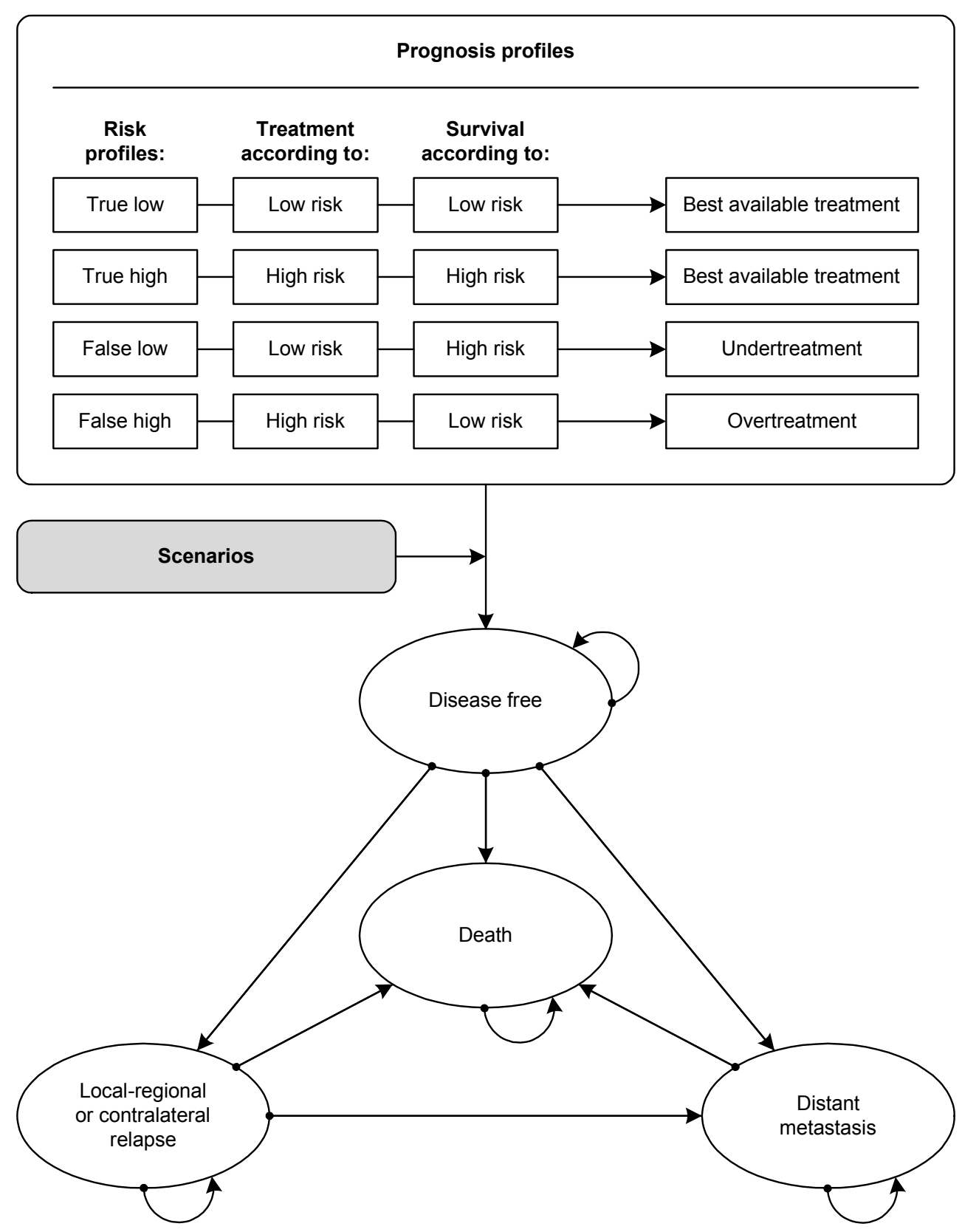

Figure 3. Model structure 


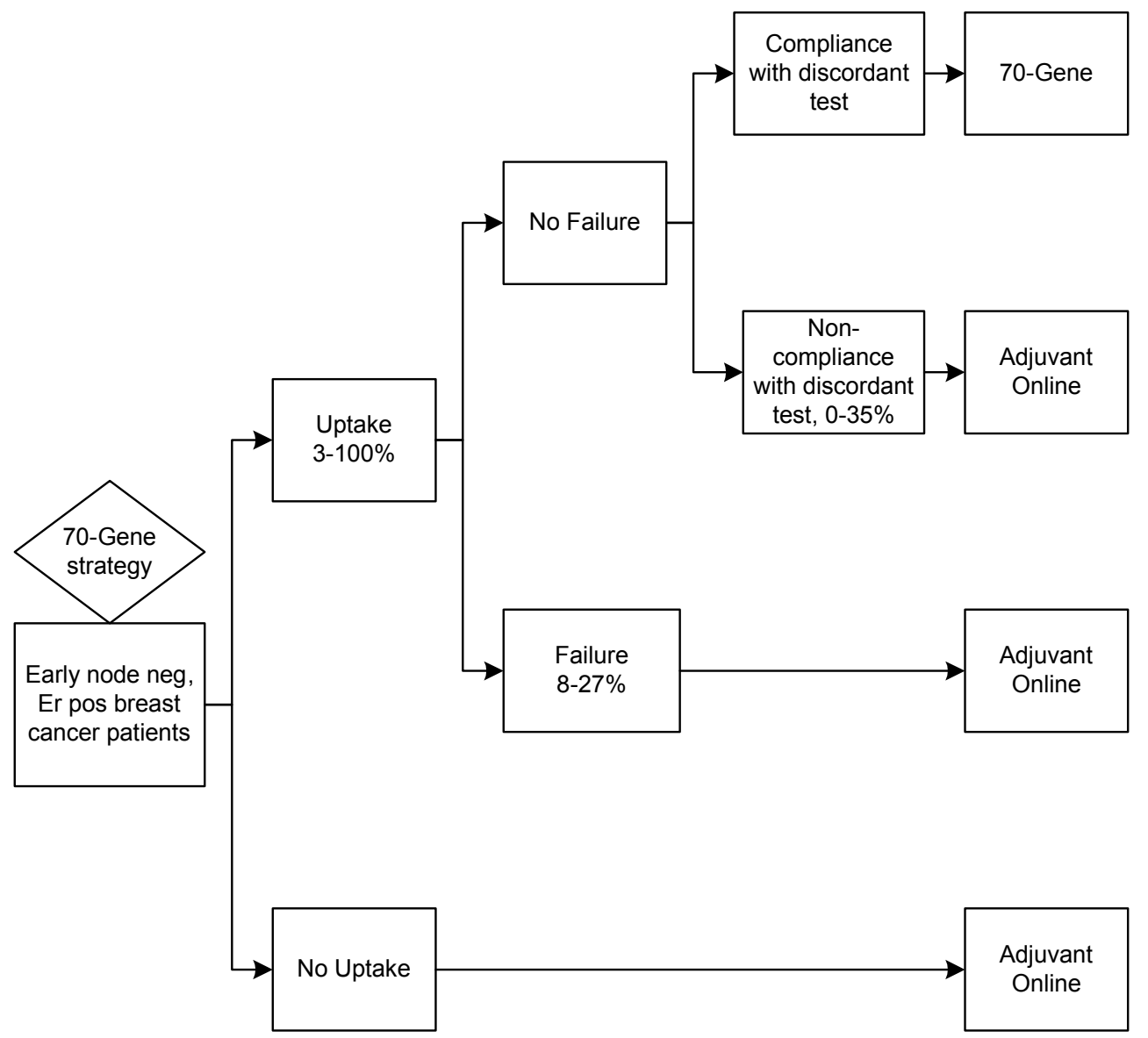

Figure 4. Scenario parameters as calculated in the model

\section{Input parameters}

To reflect the dynamics in the diffusion, values of the parameters were changed over time. Cost-effectiveness was assessed for three points in time: 2005 (early adoption, data available), 2010 (early majority phase, based on scenarios), 2020 (late majority, based on scenarios). All scenario starting in 2005 were based on data from the RASTER study ${ }^{15}$, as well as the uncertainty, which was assumed to remain constant over time. The initial value of the technical failure parameter was $27 \%$, as this occurred in the total available samples in the RASTER-study. Based on the workshop results, we assumed that the $27 \%$ failure rate would be reduced to $20 \%$ in 2010 and to $14 \%$ in 2020 . 
Non-compliance was modeled in case of a clinical high/genomic low risk (15\% in the RASTER-study) and in case of a clinical low/genomic high risk (20\%); thus in total $35 \%$ non-compliance. Based on the scenarios, the total non-compliance was likely to reduce to $26 \%$ in 2010 and to $8 \%$ in 2020 , assuming a positive result of the MINDACT trial. The "uptake" parameter was calculated with the numbers of patients who annually received a 70-gene signature divided by the incidence of the targeted group in the Netherlands. We used the numbers of signatures performed in the RASTER-study $(N=427)$ to feed the data of 2005 and the pilot study of the MINDACT trial $(n=800)$ for $2010 .^{15,29}$ The parameter could subsequently be positively influenced by the "adoption" scenario, where the 70-gene signature would be adopted optimally in Europe and embedded in guidelines in up to $92 \%$ of cases. The parameter could be negatively influenced by a "reimbursement" scenario, where the uptake of the 70-gene signature is delayed by insurance companies who do not reimburse the signature; or a competitor test could enter the market with serious effects on the likely sales, which we modeled with an uptake probability of up to $50 \%$.

\section{Model Analysis}

Four univariate scenarios were calculated out of the three factors: technical failure, non-compliance, adoption and reimbursement, by changing only one specific parameter and leaving the others fixed. In addition, three multivariate scenarios were calculated: worst case (no change in all parameters from 2005), an optimal scenario (combination of the failure, non-compliance and adoption scenarios in 2020) and a best case (no failures, no non-compliance and $100 \%$ uptake). For each scenario, the incremental costs, effects and Net Monetary Benefit (iNMB) of the 70-gene signature versus the AO were calculated for 2005, 2010 and 2020. Incremental effects and incremental costs were obtained by subtracting the effects or costs of the AO strategy from the 70-gene strategy. The incremental NMB is calculated by multiplying the difference in effects $(\Delta \mathrm{E})$ to a certain threshold value $(\lambda)$ minus the difference in costs $(\Delta \mathrm{C}){ }^{30}$

\section{$i N M B=\Delta E * \lambda-\Delta C$}

A positive iNMB implies that the 70-gene signature is cost-effective compared to the $A O$, and a negative iNMB implies that the 70-gene signature is not costeffective. The threshold reflects the maximum willingness to pay of the society, whether a strategy is deemed efficient depends on how much society is willing to pay for a gain in effect, which is referred to as the ceiling ratio. ${ }^{30}$ As a threshold for a positive decision on coverage, we used $€ 30,000$ per QALY, which reflects the $£ 20,000-30,000$ per QALY applied by the National Institute for Health and Clinical Excellence (NICE) ${ }^{31}$ Parameter values were drawn at random from the assigned 
distributions, using Monte Carlo simulation with 1000 iterations. The simulation results were used to calculate $95 \%$ confidence intervals based on the 2.5 percentile and the 97.5 percentile. Uncertainty in the input parameters was handled probabilistically, by assigning distributions to parameters. To indicate decision uncertainty, cost-effectiveness acceptability curves (CEACs) are presented. ${ }^{32}$

\section{Results}

\section{Mean results}

For the worst case scenario (2005), the effects and costs for the 70-gene signature compared to the $\mathrm{AO}$ strategy were almost equal; the incremental (difference in) QALYs were 0.0010 ( $\mathrm{Cl}: 0.0011$ to 0.0030 ) and the incremental costs amounted to $€ 1,940$ ( $\mathrm{Cl}: € 1,857$ to $€ 2,016$ ) (Table 3 \& Figure 5). The univariate analysis demonstrated that improvement of the technical failure resulted in incremental effects of 0.0011 (2010) and 0.0013 (2020), and incremental costs of $€ 2,094$ in 2010; and $€ 2,385$ in 2020. The observed higher costs for the 70-gene signature were due to more successful tests. The reduction of non-compliance scenarios showed incremental effects of 0.0011 (2010) and 0.0013 (2020), and incremental costs of $€ 1,939$ in 2010 and $€ 1,940$ in 2020 . The rate of reimbursement scenario resulted in incremental effects of 0.0095 in 2010 and 0.0592 in 2020, and incremental costs of $€ 1,883$ in 2010 and $€ 1,547$ in 2020 . The degree of adoption scenario yielded 0.0095 (2010) and 0.1089 (2020) incremental effects and $€ 1,883$ (2010) and $€ 1,211$ (2020) incremental costs.

In the multivariate analysis resulted the optimal case scenario, indicating the best possible compliance according to the scenarios (lowest failures rates and best possible uptake) in 0.0117 incremental effects and 0.1492 in 2020 , and $€ 2,026$ incremental costs in 2010 and $€ 1,171$ in 2020 . The iNMB obviously improved over time for each scenario (Figure 5). Assuming a maximum willingness to pay of $€ 30,000 / Q A L Y$, in 2005 the iNMB was negative $(-€ 1,859)$ which means that the $70-$ gene signature was not cost-effective compared to the use of $A O$ only. The NMB for the 70-gene signature increased over time with a range of $-€ 2,061$ to $-€ 1,676$ in 2010 and $-€ 2,347$ to $+€ 3,304$ in 2020 depending on the scenario used. The uptake scenarios generated the greatest impact on cost-effectiveness.

\section{Uncertainty analysis}

The CEAC-frontiers showed that the $\mathrm{AO}$ has the highest probability to be costeffective when focusing on costs per life years, and the 70-gene signature has the highest probability to be cost-effective when focusing on costs per quality adjusted life years, from the situation that the 70 -gene signature will be for $50 \%$ adopted (Figure 6). 
Table 3. Mean results, incremental effects, costs, cost-effectiveness ratio and NMB

\begin{tabular}{|c|c|c|c|c|c|c|c|c|c|c|}
\hline & \multirow[t]{2}{*}{ Time } & \multicolumn{3}{|c|}{ Values } & \multirow[t]{2}{*}{ iEffects } & \multirow[t]{2}{*}{$\mathrm{Cl}(95 \%)$} & \multirow[t]{2}{*}{ iCosts } & \multirow[t]{2}{*}{$\mathrm{Cl}(95 \%)$} & \multirow[t]{2}{*}{ ICER } & \multirow[t]{2}{*}{ iNMB } \\
\hline & & Failure & NC & Up & & & & & & \\
\hline 1 & 2005 & 0.27 & 0.35 & 0.03 & 0.0010 & $\begin{array}{l}-0.0012 \\
\text { to } 0.0031\end{array}$ & $€ 15$ & $\begin{array}{l}-€ 5 \\
\text { to } 36\end{array}$ & $€ 14976$ & $€ 5$ \\
\hline \multicolumn{11}{|c|}{ Univariate Scenarios } \\
\hline \multirow[t]{2}{*}{2} & 2010 & 0.20 & Idem & Idem & 0.0011 & $\begin{array}{l}-0.0012 \\
\text { to } 0.0033\end{array}$ & $€ 14$ & $\begin{array}{l}-€ 7 \\
\text { to } 35\end{array}$ & $€ 13157$ & $€ 7$ \\
\hline & 2020 & 0.08 & Idem & Idem & 0.0013 & $\begin{array}{l}-0.0013 \\
\text { to } 0.0038\end{array}$ & $€ 13$ & $\begin{array}{l}-€ 10 \\
\text { to } 37\end{array}$ & $€ 10428$ & $€ 12$ \\
\hline \multirow[t]{2}{*}{3} & 2010 & Idem & 0.26 & Idem & 0.0011 & $\begin{array}{l}-0.0011 \\
\text { to } 0.0030\end{array}$ & $€ 15$ & $\begin{array}{l}-€ 6 \\
\text { to } 36\end{array}$ & $€ 13526$ & $€ 8$ \\
\hline & 2020 & Idem & 0.08 & Idem & 0.0013 & $\begin{array}{l}-0.0007 \\
\text { to } 0.0033\end{array}$ & $€ 14$ & $\begin{array}{l}-€ 5 \\
\text { to } 33\end{array}$ & $€ 11079$ & $€ 11$ \\
\hline \multirow[t]{2}{*}{$\begin{array}{l}4 \\
a\end{array}$} & 2010 & Idem & Idem & 0.10 & 0.0095 & $\begin{array}{l}-0.0094 \\
\text { to } 0.0263\end{array}$ & $€ 141$ & $\begin{array}{l}-€ 23 \\
\text { to } 322\end{array}$ & $€ 14976$ & $€ 47$ \\
\hline & 2020 & Idem & Idem & 0.50 & 0.0591 & $\begin{array}{l}-0.0592 \\
\text { to } 0.1871\end{array}$ & $€ 886$ & $\begin{array}{c}-€-53 \\
\text { to } 1938\end{array}$ & $€ 14976$ & $€ 297$ \\
\hline \multirow[t]{2}{*}{$\begin{array}{l}4 \\
b\end{array}$} & 2010 & Idem & Idem & 0.10 & 0.0095 & $\begin{array}{l}-0.0094 \\
\text { to } 0.0263\end{array}$ & $€ 141$ & $\begin{array}{l}-€ 23 \\
\text { to } 322\end{array}$ & $€ 14976$ & $€ 647$ \\
\hline & 2020 & Idem & Idem & 0.92 & 0.1089 & $\begin{array}{c}-0.1355 \\
\text { to } 0.2977\end{array}$ & $€ 1630$ & $\begin{array}{c}-€ 286 \\
\text { to } 3859\end{array}$ & $€ 14976$ & $€ 547$ \\
\hline \multicolumn{11}{|c|}{ Multivariate Scenarios } \\
\hline \multirow[t]{2}{*}{5} & 2010 & 0.27 & 0.35 & 0.03 & 0.0010 & $\begin{array}{l}-0.0012 \\
\text { to } 0.0031\end{array}$ & $€ 15$ & $\begin{array}{l}-€ 5 \\
\text { to } 36\end{array}$ & $€ 14976$ & $€ 5$ \\
\hline & 2020 & Idem & Idem & Idem & 0.0010 & $\begin{array}{l}-0.0012 \\
\text { to } 0.0031\end{array}$ & $€ 15$ & $\begin{array}{l}-€ 5 \\
\text { to } 36\end{array}$ & $€ 14976$ & $€ 5$ \\
\hline \multirow[t]{2}{*}{6} & 2010 & 0.20 & 0.26 & 0.10 & 0.0113 & $\begin{array}{l}-0.0080 \\
\text { to } 0.0318\end{array}$ & $€ 133$ & $\begin{array}{l}-€ 60 \\
\text { to } 310\end{array}$ & $€ 11858$ & $€ 102$ \\
\hline & 2020 & 0.08 & 0.08 & 0.92 & 0.1729 & $\begin{array}{l}-0.1004 \\
\text { to } 0.4559\end{array}$ & $€ 1288$ & $\begin{array}{l}-€ 1411 \\
\text { to } 3892\end{array}$ & $€ 7456$ & $€ 2168$ \\
\hline \multirow[t]{2}{*}{7} & 2010 & 0 & 0 & 1 & 0.2449 & $\begin{array}{c}-0.0912 \\
\text { to } 0.5263\end{array}$ & $€ 1130$ & $\begin{array}{l}-€ 1737 \\
\text { to } 4248\end{array}$ & $€ 4614$ & $€ 3769$ \\
\hline & 2020 & Idem & Idem & Idem & 0.2449 & $\begin{array}{l}-0.0912 \\
\text { to } 0.5263\end{array}$ & $€ 1130$ & $\begin{array}{l}-€ 1737 \\
\text { to } 4248\end{array}$ & $€ 4614$ & $€ 3769$ \\
\hline
\end{tabular}

iEffects: Incremental effects of 70-gene signature compared to the Adjuvant Online, iCosts: Incremental costs of 70-gene signature compared to the Adjuvant Online, ICER: Incremental cost-effectiveness ratio; iNMB: incremental Net Monetary Benefit, NC: non-compliance, UP: uptake, Cl: confidence interval Scenarios:

1: Start;

2: Failure;

3: Non-compliance;

4a: Reimbursement;

4b: Adoption;

5: Worst case;

6: Optimal;

7: Best case 


$$
\begin{aligned}
& \text { }
\end{aligned}
$$

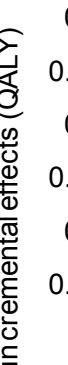

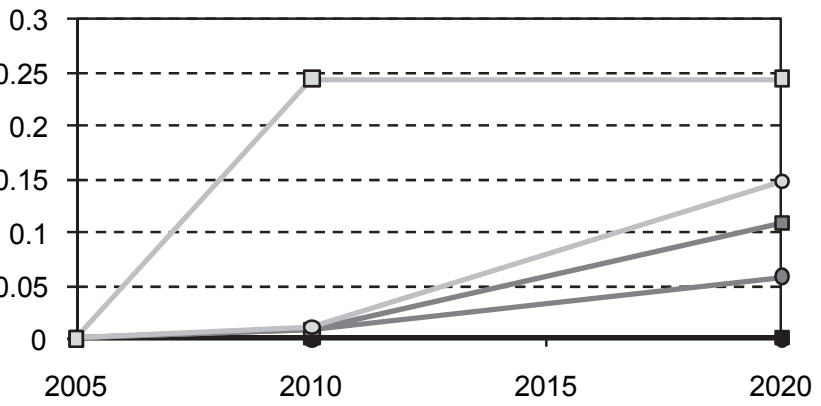

- worst case

- failure \& non-compliance

o- reimbursement

$\square-$ adoption

o- optimal

$\square$ best case

Years

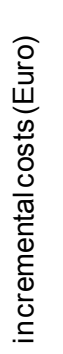

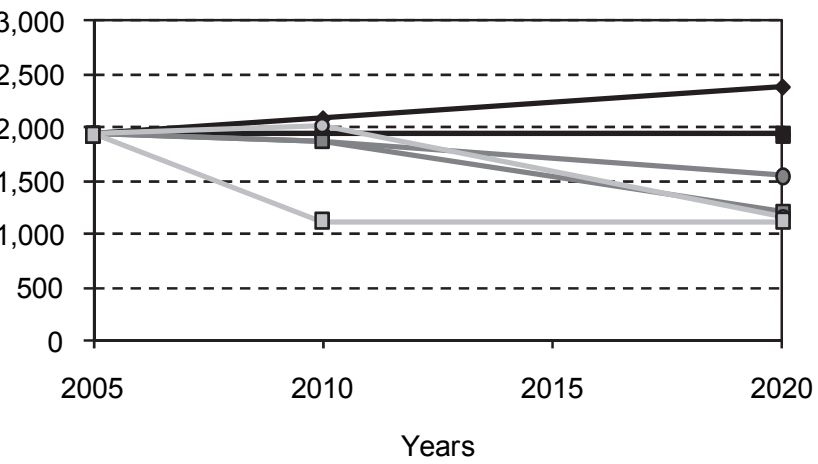

- worst case

$\longrightarrow$ failure

non-compliance

- - reimbursement

$\square-$ adoption

o- optimal

$\square$ best case

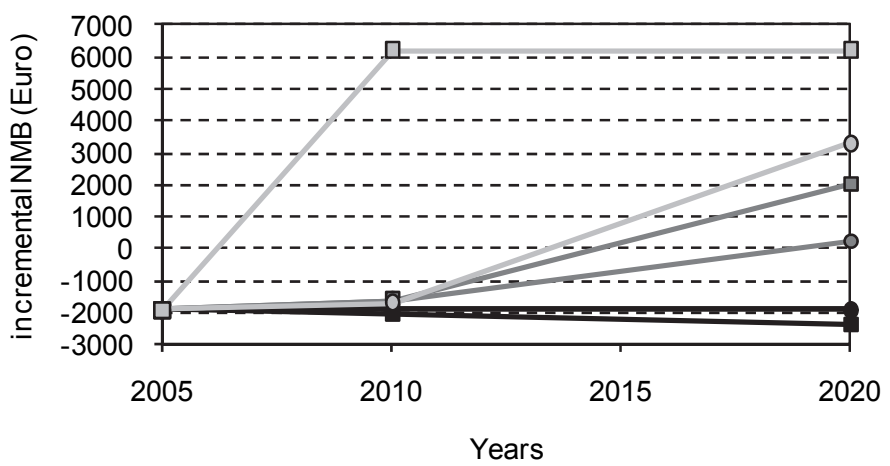

- worst case

$\longrightarrow$ failure

non-compliance

- - reimbursement

$\square$ adoption

o-optimal

$\square$ best case

Figure 5. Results of incremental (difference in) effects, costs and Net Monetary Benefit (NMB) 


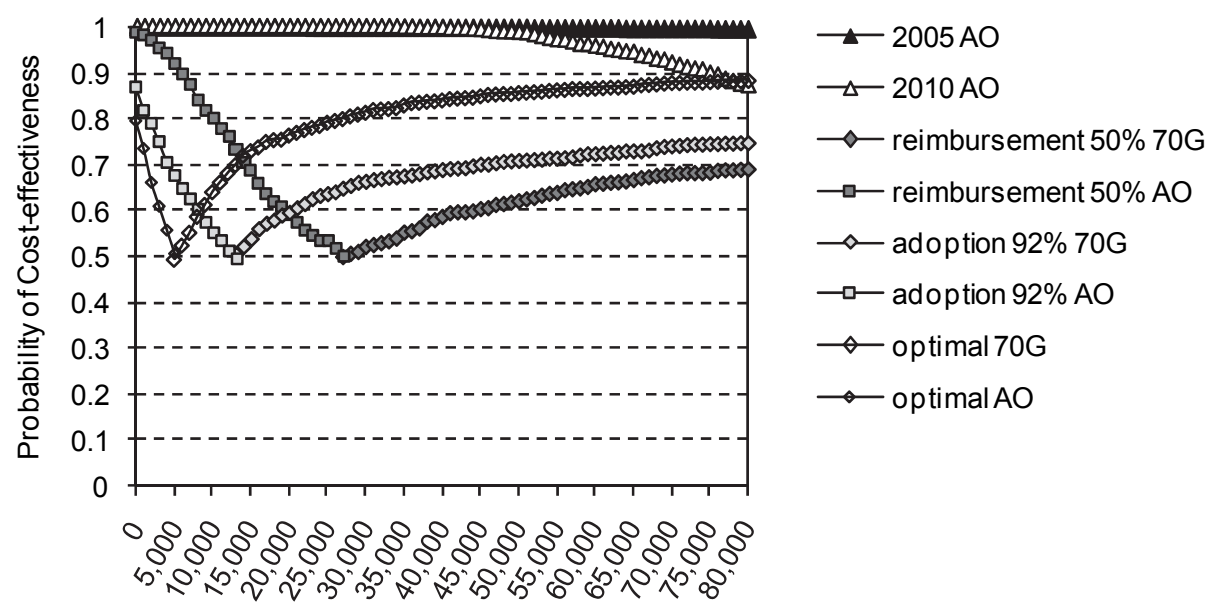

Willingness to pay for a LY (Euro)

Figure 6. Uncertainty analysis: Cost-Effectiveness Acceptability Frontiers

\section{Discussion}

The results of the dynamic CER demonstrated a wide range of possible Net Monetary Benefits over time. Furthermore, this article demonstrated that, in the absence of sufficient data, scenarios can help to anticipate the future diffusion patterns and use of technology by providing insight into future developments. When integrated in cost-effectiveness analyses, these scenarios can also improve the ability to make an informed policy decision. An advantage is that scenariodiscussion and scenario-analysis reveals factors that can be anticipated and may warrant intervention in the implementation process, in order to stimulate "appropriate use" and optimal cost-effectiveness at a population level.

In the case of the 70-gene signature, the influence of the uptake scenarios seemed to generate the highest impact on the cost-effectiveness results. As the uptake of the 70-gene signature increases, the net benefit will obviously increase and the 70-gene signature becomes cost-effective. Informing doctors and patients and generating additional evidence, for instance through "coverage with evidence development" program, are possible means to enhance uptake. When comparing the improved compliance results with the reduction of failure results, failure seemed to generate larger impact on cost-effectiveness, mainly due to remaining costs for tests which failed throughout the process. 
Compliance improvement was observed in the pilot study of the MINDACT trial with a total of $5 \%$ non-compliance in the discordant cases. ${ }^{29}$ This was, however, measured in a trial design, which may not be representative for use of the 70-gene signature. Non-believers will have the confidence after prospective data has been released. Furthermore, the ease of use could be established by using the 70-gene signature in decision making integrated into the Adjuvant! Online software as a hazard rate.

There are some remaining issues with regard to the scenario method used. First, to keep the analysis stable, we modeled the uncertainty constant over time. It is correct expecting that the uncertainty will decrease in the future, but for the ease of comprehension, we left this stable. By using value of information analysis (VOI) one can characterize, and possibly deal, with uncertainty. We are currently exploring these approaches. ${ }^{33,34}$ Second, the uptake scenario turned out to be most influential. However, we could only use the numbers of the studies conducted in 2005 and 2010, in real there could be a lot more profiles used, and thereby affect the cost-effectiveness of the 70-gene signature in a positive way. Finally, it is possible that costs of drugs used in adjuvant chemotherapy regimens may be underestimated because the costs of Taxanes, used in adjuvant chemotherapy regimen, are expected to increase in the coming years. ${ }^{35}$

The discussed method made it possible to integrate qualitative scenarios into quantitative parameters and derive scores from experts in order to obtain an impression on the most likely future developments. A next phase could be to derive more quantitative scenarios, by preparing the choices for the experts in a more quantitative way, as has been described by some authors ${ }^{36}$, and by evaluating the different options against each other. Another point of further research could be the exact timing of performing CER and (retrospective) confirmation in other studies that dynamic CER is possible.

With respect to the 70-gene signature, there is likely to be more than one "CERtruth", especially in early stages of development. If we consider expected costs and outcomes, we cannot be certain about future developments. CER in uncertain diffusion phases may be occurring more often; especially early stage cancer where researchers have to wait up to 10-20 years for relevant outcome data. Current advances in understanding cancer biology have provided leads to develop new, effective targeted therapies. However, progress is slowed by suboptimal/outdated clinical trial design paradigms and by regulatory complexity and rigidity. 
Ongoing studies such as the Investigation of Serial studies to Predict Your Therapeutic Response with Imaging And MoLecular analysis (the ISPY-trial) are recent examples that are using a new endpoint in the analyses (pathological complete response (PCR)) can be considered to evaluate study results at an earlier stage. ${ }^{37}$ It is important to support those studies with a CER in order to monitor developments and anticipate them at an early stage. Structured scenario drafting can be used as a tool in this process, and seems especially suited to integrate in decision-analytical models. This ultimately provides the decision maker an early, more detailed overview of possible developments and a likely range of cost-effectiveness results of a clinical technology, and the aspects that can be relevant, to guide further diffusion.

\section{Acknowledgements}

We acknowledge the European Organisation for Research and Treatment of Cancer (EORTC) for approval of this study and the participation of the Breast Cancer Group (TRANSBIG) during the scenario workshop in Bordeaux October 2008. We thank Dr R. de Jong and Dr F. Stewart for editing the paper and Dr M. Knauer for support via the consensus workshop. 


\section{References}

1. American College of Physicians. Information on Cost-Effectiveness: An Essential Product of a National Comparative Effectiveness Research Program. Ann Intern Med 2008; 148:957-961.

2. Tunis SR, Pearson SD. US moves to improve health decisions. BMJ 2010; 341:c3615.

3. VanLare JM, Conway PH, Sox HC. Five next steps for a new national program for comparative-effectiveness research. N Engl J Med 2010; 362:970-973.

4. Claxton KP, Sculpher MJ, Drummond MF. A Rational Framework for Decision Making by the National Institute for Clinical Excellence (NICE). The Lancet 2002; 360(9334):711-715.

5. Drummond MF, Sculpher MJ, Torrance GW, O'Brien BJ, Stoddart GL. Methods for the Economic Evaluation of Health Care Programmes. Oxford University Press, Oxford, third edition, 2006.

6. Fenwick E, Claxton KP, Sculpher MJ, Briggs A. Improving the Efficiency and Relevance of Health Technology Assessment: the Role of Iterative Decision Analytic Modeling. Technical Report 179, Centre for Health Economics, University of York, UK, 2000.

7. Spiegelhalter DJ, Abrams KR, Myles JP. Bayesian Approaches to Clinical Trials and Health-Care Evaluation. Statistics in Practice. John Wiley \& Sons Ltd., Chichester, 2004.

8. Griffin SC, Claxton KP, Palmer SJ, Sculpher MJ. Dangerous Omissions: The Consequences of Ignoring Decision Uncertainty. Health Econ. 2011 Feb;20(2):21224.

9. Ioannidis JP: Is molecular profiling ready for use in clinical decision making? Oncologist. 2007;12:301-311.

10. Buxton MJ. Problems in the economic appraisal of new health technology: The evaluation of heart transplants in the UK. In: Drummond MF ed. Economic appraisal of health technology in the European Community. Oxford: Oxford Medical Publications; 1987:103-118.

11. Van 't Veer LJ, Dai H, van de Vijver MJ et al. Gene expression profiling predicts clinical outcome of breast cancer. Nature 2002; 415:530-536.

12. Van de Vijver MJ, He YD, van 't Veer LJ et al. A Gene-Expression Signature as a Predictor of Survival in Breast Cancer. N Engl J Med 2002; 347:1999-2009.

13. Buyse M, Loi S, van't Veer L et al. Validation and Clinical Utility of a 70-Gene Prognostic Signature for Women With Node-Negative Breast Cancer. J Natl Cancer Inst 2006; 98:1183-1192.

14. Bueno-de-Mesquita JM, Linn SC, Keijzer R et al. Validation of 70-gene prognosis signature in node-negative breast cancer. Breast Cancer Res Treat 2009;117:483495.

15. Bueno-de-Mesquita JM, van Harten $W$, Retèl $V$ et al. Use of 70-gene signature to predict prognosis of patients with node-negative breast cancer: a prospective community-based feasibility study (RASTER). Lancet Oncol 2007; 8:1079-1087.

16. Cardoso F, Van't Veer L, Rutgers E et al. Clinical application of the 70-gene profile: the MINDACT trial. J Clin Oncol 2008; 26:729-735.

17. Ploem MC, Retèl VP, Linn SC et al. Tumor tissue: who is in control? Lancet Oncol 2010; 11:9-11.

18. Retèl VP, Bueno-de-Mesquita JM, Hummel MJ et al. Constructive Technology Assessment (CTA) as a tool in coverage with evidence development: the case of the 
70-gene prognosis signature for breast cancer diagnostics. Int $J$ Technol Assess Health Care 2009; 25:73-83.

19. Retèl VP, Joore MA, Knauer $M$ et al. Cost-effectiveness of the 70-gene signature versus St. Gallen guidelines and Adjuvant Online for early breast cancer. Eur $J$ Cancer 2010; 46:1382-1391.

20. Goldhirsch A, Wood WC, Gelber RD et al. Progress and promise: highlights of the international expert consensus on the primary therapy of early breast cancer 2007. Ann Oncol 2007; 18:1133-1144.

21. Ravdin PM, Siminoff LA, Davis GJ et al. Computer program to assist in making decisions about adjuvant therapy for women with early breast cancer. $J$ Clin Oncol 2001; 19:980-991.

22. Kuntz KM, Tsevat J, Weinstein MC et al. Expert panel vs decision-analysis recommendations for postdischarge coronary angiography after myocardial infarction. JAMA 1999; 282:2246-2251.

23. Ramwadhdoebe S, Van Merode GG, Boere-Boonekamp MM et al. Implementation by simulation; strategies for ultrasound screening for hip dysplasia in the Netherlands. BMC Health Serv Res 2010; 10:75.

24. Garrison LP, Jr., Veenstra DL. The Economic Value of Innovative Treatments over the Product Life Cycle: the case of Targeted Trastuzumab Therapy for Breast Cancer. Value Health 2009; 12:1118-1123.

25. Rogers EM. Diffusion of Innovations. New York: Free Press; 2003.

26. Royal Dutch Shell Company. Available at:

http://www.shell.com/home/content/aboutshell/our_strategy/shell_global_scenarios/dir global_scenarios_07112006.html .2010.7-6-20.

27. Wack P. Scenarios: uncharted waters ahead. Harvard Business Review 1985;73-89.

28. Wack P. Scenarios: shooting the rapids. Harvard Business Review 1985;139-150.

29. Rutgers EJT, Piccart-Gebhart MJ, Delaloge S, van 't Veer LJ, Rubio I, Viale G, Bogaerts J. The EORTC 10041/BIG 03-04 MINDACT trial is feasible: first results of the pilot phase. Eur.J Cancer Suppl . 2010.

30. Buxton, M. J. 2006. Economic Evaluation and Decision Making in the UK. Pharmacoeconomics 24 (11): 1133-42.

31. Lothgren $M$, Zethraeus $N$. Definition, interpretation and calculation of costeffectiveness acceptability curves. Health Econ 2000; 9:623-630.

32. Fenwick E, Claxton K, Sculpher M. Representing uncertainty: the role of costeffectiveness acceptability curves. Health Econ 2001; 10:779-787.

33. Vallejo-Torres L, Steuten LM, Buxton MJ et al. Integrating health economics modeling in the product development cycle of medical devices: a Bayesian approach. Int $J$ Technol Assess Health Care 2008; 24:459-464.

34. Retèl VP, Grutters JPC, van Harten WH, Joore MA. Value of research and value of development in early stages of development of new medical technologies. Submitted.

35. Goldhirsch A, Ingle JN, Gelber RD et al. Threshold for therapies: highlights of the St. Gallen international expert consensus on the primary therapy of early breast cancer 2009. Ann Oncol 2009; 20:1319-1329.

36. Bojke L, Claxton K, Bravo-Vergel $\mathrm{Y}$ et al. Eliciting distributions to populate decision analytic models. Value Health 2010; 13:557-564.

37. Barker AD, Sigman CC, Kelloff GJ et al. I-SPY 2: an adaptive breast cancer trial design in the setting of neoadjuvant chemotherapy. Clin Pharmacol Ther. 2009;86:97100. 



\section{Part IV}

Retrospect \& Prospect

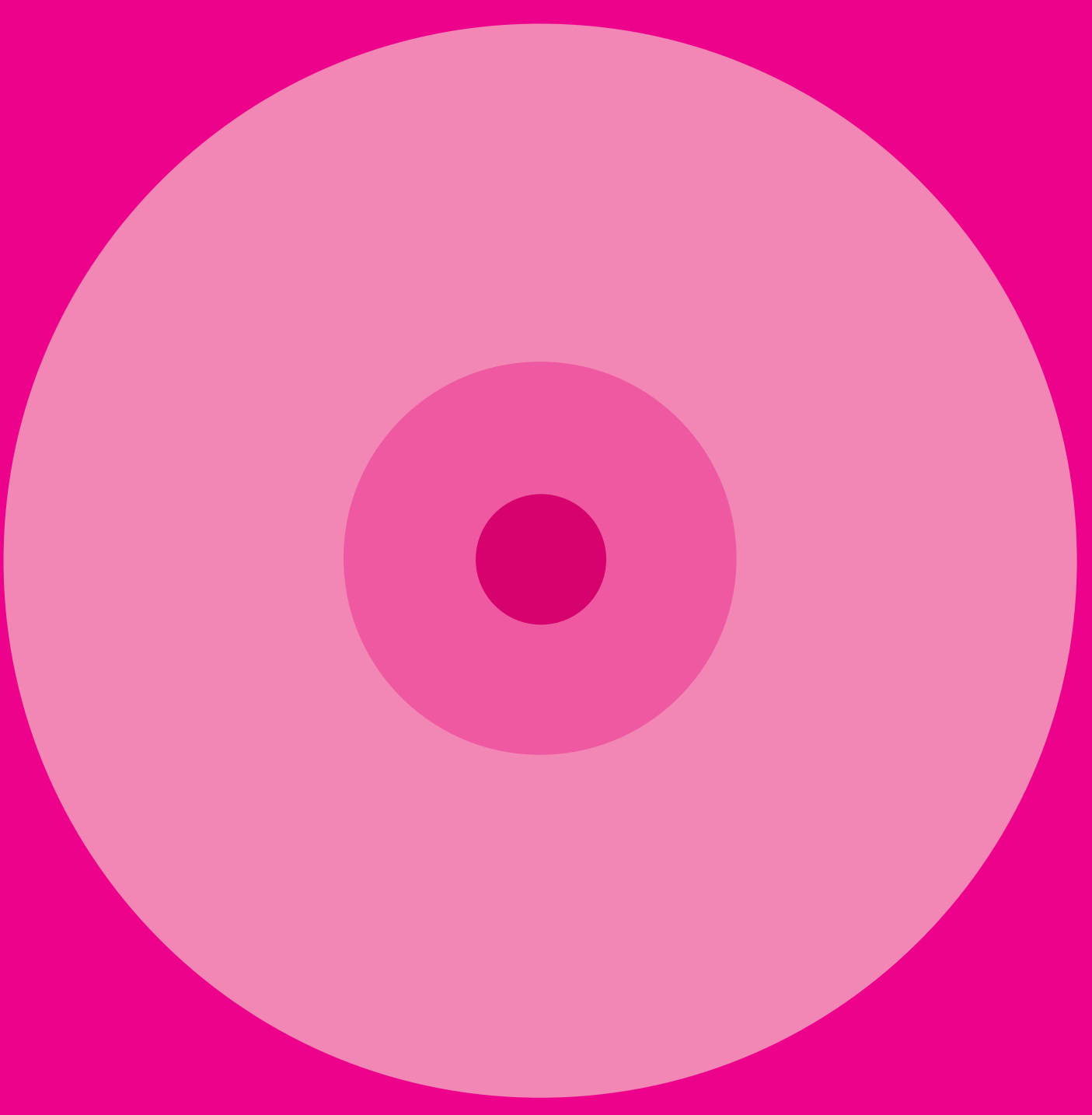




\section{Part I}

Introduction

Chapter 1

General introduction

\section{Objective 1: CTA methodology}

\section{Part II}

CTA

methodology

\section{Chapter 2}

Pilot CTA alongside RASTER

\section{Chapter 3}

Systematic review of early CTA or HTA

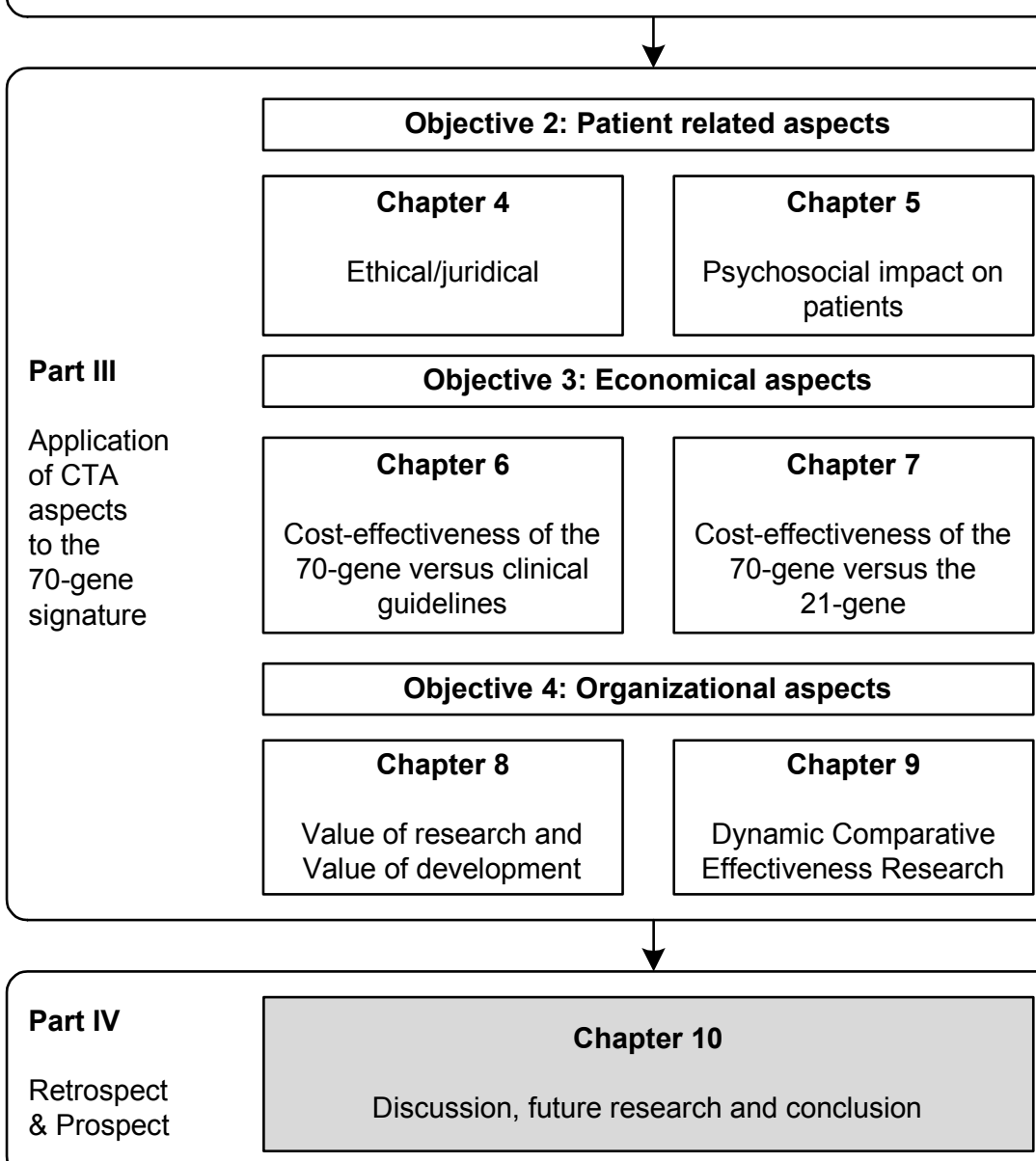




\section{Chapter 10}

Discussion, future perspectives and conclusion 


\section{General discussion}

The overall aim of this dissertation, as introduced in Chapter 1, was twofold: first, to evaluate the CTA method in early stages of technology development and second, to apply the CTA method to the case of the 70-gene prognosis signature for breast cancer, in order to support policy decisions and anticipate on the introduction of this new diagnostic test, taking different CTA aspects into account. In this final chapter, the main findings regarding the research aims are summarized and discussed, followed by the methodological considerations. Subsequently, recommendations and implications for policy and practice are described, and areas for future research are defined. Finally, concluding remarks are made.

\section{Main findings}

\section{CTA method}

The first research objective introduced in the introduction concerned the evaluation of the CTA method. In Chapter 2, we pilot tested, applied and evaluated the CTA methodology alongside the RASTER study ${ }^{1}$ as a means to guide the controlled early implementation of a promising technology and its possible use for coverage decisions. The CTA method was feasible to monitor and to support the initial introduction of a new, promising technology. The 70-gene signature for early breast cancer was tested as a promising technology in this case. It outperforms currently used clinical factors in predicting disease outcome (low or high risk for developing distant metastases) and thereby predicting which women do need chemotherapy and which will be spared chemotherapy. ${ }^{2}$ Pre-post structured surveys were conducted in 15 community hospitals concerning changes in logistics and teamwork as a consequence of the introduction of the 70-gene signature. Median implementation-time of the 70-gene signature was 1.2 months. Most changes were seen in pathology processes and adjuvant treatment decisions. Physicians valued the addition of the 70-gene signature information as beneficial for patient management. Patient-centeredness was measured by questionnaires and interviews regarding knowledge and psychological impact of the test. Respondents $(N=77$, response $78 \%)$ receiving a concordant high-risk and discordant clinical low/genomic high risk-signature showed significantly more negative emotions with respect to receiving both test-results compared to concordant low-risk and discordant clinical high/genomic low risk-signature patients. Diffusion scenarios, which are commonly applied in industry to anticipate on future development and diffusion of their products, were successfully applied in this study. The original scenario was written in 2004 and revised mid-2005, using professional feedback. The initial expectation among the directly involved researchers and professionals was that less adjuvant chemotherapy would be needed compared to guideline 
based treatment and that the impressive potential of the test would lead to swift diffusion. The current Dutch CBO 2004 guidelines, however, proved to be more restrictive in the prescription of adjuvant systemic treatment, compared to the St. Gallen guidelines on which the first analysis was based. ${ }^{3,4}$ It became apparent that the signature in combination with the $\mathrm{CBO}$ guidelines (with the physicians tending to follow the highest risk) led to more chemotherapy prescription in the RASTER study, instead of less. Foreseen in another "what if" deviation of the scenarios, basing a possible catalogue of decisions just on retrospective validation series caused serious debate in the Netherlands.

In Chapter 3, the systematic literature review, the available evidence regarding various aspects of the HTA/CTA methodology was explored in the literature in the field of nanotechnology in oncology. We found only a limited number of publications describing the application of either Health Technology Assessment (HTA) or Constructive Technology Assessment (CTA) in nanotechnologies regarding oncology. In spite of the promising conclusions of most papers concerning the benefits of clinical implementation, actual clinically relevant applications were rarely encountered, and so far only a few publications report application of systematic forms of technology assessment. In order to obtain a realistic perspective on the translation and implementation process there is a need for a broad and systematic evaluation of nanotechnologies at early stages of development. Assessment methods taking technology dynamics into account, such as Constructive Technology Assessment (CTA) should be considered for evaluation purposes.

\section{Patient related aspects}

The second research objective focused on patient related aspects, which could play a role in the introduction of the 70-gene signature. In Chapter 4, it was described that a request from a Dutch woman, previously treated for breast cancer, to have the 70-gene signature performed on her tumor tissue, led to the formation of a working group consisting of lawyers, ethicists, researchers, clinicians and patient representatives to explore and discuss the problem. This resulted in the development of a concept guideline for patient rights on tissue use and storage. Four underlying principles for the guideline were established and subsequently seven main elements were appointed into the guideline. Although the guideline was primary developed for tissue banking policy on tumor tissue, it can also be relevant for the storage of other types of tissue. It is obvious that tissue storage for clinical purposes urgently needs further attention from a medical, ethical, legal and practical perspective. The goal of Chapter 4 was to contribute to enhance further discussion, reflection and debate on this important issue. 
In Chapter 5, the focus was on the impact of the 70-gene signature on patients. Based on the interviews and questionnaires used in the pilot study alongside the RASTER (described in Chapter 2), we developed a questionnaire for the randomized controlled trial, the MINDACT (Microarray In Node-negative and 1 to 3 positive lymph node Disease may Avoid ChemoTherapy; EORTC 10041/BIG 3-04) trial. ${ }^{5,6}$ The MINDACT was designed to prospectively evaluate whether the 70-gene signature selects the right patients for adjuvant chemotherapy as compared to standard clinicopathological criteria. ${ }^{5,6}$ Issues such as information perception, risk perception, knowledge, satisfaction, and patients' well being using distress (by the Lynch scale ${ }^{7}$ ), cancer worries (by the Lerman scale ${ }^{8}$ ), and HRQoL (by the FACT$\left.B^{9}\right)$ were assessed. Women $(N=347$, response rate $62 \%)$ reported high satisfaction and good knowledge regarding the provided information. Low levels of distress were found in the clinical low/genomic low risk groups, significantly higher levels of distress were measured when patients received a high recurrence risk result from their genomic profile, a "not available" genomic risk profile or when there was discordance between genomic and standard clinical criteria for establishing recurrence risk $(p<0.001)$. Cancer worries were highest for patients with prior high risk perception and low satisfaction $(p<0.001)$. Patients reported significantly lower HRQoL by concordant high risk profiles and a "not available" genomic profile $(p<0.001)$. Our results supported earlier findings regarding satisfaction and risk perception to be important factors affecting distress levels. ${ }^{10,11}$

\section{Economical aspects}

For the third research objective, two cost-effectiveness analyses were performed. In Chapter 6, the 70-gene signature was compared to the currently used guidelines in Europe; the Adjuvant Online and St. Gallen. ${ }^{12,13}$ The results showed small differences in survival, but substantial differences in quality-adjusted survival between the prognostic tools. Based on costs per QALY, the 70-gene signature had the highest probability of being cost-effective for a willingness to pay for a QALY higher than $€ 4,600$. Based on costs per LY, St. Gallen showed the highest survival rates, but led to a substantially larger amount of adjuvant chemotherapy advice and hence higher costs, thus demanding a willingness to pay of $€ 29,326$ to save a life year.

Subsequently, in Chapter 7, the cost-effectiveness of the 70-gene signature was head-to-head compared to a competitor test developed in the US; the 21-gene Recurrence Score assay (Oncotype DX) ${ }^{14}$, based on data from two former publications. ${ }^{15,16}$ This comparison indicated that the performances of the 70-gene signature and the 21-gene assay based on reported studies were close. The 70-gene signature had the highest probability to be cost-effective when focusing on costs per QALY, while the 21-gene assay had the highest probability when 
focusing on costs per life years only. The comparison of both tests was assessed on former studies where the methods used were debated. ${ }^{17}$ However; the decision problem was prioritized above the possibly slightly lower quality input data. Based on this analysis one could conclude that more head-to-head evidence on the 70gene signature and 21-gene assay is necessary.

In addition to the latter comparison, the level of compliance based on publications ${ }^{1,8,18}$ was taken into account. Compliance regarding the 70 -gene signature increased from -in case of a clinical high and genomic low risk $60 \%$ and in case of clinical low and genomic high $43 \%$ - overall in the RASTER study to $95 \%$ in the MINDACT trial. However, these percentages were observed in trial settings and probably not representing the real-world practice. After incorporating the compliance levels into the decision model, the mean results only slightly diminished, however, more uncertainty surrounding the cost-effectiveness decision was observed.

\section{Organizational aspects}

The fourth research objective addressed the organizational aspects raised during the introduction of the 70-gene signature. In Chapter 2 organizational aspects were already pilot tested, and processed in more detail in Chapter 8. Subsequently, the scenarios were continued and expanded in Chapter 9.

In Chapter 8 a feasible framework was presented to simultaneously support adoption, development and research decisions in early stages of the development of medical technologies. The value of development was an innovative addition to this already known framework regarding adoption decision and value of research. ${ }^{19}$ The framework was applied to the original 70-gene signature, which is performed on fresh frozen tissue (70G-FFT), but could be further developed to a paraffinbased signature (70G-PAR). The results indicated that there is both value in the further development of the 70-gene signature into a paraffin based test and value in further research into this improved test in terms of cost-effectiveness.

Chapter 9 focused on how to monitor and anticipate on developments in the early and dynamic stage of a medical technology using scenario drafting, in a framework of Comparative Effectiveness Research (CER) ${ }^{20}$ Ten scenarios were drafted regarding the 70-gene signature with European breast cancer experts based on a structured approach. Four most likely scenarios, including "technical failure", "compliance", "reimbursement" and "optimal-adoption" were integrated in a decision-analytic model. We used these scenario outcomes partly in Chapter 7 , explaining the effect of compliance and Chapter 8, illustrating the effect of failures on the cost-effectiveness. In Chapter 9, we combined the effects of compliance, failures and uptake. The Net Monetary Benefit (NMB) for the 70-gene signature 
increased over time with a range of $-€ 2,061$ to $-€ 1,676$ in 2010 and $-€ 2,347$ to $+€ 3,304$ in 2020 depending on the scenario used. The uptake-scenario had a strong influence on the cost-effectiveness, followed by the reduction of technical failures and compliance. Using this case, we showed that in early stages of technology development/introduction, there is not just one outcome of CER.

\section{Methodological considerations}

Some methodological considerations arise from the use of the CTA method in evaluating the early introduction of gene expression profiling for breast cancer.

\section{CTA method}

Douma et al. ${ }^{21}$ explained the CTA method for the introduction of the 70-gene signature in clinical practice. They stated in the discussion that the exact timing of studying the specific aspects relates to the different implementation phases, as described by Rogers. ${ }^{22}$ In the current study, it was decided to first investigate the organizational and patient related aspects, because the Dutch Health Care Insurance Board (DHCIB) was of the opinion that a CEA was not yet relevant in the very early phase of the RASTER study, since the effectiveness and diffusion of the signature was not sufficiently advanced. However, the results of the CTA led to a positive decision on performing a CEA and a discussion on provisional coverage, thus a CEA could have been assessed in an earlier stage. The question is whether or not reimbursement of the 70-gene signature could now already have been established, in case the decision on coverage would have started earlier.

The design of the RASTER study was a feasibility study, a controlled introduction of the 70-gene signature in clinical practice, supported by a CTA. This design revealed on one hand very useful information regarding the early, real-world decision making and the technology related logistic changes in hospitals. Although, on the other hand, not expected when starting the RASTER, a discussion concerning the validity of the 70-gene signature led to the design of the randomized controlled MINDACT trial. This discussion resulted in an expectative attitude by physicians, and led to a prolonged early adoption phase in the diffusion process.

The selection of participating hospitals in the RASTER study was not at random. In agreement with the Dutch Health Care Insurance Board (DHCIB), regional/urban and size differences were taken into account when selecting hospitals which were interested in participating. As a consequence, all hospitals participating in the study were probably early adaptors and willing to put effort in the implementation process, which could have been negatively influenced by random selection. Other diffusion groups might not have a comparable positive attitude towards spending 
money or efforts in implementing the test. For future interested hospitals, the characteristics have to be analyzed, to identify possible other necessary measures for implementation.

\section{Patient related aspects}

The storage and use of residual tissue in the case of the 70-gene signature raised ethical and juridical issues. In general, ethical and juridical aspects are rarely taken into account in HTA. However, especially in early stages of a new era of technology, it seems important to consider these aspects in the total analysis. In the current study, we did not yet incorporate the consequences in for example a cost analysis. The outline of the current study was primarily to open the discussion on tissue banking concerning patient rights.

In the patient questionnaires, eight risk groups were distinguished based on the clinical and genomic risk status and treatment decision. The groups with discordant risk estimates tended to be quite small $(n=12(3 \%)$ and $n=25(7 \%))$, and thus may have limited power of the study to detect significant group differences. This may have caused a bias in the results of the "C-low/G-high assigned to no CT" risk group. Furthermore, the response rate in this study was moderate $(62 \%)$, however, this rate is more often reported in other randomized European Organisation for Research and Treatment of Cancer (EORTC) trials. ${ }^{23,24}$

\section{Economical aspects}

It would be ideal to perform a cost-effectiveness analysis (CEA) on a direct randomized comparison of all relevant alternatives. ${ }^{25}$ While the MINDACT trial is still ongoing, policy makers request information regarding the expected costeffectiveness of the 70-gene signature. Therefore the Markov modeling technique has been used to synthesize the currently available evidence. The performed CEA described in chapter 6 was based on three retrospective validation series assessing three prognostic tests (70-gene signature, St. Gallen (SG) and Adjuvant Online $(\mathrm{AO})$ ) in node-negative, estrogen receptor positive $(\mathrm{ER}+)$ breast cancer patients. $^{26-28}$

Besides the $S G$ and $A O$ guidelines, the 21-gene assay is a fourth relevant alternative. However, a direct comparison of the "original" assays (the compared profiles are performed on one platform and use one algorithm) of the 70-gene signature and 21-gene assay in one independent dataset is not available. The only articles in which both assays are directly compared are Thomassen et al. ${ }^{15}$ and Fan et al. ${ }^{16}$. However, they did not use the "original" assays; they based their comparison on one algorithm or, in case of the Fan series, both on the original 70gene platform. Based on this, we could have chosen to not use these data for our 
analysis. However, the decision problem requires information with regard to the cost-effectiveness of the 70-gene signature relative to also the 21-gene assay. In this dissertation, the 70-gene signature was first compared to $S G$ and $A O$, (Chapter 6), and subsequently to SG and 21-gene assay or AO and 21-gene assay (Chapter 7), separately.

A next step would be to synthesize all available evidence, comparing all alternatives in one analysis, by using mixed treatment comparison (MTC) ${ }^{29}$ MTC allows for indirect comparisons and can therefore provide very useful information for clinical and reimbursement decision-making in the absence of head-to-head data.

The cost-effectiveness outcomes were sensitive to changes in the cost inputs. We modeled in our analysis the currently used chemotherapy and hormonal therapy applications. This may have been an underestimation, since the costs of future adjuvant chemotherapy regimens are expected to increase in the coming years and hormonal therapy is expected to be prolonged from 5 to 7 years. ${ }^{30}$ Due to these facts, the cost-effectiveness for the 70-gene signature could be positively influenced.

Using QALY as an outcome in cost-effectiveness analyses in oncology is a debated issue, as it has proven to be difficult to estimate health state utilities among cancer patients. ${ }^{31}$ However, when applying a test aiming to reduce chemotherapy over-treatment, as in this study, it seems inevitable to somehow quantify the effects of treatment on the quality of life of patients with cancer. In the current study, there was not yet specific evidence available for utilities in this specific case, which was the reason to use utility scores from the literature. This emphasizes the need for more data on the quality of life of cancer patients, especially during active treatment, and the importance of research directed at possible biases and innovative methodologies in measuring health state utilities for use in economic evaluations.

In the cost-effectiveness analysis in Chapter 6, it was assumed that the 70-gene signature would be performed for every early ER+ breast cancer patient, no technical failures appeared, and that both physicians and patients would be $100 \%$ compliant to the prognostic test result. Therefore, the results of this study -and of most other cost-effectiveness studies- do just partly reflect reality. In Chapter 7 , we incorporated compliance rates from the MINDACT trial pilot. ${ }^{18}$ Although one can debate whether these compliance rates are reflecting real world compliance as they are based on a randomized setting, it appeared to be a driver for outcomes. The analysis showed slightly lower mean results on cost-effectiveness, but especially higher decision uncertainty. In the Chapters 8 and 9 we dealt with the 
effects of failures and uptake on the cost-effectiveness. Findings from these studies are reported in the next paragraphs.

\section{Organizational aspects}

The results of Chapter 8 indicated that there is both value in further development of the 70-gene signature into a paraffin based test and value in further research into this improved test. In the analysis, we calculated these possibilities assuming a non-constrained societal health care budget, which is not reality. The next step is to calculate the tradeoff between value of research and development in case of a constrained -societal- budget. The return on investment-calculations have been shown earlier by Eckermann \& Willan $^{32}$, however, they calculated from a manufacturers' perspective. If the societal perspective is taken into account, the information could be used by, amongst others, the government to make policy decisions.

Although the use of scenarios in CEA is not new; our application was based on an innovative approach, incorporating qualitative scenarios from different stakeholders at different policy levels in the model. The use of the scenario method made it possible to translate some of the qualitative scenarios into quantitative parameters, and derive likelihoods from the experts during the workshop, in order to identify and prioritize the most likely scenarios. The method of using scenarios incorporated in cost-effectiveness modeling has to be further developed, for example to refine the qualitative scenario results for quantitative input. Furthermore, to keep the analysis stable, we modeled the uncertainty constant over time. As it is expected that the uncertainty will decrease over time, this has to be incorporated in future analyses.

\section{Recommendations, implications and future research}

In the following paragraphs recommendations will be provided, policy and health care implications will be stated and future research areas are set out.

\section{CTA method}

In their methodological paper, Douma et al. ${ }^{21}$ stated the hypothesis that CTA could be a valuable addition to traditional HTA in 1) early stage technologies and/or 2) complex techniques. With the results of our study we can conclude that both hypotheses can be confirmed. CTA is especially suitable for assessing biologybased technologies, such as currently investigated in the Serial studies to Predict Your Therapeutic Response with Imaging And MoLecular analysis (ISPY-trial). The ISPY trial uses an intermediate endpoint in the analyses (pathological complete response $(\mathrm{PCR})$ ) to evaluate study results at an earlier stage. ${ }^{33}$ It is important to support those studies with, for example, a CTA in order to monitor developments 
and anticipate upon them in an early stage. Structured scenario drafting and early expert meetings could possibly facilitate a quicker transfer from biology laboratories to daily clinical practice.

Our study was performed mostly from a health policy decision maker's perspective. However, one could also take a broader perspective for the adaption of the CTA method. In our case for example, the further development of the 70-gene signature on paraffin may be interesting for the further adoption of this specific test on one hand. On the other hand, for the broader scope of future molecular medicine research, the storage of fresh frozen tissue could be more valuable. An example is the Center for Translational Molecular Medicine (CTMM) project in the Netherlands ${ }^{34}$, where a broader approach is taken for stimulating the knowledge of economy and knowledge transfer regarding molecular medicine. Molecular Medicine combines fundamental discoveries in the underlying (molecular) biology of health and disease with breakthroughs in medical technology, particularly in the areas of Molecular Diagnostics and Imaging. This enables not only earlier and more precise detection of diseases and even predisposition, but also personalized treatments that are more effective, cause fewer side effects, and are more costeffective due to stratification of specific patient risk and prediction of response to therapy. The CTA method could play a relevant role in this project, especially in terms of technology dynamics.

The results of the current study implicated that anticipation is important to be able to control and improve the diffusion rate, to maximize the potential (cost-) effectiveness, to improve patient-related aspects and to anticipate on ethical and juridical aspects in an early stage of technology introduction. Interesting is to investigate if anticipation and influencing possible future (undesirable) developments also works in very early stages.

We expect that if CTA in the future will be applied even earlier in the introduction process, the logistics for example could be more efficient and anticipated upon, and thus the new technology will be more -besides patient tailored- also "organization tailored". Furthermore, learned from the results of the current study, we would recommend organizing stakeholder meetings in an earlier stage, to investigate what is necessary for coverage, to maximize the potential costeffectiveness as soon as possible.

The introduction of the 70-gene signature had several clinical and logistic implications. The prognosis signature results in a mean of $30 \%$ discordant cases compared to current guidelines. This means that physicians have to know how to handle (after/outside the MINDACT trial) in the actual adjuvant treatment decision. The 70-gene signature and 21-gene assay are currently incorporated in clinical 
guidelines; however the exact use in which clinical case could yet be more described in detail to guide physicians. Furthermore, physicians have to be aware that this discordant patient-group could benefit from more support and counseling throughout their treatment trajectory.

Because both genomic profiles are already in use outside the ongoing trials, it is important to control the correct and efficient use of these instruments. Regarding logistic implications, the participating hospitals in the RASTER and MINDACT could act as examples for other hospitals. Hospitals who would like to implement the 70-gene signature, should take into account changes in work routines and decision making, and thus have a solid "breast cancer team", existing of all relevant professionals needed for a successful implementation. The contact between researchers and physicians in daily practice during the implementation, as Douma et al. ${ }^{21}$ and van Eijndhoven et al. ${ }^{35}$ suggested, was close and therefore fruitful, because the researchers were able to exactly observe the changes, advice and anticipate upon developments in an early stage.

\section{Patient related aspects}

A continuous discussion is necessary on patient rights concerning tissue use and storage, to prevent that tissue, necessary for patients care in the future, will be used for other purposes. We formulated seven relevant aspects in a concept guideline, which have to be further discussed in both clinical practice, and at policy level. Who will for example pay for this -desirable- double storage, and which ethical decisions have to be taken on informing patients with regard to the development and implementation of new tests? And will the performance of such a test, years later, have the same -or still a medical useful- effect? The next step would be legislation on the concept guidelines and handle the practical issues to ensure the necessary logistics. We recommend double tissue storage; the pathologist should divide the received residual tissue in two pieces, one for research and one for the patients' future. However, these recommendations will imply increasing administration and therewith costs.

We recommend the physicians to maintain their current patient information and keep informing the patients as they do. This is based on our results of Chapter 5 regarding impact of genomic testing on patients, which showed that patients have a good understandability of the results and consequences of the 70-gene signature and are satisfied regarding the information they receive. However, there could be some extra attention to the discordant patients; they could use some more information and guidance through the decision trajectory. Furthermore, we recommend handling the results from prognostic tests in one occasion to prevent the so called "reference point effect", where according to the prospect theory the 
way content is presented influences the opinion people develop. ${ }^{36}$ This is specifically the case in communicating discordant risk results.

Furthermore, it would be interesting to further investigate the link between factors such as understandability, the provided information, satisfaction and knowledge with levels of distress, worries or HRQoL, by means of Structural Equation Modeling (SEM). ${ }^{37}$ SEM allows for both confirmatory and exploratory modeling, meaning they are suited to both theory testing and theory development. Confirmatory modeling usually starts out with a hypothesis that is represented in a causal model. The concepts used in the model must then be operationalized to allow testing of the relationships between the concepts in the model. This analysis requires however a larger patient population.

Discrete choice experiments (DCE) is another method that could have been used to investigate patient preferences. ${ }^{38}$ A DCE is a survey methodology capable of establishing preferences, which is grounded in economic theory, and has an advantage over traditional satisfaction questionnaires, in that it enables the researcher to measure strength of preferences for different characteristics of follow-up and the tradeoffs made between them. DCEs are found to be a valid and reliable approach to elicit preferences in a health care context and are recognized as a useful tool for medical decision making.

\section{Economical aspects}

In this era of rapid innovation and thereby steadily increasing costs in cancer care, further research is necessary towards cost-effectiveness in early technology stages. Especially in early stages of technology development, value of information (VOI) analysis is a valuable method to determine if there is need for further information, in case of an adoption decision. ${ }^{39}$ The Expected Value of Perfect Information (EVPI) could identify the value of further information, the Expected Value of Perfect Partial Information (EVPPI) could identify even the specific uncertain elements in the adoption. With this information, decisions could be made on for example the necessity of a clinical trial. Using Expected Value of Sampling Information (EVSI), the optimal sample size of this trial can be calculated. Eventually, coverage decisions could be made in early stages, for example in the framework of coverage with evidence development (CED).

In the case of the 70-gene signature, there is an ongoing debate concerning the best way to use the 70-gene signature, and in which different subgroups the 70gene signature has an added value, and which thus would be cost-effective. According to new insights, Knauer et al. distinguished more subgroups according to the HER2 status and ER status, which could influence the cost-effectiveness as well. ${ }^{40}$ Mook et al. suggests to include also the 1-3 node positives besides the node 
negatives, which could cause a shift in the adjuvant treatment in the high risk groups ${ }^{41}$ Furthermore, Mook et al. also identified a ultra-low group within the low risk group, who have an ultra low risk of developing metastasis. ${ }^{42}$ And Knauer et al. showed besides the prognostic value of the 70 -gene signature also the predictive value. ${ }^{43}$ Further research into the cost-effectiveness for these specific subgroups where the 70-gene signature would be most efficient could be a next step.

For a high quality (cost) effectiveness comparative analysis, we recommend that the 70-gene signature and the 21-gene assay are compared in one good quality dataset with long term follow-up. A comparative effectiveness research on the 70gene signature and 21-gene assay should be designed to eventually know which test is best to use in which specific case. If this is not possible, the next step to undertake after the current study showed in Chapter 7 is Mixed Treatment Comparison (MTC). With MTC, the relative efficacy (or safety) of a particular intervention versus competing interventions can be obtained in the absence of head-to-head comparisons; indirect comparison of two interventions is made through a common comparator. ${ }^{29}$ Using MTC we should be able to calculate the comparison between the 70-gene signature and 21-gene assay indirectly, correcting for the fact that they are originating from different datasets.

Taking technology or environmental dynamics into account in CEAs should also be further explored. Compliance was one of the dynamical aspects incorporated in a CEA, which showed to have clinical implications on micro/meso level. The level of implementation is likely to be related with the level of information. And, the provision of information would alter the adherence to guidance, for instance through publication of research evidence (in the case of the MINDACT trial), as described by Hoomans et al. ${ }^{44}$ However, compliance may be already improved by giving more information regarding the use and consequences of the 70-gene signature.

\section{Organizational aspects}

In general, further research into other technologies and their specific innovations or improvements incorporating in CEAs could be interesting to investigate. Developing specifically the 70-gene signature based on paraffin instead of fresh frozen tissue could establish a higher cost-effectiveness and thus a worthwhile investment. If this paraffin based 70-gene signature comes into the market, the use is assumed to increase, because this test is more user-friendly compared to the current test. We recommend further research into the possibilities of developing the 70-gene signature on paraffin, in order to give every hospital the chance to use the 70-gene signature. 
In the framework of a constrained budget, it would be interesting to further look into how a fixed budget should be allocated over different activities aimed at either further development or further research. To solve this issue, portfolio management, based on return on investment calculations, could be used. ${ }^{32}$ An additional question is whether we should wait for new evidence before further development. This question could be informed by a Real Options Analysis (ROA). ${ }^{45}$ Girling et al. presented a method for valuing a new medical technology at the concept stage from the perspective of the manufacturer. It could be interesting to investigate if it is possible to integrate the two perspectives of the manufacturer and society in one analysis. ${ }^{46}$

Scenarios regarding failure, compliance and uptake were found to have impact on the cost-effectiveness. Therefore, it could be interesting to look closer into the mechanisms of these aspects, as they could also be an example for other new technology introductions. For example, why do physicians decide whether or not to follow the guideline or the genomic test result? Furthermore, the uptake of the 70gene signature appeared to have the largest impact on the cost-effectiveness, which the chain-reaction is herein the difficult aspect. More in specific, for example, in case the 70-gene signature would be reimbursed, the uptake will increase, and in reaction, the compliance will increase, because the 70-gene signature is more used and discussed. The Coverage with Evidence (CED) program should play a more prominent role in this issue. Finally, countries can have different implementation and diffusion patterns, possibly related to their attitude towards technology innovation. While the 70-gene signature was FDA approved in the US based on the available validation studies, basing a possible catalogue of decisions just on retrospective validation series caused serious debate in the Netherlands. Consensus among opinion leaders on the value of this type of prognostics appears to be essential for further diffusion.

The incorporation of multiple scenarios on different micro/meso/macro levels has to be further investigated, in order to have a multi-level overview of the expected costs and outcomes. A next phase could be to derive more quantitative scenarios, by preparing the choices for the experts in a more quantitative way, as has been described by some authors. ${ }^{47}$ Furthermore, the scenarios were chosen based on the likelihoods, prioritized by the breast cancer experts. To incorporate the likelihoods as parameter uncertainty, a method such as parameterizing could be a solution. ${ }^{48}$

Also, the question is on which scenario(s) do the policy makers have to make their decision? Because, for example, from the perspective of the 70-gene signature case, we recommend further research into the possibilities of developing the 70-gene signature on paraffin, in order to give every hospital the chance to use the 
70-gene signature. However, on the other hand, maintaining the fresh frozen tissue logistics could be very important for future clinical research in general, as is known that the quality of DNA decreases in paraffin embedded tissue blocks.

\section{Concluding remarks}

This study showed that the CTA methodology could be a useful tool to guide controlled early implementation of a promising technology and its possible use for coverage decisions, in this case the 70-gene prognosis signature in the treatment of breast cancer patients. Regarding future tissue banking we hope that our concept guideline will lead to a debate and further investigation regarding the consequences of residual tissue for patients. The patient information regarding the result and consequences of the 70-gene signature was clear and satisfactory and resulted in a good understanding of (the consequences of) the genomic profile. The 70-gene signature is most cost-effective in terms of quality adjusted life years compared to clinical guidelines and the 21-gene assay. Somewhat more sensitive tests deliver more life years, but lead to a substantial larger amount of using adjuvant chemotherapy and hence higher costs, thus demanding a higher willingness to pay. Developing the 70-gene signature based on paraffin instead of fresh frozen tissue could establish a higher cost-effectiveness and could thus be a worthwhile investment; however on the other hand, fresh frozen tissue is more valuable of future research in general. Finally, when incorporating scenarios, it is apparent that early anticipation on certain aspects is necessary to reach the potential cost-effectiveness. Learned from the results of the current study, we would recommend organising stakeholder meetings in an earlier stage, to investigate what is necessary for coverage.

As a final remark, the best results will be reached when all relevant stakeholders will optimally communicate, anticipate and work together. The four most influential parties in the case of the 70-gene signature were the (fundamental) biomedical researchers, physicians (hospital policy), the health economists and the (national) health insurance companies. The 70-gene signature was one out of three first new technologies studied in a "Coverage with Evidence Development" (CED) program in the Netherlands, which is one of several policy options that have been posited to overcome the problems associated with making coverage decisions under uncertainty. In this perspective, each party must be working with and towards the same goal, namely; to ensure that worthwhile technology can be used by every beneficiary patient. 


\section{References}

1. Bueno-de-Mesquita JM, van Harten W, Retèl V et al. Use of 70-gene signature to predict prognosis of patients with node-negative breast cancer: a prospective community-based feasibility study (RASTER). The Lancet Oncology 2007; 8:10791087.

2. Van 't Veer LJ, Dai H, van de Vijver MJ et al. Gene expression profiling predicts clinical outcome of breast cancer. Nature 2002; 415:530-536.

3. Goldhirsch A, Glick JH, Gelber RD et al: Meeting highlights: International Consensus Panel on the Treatment of Primary Breast Cancer. Seventh International Conference on Adjuvant Therapy of Primary Breast Cancer. J Clin Oncol 2001; 19:3817-3827.

4. Kwaliteitsinstituut voor de Gezondheidszorg $\mathrm{CBO}$, Vereniging voor Integrale Kankercentra: Adjuvante Systemische Therapie voor het Operabel Mammacarcinoom. Richtlijn Behandeling van het Mammacarcinoom. 2005:46-70.

5. Bogaerts J, Cardoso F, Buyse M et al: Gene signature evaluation as a prognostic tool: challenges in the design of the MINDACT trial. Nat Clin Pract Oncol 2006;3:540-551.

6. Mook S, Van't Veer LJ, Rutgers EJ et al: Individualization of therapy using Mammaprint: from development to the MINDACT Trial. Cancer Genomics Proteomics 2007;4:147-155.

7. Lynch HT, Lemon SJ, Durham $C$ et al. A descriptive study of BRCA1 testing and reactions to disclosure of test results. Cancer 1997; 79:2219-2228.

8. Lerman $C$, Daly M, Masny $A$ et al. Attitudes about genetic testing for breast-ovarian cancer susceptibility. J Clin Oncol 1994; 12:843-850.

9. Brady MJ, Cella DF, Mo F et al. Reliability and validity of the Functional Assessment of Cancer Therapy-Breast quality-of-life instrument. J Clin Oncol 1997; 15:974-986.

10. Lo SS, Mumby PB, Norton J et al. Prospective multicenter study of the impact of the 21-gene recurrence score assay on medical oncologist and patient adjuvant breast cancer treatment selection. J Clin Oncol 2010; 28:1671-1676.

11. Richman AR, Tzeng JP, Carey LA et al. Knowledge of genomic testing among earlystage breast cancer patients. Psycho-Oncology 2010.

12. Ravdin PM, Siminoff LA, Davis GJ et al: Computer program to assist in making decisions about adjuvant therapy for women with early breast cancer. J Clin Oncol 2001;19:980-991.

13. Goldhirsch A, Wood WC, Gelber RD et al. Progress and promise: highlights of the international expert consensus on the primary therapy of early breast cancer 2007. Ann Oncol 2007; 18:1133-1144.

14. Paik S, Shak S, Tang G et al. A multigene assay to predict recurrence of tamoxifentreated, node-negative breast cancer. N Engl J Med 2004; 351:2817-2826.

15. Thomassen $M$, Tan Q, Eiriksdottir $F$ et al. Comparison of Gene Sets for Expression Profiling: Prediction of Metastasis from Low-Malignant Breast Cancer. Clin Cancer Res 2007;13(18):5355-5360.

16. Fan $C$, Oh DS, Wessels $L$ et al. Concordance among gene-expression-based predictors for breast cancer. N Engl J Med 2006; 355:560-569.

17. Haibe-Kains B, Desmedt C, Piette $F$ et al. Comparison of prognostic gene expression signatures for breast cancer. BMC Genomics 2008; 9:394.

18. Rutgers EJT, Piccart-Gebhart MJ, Delaloge S, van 't Veer LJ, Rubio I, Viale G, Bogaerts J. The EORTC 10041/BIG 03-04 MINDACT trial is feasible: first results of the pilot phase. Eur.J Cancer Suppl . 2010.

19. Claxton K, Sculpher M, Drummond M. A rational framework for decision making by the National Institute For Clinical Excellence (NICE). Lancet 2002; 360:711-715. 
20. American College of Physicians. Information on Cost-Effectiveness: An Essential Product of a National Comparative Effectiveness Research Program. Ann Intern Med 2008; 148:957-961.

21. Douma KF, Karsenberg K, Hummel MJ et al: Methodology of constructive technology assessment in health care. Int J Technol Assess Health Care. 2007; 23:162-168.

22. Rogers EM: Diffusion of Innovations. 5th edition. New York: Free Press, 2003.

23. Curran D, van Dongen JP, Aaronson NK et al. Quality of life of early-stage breast cancer patients treated with radical mastectomy or breast-conserving procedures: results of EORTC trial 10801. The European Organization for Research and Treatment of Cancer (EORTC), Breast Cancer Cooperative Group (BCCG). Eur J Cancer 1998;34(3):307-14.

24. De Haes JCJM, Curran D, Aaronson NK et al. Quality of life of breast cancer patients aged over 70 years, participating in the EORTC 10850 randomised clinical trial. Eur $\mathrm{J}$ Cancer 2003;39(7):945-51.

25. Drummond MF, Sculpher MJ, Torrance GW et al. Methods for the economic evaluation of health care programmes. Oxford: Oxford University Press; 2005.

26. van de Vijver MJ, He YD, van 't Veer LJ et al. A Gene-Expression Signature as a Predictor of Survival in Breast Cancer. N Engl J Med 2002; 347:1999-2009.

27. Buyse M, Loi S, van't Veer L et al. Validation and Clinical Utility of a 70-Gene Prognostic Signature for Women With Node-Negative Breast Cancer. J Natl Cancer Inst 2006; 98:1183-1192.

28. Bueno-de-Mesquita JM, Linn SC, Keijzer R et al. Validation of 70-gene prognosis signature in node-negative breast cancer. Breast Cancer Res Treat 2009;117(3):483495.

29. Jansen JP, Crawford B, Bergman G, Stam W. Bayesian Meta-Analysis of Multiple Treatment Comparisons: An Introduction to Mixed Treatment Comparisons. Value in Health 2008;11(5):956-964.

30. Goldhirsch A, Ingle JN, Gelber RD et al. Threshold for therapies: highlights of the St. Gallen international expert consensus on the primary therapy of early breast cancer 2009. Ann Oncol 2009; 20:1319-1329.

31. Earle CC, Coyle D, Evans WK. Cost-effectiveness analysis in oncology. Ann Oncol 1998; 9:475-482.

32. Eckermann \& Willan. Expected Value of Information and Decision Making in HTA. Health Economics 2007;16:195-209.

33. Barker AD, Sigman CC, Kelloff GJ et al. I-SPY 2: an adaptive breast cancer trial design in the setting of neoadjuvant chemotherapy. Clin Pharmacol Ther. 2009;86:97100.

34. Center for Translational Molecular Medicine, available at: www.ctmm.nl .

35. Van Eijndhoven JCM. Technology Assessment: product or process. Technological Forecasting and Social Change 1997;54:269-286.

36. Tversky A and Kahneman D. Advances in Prospect Theory: Cumulative Representation of Uncertainty. Journal of Risk and Uncertainty 1992;5(4):297-323.

37. Hoyle, R H (ed) (1995) Structural Equation Modeling: Concepts, Issues, and Applications. SAGE, ISBN 0-8039-5318-6.

38. Ryan M, Gerard K. Using discrete choice experiments to value health care programmes: Current practice and future research reflections. Appl Health Econ Health Policy 2003;2:55-64.

39. Briggs A, Claxton K, Sculpher M. Decision Modeling for Health Economic Evaluation. Chapter 6; Decision-making, uncertainty and the value of information. Oxford University Press 2006, ISBN 0-19-852662-8. 
40. Knauer M, Cardoso F, Wesseling J, et al. Identification of a low-risk subgroup of HER2-positive breast cancer by the 70-gene prognosis signature. $\mathrm{Br} \mathrm{J}$ Cancer 2010;103:1788-1793.

41. Mook S, Schmidt MK, Viale G et al. The 70-gene prognosis-signature predicts disease outcome in breast cancer patients with 1-3 positive lymph nodes in an independent validation study. Breast Cancer Res Treat 2009; 116:295-302.

42. Mook S, Knauer M, Bueno-de-Mesquita JM. Metastatic potential of T1 breast cancer can be predicted by the 70-gene MammaPrint signature. Ann Surg Oncol. 2010 May;17(5):1406-13.

43. Knauer M, Mook S, Rutgers EJT. The predictive value of the 70-gene signature for adjuvant chemotherapy in early breast cancer. Breast Cancer Res Treat. 2010 Apr;120(3):655-61.

44. Hoomans T, Fenwick E, Palmer S, Claxton K. Value of Information and Value of Implementation: Application of an Analytic Framework to Inform Resource Allocation Decisions in Metastatic Hormone-Refractory Prostate Cancer. ViH 2009; 12:315-324.

45. O'Brien BJ, Sculpher MJ. Building uncertainty into cost-effectiveness rankings: portfolio risk-return tradeoffs and implications for decision rules. Med Care 2000; 38(5):460-8.

46. Girling A, Young T, Brown $C$ et al. Early-stage valuation of medical devices: the role of developmental uncertainty. Value Health 2010; 13:585-591.

47. Bojke L, Claxton K, Bravo-Vergel $Y$ et al. Eliciting distributions to populate decision analytic models. Value Health 2010; 13:557-564.

48. Bojke L, Claxton K, Sculpher M, Palmer S. Characterizing structural uncertainty in decision-analytic models: a review and application of methods. Value in Health. 2009; 12:739-49. 



\section{Chapter 11}

Summary/Samenvatting 


\section{Summary}

\section{Introduction}

Health Technology Assessment (HTA) is a field of research, which has become the mainstream in evaluation research in health care over the last decennia. The definition of HTA is "a multi-disciplinary field of policy analysis that examines the medical, economic, social and ethical implications of the incremental value, diffusion and use of a medical technology in health care". HTA can be seen as a bridge between the scientific evidence and policy decision-making. The results of HTA could be used by various groups of (health care) professionals at different levels of decision making. Nowadays, HTA is frequently used to enable decisions on coverage and reimbursement of new technologies.

An HTA generally starts after the technology is stabilized and proven to be valid in clinical trials, to be able to choose between comparable technologies or alternatives for the existing situation. While the usual path of adoption in clinical practice would take at least 8-10 years, including a prospective randomized trial, many changes in available treatments can occur during this time, which results in HTA subsequently answering -at least partly- outdated questions. However, if we wait to perform an HTA, it might very well be that worthwhile technology is withheld from the public.

Constructive Technology Assessment (CTA) can be used as a complementary approach to HTA, especially for the early and dynamic introduction of new technologies in a controlled way. CTA is based on the idea that during the course of technology development, choices are constantly being made about the form, the function, and the use of that technology.

A new diagnostic tool for breast cancer patients, the 70-gene signature, identified in 2002 using microarray analysis for lymph node-negative breast cancer patients, is a promising technology. It outperforms currently used clinical factors in predicting disease outcome and thereby predicting which women do need chemotherapy and which will be spared chemotherapy. Patients with a "good" signature were deemed to have a good prognosis and, therefore, could be spared adjuvant systemic treatment, whereas patients with a "poor" signature were judged to have a poor prognosis or a high risk of development metastasis and should be considered for adjuvant systemic treatment. To introduce this technology in a controlled way into clinical practice, it was chosen to perform a CTA, which takes technology dynamics into account. 
As elucidated in Chapter 1, the overall aim of this dissertation was two fold: first to develop the CTA method in early stages of technology development and second, to apply the CTA method to the case of the 70-gene signature for breast cancer, in order to support and anticipate on the introduction of this new diagnostic test, specified in different CTA aspects.

This research was performed alongside two clinical studies, the RASTER and MINDACT. In the RASTER study, the adjuvant treatment decision is made by the patient and the physician, based on the 70-gene signature and clinical guidelines. In the MINDACT trial discordant patients (genomic low/clinical high or genomic high/clinical low) are randomized between the decision of adjuvant CT based on the genomic or clinical assessment.

\section{CTA method}

In Chapter 2, we pilot tested the CTA method to support the introduction of the 70-gene prognosis signature (MammaPrint ${ }^{\top \mathrm{M}}$ ) for node-negative breast cancer patients. CTA is described as a means to guide early implementation of new developments in society, and useful as an evaluation tool for Coverage with Evidence Development (CED). Studied aspects during this introduction were organizational, patient related and economical aspects. Pre-post structured surveys were conducted in 15 community hospitals concerning changes in logistics and teamwork as a consequence of the introduction of the 70-gene signature. Patient-centeredness was measured by questionnaires and interviews concerning knowledge and psychological impact of receiving the test. Diffusion scenarios, which are commonly applied in industry to anticipate on future development and diffusion of their products, have been applied in this study. Median implementationtime of the 70-gene signature was 1.2 months. Differences in implementation speed and changes in treatment decisions were seen. Impact on patients seemed especially related to discordant test results with clinical guidelines and its successive communication. Finally, it was found that CTA can be useful as a tool to guide CED by adding monitoring and anticipation on possible developments during early implementation, to the assessment of promising new technologies.

In Chapter 3, we presented a systematic review of the literature regarding early technology assessments of nanotechnologies in oncology, with particular emphasis on clinical efficacy, logistics, patient-related features and technology dynamics. Due to the current stage of development of most nanotechnologies, we found only a limited number of publications describing the application of either HTA or CTA. In spite of the promising conclusions of most papers concerning the benefits of clinical implementation, actual clinically relevant applications were rarely encountered, and so far only a few publications report application of systematic 
forms of technology assessment. To obtain a realistic perspective on the translation- and implementation process there is a need for a broad and systematic evaluation of nanotechnologies at early stages of development. Assessment methods taking technology dynamics into account, such as Constructive Technology Assessment (CTA) should be considered for evaluation purposes.

\section{Patient related aspects}

In Chapter 4, a request from a Dutch woman to have her tumor tissue tested years after treatment confronted the Netherlands Cancer Institute (NKI) and its staff with legal, ethical, and practical questions regarding patients' rights in relation to residual tissue storage and its use for clinical purposes. Was her tissue still available? If so, could she demand that the test be carried out or her tissue be transferred to another hospital? As it became apparent that appropriate guidance was lacking in this area, we organized meetings with the involvement of relevant professionals and patient representatives within the framework of a Technology Assessment project. In these meetings, we explored four general principles, using legal and ethical related documents, and seven main elements were described in the newly developed guideline. It is obvious that tissue storage for clinical purposes urgently needs further attention from a medical, ethical, legal and practical perspective. Hopefully, the guidelines we proposed will contribute to the discussion on this important issue.

In Chapter 5, the primary aims were to evaluate the impact of receiving a gene expression profile on breast cancer patients' well being. Participants were Dutch women being treated for early stage breast cancer who were participating in a randomized clinical trial, called as the MINDACT (Microarray In Node-negative and 1 to 3 positive lymph node Disease may Avoid ChemoTherapy) trial. After surgery, the patients received a recurrence risk estimate from the 70-gene signature and the Adjuvant Online program. We send a questionnaire assessing distress, cancer worries, and HRQoL. Women $(N=347$, response rate $62 \%)$ reported high satisfaction and good knowledge regarding the provided information. Low levels of distress were found in the clinical low/genomic low risk groups, significantly higher levels of distress were measured when patients received a double high risk result, an "not available" genomic risk profile or when there was discordance between genomic and the clinical guideline $(p<0.001)$. Cancer worries were highest for patients with prior high risk perception and low satisfaction $(p<0.001)$. Patients reported significantly lower HRQoL by concordant high risk profiles and a "not available" genomic profile $(p<0.001)$. Recommendations for clinical use of expression profiles are to increase awareness that genomic test results can affect patients' well being, and by providing more specific support for patients with discordant- and high risk distress may be reduced. 


\section{Economical aspects}

In Chapter 6, a cost-effectiveness analysis of the 70-gene signature compared to the commonly used clinical-pathological guidelines in Europe, such as the Adjuvant! Online and the St. Gallen was performed. For this comparison, a Markov decision model was used to simulate the 20-year costs and outcomes (survival and quality-of-life adjusted survival (QALYs)) in a hypothetical cohort of node-negative, estrogen receptor positive breast cancer patients. Sensitivity and specificity of the three prognostic tools were based on 5 and 10 years breast cancer specific survival and distant metastasis as first event, derived from a dataset consisting of 305 tumor samples from 3 previously reported validation studies concerning the 70-gene signature. Small differences in survival, but substantial differences in quality-adjusted survival between the prognostic tools were observed. Qualityadjusted survival was highest when using the 70-gene signature. Based on costs per QALY, the 70-gene signature has the highest probability of being cost-effective for a willingness to pay for a QALY higher than $€ 4,600$. St. Gallen showed the highest survival rates, but led to a substantial larger amount of adjuvant chemotherapy advice and hence higher costs, thus demanding a willingness to pay of $€ 29,326$ to save a life year.

In Chapter 7, the 70-gene signature was compared to a competitor test, the 21gene assay Recurrence Score, developed in the US. For the comparison of the two genetic tests, only two (smaller) datasets were available wherein both the 70-gene signature and 21-gene assay were compared with clinical guidelines. Additionally, we incorporated compliance rates derived from literature. The analyses indicated that the performances of the 70-gene signature and the 21-gene assay based on reported studies are close and highly uncertain. When incorporating compliance rates, the 70-gene signature was more cost-effective compared to the 21-gene assay. The mean results only slightly diminished, however, more uncertainty surrounding the cost-effectiveness decision was observed.

\section{Organizational aspects}

Chapter 8 presented a framework to simultaneously support three decisions with regard to the adoption, further development, and further research of the new technology. The value of development was an innovative addition to this already known framework. The framework is applied to the 70-gene signature, performed on fresh frozen tissue (70G-FFT), but could be further developed to a paraffinbased signature (70G-PAR). The previous Markov decision model was used, comparing the 70G-FFT and the clinical guideline Adjuvant Online, the 70G-PAR was added as a comparator. The results indicated that there is both value in the further development of the 70G-FFT into a paraffin based test (70-PAR had the 
highest Net Monetary Benefit (NMB), with ENBD of $€ 110$ million) and value in further research into this improved test (ENBS of $€ 21$ million for the optimal sample size of a $N=3,000$ trial).

In Chapter 9, the cost-effectiveness model was used to reflect the dynamics of an early technology, in the perspective of a Comparative Effectiveness Research (CER). We developed a multi-parameter method to perform dynamic CER to determine the cost-effectiveness of possible future diffusion patterns of new technologies. Ten possible scenarios regarding the introduction of the 70-gene signature were drafted with European experts. Subsequently, the five most likely scenarios were quantitatively integrated in a decision-analytical model. For each scenario, the cost-effectiveness of the 70-gene signature expressed in NMB was compared to clinical guidelines, calculated from 2005-2020. The NMB for the 70gene signature increased over time with a range of $-€ 2,061$ to $-€ 1,676$ in 2010 and $-€ 2,347$ to $+€ 3,304$ in 2020 depending on the scenario used. The "uptake"-scenario had a strong influence on the cost-effectiveness, followed by the "non-believers" and "technical-failure" scenarios. We showed that there is not one outcome of costeffectiveness. Scenarios incorporated into decision modeling can be useful in CER to reflect the dynamics in the development and gives the possibility to anticipate and act upon those developments.

\section{Conclusion and discussion}

This study showed that the CTA methodology can be a useful tool to guide controlled early implementation of a promising technology and its possible use for coverage decisions, in this case the 70-gene signature for breast cancer patients. Regarding future tissue banking we hope that our concept guideline will lead to a debate and further investigation regarding the consequences of residual tissue for patients. The patient information in the MINDACT trial appeared to be clear and satisfactory and resulted in a good understanding of (the consequences of) the genomic profile. In general, the 70-gene signature seems most cost-effective in terms of quality adjusted life years; the slightly more sensitive tests deliver more life years, but leads to a substantial larger amount of adjuvant chemotherapy and hence higher costs, thus demanding a higher willingness to pay. Developing the 70-gene signature based on paraffin instead of fresh frozen tissue could establish a higher cost-effectiveness and could thus be a worthwhile investment. Finally, when incorporating scenarios in the decision model, it became apparent that early anticipation on certain aspects is necessary to reach the potential costeffectiveness. 


\section{Nederlandse Samenvatting}

\section{Introductie}

Door de stijgende kosten in de gezondheidszorg dient bij nieuwe technologieën naast de medische effectiviteit ook een afweging te worden gemaakt of deze nieuwe technologie ook doelmatig is. Health Technology Assessment (HTA) is een methode om nieuwe technologieën in de gezondheidszorg te evalueren, dit kan uiteenlopen van medicijnen tot diagnostische tests en organisatieveranderingen. Bij dergelijk onderzoek naar een medische technologie en/of zorgvoorziening wordt naast de medische effectiviteit één of meer andere aspecten (economische, sociaal-culturele, juridische, ethische en organisatorische) beoordeeld. Met als resultaat informatie voor besluitvorming betreffende de kwaliteit en doelmatigheid van de zorg.

Een HTA onderzoek start normaal gesproken nadat de medische effectiviteit van een nieuwe technologie is aangetoond. Dit proces neemt vaak zo'n 8-10 jaar in beslag, vooral in kanker onderzoek. Tot die tijd kan de technologie maar voor een beperkt aantal patiënten worden toegepast, veelal in studie-verband. In een vroeg stadium van een nieuw ontwikkelde, veelbelovende, en vaak nog een in ontwikkeling zijnde, technologie worden besluitvormers uitgedaagd om deze techniek zo snel mogelijk in te voeren in de dagelijkse praktijk om zoveel mogelijk patiënten van deze test te kunnen laten profiteren. Het probleem is dat HTA hierop niet is ingericht, dus er is vraag naar een methode die hierop wel aansluit. In een nieuwe vorm van HTA, Constructive Technology Assessment (CTA) kan wel rekening gehouden met de dynamische toestand van een nog in ontwikkeling zijnde techniek, en kan beleidmakers ondersteunen in de beslissing om de techniek zo snel mogelijk in te voeren in de dagelijkse praktijk van de gezondheidszorg.

Een voorbeeld van zo'n veelbelovende techniek is het gen expressie profile, ofwel het 70-genen profiel voor borstkanker patiënten. Het 70-genen profiel, ook wel MammaPrint ${ }^{\mathrm{TM}}$ genoemd, is ontwikkeld in het Nederlands Kanker Instituut-Antoni van Leeuwenhoek (NKI-AVL) en voor het eerst gebruikt in 2004. Het 70-genen profiel wordt gebaseerd op een kopie van DNA, het RNA, wat zich in het tumor weefsel bevindt. Dit weefsel wordt afgenomen tijdens de operatie wanneer de tumor uit de borst wordt verwijderd. Vervolgens kan het profiel het individuele risico op afstandsmetastasen inschatten en daarbij de patienten selecteren die van aanvullende behandeling zullen profiteren. Bij een laag risico profiel wordt de patient geen aanvullende behandeling zoals chemotherapie geadviseerd, bij een hoog risico profiel zal de patient wel geadviseerd worden om chemotherapie te ondergaan. 
Het doel van dit proefschrift is tweeledig: ten eerste is de CTA methode verder ontwikkeld voor gebruik in een vroeg stadium van technologische ontwikkeling. Vervolgens is de CTA methode op het 70-genen profiel voor borstkanker toegepast, met het oog op ondersteuning van de invoering van deze nieuwe diagnostische test in de dagelijkse praktijk.

Het onderzoek is uitgevoerd naast twee lopende studies, namelijk de RASTER en MINDACT studie. Bij de RASTER studie beslisten de patienten samen met hun arts m.b.v. het 70-genen profiel en een klinische richtlijn hun eventuele adjuvante behandeling. Bij de MINDACT studie worden patienten gerandomiseerd waarbij de test uitslagen discrepant waren, zoals een 70-genen laag risico/ klinisch hoog risico of een 70 -genen hoog/klinisch laag risico.

\section{CTA methode}

In Hoofdstuk 2 is de CTA methode getest om de introductie van het 70-genen profiel te ondersteunen voor klier-negatieve borstkanker patiënten. CTA wordt beschreven als een middel om de implementatie van vroege en met name dynamische nieuwe technologieën in de gezondheidszorg te ondersteunen. Het blijkt ook nuttig te zijn als een evaluatie-instrument voor een Coverage with Evidence Development (CED) programma. In een CED programma wordt een nieuwe technologie onder voorwaarde dat er verder onderzoek gedaan wordt, vergoed. Tijdens de introductie van het 70 -genen profiel zijn patiëntgerelateerde, economische en organisatorische aspecten bestudeerd. Voor- en na de introductie zijn er gestructureerde interviews uitgevoerd in 15 participerende ziekenhuizen met het gehele team. Deze interviews hadden betrekking op mogelijke wijzigingen in de logistiek en teamwork als gevolg van de invoering van het 70 -genen profiel. De patiëntgerelateerde aspecten werden gemeten door middel van vragenlijsten en interviews waarin naar kennis, ervaringen en de impact van het ontvangen van de test uitslagen werd gevraagd. Scenario's, die gewoonlijk in de commerciële industrie gebruikt worden om te anticiperen op toekomstige ontwikkelingen en verspreiding van hun producten, zijn toegepast in deze studie. De mediane implementatietijd van het 70 -genen profiel was 1.2 maanden. Er werden vooral verschillen in snelheid van uitvoering en beïnvloeding van behandelbeslissingen gezien. Impact op patiënten leek vooral betrekking te hebben op conflicterende testresultaten met klinische richtlijnen en de opeenvolgende communicatie van deze testuitslagen. Ten slotte lijkt de CTA methode nuttig als een instrument voor het CED programma, door de meerwaarde van vroege monitoring en de mogelijkheid tot anticiperen op mogelijke ontwikkelingen tijdens de vroege introductie van veelbelovende nieuwe medische technologieën. 
In Hoofdstuk 3 wordt een overzicht van de literatuur gepresenteerd met betrekking tot vroege evaluaties van nanotechnologieën in de oncologie. Hierbij hebben we gekeken naar evaluaties waarin naast de klinische effectiviteit ook efficiëntie, logistiek, patiënt-gerelateerde en technologie-dynamiek aspecten gemeten werden. Als gevolg van de huidige fase van de ontwikkeling van de meeste nanotechnologieën is nog beperkt gepubliceerd over evaluaties waarin ofwel HTA dan wel CTA gebruikt wordt. Voor het verkrijgen van een realistisch beeld van het implementatieproces is er behoefte aan een brede en systematische evaluatie van nanotechnologieën in een vroeg stadium van ontwikkeling. Evaluatie methoden waarin rekening gehouden wordt met technologiedynamica zoals CTA dienen overwogen te worden voor evaluatie doeleinden.

\section{Patiëntgerelateerde aspecten}

In Hoofdstuk 4 werd het personeel van het NKI-AVL geconfronteerd met verzoek van een ex-patient om haar tumorweefsel 4 jaar na behandeling te testen met het 70-genen profiel. Hierdoor rezen juridische, ethische en praktische vragen over de rechten van patiënten in relatie tot opslag van restweefsel en de gebruiken voor klinische doeleinden. Was het weefsel van deze patiënte nog beschikbaar? Zo ja, kon de patiënte eisen dat de test zou worden uitgevoerd of haar weefsel zou worden overgedragen naar een ander ziekenhuis? Toen duidelijk werd dat passende richtlijnen ontbraken in dit gebied, hebben we concept-richtlijnen ontworpen over deze kwestie, met de betrokken relevante professionals en patiëntenvertegenwoordigers. Met behulp van juridische en ethische documenten werden er, gebaseerd op vier algemene principes en de beginselen die betrekking hadden op deze casus, een aantal belangrijke elementen beschreven in de richtlijn. Het werd duidelijk dat weefselopslag voor klinische doeleinden dringend meer aandacht vanuit een medisch, ethisch, juridisch en praktisch perspectief nodig heeft. Wij geloven dat deze concept richtlijn een bijdrage kan leveren aan de discussie over dit belangrijke onderwerp.

De doelstelling van Hoofdstuk 5 was het evalueren van de impact die het ontvangen van het 70-genen profiel had bij borstkankerpatiënten. De deelnemers waren Nederlandse vrouwen die werden behandeld voor een vroeg stadium van borstkanker en deelnamen aan een gerandomiseerde klinische study, the MINDACT trial ("Microarray In Node-negative and 1 to 3 positive lymph node Disease may Avoid ChemoTherapy; EORTC 10041/BIG 3-04"). Na de operatie kregen de patiënten de risico-inschatting van het nieuwe 70-genen profiel en de klinische richtlijn Adjuvant! Online. Na de operatie werd een vragenlijst opgestuurd om aspecten zoals kennis en tevredenheid over, en de impact van het krijgen van het 70 -genen profiel te beoordelen. De deelnemers $(N=347$, respons $62 \%)$ rapporteerden hoge tevredenheid en goede kennis over de verstrekte 
patiënteninformatie. Lage stressniveaus werden gevonden bij patienten met een 70 -genen laag/klinisch laag risico, een beduidend hoger niveau van stress werd gemeten bij patiënten met een dubbel hoog risico, bij een "niet beschikbaar" 70genen profiel, of wanneer er discrepantie bestond tussen het 70-genen profiel en de klinische richtlijn $(p<0,001)$. Zorgen over kanker waren het hoogst bij patiënten met een voorafgaand hoog risico perceptie en lage tevredenheid $(p<0,001)$. Patiënten rapporteerden een significant lagere kwaliteit van leven bij een concordant hoog risico profiel en een "niet beschikbaar" genen profiel $(p<0,001)$. Aanbevelingen voor de klinische praktijk van gen-expressie profielen zijn bewustwording van het feit dat gen-expressie testresultaten het welzijn van patiënten kan beïnvloeden en dat door meer specifieke ondersteuning van patiënten met discrepante- en hoog risico profielen wellicht stress kan worden verminderd.

\section{Economische aspecten}

In Hoofdstuk 6 wordt de kosten-effectiviteit van het 70-genen profiel vergeleken met de veel gebruikte klinische richtlijnen in Europa, zoals de Adjuvant! Online en de St. Gallen. Voor deze vergelijking werd een Markov beslissingsmodel gebruikt voor simulatie van de 20-jarige kosten en uitkomsten (overleving en kwaliteit van leven gecorrigeerde overleving (QALYs)) in een hypothetisch cohort van kliernegatieve, oestrogeen-receptor positieve borstkanker patiënten. Sensitiviteit en specificiteit van de drie prognostische tests (het 70-genen profiel, Adjuvant! Online en de St. Gallen klinisch-pathologische richtlijnen) was gebaseerd op 5 en 10 jaar borstkanker specifieke overleving (BCSS) en metastasen op afstand (DM). Deze zijn afkomstig uit een dataset bestaande uit 305 tumorsamples van 3 validatie studies van het 70-genen profiel. Kleine verschillen in overleving maar substantiële verschillen in voor kwaliteit gecorrigeerde overleving (QALYs) werden waargenomen tussen de prognostische tests. De QALY was het hoogst bij gebruik van het 70-genen profiel. Op basis van kosten per QALY heeft het 70-genen profiel heeft de hoogste kans op kosteneffectiviteit, als de maatschappij bereid is om voor een QALY meer dan $€ 4,600$ te betalen.

In Hoofdstuk 7 wordt het 70-genen profiel vergeleken met een concurrerende test, het 21-genen profiel, ontwikkeld in Amerika. Momenteel is er weinig vergelijkingsmateriaal van deze twee tests, er zijn maar twee (kleinere) datasets beschikbaar, waarbij zowel de 70-genen profiel en 21-genen profiel worden vergeleken met klinische richtlijnen. Het nadeel van deze publicaties is dat ze beide niet de originele platformen gebruiken waarop de tests oorspronkelijk zijn ontwikkeld. Daarnaast is de naleving van de voorschriften (compliance), gebaseerd op de literatuur, meegenomen in de analyse. De analyses lieten zien dat de prestaties van het 70-genen profiel en het 21-genen profiel dicht bij elkaar liggen 
en zeer onzeker zijn. Op basis van kosten per QALY heeft het 70-genen profiel heeft de hoogste kans op kosteneffectiviteit. De verwerking van het naleven van de richtlijnen bleek dezelfde trend. De belangrijkste boodschap in dit hoofdstuk is dat er meer onderzoek noodzakelijk is voor de directe klinische vergelijking van het 70 genen profiel ten opzichte van het 21-genen profiel.

\section{Organisatorische aspecten}

Hoofdstuk 8 biedt een kader voor het gelijktijdig ondersteunen van drie beslissingen die betrekking hebben op een (nieuwe) technologie (I) de adoptie, (II) verdere ontwikkeling, en (III) verder onderzoek naar (onderdelen van) de betreffende technologie. Het kader werd toegepast op het huidige 70-genen profiel, welke wordt uitgevoerd op vers ingevroren weefsel (70G-FFT), vergeleken met een nog verder te ontwikkelen profiel uitgevoerd op paraffine (70G-PAR). Het al eerder ontwikkelde Markov-model (kosten-effectiviteis model, hoofdstuk 6) werd gebruikt voor het vergelijken van de 70G-FFT met Adjuvante Online, vervolgens werd de 70G-PAR toegevoegd aan deze vergelijking. De Net Monetary Benefit (NMB) (I), het verwachte netto voordeel van de ontwikkeling (ENBD) (II), en het verwachte netto voordeel van verder onderzoek (ENBS) (III) werden berekend. De NMB van de 70G-PAR was het hoogst, dus het meest kosteneffectief. De resultaten gaven aan dat er zowel waarde in de verdere ontwikkeling van de 70G-FFT in een paraffine gebaseerde test (70-PAR) was (met een ENBD van $€ 110$ miljoen), en in verder onderzoek naar deze verbeterde test (met een ENBS van €21 miljoen voor de optimale steekproefgrootte van een trial $N=3,000$ ).

In Hoofdstuk 9 werd het reeds eerder ontwikkelde Markov model (hoodfstuk 6) gebruikt om de dynamiek in de technologie van het 70-genen profiel te weerspiegelen in het perspectief van Comparative Effectiveness Research (CER). Wanneer de optimale verspreiding van een technologie wordt gevraagd, kan integratie van proces-onzekerheid in de analyse onverwachte ontwikkelingen onthullen en daarmee helpen bij de implementatie doordat er dan de mogelijkheid bestaat om snel te anticiperen. We hebben een multi-parametermethode ontwikkeld om de kosten-effectiviteit van mogelijke toekomstige diffusie patronen van het 70-genen profiel te bepalen. Tien mogelijke scenario's met betrekking tot de invoering en diffusie van de 70-genen profiel zijn opgesteld en getoetst met 80 Europese borstkanker-deskundigen tijdens een consensus bijeenkomst. Vervolgens werden de vijf meest waarschijnlijke scenario's kwantitatief geïntegreerd in het Markov model. Voor elk scenario is de kosten-effectiviteit van het 70-genen profiel vergeleken met klinische richtlijn uitgerekend van 2005-2020, uitgedrukt in Net Monetary Benefit (NMB). De NMB voor het 70-genen profiel nam in de loop der tijd toe met een range van $-€ 2,061$ naar $-€ 1,676$ in 2010 en van $-€ 2,347$ naar $+€ 3,304$ in 2020, afhankelijk van het gebruikte scenario. 
Het "uptake"-scenario (mate van invoering) had de sterkste invloed op de kosteneffectiviteit, gevolgd door de "non-believers" (professionals die nog niet in het 70genen profiel geloven) en "failure" scenario's (technisch mislukte testen).

We hebben geconcludeerd dat er niet één resultaat van kosteneffectiviteit bestaat, maar dat het reëler is om een range aan te geven. Het opnemen van scenario's in CER kan nuttig zijn om de dynamiek in de ontwikkeling van een nieuwe technologie weer te geven en daarnaast geeft het de mogelijkheid om in een vroeg stadium te anticiperen en te reageren op deze ontwikkelingen.

\section{Conclusie, discussie en aanbevelingen}

Hoofdstuk 10 presenteert de belangrijkste bevindingen van dit proefschrift en bespreekt een aantal methodologische overwegingen, beleidsmatige en klinische aanbevelingen, terrein voor toekomstig onderzoek en trekt de belangrijkste conclusies. Deze studie heeft laten zien dat de CTA-methode een nuttig instrument kan zijn bij een vroege, gecontroleerde introductie van een veelbelovende technologie, in dit geval het 70-genen profiel. Met betrekking tot toekomstig weefsel opslag hopen we dat onze conceptrichtlijn tot verdere discussie zal leiden over patienten rechten en weefsel gebruik en opslag. De deelnemers van de MINDACT trial gaven aan dat de patiënteninformatie duidelijk was en resulteerde in een goed begrip van (de gevolgen van) het 70-genen profiel. Dit is waardevolle informatie voor de klinische praktijk om de huidige manier van benaderen van patiënten te behouden, maar ook wat meer aandacht te besteden voor patiënten die discrepante test resultaten hebben ontvangen. In het algemeen, is het 70genen profiel kosten-effectief in termen van voor kwaliteit gecorrigeerde levensjaren. De iets meer gevoeligere tests leveren misschien iets meer levensjaren, maar leiden tot een aanzienlijke hoger gebruik van adjuvante chemotherapie met de hierbij horende bijwerkingen en hogere kosten. De ontwikkeling van het 70 -genen profiel op basis van paraffine in plaats van vers ingevroren weefsel kan een hogere kosteneffectiviteit bewerkstelligen en zou dus een waardevolle investering kunnen zijn. Tevens blijkt verder onderzoek naar deze verder te ontwikkelen test waardevol. Ten slotte, wanneer scenario's worden gehanteerd, is het duidelijk dat een vroege anticipatie op bepaalde aspecten die nodig is om de potentiële kosten-effectiviteit te bereiken. 



\title{
Chapter 12
}

Dankwoord

\author{
Curriculum vitae
}

List of publications 


\section{Dankwoord}

Met veel plezier heb ik aan dit proefschrift gewerkt, dat mede tot stand is gekomen door de hulp en inzet van verschillende mensen om mij heen. Graag wil ik iedereen hiervoor bedanken, en een aantal personen in het bijzonder.

Allereerst gaat mijn dank uit naar mijn promotor en co-promotor. Prof. dr. Wim van Harten, beste Wim, graag wil ik je bedanken voor alles wat je voor mij hebt gedaan, opgelost, opgehelderd en aangeboden. Ik bewonder je stiptheid en je strategische blik, maar ook je vermogen om 2x! de l'Alpe d'Huez te beklimmen. Ik hoop dat onze wegen elkaar in de toekomst weer zullen kruisen.

Dr. Manuela Joore, beste Manuela, jij was mijn steun en toeverlaat in Maastricht. Jij was de vertaalslag van CTA naar HTA, van kwalitatief naar kwantitatief. Met je heerlijk heldere geest had ik altijd het idee dat ik weer sprongen vooruit was gekomen, eenmaal weer in de trein van Maastricht terug naar Amsterdam. De reizen voor iHEA naar Beijing en Toronto had ik niet willen missen!

Mijn dank gaat ook uit naar de leden van de promotiecommissie, Dr. Sabine Linn, Prof. dr. Hans Severens, Prof. dr. Maarten IJzerman, Prof. dr. Theo Ruers, voor het beoordelen van mijn proefschrift. Beste Sabine, wat heb ik veel van jou geleerd tijdens de RASTER studie, heerlijk om jouw schaterlach over de gang te horen. Beste Hans, ik leerde je kennen in Maastricht bij de HTA cursus, maar vooral tijdens iHEA 2009 in Beijing, waar we achter onze gezamenlijke liefde voor cellomuziek kwamen, onze afspraak voor een cello-concert staat nog steeds! Beste Maarten, bedankt voor ons interessante gesprek over CTA en early HTA, dat heeft mijn interesse in dit gebied zeker aangewakkerd.

Alle patienten wil ik bedanken voor het deelnemen aan de studies, voor de inzet en moeite om de vragenlijsten in te vullen. Bedankt voor deze informatie en de ontroerende verhalen. Daarnaast wil ik alle medewerkers van de RASTER- en MINDACT ziekenhuizen bedanken die veel voor mij hebben betekend in de ondersteuning van de patiënt-vragenlijsten en de teaminterviews.

Vele co-auteurs wil ik bedanken voor hun kritische blik en ondersteuning vanuit de diverse onderzoeksgebieden. Prof. dr. Rutgers, beste Emiel, bedankt voor al je inzet voor onze studie, ik ben erg benieuwd hoe de MINDACT cijfers eruit zullen zien! Beste Corrette, wij waren een goed team in 2009 met ons ethisch/juridisch project! We hebben het toch mooi voor elkaar! Beste Janneke, jij kan zulke scherpe vragen stellen, waardoor er zaken voor mij op zijn plaats doen vallen. Ik wens je veel succes met je loopbaan als onderzoeker. 
I would like to thank the members of the TRANSBIG/EORTC/MINDACT steering committees for their support and participation in the scenario workshop in October 2008 in Bordeaux. Prof. dr. Laura van 't Veer, beste Laura, ik wil je graag bedanken voor je heldere inzichten tijdens een aantal prettige gesprekken. Ik heb veel gehad aan je "helikopterview". De medewerkers van Agendia wil ik graag bedanken voor de waardevolle input en de samenwerking van de afgelopen jaren.

Mijn collega's op de pathologie hebben mijn start mogelijk gemaakt; Jolien en Stella, wat heb ik veel van jullie geleerd! Jolien, van jou heb ik mogen afkijken hoe je de zaken strategisch aanpakt. Bedankt voor je kritische blik maar ook voor je luisterend oor. En Stella, van jou heb ik projecten leren doorgronden, te letten op details en dingen goed af te maken. Inge en Jolanda, jullie waren mijn steun en toeverlaat, bedankt voor het luisteren naar mijn verhalen en de vele gezellige koffie/thee uurtjes! Michael, for one year in the "RASTER/MINDACT-team" you were a very pleasant roommate, good luck with your career and family.

Op de $5^{e}$ etage van het $\mathrm{AVL}$, op de KNO-afdeling is het allemaal begonnen. Prof. dr. Tan, beste Bing, en Linda Hofland, dank voor het ondersteunen van mijn scriptie voor mijn studie gezondheidswetenschappen. Deze scriptie heeft de basis gelegd van mijn "loopbaan" als HTA-onderzoeker. Mijn roommates van toen wil ik ook graag bedanken voor het sparren; Jacqueline, Marja en Josselyn, bedankt voor de vele "expert-uurtjes"! Ik wil ook graag al mijn collega's en teamleiders van $5 \mathrm{~A}$, $\mathrm{B}$ en $\mathrm{C}$ bedanken voor hun interesse, ook na mijn vertrek van de afdeling.

Alle medewerkers van de PSOE, bedankt dat jullie een aantal van mijn presentaties hebben aangehoord, wat voor jullie niet helemaal bekend terrein was, maar toch voor mij kritische en goede input leverden.

Met de collega's van de Universiteit Maastricht heb ik vooral leuke tijden beleefd in Beijing en Toronto tijdens de iHEA congressen. Beste Silvia, Saskia, Janneke, Bram, Mitchel, Thea, Carmen, Merel, Aukje en Manuela, bedankt dat ik mocht deelnemen in jullie team!

Bij de Universiteit Twente wil ik graag Marjan bedanken voor de ondersteuning in het begin van mijn promotie traject. Beste Karin, ik heb veel geleerd van ons artikel, bedankt dat je mij daar doorheen hebt geloodst. Beste Lotte, ik heb jou leren kennen eigenlijk met de projecten naast mijn promotie, maar je was toch ook bij het laatste stuk erg betrokken. Jij wist precies wat er in mijn hoofd omging, het was en is erg leuk om met je samen te werken!

Wineke, jij bent mijn maatje als co-promovenda bij Wim. Samen hebben we kunnen sparren over onze introductie, discussie en stellingen. Maar vooral: waar is die rode draad? Nog even volhouden, jij bent er ook bijna! 
Jorrita en Marianne, wat een goed stel PA's zijn jullie van Wim! Bedankt dat jullie altijd voor mij klaarstonden, al was het nog zo druk. Zelfs de mails die ik's avonds laat verstuurde, werden vaak direct beantwoord. Jorrita, als je nog eens Zwitserse kruiden nodig hebt, ik kom ze met alle liefde brengen!

Mijn vrienden wil ik graag bedanken voor alle fijne tijd die we samen hebben doorgebracht. Veelal in de orkesten, maar ook lekker in het café onder het genot van een "klein" drankje: Richard \& Marjolein, Thijs \& Noortje, Erik \& Eline bedankt voor het meeleven en meedenken maar ook zeker voor alle lol! We gaan snel weer Bang spelen!

Lieve Hanneke \& Gilbert, Steffie \& Jort, onze avonden afwisselend in Amsterdam of Amersfoort zijn altijd erg gezellig en ik ben benieuwd wat de toekomst ons gaat brengen! Lieve Laura, Esmé, Femke \& Paul en Sacha, jullie hebben al die jaren door mijn verhalen aangehoord over het wel en wee in het ziekenhuis. Meiden, hopelijk tot snel weer voor een gezellige avond samen! Lieve Berbe \& Frans, Barbara \& Michel, Odette \& Steven, hopelijk kunnen we snel weer samen Brahms spelen! Lieve Marieke \& Joost, ik vond het heel bijzonder om getuige te zijn bij jullie bruiloft, fijn dat jullie erbij zijn!

Beste Ine, super dat je mijn cover hebt willen ontworpen, dat waardeer ik heel erg. I $\mathrm{k}$ vind het heel mooi geworden!

Chers collègues du Registre Genevois des Tumeurs, je vous remercie pour votre chaleureux accueil et pour l'intérêt que vous m'avez porté. En travaillant au sein du Registre, j'apprends beaucoup, et ne cesse d'enrichir mes connaissances sur l'épidémiologie du cancer. J'espère que nous pourrons continuer à effectuer des études intéressantes et que mon français s'améliorera.

Lieve Cindy \& Ivar en Wendy \& Bas, ik wil jullie graag bedanken voor jullie onvoorwaardelijke steun. Cindy, we kennen elkaar al vanaf de HBO-V, we hebben samen de studie doorlopen, samen voor onze laatste stage in het NKI-AVL beland en ook beide gezondheids-wetenschappen gestudeerd. Ik bewonder je om je luisterend oor, jij weet altijd wat er in iemand omgaat. Ik vind het dan ook fantastisch dat jij mijn paranimf wilt zijn tijdens mijn verdediging. 
Mijn familie wil ik bedanken voor jullie belangstelling. Mijn "schoonfamilie" wil ik graag bedanken dat jullie altijd klaar staan met een helpende hand, het is bij jullie altijd een warm thuis.

Uiteraard werd de vroegste basis voor alles in mijn leven, dus ook dit, gelegd door mijn ouders. Lieve papa en mama, bedankt voor alles wat jullie hebben betekend en nog betekenen. Stéphanie, mijn lieve zusje, bedankt dat jij er ook altijd bent, ik wens je heel veel geluk toe.

En dan natuurlijk Christian, mijn paranimf en mijn grote liefde. Jij bent de zon in ons huis. Dank dat je altijd zo vrolijk, optimistisch en heerlijk nuchter bent. En dank voor alle ruimte en steun die je me geeft, zonder jou was dit proefschrift er zeker niet zo snel gekomen. Vanaf nu kunnen we echt gaan genieten van Zwitserland!

Allen heel erg bedankt!

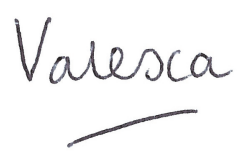

Valesca Retèl, Lausanne, 2011 



\section{Curriculum Vitae}

List of publications 


\section{Curriculum Vitae}

Valesca Retèl was born on May 23, 1980, in Alkmaar, the Netherlands. She attended primary school at the Paulusschool and secondary school at the Jac $P$ Thijsse college in Castricum. After graduation she studied nursing at the Hogeschool InHolland in Amsterdam. Besides her work as a nurse in the Netherlands Cancer Institute-Antoni van Leeuwenhoek Hospital (NKI-AVL), she studied Health Science at the University of Maastricht, with specialization Care Science, from which she graduated in 2006. The subject of her Master thesis was a cost-effectiveness analysis of photodynamic therapy versus usual care for patients with head \& neck cancer, accomplished in the NKI-AVL. In 2006, she started her $\mathrm{PhD}$ research in the NKI-AVL working on a Constructive Technology Assessment of genomic profiling for breast cancer patients. End 2010, she moved to Switzerland and started as a research fellow at the University of Geneva, at the epidemiology department of the Geneva Cancer Registry, while finishing her PhD research at the NKI-AVL. 


\section{List of publications}

Retèl VP, Joore MA, van Harten WH. Head-to-head comparison of the 70-gene signature versus the 21-gene assay: Cost-effectiveness and the effect of compliance. Accepted for publication in Breast Cancer Research and Treatment.

Esserman LJ, Shieh Y, Rutgers EJT, Knauer M, Retèl VP, Mook S, Glas AM, Moore DH, Linn SC, van Leeuwen FE, van 't Veer LJ. Impact of mammographic screening on the detection of good and poor prognosis breast cancers. Accepted for publication in Breast Cancer Research and Treatment.

De Bruin-Visser JC, Ackerstaff AH, Rehorst H, Retèl VP, Hilgers FJ. Integration of a smoking cessation program in the treatment protocol for patients with head and neck and lung cancer. Eur Arch Otorhinolaryngol. 2011 Jun 23. [Epub ahead of print]

Richman AR, Tzeng JP, Carey LA, Retèl VP, Brewer NT. Knowledge of genomic testing among early-stage breast cancer patients. Psycho-Onc 2011;20(1):28-35.

Mook S, Knauer M, Bueno de Mesquita JM, Retèl VP, Wesseling J, Linn SC, van 't Veer LJ, Rutgers EJT. Metastatic potential of T1 breast cancer can be predicted by the 70-gene MammaPrint signature. Ann Surg Oncol 2010 May;17(5):1406-13.

Retèl VP, Joore MA, Knauer M, Linn SC, Hauptmann M, van Harten WH. Cost Effectiveness Analysis of the 70-gene prognosis signature for node-negative breast cancer patients. European Journal of Cancer 2010; 46(8):1382-1391.

Ploem MC, Retèl VP, Linn SC, Schmidt MK, van Boven HH, de Jong JP, Gevers JMK, van Harten WH. Tumor Tissue; who is in control? The Lancet Oncology 2010;11(1):9-11.

Retèl VP, Bueno de Mesquita JM, Hummel MJM, Van de Vijver MJ, Douma KFL, Karsenberg K, Van Dam FSAM, Van Krimpen C, Bellot FE, Roumen RMH, Linn SC, Van Harten WH. Constructive Technology Assessment (CTA) as a tool in coverage with evidence development: the case of the 70-gene prognosis signature for breast cancer diagnostics. Int J Technol Assess Health Care 2009; 25:73-83.

Retèl VP, Hummel MJ, van Harten WH. Review on early technology assessments of nanotechnologies in oncology. Mol Oncol 2009; 3(5-6):394-401.

Retèl VP, Hummel MJ, van Harten WH. Early phase Technology Assessment of nanotechnology in oncology. Tumori 2008; 94:284-290. 
Retèl VP, Rutgers EJT, Joore MA, van Harten WH. Establishing of costeffectiveness of genetic targeting of cancer therapies. EJHPP 2008; 14:52-54.

Bueno-de-Mesquita JM, van Harten WH, Retèl VP, van 't Veer LJ, van Dam FSAM, Karsenberg K, Douma KFL, van Tinteren H, Peterse JL, Wesseling J, Wu TS, Atsma D, Rutgers EJT, Brink G, Floore AN, Glas AM, Roumen RMH, Bellot FE, van Krimpen C, Rodenhuis S, van de Vijver MJ, Linn SC. Use of 70-gene signature to predict prognosis of patients with node-negative breast cancer: a prospective community-based feasibility study (RASTER). The Lancet Oncology 2007; 8:1079-1087.

\section{In revision}

Retèl VP, Grutters JPC, van Harten WH, Joore MA. Value of research and value of development in early stages of development of new medical technologies.

In revision for Value in Health

Steuten LMG, Van de Weetering G, Groothuis-Oudshoorn CGM, Retèl VP, IJzerman MJ. Systematic and critical review of the evolving methods and applications of Value of Information methods in academia and practice.

In revision for PharmacoEconomics, invited paper

\section{Under review}

Retèl VP, Joore MA, Rutgers EJT, Linn SC, van Harten WH. How to anticipate future developments in Comparative Effectiveness Research?

Retèl VP, Groothuis-Oudshoorn CGM, Aaronson NK, Rutgers EJT Brewer NT, van Harten WH. Impact of genomic testing on breast cancer patients.

Retèl VP, van der Molen L, L'Ortye A, Hilgers FJM, Steuten L, van Harten WH. A cost-effectiveness analysis of a preventive exercise program for patients with advnaced head and neck cancer treated with concomitant chemoradiotherapy.

\section{Bookchapter}

Retèl VP, Rutgers EJT, Joore MA, van Harten WH. Establishing of costeffectiveness of genetic targeting of cancer therapies. Pharmacoeconomics for European Hospital Pharmacists, Chapter. Published March 2010, Nice, France. 


\section{Presentations}

Retèl VP, Grutters JPC, Joore MA, van Harten WH. Value of research and value of development in early stages of the development of new medical technologies. Health Economics Suppl July 2011. International Health Economic Association congress (iHEA), Toronto, Canada.

Retèl VP, Joore MA, Rutgers EJT, van Harten WH. Cost-effectiveness and Budget impact of the 70-gene signature for node-negative breast cancer. Eur $\mathrm{J}$ Cancer Suppl March 2010: abstract \#529. European Breast Cancer Conference (EBCC7), Barcelona, Spain.

Retèl VP, Joore MA, van Harten WH. Scenario drafting as a tool to perform early cost-effectiveness analyses: the case of the 70-gene prognosis signature in breast cancer. Health Economics Suppl July 2009. International Health Economic Association congress (iHEA), Beijing, China.

Retèl VP, Joore MA, Rutgers EJT, van Harten WH. Scenario use as an instrument to guide technology introduction: 70-gene signature prognostics in breast cancer treatment. Ann Oncol Suppl March 2009: abstract \#241. St. Gallen Breast Cancer Conferences, Sankt Gallen, Switzerland

Retèl VP, Bueno-de-Mesquita JM, Hummel MJ, van Harten WH. Implementation assessment of the 70-gene prognosis signature for breast cancer diagnostics. J Clin Oncol 26:2008 (May 20 suppl; abstract \#6575) ASCO Annual Meeting, Chicago, US.

Retèl VP, Joore MA, Tan BI. A cost-utility analysis of photodynamic therapy (Foscan-PDT) versus standard treatment for patients with small superficial tumors of the oral cavity and oropharynx. Health Services Research Suppl June 2007 9th Annual Research Meeting, Academy of Health, Orlando, Florida, US. 


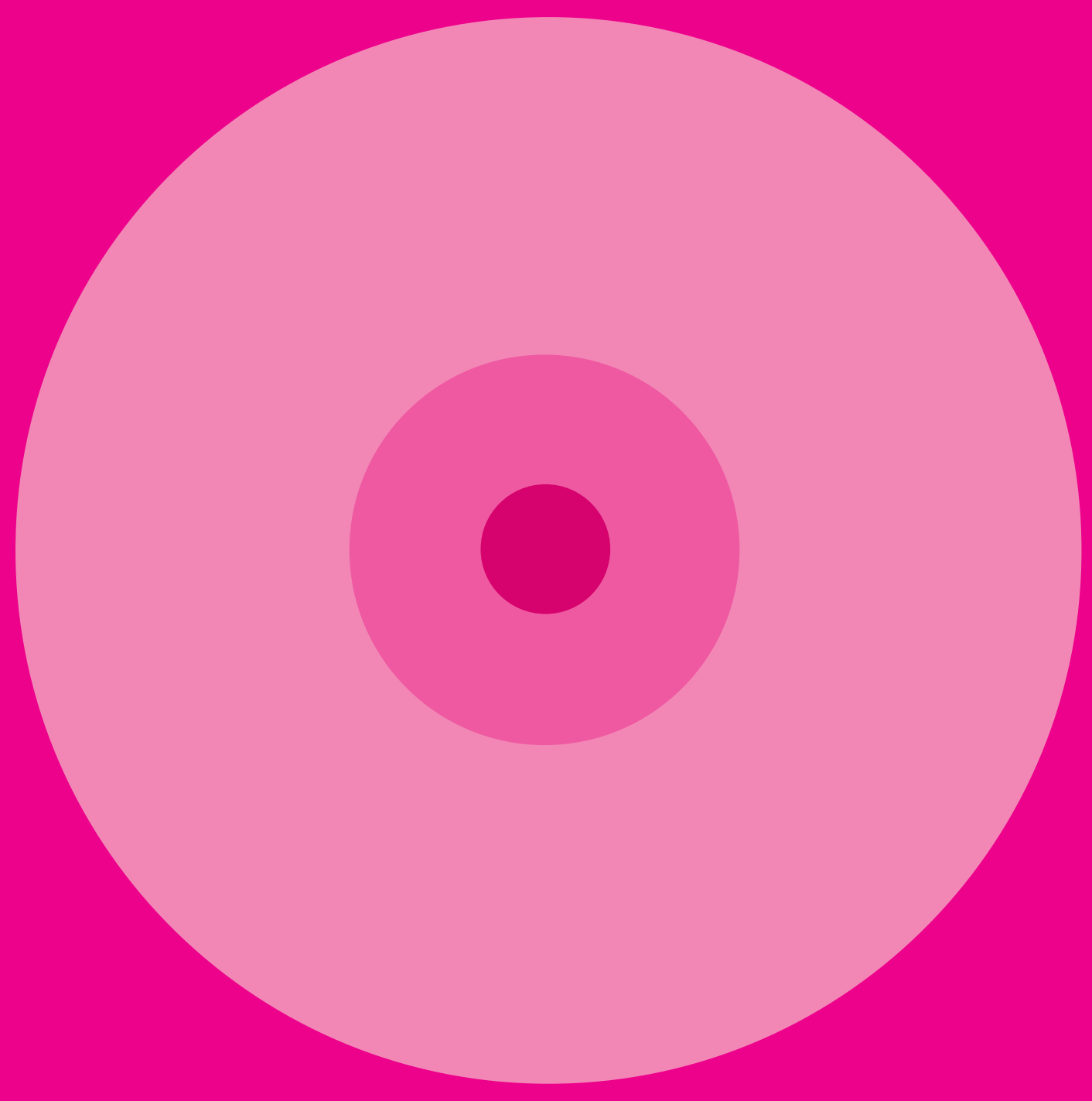




\title{
Stellingen behorende bij het proefschrift \\ "Constructive Technology Assessment of gene expression profiling for breast cancer"
}

\author{
Valesca Retèl, oktober 2011
}

1. Constructive Technology Assessment is een belangrijke aanvulling op huidige evaluatiemethodes om complexe medische technologieën in een vroeg stadium van ontwikkeling te onderzoeken. (dit proefschrift)

2. Constructive Technology Assessment is een praktisch instrument om de invoering van nieuwe technologieën in de dagelijkse praktijk van de gezondheidszorg te ondersteunen. (dit proefschrift)

3. Wanneer de kosteneffectiviteit van een medische technologie van breed gebruik en voldoende diffusie afhankelijk is, is het essentieel om in een vroeg stadium implementatie bevorderende factoren in kaart te brengen. (dit proefschrift)

4. In toevoeging tot de bestaande methoden in de gezondheidszorg om technologieontwikkeling te evalueren, kunnen scenariomodellen zoals in gebruik bij het bedrijfsleven een blikverruimend perspectief bieden. (dit proefschrift)

5. Het adoptie proces van het 70-genen profiel verloopt sneller bij patiënten dan bij artsen.

6. Hoewel het bij multimodaal onderzoek (bijv. psychosociaal, gezondheidseconomisch, ethisch/juridisch, epidemiologisch en klinisch) moeilijk is om op elk gebied de hoogste kwaliteit te halen, leidt de combinatie van de diverse invalshoeken juist vaak tot nieuwe inzichten.

7. Kennisoverdracht en communicatie tussen onderzoekers, artsen en zorgverzekeraars met betrekking tot de (verwachte) effectiviteit van complexe nieuwe medische technologieën is cruciaal voor een succesvolle vroege adoptie ervan.

8. Onderzoek uitvoeren is als spelen in een orkest; je moet weten wie je partners zijn om tot een harmonieus resultaat te komen.

9. "Het kunnen tellen van een vierkwartsmaat is -met name voor amateurorkestledenomgekeerd evenredig met intelligentie." (Daan Admiraal, dirigent)

10."I would rather have ideas and some difficulties of technique than a perfect technique and no ideas." (Mstislav Rostropovich (cellist, 2007†)) 